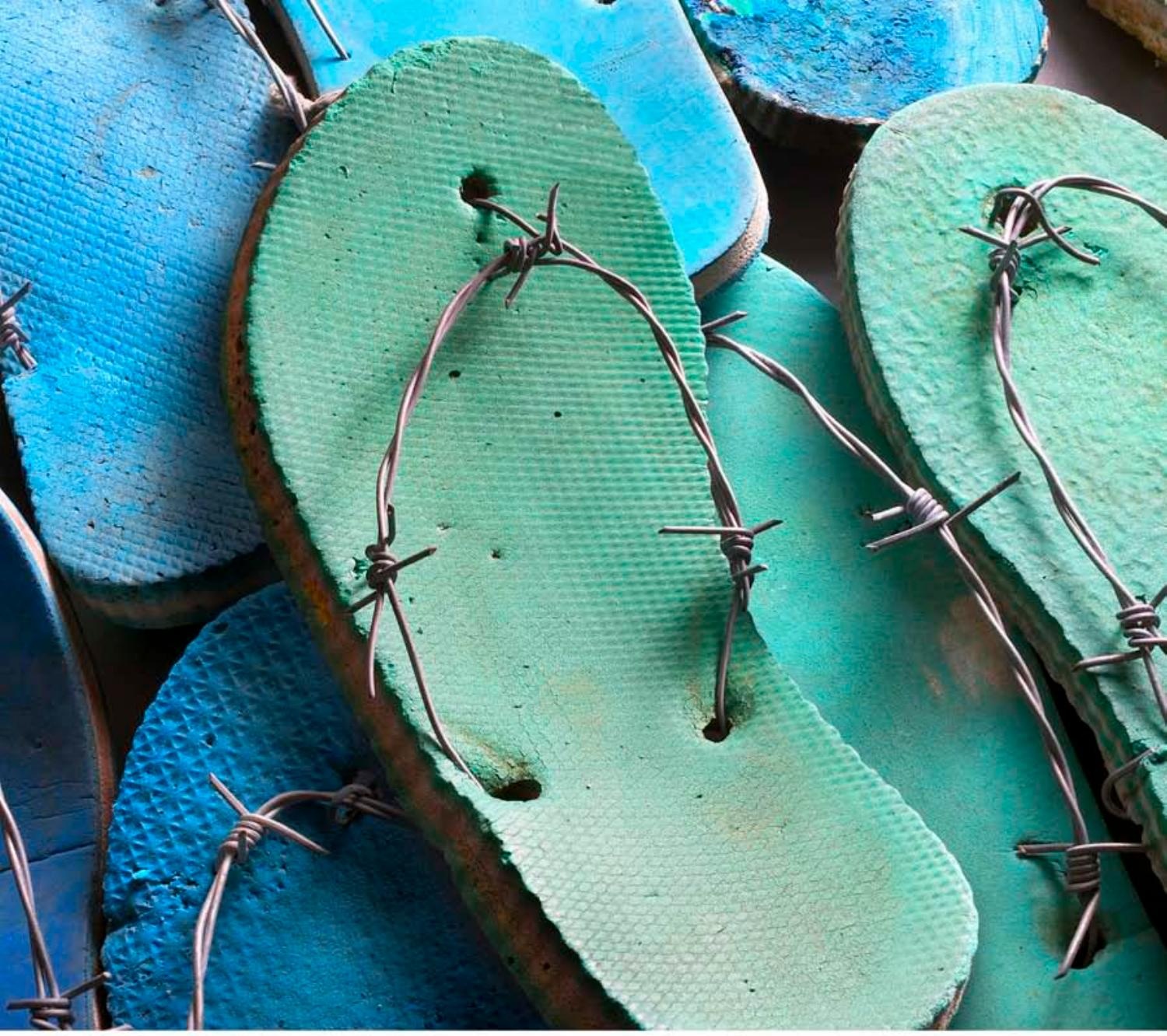

Allegories of the Anthropocene Elizabeth M. DeLoughrey

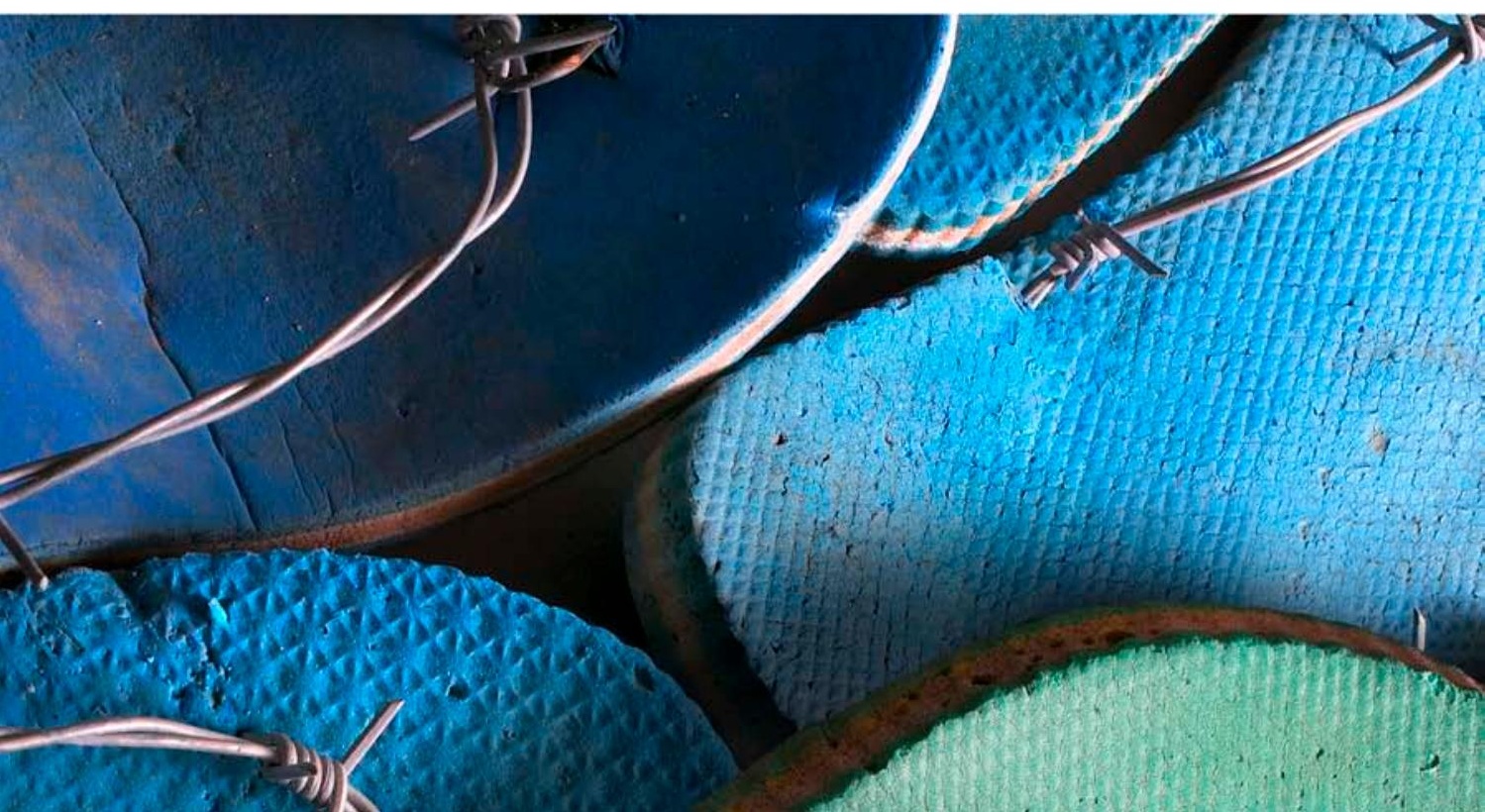


Allegories of the

Anthropocene 
This page intentionally left blank 
Elizabeth M. DeLoughrey

\section{Allegories of the Anthropocene}


(C) 2019 Duke University Press

All rights reserved

Printed in the United States of America on acid-free paper $\infty$

Designed by Courtney Leigh Baker

Typeset in Garamond Premier Pro and Helvetica Neue

by Westchester Publishing Services

Library of Congress Cataloging-in-Publication Data

Names: DeLoughrey, Elizabeth M., [date] author.

Title: Allegories of the Anthropocene / Elizabeth M. DeLoughrey.

Description: Durham : Duke University Press, 2019. | Includes bibliographical references and index.

Identifiers: LCCN 20I8050I5I (print)

LCCN 2019006483 (ebook)

ISBN 978 I 478005582 (ebook)

IS BN 9781478004103 (hardcover : alk. paper)

IS BN 978I478004714 (pbk. : alk. paper)

Subjects: LCSH: Climatic changes-Effect of human beings on. | Climatic changes in literature. | Human ecology in art. | Caribbean literature-2ist century-Themes, motives. | Pacific Island literature—2Ist century-Themes, motives. | Art, Caribbean2ist century-Themes, motives. | Art, Pacific Island-2ist century-Themes, motives. | Postcolonialism in literature. | Postcolonialism and the arts. | Climatic changes-Social aspects-Caribbean Area. | Climatic changes-Social aspects-Islands of the Pacific.

Classification: LCC PN849.C3 (ebook) | LCC PN849.C3 D 442019 (print) | DDC $809 / .93355609729-\mathrm{dc} 23$

LC record available at https://lccn.loc.gov/201805015I

Cover art: Tony Capellán, Mar Caribe (detail), 1995. Photo courtesy of Dennis Helmar.

Author royalties from the sale of this book will be donated to the Refugee and Immigrant Center for Education and Legal Services (RAICES).

This title is freely available in an open access edition thanks to the томЕ initiative and the generous support of Arcadia, a charitable fund of Lisbet Rausing and Peter Baldwin, and of the UCLA Library. 


\section{CONTENTS}

vii Acknowledgments

I Introduction: Allegories of the Anthropocene

33 ONE. Gendering Earth: Excavating Plantation Soil

63 TwO. Planetarity: Militarized Radiations

98 THREE. Accelerations: Globalization and States of Waste

I33 FOU R. Oceanic Futures: Interspecies Worldings

i65 FIVE. An Island Is a World

I97 Notes

257 Index 
This page intentionally left blank 


\section{ACKNOWLEDGMENTS}

In June 2010, I discovered that ten years' worth of my research and notes for a book project on the cultural ecologies of transplantation were lost in a move and likely ended up in a Los Angeles landfill. The project had been partially drafted; it was to be an examination of the various ontological claims to soil as created by exchange across the tropics of foods and commodities: breadfruit, coconut, sugarcane, and yam. The damage of that loss is probably significant to an overall claim in this book about an Anthropocene epoch that figures allegorical narratives of decline, fragmentation, and waste and the possibilities of adaptation and growth. While that book was lost, a fragment, one root, remains in the opening chapter of Allegories of the Anthropocene.

I have been fortunate to have a broad network of support in rebuilding a new book project out of the ruins. This includes my colleagues at UCLA who have read and commented on these chapters and to whom I give my most heartfelt thanks: Victor Bascara, Judith Bettelheim, Keith Camacho, Chris Chism, Robin Derby, Helen Deutsch, Lowell Gallagher, Lauren Hirshberg, Gil Hochberg, Rachel Lee, Françoise Lionnet, Jorge Marturano, Kathleen McHugh, Shu-mei Shih, and Jenny Sharpe. I have also learned much from the intellectual engagement with my colleagues Andy Apter, Ali Behdad, Judy Carney, Allison Carruth, Jessica Cattelino, Jon Christensen, Michelle Erai, Mishuana Goeman, Akhil Gupta, Sandra Harding, Susanna Hecht, and Ursula Heise. My students have all contributed in many ways to my thinking through ecological approaches to literature, arts, empire, and history. I wish to note in particular Nasia Anam, Kristen Cardon, Lauren Dembowitz, Deb Donig, Yu-ting Huang, Dana Linda, Marilu Medrano, Alexei Nowak, Courtney Ryan, Joyce (Pua) Warren, and my research assistant 
Sophia Lykke for our invigorating conversations about these texts and contexts in and out of the classroom, and on many dog walks.

My sincere thanks to the following people for inviting me to share my work-I benefited greatly from the encouragement to prepare new work and from some excellent feedback from my hosts and from the people gathered for each event: Godfrey Baldacchino and Eric Clark, coordinators of the International Geographical Union conference in Sven, Sweden; Byron Caminero-Santangelo, University of Kansas; Dipesh Chakrabarty, University of Chicago; Paulla Ebron, Stanford University; Sarah Fekadu, LudwigMaximilians-Universität, Munich; Paul Giles, Lisa Samuels, and Brenden O'Connor, coordinators of the Australia-New Zealand American Studies Association gathering at the University of Sydney; George Handley, Brigham Young University; Otto Heim, University of Hong Kong; Hsinya Huang, National Sun Yat-sen University and the Ocean and Island Ecology Research Network; Peter Hulme, University of Essex; Rosanne Kennedy, Australian National University; Yolanda Martínez-San Miguel and Michelle A. Stephens, Archipelagos Seminar, Rutgers University; Anne-Marie McManus, Nancy Reynolds and Vasiliki Touhouliotis, Washington University, St. Louis; Sean Metzger, Francisco-J. Hernández Adrian, and Michaeline Crichlow, Duke University; Martin Munro, Florida State University; Mike Niblett, University of Warwick; Viet Nguyen and Janet Hoskins, University of Southern California; Ineke Phaf, Humboldt University, Berlin; Hannah Boast and the Postcolonial Studies Association, University of York, UK; Ato Quayson, University of Toronto; Sangeeta Ray, University of Maryland, College Park; Johnny Riquet and Ana Sobral, University of Zurich; Modhumita Roy, Tufts University; and Nicole Waligora-Davis and Cary Wolfe, Rice University.

The thinking about and writing of this book has also been made possible by the generous support of fellowships and research grants. Special thanks to Christof Mauch at the Rachel Carson Center for Environment and Society (RCC) for his support of our workshop "Imperialism, Narrative and the Environment" and to all of the workshop participants. It remains to me one of the most important gatherings for my thinking through the relationship between postcolonial studies and the environmental humanities. I was fortunate to have received an ACLS Frederick Burkhardt Residential Fellowship at the Huntington Library, which provided an invaluable break from my teaching and service commitments at UCLA. The University 
of California Humanities Research Initiative Grant funded our "Global Ecologies: Nature/Narrative/Neoliberalism” conference, and I extend my thanks to all of the presenters and participants at that event, which continued and expanded an invaluable discussion begun at the RCc. The University of California Pacific-Rim Grant, UCLA International Institute Faculty Research Award, and Burkle Center Faculty Research Grant supported my colleagues Victor Bascara and Keith Camacho and me in organizing workshops on militarization at home and at the University of the South Pacific, Fiji, which were integral to my research on radiation ecologies and to my learning about comparative militarism in this book and beyond.

In addition to the names already mentioned I have been buoyed by the friendship, support, and intellectual engagements of Joni Adamson, Blake Allmendinger, LeGrace Benson, Catherine Burwell, Ralph Crane, Gaurav Desai, Jill Didur, Germán Esparza, Esther Figueroa, Arianne Gaetano, Amy Griffiths, Graham Huggan, Peter Hulme, Anne Keala Kelly, Ilan Kelman, Jorge Marcone, Sarah Mattaliano, Dan Taulapapa McMillan, Radhika Mohanram, Susan Najita, Rob Nixon, Lisa Paravisini-Gebert, Crystal Parikh, Jon Pugh, Jenny Price, Karen Salt, Elaine Savory, Geoffrey Schramm, Malcolm Sen, Flavia Sparacino, Phil Steinberg, Nina Sylvanus, Thom Van Dooren, Nicole Waligora-Davis, Linda Williams, Briar Wood, and Yetunde Zaid. As with my first book, Sangeeta Ray worked through many ideas with me and I am thankful for those years of unwavering mentorship. I also want to acknowledge Anitra Grisales for her editing support during the early drafts, and to the wonderful staff at Duke University Press for ushering this book through—particularly Courtney Berger, Sandra Korn, and Christopher Catanese.

Most of all, I am indebted to my father, who came out to Los Angeles in August 2015 at a moment of crisis and saved my life. Recovering from that apocalyptic event was possible only due to the love from my family and friends, especially those who live in the heart of my home: Gregg, Pōtiki, Ray, and Luna.

I dedicate this book to the living memory of four people who have profoundly influenced my thinking and who all passed away during the years in which this book was written: the wonderful artist and dear friend Tony Capellán, whose work graces the cover; my dear collaborator and friend Anthony Carrigan; the visionary writer and my patient interlocutor, Wilson Harris; and finally, a vital demilitarism collaborator, Teresia 
Teaiwa. Their work continues to sustain and inspire in the wake of loss and ruin.

Portions of the book have been published in the journals Modern Fiction Studies, Small Axe, Real: Research in English and American Literature, and in the volume Global Ecologies and the Environmental Humanities (2015). 


\author{
Introduction \\ Allegories of the Anthropocene \\ tell them about the water-how we have seen it rising \\ flooding across our cemeteries \\ gushing over the sea walls \\ and crashing against our homes \\ Tell them what it's like \\ to see the entire ocean _ level_ with the land \\ —KATHY JETÑIL-KIJINER, "Tell Them"
}

Our increasing awareness of climate change is catalyzing new imaginaries and, by extension, new allegorical forms to address the dynamism of our planet. I open this book with the words of Kathy Jetñil-Kijiner, a performance poet from the Marshall Islands, who is probably the best-known figure to use poetry in the service of climate justice. She received a standing ovation at the United Nations Climate Summit in 2014 for her passionate testimony about the impact of sea-level rise on the Pacific Islands and for a galvanizing poem about the global climate future that she imagines for her infant daughter. ${ }^{1}$ "Tell Them" poses a challenge to how we understand and represent the active relationship between people and place. More specifically, the poem employs allegory to figure the island as a world in ecological crisis, depicts an active, nonhuman ocean agent, and articulates the imperative to both witness and testify to a dynamic, changing Earth. All three of these allegorical tropes are vital to this book's exploration of the relationship between the Anthropocene and empire in an era of accelerating environmental catastrophe. 
The rapid increase in atmospheric carbon; extreme weather events such as drought, flooding, fire, and hurricanes; cataclysmic species extinctions; sea-level rise; ocean acidification; and a warming planet all testify to a crisis of global climate change known as the Anthropocene. This is a twenty-firstcentury term that some scholars use to signal that human activity has attained the scale of a geological force akin to a volcanic eruption or a meteorite, changing the Earth as a system. ${ }^{2}$ While there has been a virtual cottage industry of new journals and publications exploring the Anthropocene in recent years, the conversation has been dominated by the geophysical and social sciences, which tend to privilege positivist methods and have little to say about the vitality of the arts and humanities. Scholarship that does turn to the role of the Anthropocene cultural imaginary is focused almost exclusively on the viewpoints of the global north. This body of work has tended to favor literary forms such as the novel and white (settler) cultural production from the United States, Australia, and Europe.

The lack of engagement with postcolonial and Indigenous perspectives has shaped Anthropocene discourse to claim the novelty of crisis rather than being attentive to the historical continuity of dispossession and disaster caused by empire. In this sense Anthropocene scholarship produces a globalization discourse that misses the globe. Thus its cultural geographies and methods are still insufficient to address a complex crisis of planetary scale. This book argues that in an era of a truly global environmental crisis, Anthropocene scholarship cannot afford to overlook narratives from the global south, particularly from those island regions that have been and continue to be at the forefront of ecologically devastating climate change.

Due to their enormous scales and their discursive histories, the figures of nonhuman nature, the human, Earth, and now the Anthropocene share a universalizing geologic. Allegories of the Anthropocene stages an interdisciplinary dialogue between the (social) sciences and the humanities, with particular attention to how the universalizing figure of the Anthropocene might be grounded by engaging specific places such as postcolonial islands. This demands a multiscalar method of telescoping between space (planet) and place (island) in a dialectic or "tidalectic" way to see how they mutually inform each other. ${ }^{3}$ Bringing together the work of postcolonial, Indigenous, and Anthropocene discourses, I argue that we must "provincialize" the Anthropocene, much as postcolonial studies "provincialized" the universalizing discourse of Europe, to borrow from Dipesh Chakrabarty. ${ }^{4}$ This is not a casual analogue: the "universal and secular vision of the human" that 
Chakrabarty sought to decenter in European discourse has been regenerated in much Anthropocene scholarship of the "Age of Man," resurrecting a figure who reigns as a singular (masculine) "species." Both of these discourses are inextricably tied to histories and discourses of empire-particularly, as I argue here, through the use of narratives of disjunction and rupture.

Turning to literature, film, and the arts, this book asks: what kinds of narratives help us navigate an ecological crisis that is understood as local and planetary, as historical and anticipatory? Questions about narrative and representation are vital to understanding the Anthropocene because, as an epoch that reflects a radical break from the past, it poses specific epistemological and ontological challenges, which Chakrabarty has been the first to articulate. ${ }^{6}$ Of course, the Anthropocene is material in that it concerns what can be measured and experienced, and it is representational in that it raises vital questions as to how the planet as a system can be signified. While a cacophony of voices are theorizing the Anthropocene, most argue that it reflects a moment of disjunction and rupture in geological history and perhaps in knowledge-making itself.7 Of course, this discourse of rupture is deeply familiar to postcolonial and Indigenous studies in its theorization of the "irruption into modernity" that characterizes the ongoing experience of empire. ${ }^{8}$

The primary rupture in knowledge constitutive to the Anthropocene is that our experience of local weather is not commensurate with understandings of global climate. In other words, due to the difficulty of Earth systems modeling, Hurricane Maria-which pummeled the Caribbean in 2017-cannot, on its own, provide evidence of global climate change. 'This break between the local experience of extreme weather and its abstraction at a global scale is evident in the concluding lines of Jetñil-Kijiner's poem:

tell them

we are afraid

tell them we don't know

of the politics

or the science

but tell them we see

what is in our own backyard

But most importantly you tell them

we don't want to leave

we've never wanted to leave 
and that we

are

nothing

without our islands. ${ }^{10}$

This claim that "we don't know" - in a poem that declares the audience must "tell them" - is an interesting choice by the author, signaling a rift in knowledge production and circulation. Marshallese diplomats have been some of the most influential figures at every climate change summit and have galvanized a critical bloc of postcolonial island states to help to lower the targeted two-degree limit of global temperature increase. Some have even likened the major carbon emitters to contributing to cultural genocide. ${ }^{11}$ Yet here the poet deliberately minimizes their historical participation in the arena of politics and science to bring forward an allegorical disjuncture between the experience of place ("we see/what is in our own backyard") and the abstract realm that "we don't know" (the politics and science). While theorists have called attention to the challenges posed by this break between experience and knowledge, Jetñil-Kijiner's poem allegorizes Marshallese experience to make a claim for a cultural geologic that is not reducible to a universalized climate science of the Anthropocene. As such, culture, climate, experience, knowledge, and the Anthropocene are all placed in disjunctive relation. Yet these ruptures and disjunctions in narrative and in knowledge do not collapse neatly into one another. Moreover, the repeated imperative to "tell them" enlists allegory's pedagogical incentives and its incitement to action. ${ }^{12}$

This book claims that allegory has been revitalized and reinvented to represent this perceived disjunction between humans and the planet, between our "species" and a dynamic external "nature." This is a spatial as well as temporal rupture. Engaging with the Anthropocene means that we must simultaneously consider the deep geological time of the planet-in comparison with previous epochs-as well as the futurity of the human as a species. ${ }^{13}$ Futurity is marked not just by concerns about human survival, or ameliorating species extinctions, but also by the fact that one cannot locate a stratigraphic marker for this epoch until a geologically significant period of time-such as tens of thousands of years-has passed. ${ }^{14}$ Thus, the Anthropocene is both forward-looking and a future retrospective, characterized by "anticipatory logics" and anticipatory mourning. ${ }^{15}$ The Anthropocene epoch is constituted by a deep geological sense of the longue durée, as well as dis- 
junctive spatial relations between the enormity of the planet and the experience of local place. Due to its ability to represent both historical and scalar relations, allegory has arisen as a notable form for this moment of planetary climate crisis. Perhaps this is not surprising because allegory is known for its embeddedness in history (time), its construction of a world system (space), and its signification practices in which the particular figures for the general and the local for the global.

In fact, environmental discourse is rife with allegorical modes. For example, the popular rallying cry "Save the Planet" employs a metonymic or substitutive component of allegory in which "Planet" stands in for a particular speciesmost notably, the human. The synecdochical, or part-for-whole, function of allegory is evident in claims that we are in an era of "anthropogenic" climate change when the crisis actually derives from the activities of a powerful minority of human beings. ${ }^{16}$ Following Sylvia Wynter's postcolonial critique, we know that a particular bourgeois "ethnoclass" that calls itself Man "overrepresents itself as if it were human." ${ }^{17}$ Yet, as Joni Adamson and other have argued from Indigenous, postcolonial, and feminist perspectives, "we have never been Anthropos."18 Allegory is more than the use of rhetorical tropes. It is the animation of universalizing figures such as planet, species, nature, and the human into narrative- and thereby into space and time.

Concurrent with the recent Anthropocene turn, there has been a rise in allegorical representation in literature, film, and visual arts. Allegory stages other worlds to draw parallels and disjunctions between the present and an often dystopic future. This is particularly evident in the spike in climate apocalypse films that employ allegory, such as The Day after Tomorrow and 2012 (Roland Emmerich), Noab (Darren Aronofsky), and Snowpiercer (Bong Joon-ho), to name only a few. This uptick is attributable to the fact that allegory appears in moments of acute historical crisis, as Walter Benjamin has demonstrated. In his reading, modern allegory triggered a new relationship with nonhuman nature that recognized it as a historical rather than an abstract ideal. When modern allegory engages nature as history (what Benjamin termed "nature-history"), then history becomes subject to nature and therefore to decline. ${ }^{19}$ Western philosophy assumes a split between nonhuman nature and history that other epistemologies do not accept. Benjamin's dialectical engagement with nature, history, and allegory demarcated a radical shift from a universalized nature to its parochialization. Thus the split noted by many Anthropocene scholars who are working in the context of western philosophical traditions had already been theorized 
by Benjamin. Analysis of narrative is one of the important labors of the environmental humanities. Thus engaging the work of allegory-particularly the allegoresis of nature-history-opens the possibility of reading the many stories of climate change and the Anthropocene. ${ }^{20}$

We can see how Benjamin has laid the groundwork for theorizing Anthropocene discourse in that the latter also remarks on a disjuncture between humans (history) and the planet (nature) while suggesting both are anticipated to decline. Decline is represented in Benjaminian allegory and Anthropocene scholarship as ruins. In the Anthropocene context this is quite literal, as our reading of geological epochs is dependent on the legibility of fossils and radiocarbon decay. As such, both produce allegorical speculations on the future as ruins. The recognition of this seemingly new disjunctive relationship between the human and the planetary environment represents a crisis of ecological modernity in which allegory appears as one of its primary narrative records. This is the central argument of Allegories of the Anthropocene.

In an age of thinking about the totality of the planet, it is significant that of all modes, allegory is best known for constructing a model of the world or cosmos. As Bruce Clarke has argued, "Allegory typically models a concept of world-space through an articulation of nested structures, universal systems with a montage of ontological levels." ${ }^{21}$ These worlds are always separate from the reader/viewer, figured as necessarily disjunctive due to their utopian, dystopian, or perhaps subaltern difference from the audience. This is why the trope of the isolated island has been such a powerful constellation for thinking allegorically. From an early Arabic novel, Hayy ibn Yaqdhan, to English literature classics such as Utopia, Robinson Crusoe, and Lord of the Flies, allegory has long relied on the figure of the island to engage the scalar telescoping between local and global, island and Earth. The island's simultaneous boundedness and its permeability to travelers-and therefore its susceptibility to radical change-have made it a useful analogue for the globe as a whole. ${ }^{22}$ Of course, the island also represents finitude, a cautionary concept for the Anthropocene epoch of planetary boundaries that include threats to biodiversity and mass extinctions. ${ }^{23}$ This part-for-whole analogy is discernible in island extinction stories, such as the history of the dodo of Mauritius, the ecological cautionary tales of Rapa Nui (Easter Island), and, more recently, the example of the Marshall Islands.

The island has long been a figure for radical "climate change," a term I use here as it is more generally understood as an upheaval of an ecologi- 
cal system. In keeping with work in feminist, postcolonial, and Indigenous studies that does not bifurcate nature and culture, the concept of ecology as it is used here always includes the human. Thus, I turn to contemporary postcolonial island texts and contexts as a means of allegorizing the Anthropocene, arguing that it is vital to bring the theoretical discourse of the global north into dialogue with communities that both are at the forefront of present climate change and its historical survivors. In grounding the abstract discourse of the Anthropocene by tying it to specific histories and places we can learn much about the contextual nuances of narrativizing the relationship between human and more-than-human nature. Moreover, we might historicize a long history of rupture in small-scale climate systems such as islands. Of course, the galvanizing tendency of allegory to elicit action may also help to produce more effective modes of bringing about ecological and political change.

Some may rightly question whether the claim of Anthropocene discourse that we have an entirely new ecological crisis is, in fact, belated. Turning to Indigenous and postcolonial island writers and artists, we can see that catastrophic ruptures to social and ecological systems have already been experienced through the violent processes of empire. In other words, the apocalypse has already happened; it continues because empire is a process. ${ }^{24}$ For writers and artists engaging the history of plantation slavery or nuclearization, the apocalyptic or declensionist narrative of the Anthropocene is not only a future anticipation of the "end of nature" but also a remembrance of a violent historical past with ongoing repercussions for the present. ${ }^{25}$ As Heather Davis and Zoe Todd observe, "the Anthropocene-or at least all of the anxiety produced around these realities for those in Euro-western contexts-is really the arrival of the reverberations of that seismic shockwave into the nations who introduced colonial, capitalist processes across the globe in the last half-millennium in the first place." 26

Thus, my definition of "climate change" throughout this book refers to a world-changing rupture in a social and ecological system that might be read as colonization in one context or sea-level rise in another. While many of the texts examined here could be categorized under the popular neologism "cli-fi" (climate fiction, or climate film), they engage climate in ways that deepen our geographic and historical understandings of adaptation and resistance to world-shattering change. These works often revitalize and reformulate allegorical modes that are integral to mitigating our ecological futures. In an 
era of crisis about our "Earth Island," island writers and artists provide a prescient perspective about the part's relationship to the whole.

A humanities-based approach to the concept of the Anthropocene calls attention to the ways in which stories are told and to how crises are narrated or visualized. Allegory is a form that is particularly noted for how it stages the present's relationship to the past; this is often articulated in terms of an engagement with tradition and a search for origins. A flurry of debates has arisen in the past few years alone about to how to pinpoint the stratigraphic (sedimentary) origin of the Anthropocene, generally understood as a moment when (some) humans exceeded their "natural" limits and boundaries-what Anna Tsing terms "inflection points"-and impacted the planet's geology in ways that will leave isotopic traces for millennia. ${ }^{27}$ These are narratives of a rupture in the human relationship to the planet, a way of reckoning ecological modernity. Kathryn Yusoff has called attention to a heightening of "anthropogenesis" narratives of the Anthropocene, stories that are as much about beginnings as they are about an "imagined ending" for the human. ${ }^{28}$ To date, many anthropogenesis narratives are being proposed, without any consensus or attempt to link them in a chronology. Possible markers include the global rise of agriculture thousands of years ago; transatlantic European colonization, genocide, and ecological imperialism; the rise of capitalism, industrial modernity, and its legacies of fossil fuel; the radioactive isotopes from Cold War nuclear testing; and the "Great Acceleration," a term for the advent of globalization, in which expansion of agribusiness, urbanization, manufacturing, technology, and waste are now part of the planetary fossil record. ${ }^{29}$

I organize this book around these moments of rupture, of perceived turning points in the human relationship to the planet, following Benjamin's work on the "flash" of understanding in which "thought comes to a standstill in a constellation saturated with tensions." ${ }^{30}$ These constellations of the Anthropocene are thought to signal planetary turning points and shape the structure of this book. Allegories of the Anthropocene engages literary and visual cultures of the Caribbean and Pacific Islands through five constellations that are thought to either originate or encapsulate global climate change: the plantation (agriculture); radiation (militarism); waste (globalization); ocean (sea-level rise); and island (world). While I engage with anthropogenesis narratives, I am not interested in fixing an origin for the Anthropocene or in posing a chronology. Postcolonial studies has long criticized the unilinear narratives of progress that are constitutive to em- 
pire, and substituting one homogenizing telos with a narrative of decline still takes a model of "single, homogenous, and secular historical time for granted." 31 Instead, I adopt an allegorical frame of engaging constellations in which "paradox has the last word," to paraphrase Benjamin. Drawing from the work of Benjamin and Indigenous and postcolonial studies, I use a more dialectical method that foregrounds rupture as an analytic to explore a constellation of different allegorical forms that comment on this perceived human disjunction from our earthly place. Thus, the structure of the book itself uses allegorical techniques of disjunction within and between chapters. Each chapter is written for different types of audiences, with a particular resistance to telos or narrative development.

A humanities approach to the Anthropocene demands an engagement with multiple types of allegories, figured as cultural and historical codes, commentaries, genres, thematics, and contingent systems of meaning. Consequently, this book, following Gayatri Chakravorty Spivak, pursues "allegoric tendency" in literary and visual representations of the Anthropocene rather than a singular rigid form that is applied across contexts. ${ }^{32}$ Interpretation, of course, has been described as an "allegorical act," so in that sense this book figures allegory and allegoresis as method, form, and thematic. ${ }^{33}$ Moreover, my approach to allegory, like the Anthropocene, is decidedly ambivalent. As a mode, allegory can be utilized to comment effectively on the ways in which colonialism has ruptured cultural and ecological relations to the past, yet its anachronistic tendencies can also be employed to naturalize colonial discourses that depict non-European cultures as outside modern time. ${ }^{34}$ I concur with Spivak's claim that "allegory should be one of the global terms in the rhetoric of fiction" and the arts, ${ }^{35}$ yet I consider it a mode that is adaptive and fluid depending on time, space, narrative, and context. Thus one must parochialize allegory as much as the Anthropocene. Accordingly, I employ different critical frames of allegoresis while engaging with the novel, short stories, poetry, visual arts, and documentary film to trace out the constellations that structure Allegories of the Anthropocene.

This book intervenes in debates in the humanities that argue that we need to think in localized, "small is beautiful" terms to best mitigate ecological disaster versus another equally prominent body of work that claims that we must think at the grand scale of planetarity and hyperobjects. ${ }^{36}$ This is why the island is such an important figure for this simultaneous relationship between the part and whole, the local and global. If we have learned anything from globalization studies, it is that a planetary scale needs 
to be placed in a dialectical relation with the local to render their narratives meaningful. This does not mean that these dialectics are transparent or even translatable, just as global climate, a planetary phenomenon, is not reducible to local weather. This scalar telescoping follows a long tradition in postcolonial studies in which universalizing narratives are troubled, contested, and provincialized. Following postcolonial models, the dialectic between part and whole is also diachronic. This is to say that it is necessarily entangled with the longue durée of empire and ecological imperialism, what Rob Nixon terms "slow violence," as well as catastrophic ruptures and accelerations. Island writers and artists have long engaged such questions of modernity, rupture, and ecological violence that result from empire. Now at the forefront of climate change, they have a complex history of staging paradoxical relations between the local and global, posing allegorical antinomies or paradoxes for figuring the island as a world.

\section{Allegory: Antinomies of (Postcolonial) Modernity}

Allegory, literally "other speaking," is polysemous and may emerge as a mode of colonial, political, and systemic critique through the use of irony, subversion, and parody. Like the declensionist narrative of the Anthropocene, modern allegory often directs our attention to narratives of progress, authority, and development as myth. In foregrounding a postcolonial approach to allegory and the Anthropocene, I argue that the antinomies or paradoxes of modernity are constitutive to both. Ever since Benjamin published his work on the Baroque Trauerspiel (mourning play), allegory has been understood as a paradoxical form that renders often irreconcilable narratives about the human relation to the past and to nonhuman nature. As John McCole explains, Benjamin's dialectical “'antinomies of the allegorical' ... involve a radical despairing alternation between unbridgeable antipodes; the comforting prospect of a harmonious synthesis is denied." ${ }^{37}$ Later, the work of Hans Robert Jauss and Paul de Man called attention to an aporia or discontinuity between the subject and the external world that allegory creates at its representational core, exposing the radical disjunction between present and past, local and global. ${ }^{38}$

After Benjamin, it is generally agreed that allegory signals an era of calamity and a way of responding, inadequately but necessarily, to crisis. As Fredric Jameson has written, "If the allegorical is attractive for the present day and age it is because it models a relationship of breaks, gaps, discontinuities, 
and inner distances and incommensurabilities of all kinds. It can therefore better serve as a figure for the incommensurabilities of the world today." ${ }^{39}$ This is why allegory is so relevant for reckoning with the Anthropocene, an understanding of the human as a geological agent that, as Chakrabarty has argued, cannot be understood phenomenologically. He writes, "We humans never experience ourselves as a species. We can only intellectually comprehend or infer the existence of the human species but never experience it as such. ${ }^{\prime 0}$ It is precisely at this disjuncture between our awareness of the planet as a totality and our experience of embedded place that allegory plays a vital role. When faced with the rupture between the space of the planet and local place, allegory appears as a mode that best engages these antinomies. As we see in Jetñil-Kijiner's opening poem, the island is a world but one characterized by opacity - this reflects an aporia in the representational capacity of the human ability to reckon the totality of the planet. ${ }^{41}$

Like allegory, the Anthropocene in this book is also a figure of ambivalence. Geologists are now positioned in an interesting and vexed role as historians of the Anthropos, a radical disciplinary shift that has created a new genre of geological allegories of the human as a "species." There is an unprecedented production of climate change books written by geologists, in which an undifferentiated "man" has a starring role in the history of the planet, causing speculation about the behavior of the species in the past and dire warnings about its actions in the future. ${ }^{42}$ These environmental morality tales are, of course, allegories of a universal masculine subject who is not subject to cultural, historical, or sexual difference. When Anthropocene journalists insist that the term "man" is gender neutral, it seems as if the decades of work about context and difference in the humanities never existed. ${ }^{43}$ As Chakrabarty warns, "A crisis that concerns humanity as a whole cannot ever be adequately addressed if the issues of justice, power, and inequality that divide and fragment the same humanity are overlooked in the narratives we tell ourselves." ${ }^{\circledR 4}$ The unmarked gendering of the new subject of "the Age of Man" has been so relentless that it has spurred a parodic debate about the "Manthropocene." ${ }^{45}$ Stacy Alaimo reminds us that "feminist theory, long critical of "man," the disembodied, rational subject; and material feminisms, which stress inter- or intra-actions between humans and the wider physical world, provide alternatives to accounts that reiterate man as a bounded being endowed with unilateral agency." ${ }^{\prime 6}$ This tension demonstrates the challenges posed to a kind of interdisciplinary work in which positivist, universalist modes of thinking about the human as species come 
up against humanities approaches that are attuned to cultural and historical context, and especially human difference.

This Anthropocene discursive flattening of the figure of the human into an unmarked masculine species deriving from the global north (bomo industrialis, or homo economicus) means that a humanities approach that engages feminist, postcolonial, and Indigenous methods is essential. While I agree that the Anthropocene focalizes the necessity of new modes of figuring the relation between humans and the planet, I cannot fully concur with Chakrabarty's provocative claim that "what scientists have said about climate change challenges not only the ideas about the human that usually sustain the discipline of history but also the analytic strategies that postcolonial and postimperial historians have deployed in the last two decades in response to the postwar scenario of decolonization and globalization." ${ }^{47}$ Postcolonial methods, incredibly diverse in their own right, have much to say about the human relation to the planet in ways that cannot be reduced to an analytic of global capital or a concern with climate justice, as vitally important as these are. ${ }^{48}$ In fact, an enormous body of work in the field of postcolonial ecologies has been actively engaging these vexed questions about the disjunctive relationship between humans and between humans and nonhuman nature, politicizing ecological thought in relation to totalizing regimes of empire, from the colonial past to the neoliberal present. ${ }^{49}$ So this is to say that postcolonial studies has long been engaged with theorizing the Earth as well as the human - two of the essential figures of the Anthropocene. Yet postcolonial critiques of the world-making claims of ecology and empire have been overlooked in the scramble for originary claims about the Anthropocene. This suggests a lack of dialogue not just across the humanities but between definitions of the human. Postcolonial methods figure centrally here and in the chapters to come, particularly in terms of theories of disjunctive time and place and in relation to allegorical representations of the human subject.

\section{Modernity and Totality}

Postcolonial approaches are essential because they have long been reckoning with the concepts of modernity and totality, two figures that underwrite the relationship between allegory and the Anthropocene. Scholarship on allegory engages modernity but overlooks how it is constituted by the history of European empire and capitalism. After Benjamin, critics argued that the 
mode is "a response to the sense of perpetual crisis instilled by modernity; the awareness of an unbridgeable chasm separating an incomprehensible past from an always confusing present moment." ${ }^{\text {0 }}$ Building on the work of Jean-François Lyotard, Deborah Madsen suggests that allegory and modernity function on the premise of an "awareness of an absolute distinction between the temporal or human realm and the timeless or divine." 51 This observation has provocative implications for the Anthropocene in that if we recognize the "Age of Man" as a gendered discourse of secular nature, the scientific reckoning of what was perceived as "the divine" is now all too human. ${ }^{52}$ But these assumptions about modernity beg for a postcolonial intervention. In her reading of Jauss and de Man, Madsen observes that their theories of allegory point to a break in the Romantic era in the harmony expected between the human and more-than-human nature. This is why the Romantics eschewed allegory for the harmonizing symbol. ${ }^{53}$ In this reading of European thought, the allegorical mode captures the lack of continuity between self and world signaled in the Romantic era.

A postcolonialist might ask: in what ways has transatlantic empire contributed to the European realization that there is a break between the subject and "his" inhabited world? A postcolonial approach drawing on the work of C. L. R. James, Sidney Mintz, Michel-Rolph Trouillot and others might suggest that the modernity associated with eighteenth-century Europe was belated when compared with the experiences of those in the colonies who were displaced by diaspora and genocide, or who experienced the violence of modernity in their own home territories due to the reach of empire and its universal practices of land alienation. ${ }^{54}$ The recognition of a break in continuity between the subject and the outside world-between sign and referent that is constitutive to allegory, according to de Man's reading of Romantic literature-would have been very familiar to the dispossessed subjects of empire well before the Romantic (and even Baroque) era. It is hardly news that the Romantic writers and philosophers were deeply engaged and informed by contemporaneous events of empire-for instance, the influence of the Haitian Revolution on Hegel's theory of universal history-but this has not been connected to the representational rupture that has been associated with allegory. ${ }^{55}$

The reading of modernity and allegory-where the subject experiences an epistemological break with language and the experience of place and history becomes ruins_-can be traced back to Benjamin's observations on the German Baroque. Writing from the ruins of World War II, he interpreted 
the Trauerspiel as it encapsulated the violence and fragmentation of the Thirty Years War (1618-48). Benjamin found the war-torn ruins of the present in his interpretation of the past, rendering a break from Platonic modes of truth and transcendent theological thought. ${ }^{56}$ Through the lens of a fragmented modernity, allegory stages what Benjamin referred to as a "natural history" (Naturgeschichte) signified by ruins rather than through symbols of progress. To Benjamin, the shape of the present is a critical hermeneutic for reading the past, even as these historical constellations are never deemed continuous. While many have noted the parallels between the wartime violence of modern Europe and the ruins Benjamin located in seventeenthcentury drama, most have overlooked the thematic contents of the esoteric works that informed his study. Jenny Sharpe points out that his theories of allegory derive from Orientalist plays that "describe the decadent and tyrannical rule of the Eastern empires." 57 Thus, the first stitching together of the relation between allegory and modernity is in part inspired by a Baroque staging of the violence of empire, a concern with a rupture between material, economic, and cultural systems that so encapsulates postcolonial engagements with modernity.

Overall, this book connects allegory's propensity to figure rupture, ruins, and the destabilization of the signifying potential of language with the history of empire, building on postcolonial work that has long identified the colonies as originary spaces of the violence of modernity. While I engage many registers and contexts of allegory in this book, they share a representational and historical relationship to what Édouard Glissant describes as the "irruption into modernity, the violent departure from tradition, [and] from literary 'continuity." 58 The postcolonial critique of modernity is integral to understanding both allegory as a form that signifies rupture and attempts by scholars of the Anthropocene to periodize a break in the human relation to the planet, a perceived rupture between people and place.

The figure of totality also underlines the relationship between allegory and the Anthropocene. A totality, like modernity, has myriad definitions and contexts, but in this book I use the term to signal that which represents enormous temporal and spatial scale and can be only partially understood. Scale is one keyword of the Anthropocene, although scholars are using other terms for totality, such as planetarity, enormities, and hyperobjects. ${ }^{59}$ The monumental scale of the planet poses a challenge to both climate modeling, which is necessary yet always inadequate, and our ability in 
the humanities and social sciences to theorize the relationship between the human and a rapidly changing Earth. This is the major challenge to previously anthropocentric models of history. Building on Chakrabarty, Bruno Latour has written, "Physically insignificant Homo sapiens have emerged (through harmful activity towards the environment) as an ecologically destructive force with the capacity of a 'mass meteorite,' but the disconnect between humanity's own day-to-day mortal existence and apocalyptic ramifications of its activity makes it all the more difficult for the species-despite extensive rational analysis-to effectively realize its behavior." ${ }^{60}$ Expanding from Latour, we might add that, in addition to the concept of planet, force has become a figure of totality, a universalizing that Ato Quayson has critiqued from a postcolonial perspective. ${ }^{61}$ As we know, these totalities necessarily obscure the differences across Anthropos, and many have countered Latour's position with concepts such as the "hybrid" human (Wynter) or the multispecies human assemblage (Haraway). ${ }^{62}$

Clearly the Anthropocene dictates that we need multiscalar theorizing of the human; allegory provides its disjunctive narrative. Jameson has demonstrated that allegory is constitutive to the cartographic drive and to "cognitive mapping" as a whole. "The world system is a being of such enormous complexity that it can only be mapped and modelled indirectly, by way of a simpler object that stands as its allegorical interpretant." ${ }^{33} \mathrm{Of}$ course, his theory of "Third World allegory" was famously debated, but his work has demonstrated that once we begin theorizing the whole, we cannot step outside the concept of totality, which is best explicated by allegory. His later scholarship turns to the "geopolitical unconscious," a way to theorize postmodern capital that relies on allegory as a "conceptual instrument for grasping our new being-in-the-world." ${ }^{64}$ His "geopolitical unconscious" represents an engagement with geopolitics, not the Earth as such. Consequently, he is not engaging the "geo-" in ways we have seen proliferate in Anthropocene thinking, such as Bruno Latour's turn to our "common geostory," Kathryn Yusoff's theory of "geologic life," and Elizabeth A. Povinelli's "geontologies." ${ }^{\prime \prime}$ However, Jameson's theory of the "geopolitical aesthetic" of 1992 is prescient for Anthropocene thinking. He asks "how the local items of the present and the here-and-now can be made to express and to designate the absent, unrepresentable totality; how individuals can add up to more than their sum; what a global or world system might look like after the end of cosmology." 66 These are precisely the questions raised by scholars 
of the Anthropocene-how can we understand our ecological present in relation to the epochal periodization of the geological past and its anticipated future? How can the individual human be "scaled up" to the species? How might we understand a totality like the Anthropocene as signifying the "end of cosmology"? In most Anthropocene discourse, figures of the divine such as god and nonhuman nature have become anthropomorphized because geological force and the planet are now understood to be anthropogenic. This has led to grandiose claims of humans as "the god species." ${ }^{67}$ By engaging the relation between modernity and totality, we can more readily see Anthropocene discourse (not the epoch) as a secular and in some cases positivist allegory of the planet, a substitution of the alterity of the nonhuman divine with anthropogenic force. ${ }^{68}$

Jameson's coupling of allegory with totality was not well received in many postcolonial circles, but Imre Szeman's reflections on this vigorous debate of the 1980 s helps us better see the ways in which postcolonial studies was already engaged with different modes of totality. ${ }^{69} \mathrm{He}$ points out that postcolonialists, committed to the critique of Enlightenment universalisms and narratives of progress and development, were rightly suspicious of any connections to this form of "bad' totality." Interestingly, the debates of the 1980 s spurred by Jameson's argument about "Third World" allegory and its resistance to the totalizing mechanisms of postmodern capital are being reconfigured around the concept of the human as species in the Anthropocene. For instance, Chakrabarty's claim that postcolonial studies must move beyond the logic of the human as a figure of difference in order to theorize the human as a species is a conceptual leap that authorizes what some find to be a "bad totality." (This parallels a related debate over whether this is a "bad Anthropocene" or a "good Anthropocene." ${ }^{\text {) }}$ ) While these debates about scale and agency will continue, I want to draw from Szeman's engagement with what he calls Jameson's "political allegory," one that brings us to a systemic, global critique beyond the frame of the nation-state. He argues that as critics we are always entangled with totalities; they reflect "the possibility of metacommentary-not as a secondary step in interpretation, but as a condition of interpretation per se." ${ }^{.73}$ Allegory shapes these conditions of analysis. This critical posture toward narratives of "history in its totality" is vital to allegory, as Benjamin demonstrated. ${ }^{74}$ Thus, totality functions as both the possibility of critique and a momentary flash of history in a (discontinuous) series of constellations. ${ }^{75}$ Thus, allegoresis is necessarily caught up with totalities as the very conditions of possibility for analysis, figuring 
disjunctive relations between local and global, island and Earth. These are the antinomies of allegory in the Anthropocene.

\section{Postcolonial Histories, Island Spaces}

Jameson famously claimed that the "Third World" is a politically viable space for allegory because the part-for-whole relationship between the individual and the community was not shattered by bourgeois individualism. Despite the well-known critiques, many postcolonial scholars have found allegory to be integral to figuring the power of colonial relations. ${ }^{76}$ For example, Abdul JanMohamed identified what he called "Manichaean allegory" as constitutive to understanding the racial and cultural hierarchies of colonial texts such as Heart of Darkness, in which allegory allows a series of exchanges "of denigrating images which can be used to maintain a sense of moral difference; they also allow the writer to transform social and historical dissimilarities into universal, metaphysical differences." ${ }^{\text {"7 }}$ Sharpe demonstrated in her Allegories of Empire that "the Christian allegory of human salvation provided a powerful iconography for the social mission of the British rule in India" and beyond. ${ }^{78}$ This is why allegory is both powerful and a figure of ambivalence. Because while its tendency to refigure and thus authorize authority enabled it to serve the rhetoric of an expanding British empire, its flexible modes also produced what Sharpe has called "counterallegories," evident in how the violence of rape could be reconfigured as an allegory of colonial exploitation..$^{79}$ In sum, allegory and allegoresis has been engaged in a wide variety of colonial contexts to examine the (gendering) of the worlding process and its representations. ${ }^{80}$ Postcolonial and Indigenous writers continue to engage allegorical devices as mutable and vital responses to empire, dictatorship, globalization, settler colonialism, and ecological crisis, and a large body of critics have argued, persuasively, that the questioning of history and authority that is constitutive to allegory has been integral to the critique of empire and systems of totality and dominance. ${ }^{81}$

While there are many intersections between the history of colonial representations and allegory, I focus specifically on the postcolonial island because it so clearly engages with allegory's figuring of both multiscalar space and time. In turning to the postcolonial islands of the Caribbean and Pacific, I engage with so-called peripheral geographic spaces. We know that "mapping the social totality is structurally available to the dominated rather than dominating classes." 82 But as M. NourbeSe Philip reminds us, the 
margins are also a frontier-historically in terms of empire, as well as how postcolonial subjects have creatively imagined ways to survive amid a long history of ecological violence. ${ }^{83}$ So while island nations have contributed negligible amounts to our current carbon crisis, they have been at the forefront if its devastating ecological impact, as the survivors of Hurricane Maria in 2017 know all too well. Caribbean novelist Wilson Harris has argued that "the truly creative alchemical response to crisis and conflict and deprivation ... may well come from the other side of a ... dominant civilization, from extremities, from apparently irrelevant imaginations and resources." ${ }^{84}$ In revitalizing allegorical forms, island writers and artists provide prescient perspectives about the part's relationship to the whole, as well as about visions that are integral to mitigating our varied ecological futures.

This book argues that allegory is the fundamental rhetorical mode for figuring the planet as well as the historical rift between part and whole that is symbolized by the Anthropocene. The island is a foundational figure for the micro- and macrocosmos; given its long association with ecological imperialism, extinction, plantation slavery, and sea-level rise, it has been vital to tracking a historical and spatialized narrative of the Anthropocene. The subsequent chapters engage with tropes of the Anthropocene that encapsulate Benjamin's dictum that "allegories are, in the realm of thoughts, what ruins are in the realm of things." $" 5$

Challenging the colonial model of history as a narrative of progress, each of these chapters engages the ruins of empire. ${ }^{86}$ This is figured through the aftermath of the slave plantation and the challenges of forging a new relationship to earth/Earth in the Caribbean novel; the fallout of Cold War nuclear radiation as carried in the bodies of Indigenous Pacific peoples and the challenges of representing these wars of light; and the impact of the waste of globalization and its construction of "wasted lives" in Caribbean visual arts and in novels about poverty in Jamaican urbanization. ${ }^{87}$ The final two chapters turn to the figure of the ocean in an era of sea-level rise and its transmorphic effects on the human and its multispecies companions, as well as to how current documentaries about climate change figure the sinking tropical island as an "ecological morality tale." ${ }^{88}$ This is countered by performance poetry that positions the island-in-the-world as an allegory of women's cultural labor, intergenerational care, and climate change justice. While all of the allegories examined here emphasize not "eternal life so 
much as that of irresistible decay," ${ }^{\circ 9}$ they are not dystopic because they make no teleological claims and because their allegoresis demands something of the audience-at the least, active interpretation and, possibly, the ordinary labor of ecological and political engagement.

\section{Constellations of the Anthropocene}

The Anthropocene refers to a totality due to its imbrication with deep geological time and enormous planetary space. Accordingly, there are heated debates about its origins and even its relevance. Here I will sketch a brief genealogy of constellations of the Anthropocene. Before the coining of the term "Anthropocene," there were flashpoints where "man's role in changing the face of the Earth," to quote the title of an important interdisciplinary symposium of 1955 , was being scrutinized. ${ }^{0}$ Cold War geopolitics created a sense of planetary fragility of our "Earth Island," leading to other collaborative efforts across political and disciplinary divides such as the International Geophysical Year (1957-58). There are precedents for recognizing the impact of humans on the planet as a system, although they have not been tied specifically to the various colonial contexts in which they have arisen. In terms of originary moments cited by geologists and geographers, many date the concept back to the late 1700s, when Comte de Buffon imagined the Earth's final epoch to be a human one. ${ }^{91}$ George Perkins Marsh's Man and Nature; or Physical Geography as Modified by Human Action (1864) has been cited as an originary text examining the disjunctive relationship between the human and nonhuman world. Marsh, in turn, was in conversation with the work of the Italian geologist Antonio Stoppani, credited with coining the phrase "Anthropozoic era." ${ }^{2}$ Yet the dates for the "origin" of the Anthropocene concept are continually pushed back into the past; at the time of writing, scholars attribute it to the Welsh geologist Thomas Jenkyn's writing on "the human epoch" and the "Anthropozoic."93 Our current epoch, the Holocene ("recent" era), already includes the impact of the human, suggesting to some that the neologism "Anthropocene" is not necessary and raising questions as to why scholars suddenly contend that our Earth has radically changed in ways that can never be fully comprehended. ${ }^{94}$ Certainly the rise of the term's concurrence with the second millennium and its associated post-9/II narratives of apocalypse and extinction are not coincidental, as I explore in chapter 5 . Some Anthropocene discourse seems to be an elegy 
for a loss of the fantasy of "western civilization" and the (overrepresented) figure of "man."

The Anthropocene is a story of both novelty (a human rupture into a "natural" system) and decay (anthropogenic sedimentary fossils). The past decade of work on the Anthropocene has been updating the dismal ecological reports of the present while uncovering antecedents of the concept in the past. This both authorizes the concept and reiterates the western break between nature (read, the planet) and the human (read, pollutant). In turn, popular Anthropocene discourse reproduces the "fall from nature" narrative, but this time it is a secular one. In this secular fall, history is "subject to nature," an allegory of "irresistible decay." "95 In the words of Benjamin, "It is fallen nature which bears the imprint of the progression of history."

Articulating a beginning, Edward Said once noted, "is the first step in the intentional production of meaning." ${ }^{97}$ These Anthropocene claims to origins are significant in their obvious authorizing function, which prioritizes a particular kind of European scientific knowledge production. More interesting is their implicit claim to make meaning out of moments in which the human is theorized in disjunctive relation to the planet, an attempt to provide a history of the human's alienation from "his" home and a break between "man" and "nature." This historicizing process itself is, paradoxically, a way to render the consciousness of alienation visible. The construction of beginnings is, Said reminds us, an "activity whose circumstances include a sense of loss. ${ }^{98}$ In this case, the Anthropocene story is about the loss of nonhuman nature at the same time that it is a self-authorizing narrative for the Anthropocene as a concept. Seeking a history of the split between "man" and "nature" and making a claim to find its narrative origin in the global north (Comte de Buffon, Marsh, Jenkyn, Stoppani, Vernadsky, and so on) provides an intellectual origin story for contemporary theorists of the Anthropocene, who are also located in Euro-American academies. Perhaps more interesting is the way in which contemporary Anthropocene theorists discover their antecedents who in turn were authorizing a natureculture rupture that could be sutured only by theorization. Therefore, part of the academic work in defining the Anthropocene is not just the stratigraphic claims, but the use of a scientific geologic as a way to authorize specific and select cultural histories. While claiming the scale of the planet, they continue to be exceedingly provincial, not to say masculinist and ethnocentric. This is one of the many reasons the Anthropocene must be provincialized. 
Paul Crutzen and Eugene Stoermer famously historicized the Anthropocene by tying it to the creation of the steam engine (1784), rooting anthropogenesis in a fossil fuel-based industrialism. ${ }^{99}$ Their argument was based on a possible stratigraphic marker of the rise of $\mathrm{CO}_{2}$, which appeared in the fossil record many years later, along with other industrial isotopes such as lead, nitrogen, sulfur, and militarized radiation. ${ }^{100}$ I would argue that the steam engine is less of a data point than a geologic for transatlantic modernity, an age in which (European, male) humans thought themselves to have been separated from nature. Therefore, the steam engine is not just a technology; its appearance in this Anthropocene origin story is an allegory for Enlightenment tropes such as rationality, secularism, urbanization, individualism, property, freedom, rights, masculinity, and wage labor.

The steam engine anthropogenesis story was hardly contested for nearly a decade, precisely because it already spoke to a popular allegory of man's break with nature as simultaneous with the rise of modernity and technology. This is how the European Enlightenment became re-universalized, authenticated by its appearance in the strata of the Earth. Yet decades of work in the humanities and social sciences had already provincialized the Enlightenment and European industrialism, tying it specifically to a long history of empire. Outside the fields of geology, scholars have established that transoceanic empire and the violent exchange of flora, fauna, and humans made both capitalism and industrialism possible. This anthropogenesis narrative was largely ahistorical until the geographers Simon Lewis and Mark Maslin engaged the work of historians of empire to argue:

Industrialization and extensive fossil fuel use were only made possible by the annexing of the Americas. Thus, the agricultural commodities from the vast new lands of the Americas allowed Europe to transcend its ecological limits and sustain economic growth. In turn, this freed labour, allowing Europe to industrialize. That is, the Americas made industrialization possible owing to the unprecedented inflow of new cheap resources (and profitable new markets for manufactured goods). This "Great Divergence" of Europe from the rest of the world required access to and exploitation of new lands plus a rich source of easily exploitable energy: coal. ${ }^{101}$

Accordingly, they backdate the Anthropocene to I6ro to recognize the historical process that made the invention of the steam engine-and European industrialism—-possible. In a similar vein, Andreas Malm (who coined the 
term "Capitalocene") and Alf Hornborg argue that the rise of the steam engine was "predicated on highly inequitable global processes" and that "uneven distribution is a condition for the very existence of modern, fossilfuel technology." 102 The geologist Jan Zalasiewicz and his colleagues have concurred, remarking that "it is not so much the technology as much as its reflection of a long process of global inequities, and to argue that those who benefitted from those technologies represent the Anthropos causes a further violence in its erasure of the majority of humans on the planet." ${ }^{03}$ Thus, a decade after the coining of the term "Anthropocene" we begin to see the start of a robust dialogue about the origins of our environmental crisis-variously attributed to the dominance of capitalism (Capitalocene, Econocene, Necrocene), transatlantic empire (Plantationocene), patriarchy (Manthropocene), European/white settler colonialism (Eurocene), twentieth-century globalization and its regimes of disposability (Plasticene), or all of the above and their engagements with a frightening alterity (Chthulucene). ${ }^{104}$

In reading the human in the science of the planet, most geologists have tended to favor narrow histories of the global north that are not engaged with human complexity. As the historian Libby Robin observes, "Anthropocene origin stories follow the deep wheel ruts of northern hemisphere history." 105 I frame my chapter summaries with this debate because I want to foreground the ways in which allegory is at work in even the most geological approaches to the Anthropocene and to demonstrate that empire is essential to thinking about ecological change to the planet. This debate about "anthropogenesis" is loosely adopted to structure the argument of this book. ${ }^{106}$ It is with this sense of figuring the past as a parable for the future that I turn to these origin stories and draw them out as constellations, as allegories for the Anthropocene. The first three chapters focus on constellations of anthropogenesis, figures of what Benjamin would call "petrified unrest"-agriculture (the plantation), radiation (militarism), and waste (globalization) - that haunt the Anthropocene. The final two chapters examine a newly anthropomorphized "geos"-oceans and islands, two spaces in which the Anthropocene is rendered most visible-to engage transmorphic relations to nonhuman others, sea ontologies, as well as a body of climate change literature and film that has been termed "cli-fi." Overall these chapters inquire how the perceived rift in the human relationship to the planet is articulated in visual and written narratives from the islands of the global south, and how this grand narrative of a rift is parochialized through postcolonial and Indigenous allegories and ontologies. 


\section{Gendering Earth: Excavating Plantation Soil}

While the prehistoric use of fire is probably the earliest claim for the Anthropocene, a more popular early origin story is the rise of agriculture, particularly its associated deforestation, crop irrigation, and production of anthropogenic soils. ${ }^{107}$ The paleoclimatologist William Ruddiman has argued that the Anthropocene began with the agricultural clearing of forests in Europe and Asia nearly eight thousand years ago, which led to an increase in $\mathrm{CO}_{2}$ and methane emissions and a global warming that may have prevented a new ice age. This "early Anthropocene" can be identified in the stratigraphic records. ${ }^{108}$ While some have argued that the emission of carbon and methane is within the range of natural variability for this era or can be attributed to other, nonanthropogenic sources, ${ }^{109}$ my interest is less in the stratigraphic debates than in what the larger disciplinary and narrative claims are for understanding the human relationship to the planet.

This is a strange era in which paleoclimatologists, atmospheric chemists, and geologists are writing new histories of "man," producing allegories in their scalar telescoping between current and deep time and making universalizing claims about human behavior. In an egregious example, Ruddiman traces out an eight-thousand-year history of deforestation but never contextualizes the histories of human violence. Consequently, in explaining those eras in which $\mathrm{CO}_{2}$ did not rise due to a significant drop in the production of agriculture caused by death, he likens the plague in Medieval Europe to the decimation of 90 percent of the Indigenous peoples of the Americas, referring to it simply as a "pandemic" rather than genocide. ${ }^{110}$ Accordingly, the unprecedented drop in $\mathrm{CO}_{2}$ levels from 1550 to 1800 -due to a population collapse of more than fifty million people with causal links to colonization, slavery, war, displacement, containment, and outright ethnic cleansing-is attributed to smallpox. ${ }^{111}$ This reflects for me one of the disturbing disciplinary barriers for Anthropocene scholarship, which, in ignoring the historicist and contextual contributions of the humanities, makes wildly inaccurate truth claims for history under the positivist guise of science.

More recent work in Anthropocene scholarship has started to engage a broader interdisciplinary rubric. Lewis and Maslin take what was a footnote to Ruddiman's focus on prehistoric agriculture and link the science with scholarship in history and sociology to foreground the violent process of empire and integrate the beginnings of capitalism, which is constitutive to transatlantic slavery and colonization. They pinpoint the dip in 
atmospheric carbon to I610 and refer to their origin story of the Anthropocene as the "Orbis hypothesis," which foregrounds empire, capitalism, the exchange of biota, and the process by which the two hemispheres of the world were violently connected. ${ }^{112}$ They recognize that a focus on 1610 would foreground the fact that "colonialism, global trade, and coal brought about the Anthropocene." 113 In concert with a large body of scholarship on ecological imperialism, they argue that "the transoceanic movement of species is an unambiguously permanent change to the Earth system." 114 This provides a leaping-off point for my first chapter, which turns to the history of the representation of the Caribbean plantation system and the violence of modernity created by monocrop agricultural systems and slavery. Recently, scholars have termed this the "Plantationocene" in an effort to foreground the planetary impact of transatlantic colonialism and to pinpoint its operative national and economic agents. ${ }^{115}$

My first chapter takes as its backdrop the global dispersion of flora, fauna, and microorganisms due to the expansion of western European empires, a process of planetary change in which the diaspora, indenture, and enslavement of poor Europeans, Africans, Asians, and Indigenous people across the world was entirely unprecedented. This brought about what Mary Louise Pratt has called a new era of "planetary consciousness" that geologists are now able to locate in the stratigraphic record. This early phase of globalization led to radical changes in landscape, in which the transplantation of commodities (such as sugarcane) and food crops (maize, yam, potato) altered human diets, changing ecosystems and human bodies. As Alfred Crosby has demonstrated, food exports from the Americas contributed to the doubling of the size of populations in parts of Asia, Europe, and Africa, which, in turn, contributed to development and industrialization. ${ }^{116}$ European colonization facilitated the global exchange of plants, animals, and pathogens, creating "new hybrid species, and a global homogenization of Earth's biota." 117 Thus, what began as the Columbian exchange led to a "radical reorganization of life on Earth without geological precedent." 118

Accordingly, the first chapter turns to plantation slavery as an early marker of the Anthropocene and a vital constellation of radical social and ecological climate change. This history frames my engagement with Erna Brodber's allegorical "cli-fi" novel The Rainmaker's Mistake (2007), which excavates the plantation history of the Caribbean islands and speculates on the ecological future of the human relation to soil. Published to commemorate the bicentennial of the British abolition of the slave trade, Brodber's 
novel raises questions about the relationship between narratives of plantation slavery and the more hidden histories of slave provision grounds, "plots" of land that provide sustenance to the community and that figure in her novel as allegorical emplotments. Reading her novel as an allegory of plantation history, in which roots, soil, and rot become visible ruins of the past, I argue that her work helps us understand the complexities of the colonial rift created between humans and the earth/Earth that is signified by the agricultural stratigraphy of the Anthropocene. While she might agree with de Man that history is ultimately irretrievable via allegory, her work calls attention to the allegorical process of excavating the soil that uncovers the decaying corpses of a white slave master and subterranean African mothers. While they are not quite the Benjaminian grinning skull or death's head, ${ }^{119}$ these are corpses that demand allegoresis, that must be deciphered to uncover maternal origin narratives, earthly ontologies, as well as an unexpected history of African contributions to flooding and climate change. Thus, the novel provides a feminist critique of the "Age of Man" as an allegory of history and foregrounds the ways in which Anthropocene discourse relies on the excavation of sediment, fossils, and earth to articulate an allegory of Earth. In excavating these corpses, figures of "petrified unrest," the novel poses a challenge to the familiar historical frame of reading the Caribbean through the plantation model by uncovering other (feminized) "roots" and agents, a challenge we might well pose to the model of the Plantationocene.

\section{Planetarity: Militarized Radiations}

The violence of transatlantic empire is one recognized marker or constellation of the Anthropocene, but scholars have been slow to engage the unprecedented rise in nuclear militarism that marks another. It is not an accident that the atmospheric chemist best known for his promotion of the term "Anthropocene" was also the coauthor of an important Cold War text warning of the dangers of nuclear winter. ${ }^{120}$ Climate science and nuclear weapons testing have an intimate relationship. The rise of Cold War science contaminated the planet's atmosphere with artificial radioisotopes while also supplying the means by which to measure their movement throughout the biosphere. Thus, the tracking of radioactive carbon-I4 derived from nuclear tests enabled meteorologists to determine that carbon dioxide levels were uniform and consistent across the atmosphere, leading to a baseline for 
monitoring the rise and fall of $\mathrm{CO}_{2}{ }^{121}$ While there was a concerted effort on the part of the Atomic Energy Commission to frame radiation as a product that was as "natural" and life-giving as the sun, the transuranium elements, which are highly unstable, are all produced in laboratories; nearly thirty additional elements were manufactured by Cold War military science.

Even though there is ample evidence of the planetary-wide radioactive legacy of atmospheric weapons testing, isotopes that we all carry in our bodies today, it was only in 2014 that militarized radiation was first recognized by scientists as a stratigraphic marker of the Anthropocene. This enables us to connect legacies of one era of (European) empire after I492 to a more recent militarized one of the Cold War, even if most scientists continue to remark on it dispassionately and situate the connections outside of human agency, accountability, and ethics. ${ }^{122}$ This recognition by geologists is belated because the language of climate change has long been formulated in relation to narratives of nuclear annihilation, as Spencer $\mathrm{R}$. Weart and many others have demonstrated. ${ }^{123}$ To list just a few examples-the NASA physicist James Hansen's warnings since the 1980 os of what was then called the "greenhouse effect" were published in terms of a "climatic bomb" and, later, a "time bomb," drawing from the discourse of nuclear threat. ${ }^{124}$ Similarly, the Bulletin of Atomic Scientists' "Doomsday Clock," launched in 1947 to signal the worldwide threat of nuclear weapons, added climate change to its apocalyptic countdown in $2007 .{ }^{125}$

Zalasiewicz and his colleagues in the Anthropocene Working Group propose the day and time of the world's first atomic test-Trinity, at Alamogordo, New Mexico, on July 16, 1945-to mark the Anthropocene. While more than two thousand nuclear tests have been conducted on Earth since that date, this team focuses on the legacy of their global distribution of cesium-I37, strontium-90, plutonium-239, carbon-I4, and other artificial isotopes. ${ }^{126}$ Since dating the Anthropocene entails both a stratigraphic marker for the present and one that will be detectable into the far future, carbon-I 4 is particularly well suited due to its 5,700 year half-life, which will demonstrate a chemostratigraphic "spike" for another fifty thousand years. ${ }^{127}$ Building on this work, Lewis and Maslin have added to the "Orbis spike" of I6ro the "bomb spike peak" of $1964 .{ }^{128}$

In pursuing this complex relationship between Cold War ecology and radiation, I examine what I call a "heliotrope," or turning to the sun and radiation as an invisible yet permeable sign of the Anthropocene. This is an altogether different kind of universalism in which the figures of light 
and radiation become material and parochialized. Light and the sun have long been essential to allegory as a daemonic or intermediary figure between the local and the global, Earth and universe. ${ }^{129}$ Moreover the figure of radiation is one of the alterity of the planet-or, in Spivak's terms, "planetarity" - which foregrounds the limits to both knowledge and representation. Engaging the figure of radiation has important consequences for the interpretation of figures of nonhuman nature, as well as implications for understanding how Indigenous writers of Aotearoa New Zealand (Hone Tuwhare, James George) and Tahiti (Chantal Spitz) have configured the imbrication between "nature" and militarism. Chapter 2 explores how they have inscribed an allegorical poetics of solar ecologies, representing the complex and often apocalyptic ways in which radiation permeates both the atmosphere and the human body. While I am tempted to term this the "Nuclearocene," I believe we have produced enough awkward neologisms. The rise of global consciousness produced by the fallout of Cold War nuclearization is an important precursor for our global imaginations of a world of ruins, producing a dialectical "flash" of understanding of a militarized Anthropocene.

\section{Accelerations: Globalization and States of Waste}

The Cold War era of radioactive militarism marks one constellation of the Anthropocene, while the rise of globalization and economies of disposability mark another. The Great Acceleration, a term proposed by Will Steffen and his colleagues, ${ }^{130}$ has been proposed to encapsulate post-1950s developments in nation building, agribusiness, manufacturing, shipping, energy use, consumption, and disposability. In sum, they refer to the material "fallout" of globalization. In fact, their turn to the Great Acceleration helps us to see that the Anthropocene is a new constellation of globalization; it is a recognition of a "disembedding" of the human from place, ${ }^{131}$ in relation not just to the mobility of circuits of capital and culture, but also to the planet itself. Thus, the earlier concerns of globalization-scale, technology, politics, acceleration, urbanization, rupture, violence, and time/space compression-are finding new idioms, providing them with a new terrain in which the anthropocentric thrust of globalization is transformed by the recognition of an active, nonhuman nature and planet. ${ }^{132}$ Read in this genealogy, we might see the Anthropocene as the latest shift in the "spatial turn" that has characterized post-World War II discourse. ${ }^{133}$ Geographers 
are claiming that "human activity is now global" in an altogether new and different way from the wave of globalization discourse of the 1990s. ${ }^{134}$

The Great Acceleration reflects an age of speed, causing "a geologicallypaced plasticity" that, Nixon has cogently argued, must be countered by a rethinking of speed itself, a recognition of slow violence. ${ }^{135}$ To turn to slow violence is to historicize the discourse of globalization and to recognize that the experience of disembedding from place, time/space compression, and modernity itself were first experienced in the colonies. Thus, as I explain, island artists and writers have a particularly historical viewpoint of how these new forms of globalization are constellated through allegories that condense histories of empire, the human, and the more-than-human environment.

The Great Acceleration has been tied specifically to the creation of new materials-Cold War products_-such as minerals, plastics, pollutants, and inorganic compounds. ${ }^{136}$ This inaugurates the era of the "technofossil," a new stratigraphic signal of the Anthropocene produced by plastics and other materials that are globally distributed, such as CDs, cell phones, and ballpoint pens. ${ }^{137}$ Some claim that this "emerging technosphere ... may represent the most fundamental revolution on Earth since the origin of the biosphere." ${ }^{138}$ This era of disposability and the outsourcing of risk to poor communities across the globe has created an epidemic in worldwide waste and waste imperialism.

Since the allegorical mode is often communicated through powerful visual symbols, chapter 3 turns to the Dominican artist Tony Capellán, whose work placing recycled waste materials (flip-flops, plastic bottles) into a montage installation foregrounds Caribbean susceptibility to waste imperialism. Moreover, in connecting waste materials to state abuses of the Caribbean poor, particularly refugees, he allegorizes the economies of disposability that render objects and peoples as "matter out of place," to borrow from Mary Douglas. To render waste visible is to destabilize the hierarchies of social order. While Benjamin emphasized allegory's engagements with figures of entropy, Capellán displays plastic materials that are impermeable to decay: "hyperobjects," as Timothy Morton would term them, that foreground the new modes of more-than-human temporality of the Anthropocene, but in this case they are inseparable from trajectories of human mobility.

After a discussion of the "seametrics" of Kamau Brathwaite, the final part of the chapter shifts from the waste-making of the contemporary neoliberal state to the nascent nation-state of Jamaica in the 1960 s and its segregation of the urban poor into the "Dungle," a space of displaced agricultural 
migrants to the city treated by the pigmentocracy as "matter out of place." It continues a dialogue initiated in the opening chapter of the book about the relationship between the Earth, soil, and ruins, examining how allegory emerges in moments of social crisis. I examine how Orlando Patterson's first novel, Children of Sisyphus, positions the layering of human waste in the Dungle as a space of history. Through an allegory of ruins, Patterson depicts the ways in which urbanization transforms animated earth such as agricultural soil, clay, and cemetery dirt into the waste of the masses. In this way, Capellán, Brathwaite, and Patterson foreground the role of art and literature as allegories of collecting and memorializing the wasted human remains of capitalism and globalization.

\section{Oceanic Futures: Interspecies Worldings}

While the first section of Allegories of the Anthropocene engages constellations or "flashpoints" of understanding the histories of violence that constitute the Anthropocene, the second section of the book turns to the "anticipatory logics" of the planet's futurity. The ocean and the island-as-world are two vital allegories for the planetary future. In fact, sea-level rise is perhaps our most visible sign of the Anthropocene, causing a radical remapping of our terraqueous Earth, and is of particular concern for coastal and island residents, particularly in the global south. The ocean is integral to our climate system and life on the planet; consequently, shifts in ocean acidification, warming, currents, and thermal expansion affect all life on Earth. Studies of the ocean were first catalyzed by the early naval empires and, more recently, by Cold War science and extractive industries, paradoxically creating both the knowledge for exploitation and environmental awareness and stewardship. ${ }^{139}$ Like the Cold War atmospheric sciences that mapped the militarized irradiation of the atmosphere, oceanography has been critical to understanding the Anthropocene.

Chapter 4 engages with an interdisciplinary field that I have been calling "critical ocean studies," which is focused specifically on the materiality of the ocean and its nonhuman others. ${ }^{140}$ With the increasing warming of the oceans and their acidification (due to their absorption of anthropogenic carbon) we see a tremendous impact on marine species. Excess anthropogenic carbon has created a crisis for the atmospheric and oceanic commons. While the ocean is often referred to as a "carbon sink," an unfortunate term that invokes the way it has also been figured (in Latin) as the vastus, or 
waste, it is not just the water that absorbs carbon but the ocean's plankton. The $\mathrm{CO}_{2}$ that dissolves in the oceans alters the $\mathrm{PH}$ levels, thus lowering the level of available calcium carbonate that is integral to the shell forming of countless marine animals, including coral. Ocean acidity is the highest it has been for the past three hundred million years, and there has been an alarming expansion of marine dead zones due to sea floor anoxia, not to mention increasing oil spills. ${ }^{141}$

I focus here on the more-than-human aspect of sea-level rise because this chapter marks a transition from the "geo" of Anthropocene discourse to the "bio" of the field of multispecies studies. Anthropocene discourse, as much as it is concerned with historicizing the human in "nature," tends to render these terms in a binary in which their encounter becomes apocalyptic. Thus, each moment that the human alters the Earth, each moment of anthropogenesis, is depicted in an allegorical fall from "nature." Moreover, the figuring of the human as a species in geological discourse is contrary to the evidence that Homo sapiens incorporated other hominids in their evolution. In fact, we know from Donna Haraway and others that the human is inherently an interspecies figure when we consider the microbes and bacteria that maintain our bodies. This chapter turns to work in feminist and Indigenous studies that complicates the human-nature binary that the Anthropocene enacts by turning to relational ontologies, interspecies relations, and more-than-human biologies., ${ }^{142}$ While Crutzen and the journalist Christian Schwägerl have recently discovered that "nature is us," a whole body of interdisciplinary work has been deconstructing the nature-culture split that the term "Anthropocene" has thus far promoted rather than complicated. ${ }^{143}$ The humanities and social sciences have long been theorizing and complicating this binary between the human and the nonhuman world. Consequently, the fluidity of the ocean is a space in which authors have made these mergers increasingly apparent. ${ }^{144}$

While the multispecies and ontological turn is new to Anthropocene discourse, it has a long history in feminist and Indigenous studies. Therefore, this chapter 4 turns to Indigenous ontologies of the oceanic, or what Povinelli terms "geontologies" that do not recognize a human-nature disjuncture and provide a more nuanced allegory of the morphological impact of sea-level rise on the human. Indigenous writers of the Pacific have turned to the ways in which the history of transoceanic voyaging has contributed to a concept of the "sea in the blood," a merger of biological and genealogical histories. I trace out this potential for a dynamic rendering of queer 
kinship with nonhuman others by turning to the Māori author Keri Hulme's collection Stonefish (2004), which inscribes the ways in which rising sea levels generate adaptive mutations in plants, shellfish, and humans. Through experiments in allegorical form, Hulme's collection makes a vital intervention into apocalyptic visions of an oceanic future for the planet. While Amitav Ghosh has called attention to the formal challenges of writing climate change fiction due to the new recognition of an "uncanny intimacy of our relationship with the nonhuman," Indigenous authors, who have never accepted the western nature-culture binary, have long troubled the borders of both the human as subject and fiction as form. ${ }^{145}$ Thus, Hulme parodies heteronormative modes of apocalyptic fiction and aquadystopias, lending an important multispecies Indigenous framework of "sea ontologies" to complicate discourses of the Anthropocene that render a singular ontology of the human species.

\section{An Island Is a World}

All of the chapters in this book draw on the production of island writers and artists and their engagement with climate change brought about by the violence of empire. In different ways, they offer "counterallegories" to the way in which the tropical island has been figured in the western imagination as a space for allegorical forms such as utopia and dystopia, a tabula rasa for the making and unmaking of worlds. While this is not a new narrative given the history of (nuclear) colonialism, one could make a case for the appropriateness of dystopic allegories in the wake of sea-level rise, a challenge posed to the survival of millions of Caribbean and Pacific Islanders. The island is all the more urgent as a space for addressing climate change because of both sea-level rise and the fact that Anthropocene mass extinctions- "estimated to be 100 to 1,000 times more than what could be considered natural" ${ }^{146}$ are the most evident in island spaces. As such, the island becomes a figure of finitude - of spatial as well as temporal earthly limits. Most importantly, Caribbean and Pacific Islander writers, artists, and filmmakers have long engaged extinction, apocalypse, and "end of the world" histories and narratives that may be instructive for the reconfiguring the dominant discourses of the Anthropocene.

Chapter 5 broadens the scope to examine the allegory of the island-asworld in an age of ruins from the perspectives of western filmmakers and Pacific Islanders who configure the island-in-the-world. It examines the recent outpouring of documentaries about the threat to low-lying atolls and 
islands in the Pacific such as Tuvalu and their reinvocation of the islandextinction narrative. Their employment of what James Clifford, in another context, has referred to as "ethnographic allegory" to raise awareness about climate change results in a genre of mourning the loss of both island and nonhuman nature that I term "salvage environmentalism." While a generation of salvage anthropologists focused on the remains and "ruins" of Indigenous culture, I read these contemporary films in light of their attempt to salvage "the environment" in an era reconfigured by anthropogenic climate change. As documentaries, they are necessarily engaged with the process of world-making, particularly through the well-known trope of the island-asa-world. I examine how, in mourning the loss of atoll culture to a rising sea, the films decouple the Pacific Islander from modernity and suppress the causal links between industrialized continents and sinking islands. While these films rely on anachronistic allegories of the Pacific, I conclude by turning to the poet who opens this book, Kathy Jetñil-Kijiner, examining the ways in which she employs an Indigenous allegory of a gifted basket to foreground an intimate-and gendered-relationship with her readers/ audience that insists on both labor and accountability. Her poetry allows us to engage with a more complex and historically rooted allegory of the island-as-a-world that ultimately demands allegoresis-interpretive reflection, culpability, and action.

Bruno Latour argues that it "will be utterly impossible to tell our common geostory without all of us-novelists, generals, engineers, scientists, politicians, activists, and citizens-getting closer and closer within such a common trading zone." ${ }^{147}$ In this gathering I would be inclined to reduce the presence of generals (who are already overrepresented in their historical contribution to the violence of the Anthropocene), and to welcome postcolonialists, feminists, Indigenous peoples, agriculturalists and gardeners, fisher folk and foragers, artists and those who cannot be defined by labor, as well as more-than-human creatures, who are all at the periphery of Anthropocene scholarship and have compelling "geostories" about the complex and disjunctive relationship to place. The Anthropocene suggests that we are entering an epoch of anthropogenic fossils, of the "refuse of history," of ruins, and of the recognition of nonhuman nature as subject to history, which is to say, decay. Allegory allows us to tell that story-partially and disjunctively_-while insisting on our edification and perhaps offering an invitation to enact positive change for our ecological futures. 
CHAPTER ONE

\section{Gendering Earth}

\section{Excavating Plantation Soil}

The history of life is inextricably related to the history of soil.

—David montgomery, Dirt

The greatest event of the twentieth century incontestably remains the disappearance of agricultural activity at the helm of human life... . Now living only indoors, immersed only in passing time and not out in the weather, our contemporaries, packed into cities, use neither shovel nor oar; worse yet, they've never even seen them.

- MiCHEL SERRES, The Natural Contract

The recent scholarly turn to pinpointing an origin for the Anthropocene is caught up in the history of empire and modernity. Its allegories are primarily concerned with discourses of excavating the soil and the sediment of human history. While geologists search for the carbon and other isotopes that will mark a point at which humans trespassed a threshold point in their relation to the planet, they are coming up against humanities work that has already characterized these same moments of modernity in terms such as genocide, slavery, diaspora, and ecological imperialism. Thus, Anthropocene discourse has arrived belatedly to the scene of the violence of human history. In my effort to allegorize the Anthropocene, to place it in relation to particular contexts and histories, I seek to bring these discourses together so that they might mutually inform each other, demonstrating how Caribbean authors, who have long theorized and represented the rupture of modernity, might shed light on planetary challenges in an age of climate change. My definition of climate change, here as elsewhere, means a rupture 
to an ecological system. Following work in postcolonial studies that does not accept the settler colonial logic of dividing the human from nonhuman nature, I use the term "ecology" in this chapter, and in the book as a whole, as always already including the human. This builds on a large body of work in Caribbean studies in particular that has foregrounded the ways in which ecological imperialism has troubled western constructions of "nature" and the human relationship to place. ${ }^{1}$ In moving in scale from a planetary totality such as the Anthropocene to the figure of the postplantation island in the Caribbean, I pursue a series of allegories from Earth to earth (soil), particularly as constituted by transatlantic histories of modernity.

To parochialize the Anthropocene is to uncover its place-based allegories. This chapter argues that excavating the soil is a vital method of Anthropocene discourse and practice. In this sense the actual fragments of earth, which are material evidence of decay and the passing of time, reflect the story of the Earth writ large. One of the early origin stories of the Anthropocene (or the "Paleoanthropocene") is the rise of agriculture. In that narrative the human relationship to the soil was fundamentally altered, a process that unfolded over thousands of years that led to a stratigraphic signal of increased carbon as well as methane. This issue of enormous anthropogenic change to vast portions of the earth—a kind of early terraforming — has been brought forward into the more modern history of transatlantic empire. The geographers Simon Lewis and Mark Maslin argue that "the impacts of the meeting of Old and New World human populations-including the geologically unprecedented homogenization of Earth's biota-may serve to mark the beginning of the Anthropocene." While the word "meeting" minimizes the violence of European colonization of the Americas, we might use this as a starting point to investigate this moment of globalization in which all of the world's species, human and otherwise, were radically altered. Following Walter Benjamin's approach in which we engage a simultaneous "constellation of past and present," or, in other words, a "telescoping of the past through the present," ${ }^{3}$ we can read these multiscalar allegories of Anthropocene history as a means of figuring a contemporaneous moment of crisis in the human relationship to both Earth and earth.

\section{Allegories of Plantation Islands}

The Caribbean islands, newly positioned as originary spaces of the Anthropocene, are integral to the history of what Alfred Crosby has termed the "Columbian exchange" and ecological imperialism. ${ }^{4}$ From the decimation 
of Indigenous peoples of the region to the transplantation of Old World commodity crops such as sugarcane and coffee, European colonization radically changed the region, just as New World transplants such as tomatoes, chilies, maize, and potatoes permanently altered the diets of the majority of the people of the globe. Many have demonstrated that the food of the Americas, not to mention commodity crop labor, "undergirded Europe's rise to world dominion between the eighteenth and twentieth centuries." While the Anthropocene has been tied by Paul Crutzen and Eugene Stoermer to an originary "steam engine thesis," humanities scholars would point out that it is undergirded by the history of transatlantic empire and slavery, the radical dislocation of humans from their ancestral soil, and a violent irruption of modernity that predates the industrialization of nineteenth-century Europe. ${ }^{6}$ This history has catalyzed new terms to examine the origins of our planetary crisis. Jason W. Moore, borrowing from Andreas Malm, has developed a critique of what he calls the "Capitalocene," explaining that "capitalism is a way of organizing nature as a whole ... a nature in which human organizations (classes, empires, markets, etc.) not only make environments, but are simultaneously made by the historical flux and flow of the web of life." Since capitalism was constituted by transatlantic slavery and the plantation system, the term "Plantationocene" has recently been adopted to further specify the ways in which an economic and political system of empire is exacted on the earth. ${ }^{8}$

A critical engagement with narrative is vital to understanding the ways in which we represent ecological crises, and a fundamental contribution made by scholars in the environmental humanities.' Scholars have established that the allegorical mode was integral to representing the colonial violence of transatlantic empire and the plantation, particularly in the cartography of the island Americas. ${ }^{10}$ Cartographic allegories materially extend "Old" World landscapes onto the "New," in which American landscapes and peoples were assimilated, appropriated, and rendered familiar (and often lifeless). ${ }^{11}$ Antonello Gerbi has shown that the novelty of Caribbean flora and fauna caused a radical shift in European conceptions of human and nonhuman difference, as well as shock about the deep history of the globe. ${ }^{12}$ The island, with its terrestrial boundedness, became foundational to figuring a newly encountered world. As Richard H. Grove has explained, the tropical island became "in practical environmental as well as mental terms, an easily conceived allegory of a whole world. Contemporary observations of the ecological demise of islands were easily converted into premonitions 
of environmental destruction on a more global scale." 13 To Europeans, the island colony became a space of social and ecological experimentation and, due to the island's boundedness and finite resources, the site of the earliest environmental conservation, underlining the close relationship between ecology and empire. ${ }^{14}$ Despite Indigenous genocide, transatlantic slavery, environmental destruction, and species extinctions, colonial authors and armchair travelers continued to figure the Caribbean island in terms of Christian allegories of paradise; as Grove explains, "For this redemptive purpose the island was the ideal allegorical, practical and botanical symbol and desired place of abode." 15

As the authors of the volume Caribbean Literature and the Environment detail, ancient Greek and Christian allegories of paradise were transposed onto the Caribbean islands to render them as hyperbolic fecundity. For example, Nicolò Scillacio was convinced by travelers' reports of the Caribbean to proclaim in his epistle of 1494 that one could plant any seed in Guadeloupe, "for the soil rejoices ... and never reject[s] anything that you throw in it; it accepts nothing without giving it back much more abundantly and with great increase." ${ }^{16}$ This Edenic myth of fertility confused plant diversity with an extraordinary yield for food, suppressing the material realities of labor and leading colonists, armchair travelers, and many a current-day tourist to assume that one need not labor for sustenance in tropical climates. ${ }^{17}$ Myths of soil and climate fecundity prevailed, even when, as early as 1769 , monocrop agriculture had exhausted Barbadian soil to the extent that an attempt was made to import richer soil from Dutch Guiana.

The European allegory of the paradisiacal island took many forms and was visible in Caribbean cartographies, in poetry, and even in the naming practices of sugar plantations as "Eden" and "Hope," a suppression of the violence of genocide, diaspora, and slavery. It also permeated British poetry about the region, in which eighteenth-century writers such as James Grainger could wax on in Georgic prose about the "the cultured soil" that "charms the eye" in his epic "The Sugar Cane: A Poem, in Four Books." 18 This figuring of the Caribbean as a pastoral allegory is decidedly about the suppression of colonial modernity, the use of allegorical master narratives from Christian, classical Greek, and western European contexts to cover over the rupture of colonial violence. It is precisely this tension between "paradise and plantation," to draw from Ian Gregory Strachan's book title, that has informed a large body of work in Caribbean island writing. ${ }^{19}$ Authors such as Jamaica Kincaid, Olive Senior, Lorna Goodison, Shani Mootoo, and Merle Collins 
have turned to the allegory of the island garden and "excavated" the soil to explore the violent process of sedimentation and creolization. ${ }^{20}$ While the complex diasporas of plants and peoples in the Caribbean problematize the notion of "natural" history and its segregation from human agency, this historical process is also tied to particular literary forms, especially allegory.

Since allegory signifies a rupture between the present and the past even as it attempts to place them in symbolic relation, it has become an important narrative mode for Caribbean writers concerned with historiography. This engagement with history is figured through constellations of the present, as Édouard Glissant argues in Caribbean Discourse:

The past, to which we were subjected, which has not yet emerged as history for us, is, however, obsessively present. The duty of the writer is to explore this obsession, to show its relevance in a continuous fashion to the immediate present. This exploration is therefore related neither to a schematic chronology nor to a nostalgic lament. It leads to the identification of a painful notion of time and its full projection forward into the future, without the help of those plateaus in time from which the West has benefited, without the help of that collective density that is the primary value of an ancestral cultural heartland. That is what I call a prophetic vision of the past. ${ }^{21}$

While Benjamin's "Angel of History" is the witness to the wreckage of the debris of the past as he is blown backward into the future, Glissant's allegory of progress is constituted by an "obsession" with the past because it has not yet been excavated and narrated. ${ }^{22}$ He contends that Caribbean history is characterized by "ruptures" and "brutal dislocation," where "historical consciousness could not be deposited gradually and continuously like sediment." ${ }^{23}$ Here the soil is both material and a vital allegory for excavating the violence of the past. Not only is the narrative result is a "tormented chronology of time" and space, but it suggests that the (subjugated) past, suppressed in dominant historiography, becomes "obsessively present." 24 This history of empire, diaspora, and resettlement necessarily foregrounds the ways in which the violence of plantation societies ruptured continuous human relationships to place and thus to earth (soil) and Earth (planet). Here I want to tie this particular experience of rupture to allegory and its uses in one particular novel of speculative fiction by the Jamaican author, sociologist, and historian Erna Brodber, which allegorizes Caribbean historiography through the gendered figures of Earth, soil, plot, and plantation. 
Published to commemorate the bicentennial of the British abolition of the slave trade, Brodber's novel The Rainmaker's Mistake (2007) stages a kind of "pilgrim's progress" as her multiple characters move from their understanding of the plantation as an island "paradise" to their awakening to a recognition of slavery, freedom, sustainable agriculture, reproductive futurity, and mortality. Like Anthropocene discourse, it is very much concerned with beginnings and uses allegorical narratives to uncover the various origin stories of the people's broken relationship to agriculture, to the soil, and to the Earth. One of her characters becomes an archeologist, literally exhuming the soil for traces of their genealogical past and their subterranean slave mothers. Like the larger genre of speculative fiction to which it belongs, the novel utilizes many of the characteristic elements of allegorythe story is staged like a quest, and there is ample semiotic play between the concepts of planting and transplantation, roots and rot, seed and semen. Brodber engages the allegories of empire that constituted the naming of enslaved plantation workers by including a cast of characters named Cupid, Essex, London, Jupiter, Venus, Queenie, and Little Congo. Like Anthropocene narratives, the novel is concerned with locating and memorializing the particular history of a rupture between humans and place, earth and Earth, "species" and planet. It is by locating this rupture that her characters feel they are able to enter history. The narrative they uncover, the "rainmaker's mistake," has ecological implications that unleash what Glissant has called a "prophetic vision of the past."

The historical entanglements and ruptures I have foreground here take on spatial effects. Brodber's allegory of Caribbean history is spatialized across different islands; the characters move from their plantation past to a subterranean realm where their entombed slave mothers are buried in the sediment of history. Other locations include the "Norm," the "Future" and the "Pluperfect," a temporalizing of space that the characters visit in their travels and travails to achieve "naturalness." 5 This quest for "naturalness," a place and time when the human was not figured outside of nonhuman nature, is both a concern of Anthropocene writing as well as a larger issue for thinking about how diaspora influences a people's relationship to land, and by extension, narrative. It is integral to Glissant's contention that the violence of plantation modernity alienated humans from nature, a point made all the more visible in the body of Caribbean literature that engages nonhuman nature through the narrative tropes of plants and transplantation and through the figure of the island garden as world. ${ }^{26}$ I would like to add to this body 
of work by engaging Brodber's excavation of an alternative history of roots that are located outside the plantation fields. The Rainmaker's Mistake thus imagines the sustaining roots of the slave provision grounds, allegorizing the concept of roots as it is imagined through one African transplant-the yam-and its acclimatization to Caribbean soil. Her novel provides a vital interrogation of Caribbean historiography, that "instinct and root impulse which returns the better West Indian writers back to the soil," as George Lamming observed, ${ }^{27}$ and complicates the recent turn to the Plantationocene which overlooks the more sustaining — and feminized—underground narratives of earth/Earth.

\section{Roots, Plots, and Provision Grounds}

Caribbean historical production has mainly focused on the cultural economies of the plantation, turning to the racial terrors of forced agricultural labor to produce such important theories as "transculturation," creolization, and "nation language." 28 In the wake of this production, John Parry has countered that that Caribbean history should be "the story of yams, cassava and salt fish, no less than of sugar and tobacco," suggesting that models of Caribbean historiography have prioritized metropolitan frames of the plantation rather than local production. ${ }^{29}$ This remapping has narrative effects. As Sylvia Wynter has argued, Caribbean history and literature can be understood in the socioeconomic divisions between the master's plantation, on the one hand, and the slaves' provision grounds, on the other. ${ }^{30}$ Wynter's insights are relevant to how scholars excavate Caribbean history and the ground on which cultural archeology is conducted. In general terms, the plantation is understood to represent Euclidean grids of monoculture, defined as a European social hierarchy and as the commodity cultivation of nonsustainable crops such as sugar and tobacco for external markets. The provision grounds, with their diverse intercropping of Indigenous and African cultivars, are understood as the often unseen-but no less integralvoluntary cultivation of subsistence foods such as yams, cassava, and sweet potatoes that represent edible staples and the economically viable roots of the internal markets. Plantation monoculture drove the logic of the external markets and became the primary lens through which Caribbean historiography was initially written. Yet the diversity of crops grown in the provision grounds was integral to the diets of all social strata of Caribbean slave states and provides a broader ground for cultural archeology, figuring 
as an important "root" allegory in Brodber's novel. Moreover, this movement to rethink the material histories of the Caribbean outside the plantation system (or through its peripheries) points us to a more complex and lateral understanding of the earth/Earth than the terms "Plantationocene" or "Capitalocene" can provide. ${ }^{31}$

The recuperative power associated with the soil of the provision grounds is essential to addressing the rupture of plantation modernity and drives much of the narrative of The Rainmaker's Mistake. The Latin homo derives from the term for living soil, bumus; this etymological and ontological relationship between human presence in a particular place, ancestral roots in the soil, is of pressing concern in the Caribbean in terms of both the history of diaspora and in addressing contemporary crises in the islands-particularly flooding and soil erosion-in an era of globalization and climate change. ${ }^{32}$ Reading the constellations of the past through the crises of the present, we can see that this narrative desire to recuperate a "natural" relationship to the soil reflects both the ruptures of colonial modernity and postindependence pressures in the Caribbean that have caused agricultural alienation and outmigration. In other words, a crisis in the relationship to the soil and to Earth might be positioned simultaneously as deriving from plantation slavery and diaspora, neoliberal displacement from agricultural practices, and threats of sea-level rise and other signs of climate change that disproportionately impact tropical islands.

The perceived split between the human and nature that Anthropocene discourse renders visible is deeply tied to empire. Glissant made this legible in his well-known argument that the history of diaspora and enslavement created a rupture in the Caribbean relationship to land, creating a division between nature and culture. ${ }^{33}$ In recuperating this relationship, he explains, "Describing the landscape is not enough. The individual, the community, the land are inextricable in the process of creating history. Landscape is a character in this process. Its deepest meanings need to be understood." ${ }^{34}$ Since the etymological roots of "diaspora" derive from spore and seed, this provides an apt metaphor for the forced transplantation of peoples and plants and the ways in which countless crops, including sugarcane, breadfruit, coffee, nutmeg, mango, and other staples of the region, have adapted and been naturalized. To recuperate this inquiry into the relationship between human and natural history is, in Glissant's terms, to produce a "language of landscape." 35 This excavation of the provision grounds reflects the historical "plot" of cultural sustainability amid the terrors of plantation 
capitalism, providing vital ground for the postemancipation period and unearthing a contemporary agricultural crisis.

Wynter explicates the process by which the European colonization of the Americas alienated humans from nonhuman nature, reducing humans to labor "and nature to land." This provided little space for alternatives except through the provision grounds, which, originally intended by the planters to reduce the plantation's operative costs, created a plot system that "like the novel form in literature" became "the focus of resistance to the market system and market values." She argues that key to the development of this plot system was the noncapitalist sensibility of Africans who associated the land with life (rather than with property), who understood cultivation in terms of food production, employed nonlinear models of time, and perceived death and burial as a "mystical reunion with the earth." ${ }^{36}$ Wynter refers to the plot as "the roots of culture" and mentions only one food product of this alternative space. "Around the growing of yam, of food for survival," she writes, the provision ground laborer "created on the plot a folk culture-the basis of a social order." ${ }^{37}$

That Wynter locates the yam as the foundation-or, more literally, the root-of a new social order is not surprising, given this tuber's association with transplantation to the Caribbean across the Middle Passage by Africans. ${ }^{38}$ As Barry Higman points out, during the height of the colonial plant trade, no major efforts were made to transplant the roots and tubers that, while not especially pleasing to the eye, were key to sustaining the majority population of the globe. ${ }^{39}$ Nevertheless, when we turn our attention from descriptions of the colonial botanical gardens to eighteenth-century accounts of the provision grounds, almost all mention the yam as a primary root vegetable. ${ }^{40}$ So important was this staple to the provision grounds that they were often called yam grounds. ${ }^{41}$ The yam was a preferred food of Africans and their descendants, a bread kind that was more accessible and sustainable than the European cereal breads, the ingredients of which were imported at great cost from the temperate zones. Higman explains that the Jamaican term "food" refers to starchy roots and tubers, and the term "food-kind" is the synonym for yam and other starches such as plantain and taro (eddoes). ${ }^{42}$

Yams were vital to the provision grounds because they fit well in the ecological niche of the food forest, they were less demanding on the soil than cereal crops; their long growth and low maintenance were beneficial to the enslaved gardeners who had to travel miles to work there'; and they were essential to rooting Jamaican peasantry in the land, connecting each 
generation through cultivation, labor, and foodways. ${ }^{43}$ Thus, the yam has been an important trope in Caribbean literature, essential to human sustenance and an important figure of roots culture, in which history might be reckoned through a genealogy of cultivation traced to African ancestors. The yam's location in the provision grounds outside the plantation complex (often out of view), as well as its subsistence underground (where it stores nutrients for the community), underlines its significance as an invisible resource that must be physically and imaginatively sought, cultivated, and excavated in terms of both time and space. Temporally, the yam is directly linked to the history of African transplantation, while spatially the root reflects a shift from plantation to provision grounds and, ultimately, to an African past. Yet the symbolism of the yam is deeper as an allegory of transplanted culture, history, and even language itself.

Anthropocene scientists are concerned with excavating the sedimentation of human history, but the food systems of the post-I 492 Americas in this reckoning system are visible only in their absence. In the Anthropocene search for fossils, the genocide of Indigenous peoples of the Americas and the destruction of their agricultural systems can be registered only through the lack of carbon in the stratigraphic register after conquest. This drop in atmospheric carbon signals their absence. We know from Michel-Rolph Trouillot about the silences of history, particularly as they are created by empire. ${ }^{44}$ But rarely do we find evidence of their uncanny materiality echo across the centuries. This raises the question of the gaps in geological history, which may never register the labor of the millions of Africans transported to the plantation Americas but would register the spike in carbon from the deforestation that made the Plantationocene possible. Consequently, in the recent shift to the "geohumanities" and the turn to "geologics," we must question the facile suturing of sedimentary fossils to human histories. The fossil record is an archive that demands a dialectical interpretation that allows for the incorporation of absence as much as presence.

These questions about the missing registers of history have been critical to the region's poets and historians. For instance, Kamau Brathwaite has theorized the relationship between transplantation and subterranean history, particularly in the semantic play between the words "yam" and nyame. The Jamaican term nyam derives from a number of West African languages for the word for "to eat." ${ }^{45}$ Brathwaite excavates "underground resources" and explains nam as a "secret-name, soul-source, connected with nyam (eat), yam (root food), nyame (name of god)." ${ }^{46}$ If the act of planting naturalizes a relationship 
between people and place, the diasporic subject and his or her descendent "would plant his yam and with it... [a] little piece of Africa on mourning ground." ${ }^{47}$ In this word play between "mourning," and "mooring" Brathwaite foregrounds the relationship between land and loss. "Nam is the heart of our nation-language," he declares, and it is thus an allegory of subterranean roots as well as the vehicle of articulation and reassemblage itself. ${ }^{48}$ These narratives about recuperating a "mourning ground" are about the rupture of modernity created by the violence of empire. Since capitalism and empire turned earth/Earth into property and segregated humans from nonhuman nature, and thus nature from history, the use of organic metaphors of "roots culture" naturalizes-or, to draw from Glissant, sediments-a population in place. ${ }^{49}$

The Oxford English Dictionary defines "root" as an origin, the founder of a familial lineage, a source of sustenance, and a foundation. It also signifies the penis, highlighting how the seminal roots of diaspora often uphold a patriarchal model of colonial transplantation as well as patronymic claims on its descendants. Caribbean scholarship has troubled many of the patriarchal and ethnically absolutist claims of roots culture in an effort to explore more rhizomatic, creole identities. This creates a productive tension between the semantics of "roots" and "rhizome," a tension that fuels Brodber's speculative novel, as well as current thinking about how to position African roots as foundational in an era that speaks of the decentralizing, rhizomatic qualities of creolization. The yam thus provides a figurative model that is tied directly to Africa yet exceeds a singular root culture and emphasizes regeneration in the wake of the violence of modernity..$^{50}$ For instance, Nalo Hopkinson writes:

One threat of Caribbean history is of peoples who were forced to chop away their native languages, customs, and beliefs in an attempt to make them into ciphers without memory. But language, custom and belief are growing things. Chop them up and, like yams, they just sprout whole new plants. To re-member is to reassemble the limbs of a story, to make it whole again. A sense of history gives these next few stories limbs-branches with which to grasp at and weave centuries' worth of dis-membered deeds. ${ }^{51}$

Here the yam provides a vital allegory for articulating the violence of transplantation and to foregrounding the imbrication of African roots and the soil. Encoding the violence of cultural fragmentation, as well as potential for regrowth, the story of the yam becomes what Jenny Sharpe might call a 
"counterallegory" to the plantation plot, a narrative of African regeneration in a new soil, a sustaining root in a creolized Caribbean. ${ }^{52}$

The discourses of the Plantationocene and Capitalocene may help raise questions of accountability for our Earth crisis, but they do not allow a "grounding" in the specificities of the soil. Caribbean scholars engaged here suggest that we turn to those sites that served as foundational repositories of Indigenous and African beliefs and rebellion against plantation capitalism. The sites need to be excavated not as the Edenic gardens of the early allegories of empire but, rather, as spaces entangled with the violence of modernity and in the networks of plantation capitalism. While Africans and their descendants were able to maintain agricultural traditions with crops they imported across the Middle Passage, such as yams, ackee, gourds, and other staples, these were also valuable commodities. The provision grounds supplied the internal markets of the Caribbean and contributed a vibrant, parallel economy to the monoculture of the plantocracy. Ira Berlin and Philip Morgan estimate that by the late eighteenth century, more than ten thousand Jamaican slaves attended the Kingston market weekly. The success of the internal markets caused planters to complain that one-fifth to one-half of the currency in Jamaica and the Windward Islands was in the hands of enslaved people. ${ }^{53}$ In addition to being a stepping-stone toward liberation, the slave gardens were a powerful site of creolization. Enslaved subjects grew "a staggering array of crops," blending European, African, and American cultigens that included cashews, bananas, calabashes, calalu, okra, oranges, and other fruit and spices. ${ }^{54}$ Provision grounds were distinct from the small gardens that people grew in their "home ground" or yards; they reflected the less accessible and often mountainous land bequeathed from plantation owners because it was deemed unfit for sugarcane. ${ }^{55}$ In these distant plots, enslaved gardeners and their peasant successors cultivated root and tree crops, as well as grains and legumes, for communal use and market distribution. In these spaces, Brathwaite explains, on that "sacred plot of land where slaves wd plot," they found "groundation." 56

Caribbean planters were largely dependent on the African and Indigenous crops of the provision grounds, which were a vital component of the islands' internal economies and were integral to the region's transition to emancipation and independence. ${ }^{57}$ In islands where enslaved laborers grew the majority of their own sustenance, such as Jamaica and St. Vincent, the planters were placed in a contradictory bind. By setting aside time and space for enslaved people to cultivate root staples such as plantains, yams, taro, and 
corn, the planters saved money on food imports and discouraged runaways by providing an opportunity to cultivate a link to the soil and community. Yet they also inadvertently supported a vibrant internal market economy in which enslaved gardeners provided the majority of the region's sustenance and gained significant amounts of currency, autonomy, and even freedom. ${ }^{58}$

Recovering the "sacred plot of land where slaves wd plot," as Brathwaite terms it, foregrounds how space (a plot of land) produces narrative (emplotment). ${ }^{59}$ Likewise, Wynter has argued that the antinomy between the plantation and provision grounds remains "the distinguishing characteristic" of Caribbean narrative. Building on the work of Eric Williams and Lucien Goldmann, Wynter demonstrates how the people transplanted to the Americas and the novel itself were simultaneously the creators and products of capitalism. Thus, the novel (as form) and plantation societies are "twin children of the same parents"; the novel, like slave society, is both critique and product of the market economy, imbricated in the modernity of empire. $^{60}$

Allegory is caught up in the master narratives of tradition and thus has a particular way of staging the disjunctive relationship to the past. It is particularly useful in engaging how the plantation elites inscribe what Wynter calls the "myth of history," representing external metropolitan forces. ${ }^{61}$ This is part of a larger critique she has lobbied about the ways in which the postCopernican world of nature was systematized to overrepresent rational "Man," a colonial construct that arose from a racialized civil and legal discourse that also "legitimated the subordination of the world" through the "systematic stigmatization of the Earth" as "'vile and base matter." 22 This "quarrel with history," to borrow from the cultural critic Edward Baugh, was a major debate in anglophone literary production in the wake of independence. ${ }^{63}$ Wilson Harris and Brathwaite have shared Wynter's critique, warning that "the plantation model ... is in itself a product of the plantation and runs the hazard of becoming as much tool as tomb of the system that it seeks to understand and transform," a warning that we might liken to allegory itself. ${ }^{64}$ The provision grounds, Wynter explains, provided the space for folk knowledge, orality, and African and Indigenous continuities. The Caribbean response to the relationship between plantation and provision ground, which are also "twin children of the same parents," is characterized by "ambivalence." Moreover, this ambivalence, Wynter argues, is the "root cause of our alienation and possibly our salvation." 65 It is this question of an eartbly salvation that is an undercurrent in the allegory of the provision 
grounds, a turn to the soil to figure alternative possibilities for the past and present.

This ambivalence about the form of the plot is a foundational (but overlooked) thread of Wynter's article and has important resonance with Harris's long-term critique of realist narrative and materialist approaches to history. In History, Fable, and Myth in the Caribbean and Guianas, he argues that Marxist methods are limited because they are unable to draw on "unpredictable intuitive resources" that might liberate subjects and spaces from relations of property. ${ }^{66}$ Thus, he argues that West Indian historians have relied too heavily on the plantocracy's model of history, reducing land and slave labor to economic relations. ${ }^{67}$ Harris poses a remarkable challenge to Caribbean historiography because he implicitly critiques the progressive narrative of liberation from slavery that has informed so many regional novels. He argues that as a narrative mode, "progressive realism erases the past. It consumes the present and it may well abort the future with its linear bias." 68

In reading these allegories of the soil we can better comprehend the symbolic exchange of much Anthropocene discourse. Harris, like other Caribbean writers, excavates the local for a model of literary form that he feels more accurately reflects the complexity of Caribbean roots. He determines that the "the soil of history" is a literary resource, rendering the earth "the living fossil of buried cultures." ${ }^{69}$ Like the subterranean excavations of geologists (or archeologists in Brodber's novel), we find not dead matter but "living fossils," strata that we might read like a book about "buried cultures," paralleling an Anthropocene turn to theorizing the memory of the Earth and its chronicles of human history. ${ }^{70}$

While Brathwaite located language as arising from this "mourning ground," to Harris, the nonhuman world is also constitutive of language and therefore literary form. He writes, "When the human animal understands his [or her] genius, he [or she] roots it in the creature, in the forest, in the trees ... in the language which we are and which we acquired, not only from our mother's lips but also from ... the music of the earth as we pressed on it.... All those sounds are threaded into the language of the imagination." ${ }^{71}$ Language and knowledge production is expressed in a phenomenological rooting of the human in an active landscape, a dialogue with nonhuman nature (and therefore space/time). ${ }^{72}$ Harris poses a critique of a singular model of roots culture that does not incorporate creolization and complexity, that eschews the "contrasting spaces" of the plantation and the provision grounds, and that shrinks from "ambivalence" in both topic and form. His 
preferred genre of articulating the "density of place" is the allegorical novel, a form that has not been particularly visible in an anglophone region known for its social realist novels. Well before the debate between Fredric Jameson and Aijaz Ahmad over whether allegory was the appropriate form for postcolonial literature or merely a colonial inheritance, Harris observed that "allegory is one of the ruling concepts which our civilization has imposed on many colonial peoples," but one can approach this form "from the victimized side and renovate it ... so that allegory is not a museum piece." ${ }^{.73}$ It is this complicated relationship between place, history, and form that I would like to explore by turning to Brodber, whose work has long been influenced by Harris's theories of form. The gendered challenges she poses to the realist plot of liberation history are far-reaching, demonstrating a critical ambivalence about the relationship between the plantation and provision grounds and the mutual imbrication of their roots.

\section{The Garden and Allegory}

Allegory is polysemous and embedded in specific historical places and contexts, meaning that it does not travel easily across time. This is why it can be disorienting to read. It disrupts expectations of chronological sequencing and constructs coexisting parallel spaces and temporalities. Instead of characters, allegory employs personified concepts (such as truth, freedom and death) more than individualized human subjects. ${ }^{74}$ Even though The Rainmaker's Mistake was nominated for a Commonwealth Literature Prize in 2008, most reviews express confusion about the text, determining that the novel is "impossible to follow and yet beautiful to read." 75 In keeping with allegorical form, The Rainmaker's Mistake is not written in the realist language of individual subjectivity. In fact, the writing pushes beyond the materialist boundaries of the plantation context and historical realism. Published to commemorate the two-hundredth anniversary of the British Slave Trade Act of 1807 , the novel has a gloss from Brodber on the back cover, explaining her interest in how postemancipation people of African descent interpreted their freedom. The present anniversary thus provides a constellation through which to reflect on the past. Basing the temporal movement of the novel on the granting of freedom through the Slavery Abolition Act of 1833 , Brodber explains, "We watch the formerly enslaved as they try to handle freedom, and as they arrive at understandings concerning the issues and processes relating to their diaspora, settlement, and stunted growth." ${ }^{.76}$ 
In writing on the Anthropocene, Dipesh Chakrabarty points out that "freedom has been the most important motif of written accounts of human history of these past two hundred and fifty years," but that concept of freedom has not been linked to human geological agency and the processes that led to our current climate crisis. ${ }^{77}$ He makes an odd disjunction, because one might raise the question as to what the liberation of enslaved people from an island plantation economy would have to do with global warming, particularly when the Caribbean islands have produced a negligible amount of atmospheric methane and carbon compared with the rest of the world. Yet through allegory, a pedagogical form about the process of interpretation, Brodber stages the ways in which understanding the concept of freedom and the preplantation past leads to a dialectical—or perhaps tidalecticalengagement with "nature-history." ${ }^{78} \mathrm{By}$ extension, this generates accountability in the human relationship to the Earth. I pursue this reading in accordance with the allegorical process by which her characters come to this understanding.

Allegory disrupts chronological modes of time and space; accordingly, it is not easy to wrest a summary from this opaque novel because Brodber does not provide a plot by which we would recognize the postemancipation Caribbean. Certainly, Harris's allegorical work has influenced Brodber's novel, as she is equally concerned with ethical ideals such as truth, history, freedom, and death and, to address them, inscribes "vessels" of history such as ships, planes, and women's reproductive bodies. ${ }^{79}$ Moreover, her characters also travel between past, present, and future, collapsing linear models of time and narration. Her work differs from Harris's in that her rendering of history is about decay, figuring what Benjamin termed Naturgeschichte (nature-history), which "appears not in bud and bloom but" in "irresistible decay," representing human subjection to entropy. ${ }^{80}$

The telos of individuation so favored by the social realist novel is challenged in that The Rainmaker's Mistake is narrated by seven different characters who attempt to understand the plantation past and the concept of Freedom and embrace a mortality that is coded as "naturalness." Her figuring of the human has challenged the audience; as Carolyn Cooper notes, one person shifts into another's perspective, and in some cases characters acquire different allegorical names as their knowledge of their pasts develop. ${ }^{81}$ Like all allegories, the novel does not locate itself in any easily identifiable place or nation, and rather than charting progress (toward emancipation, nationalism, sovereignty), the novel allegorizes the desire for growth and the processes 
that bring growth into being rather than the temporal product. In that sense she depicts the human, à la Wynter, as "a praxis" rather than product. ${ }^{82}$ As a historical novel about emancipation, The Rainmaker's Mistake uses allegory to pose an ontological alternative to the teleological plot of liberation.

Allegory is concerned with founding myths and their disjunctions. Accordingly, the text opens with the first-person narration of the child named Queenie, who describes the founding myth of a man whom we later discover is her slave master. Mr. Charlie, a man who is not labeled by race but is described as "reddened and hardened by the sun," decides that he wants more than his plot of corn, plantains, and cassava. To shift from sustainable plots to plantation capitalism, he declares that he needs labor. Inspired by the "phallus-like dependents of each flower" of the African tulip tree, "an idea popped into his head": "Straightway he walked to the place where he did his 'do's." Eyes glazed and into the future, he pulled his shirt out of his trousers, loosened the flap of his fly, knelt down and with his fingers roughened and hardened by tedious labour, he dug a hole in the ground and planted a wash of seed from his body" (I-2). Literalizing the definition of "root" as penis, and "diaspora" as the spreading of seed, this act is narrated as the originary creation story of the enslaved characters and thus makes his progenitor myth their history and ancestry. Queenie explains, "[This act] made us young and old, big and small, male and female, brothers and sisters, children of one father dug from an everlasting underground source" (2). Mr. Charlie tells this story to the children of the soil when they gather at his house at a yearly naming ceremony called "founder's day." They are instructed to repeat their origin narrative to their younger siblings, reiterating how everyone has been "cultivated by Mr Charlie, Our Father, Our Maker, our Preserver" (2). Like the colonial myths of paradise, the plantation island is described as a "garden of Eden" (I6).

This is a remarkable opening to a novel concerned with the myths of origin as they are rooted in the soil, depicting the literal planting of seed into a receptive, feminized, and passive earth. As readers, we are not immediately told about the form these seeds take in the soil, and our allegoresis follows the learning process of the characters. Queenie reiterates Mr. Charlie's narrative: "That founder's day is our day to celebrate his lifting us from beneath the earth and placing us on top of the earth to realize our creativity" (6). As progenitor, narrator of their origins, and midwife to their "unearthing," Mr. Charlie takes on the patronymic role of divine creator. The novel's delay in explaining the form of these developed seeds reflects Queenie's 
own alienation from a language or narrative to articulate her origins. Consequently, it is from another source that we discover that she and her cohort are not humans but yams. This narrative comes from Woodville, the plantation overseer who describes to the children the different types of yams, the sevenand nine-month gestation periods, and the conformity of the "dark-brown" outside (7). Confusingly, the yam narrative reflects an allegory of roots culture, but with a plantation master as progenitor. In a complementary narrative of patriarchal origins - one presumably from Europe, the other from AfricaQueenie explains: "What Mr Charlie planted on that first day, Woodville tell us, developed under the ground into yams which Mr Charlie carefully releases from the bosom of the earth, removes to his nursery where they develop heads with eyes, ears, a mouth, and so on, until they are ready to be passed on to the big sisters for further growing" (8). The slave community is provided with a narrative of androgenesis: the European father/creator provides the originary seed (a genealogy ritualized through founder's day), and the African ancestor provides the plot and the form. In these origin stories of husbanding the land, the soil and earth become the stand-ins for women's reproductive roles, erasing the agency of women altogether except as a passive maternal "bosom" or receptive "sister." This is not all that different, in narrative terms, from the colonial myth of fecund islands in which European men could plant a seed and "the soil rejoices... and never reject(s) anything that you throw in it; it accepts nothing without giving it back much more abundantly and with great increase." Nor is it all that different from the masculinist "Age of Man" claimed by some theorists of the Anthropocene.

Brodber poses a challenge to the normative plot of emancipation history, employing allegory to collapse the spaces of the plantation (Mr. Charlie) and the provision grounds (the people of the yam), suggesting their mutual imbrication into ecological modernity. As a genre, allegory has been noted for its episodic structure, its summoning of ancestors into a dialogue, and the way it frames meaning through ritual and initiation (evident in the seed planting and founder's day). It is also notable for providing its own interpretive cues, directives from its characters that assist in allegoresis. ${ }^{83} \mathrm{As}$ many have noted, allegory is "other speaking" (from the Greek allos, other), a form of double talk that "inverts" meaning. ${ }^{84}$ The word "allegory" derives from agorevo, speaking in the marketplace, a suggestive etymology when considering the form's double talk in relation to creole, a codified language that developed to be impermeable to plantation masters. It also speaks to the Caribbean history of economic exchange, including the slave markets. ${ }^{85}$ 
Most significant to this novel's depiction of the ambivalence between plantation and provision ground, allegory encodes a "rift at its center," an aporia that cannot unify sign to signified, word to meaning, or present to past. ${ }^{86}$

Allegory's relationship to the past and its rupture with history has been a vital concern to theorists of the form. Stephen Slemon has argued that "awareness of the passage of time is at the heart of allegory," because the genre is in a dialogue with narratives of history and tradition. ${ }^{87}$ Deborah Madsen observes that "allegory has become a response to the sense of perpetual crisis instilled by modernity; the awareness of an unbridgeable chasm separating an incomprehensible past from an always confusing present moment." Brodber's use of allegory to commemorate the bicentennial year in 2007 highlights the way that this form "flourishes at times of intense cultural disruption," a rupture signified by Queenie's attempt to excavate the roots of transplantation associated with the natural symbolism of the yam. ${ }^{88}$ It is by denaturalizing and gendering the narrative of roots, what Annie Paul calls an allegorical transition from "yamhood to personhood," that exposes this historical and semiotic rift. ${ }^{89}$

The garden is one of the most established allegorical symbols and, as explained, has been foundational to European narratives (and material practices) of island colonization..$^{90}$ Interestingly, Brodber uses the biblical allegory of a fall from (plantation) paradise, in which growing knowledge of racial mixing, freedom, heterosexual reproduction, and history constitute a rupture in narrative and in their relationship to their androcentric origin story. She depicts a prelapsarian narrative in which originally the community renders time in terms of "the number of yam seasons" (IO) and sees the slave plantation as "the garden of Eden [where] every material need [is] met" (I6).

The garden of Eden narrative is ruptured by knowledge of the racial violence that led to Caribbean creolization and by cognizance of colonial history. Consequently, two moments of rupture disintegrate the allegory of the yam and, by extension, the characters' sense of roots. The first is an allegory of racial difference: Queenie observes that her colleague Sallywater "was yellow and we were all dark brown" and that her hair "looked like nothing seen on any other yam." Woodville does not offer any information "about that variety" but is enigmatic about her origins (9). Immediately afterward, the community is summoned to Mr. Charlie's verandah, where he informs them it is 1834 and those younger than six are free; suddenly, historical time collapses and it is 1838 and everyone "is free." The formerly enslaved subjects smile and wait, wondering about Mr. Charlie's strange behavior over "this thing called 'free'” (II). Thus, the second rupture is constellated around the 
figure of chronology (dates), the law, and freedom. While Queenie narrates the community's love of Mr. Charlie, Woodville's cynical laughter induces a tornado that "laughed the great house off its base" leaving "nothing now but a dung heap that looked as if it had been there since the beginning of time" (13). It is these ruins of empire-or, as Ann Laura Stoler terms it, "imperial debris" - that end up as integral to their quest to understand the past. The rest of the narrative recounts the community's banishment from their "Eden," their attempts to establish a sustainable island community and provision grounds, their lack of sexual knowledge, their inability to reproduce, their quest to learn their preplantation roots, and their attempts to understand the nature of mortality. Through the device of allegory, the characters are anachronistic - they live for more than two hundred years without aging, they are positioned outside of reproductive futurity, they do not comprehend death, and they are unable to access knowledge of their past.

Brodber's novel challenges the plot of the historical realist novel, depicting her slave characters as "retarded" in growth but "happy people" who have no concept of freedom. This is profoundly disconcerting for any reader expecting the normative (often masculine) models of resistance to the plot of the plantation, who might expect a slave rebellion to bring on emancipation rather than white patriarchal benevolence, and who might anticipate that any narrative of the children of the yam would uphold a (maternal) African root. Moreover, we would certainly expect that an enslaved community would have an immediate response to their freedom. Thus, reception of the novel is mixed not only because Queenie and her conarrators destabilize our assumptions about the individualist model of the realist novel, but also because the very plot of Caribbean history is destabilized by experiments in form-particularly through that most troubling of genres, allegory.

Brodber moves beyond the Plantationocene to merge the plots of the plantation and provision grounds; as a result, their narratives become an allegory of dominant models of Caribbean historicism. Initially, her slave characters seem to work happily in the sugar fields, and a white planter claims their ontological origin by planting his semen in Caribbean soil and harvesting his enslaved offspring like yams. This is a historical model of Edenic islands that arises from the plantation complex, the "myth of history," as Wynter might call it. Only the removal of the plantation father, made possible by the juridical plot of the 1838 Emancipation Act, creates a new plot for postemancipation subjects and a new formulation of narrative, which is about building sustainable provision grounds and a new "language 
of landscape," in the words of Glissant. In a complex layering of emplotment, Brodber's allegorical model rehearses the historiography of the postemancipation era. It is an allegory of allegorical representation itself, insisting that we develop a historical consciousness along with her characters, who are repeatedly likened to the questors of other allegories such as the "knights of the round table" (70). This use of allegory is familiar to postcolonial texts that refuse to accept master narratives of the colonized as "History." As Samuel Durrant points out, postcolonial allegories are not necessarily about historical events themselves. Rather, they are about our relation to the narration of these events. ${ }^{91}$ Thus, Brodber produces an allegory of Caribbean history, a narrative that would speak directly to Hayden White's well-known claim that history-making itself is allegorical. ${ }^{92}$

It is through a visceral relation with soil, roots, and rot that the characters are able to begin to enter historical time and embrace "naturalness." After emancipation, Queenie and her colleagues establish their own island community, develop autonomy outside of the plantation, and import dirt from a place they call "the past," which is integral to the growth of the community and their sustaining crops of bananas, pineapples, coconuts, and plantains. In this liberated space of the provision grounds, nourished by the literal soil of their history, they seek their ancestral roots and the plot to narrate their origins. Eventually they recover their suppressed African history through Woodville, who is washed up on their beach and is depicted as a rotting log whose knowledge of the past is foundational to the community's future.

Through the rotting corpse, Brodber's novel suggests, à la Benjamin, that history is subject to nature and therefore to decay, an experience with mortality that is crucial to the community's quest towards "naturalness." While for Benjamin the emblematic form of this decay was the facies hippocratica, or death's head, that catalyzes human mourning, Brodber turns this into a much more active, ejaculating corpse. ${ }^{93}$ Woodville is nearly dead and hardly speaks, yet his "male organ [has] a life of its own" and at odd moments the community observes that "milk came out of this independent organ" (35). While the people do not recognize this discharge because they are outside of sexual desire and reproduction, its appearance "mark[s] a momentous change" in their community and they begin to develop (42). They begin to consult with their elders about the strange nick marks on their necks, which they discover were surgically arranged by Mr. Charlie and Woodville to "fix people so that they would not want to pleasure each other with their bodies" (55). Thus, while Mr. Charlie's planting "a wash of seed from his body" is understood as essential 
to the reproductive fertility of the soil, Woodville's persistent ejaculation functions as a sign of desire, as well as a clue to re-membering their history. Brodber's use of allegory encourages these sexual puns of wood and re-membering, seed and semen. Woodville, who provides few verbal cues to their heritage, displays with his literal seed (and root) an alternative patriarchal narrative to the paternal origin story of Mr. Charlie's yams, an altogether different "Age of Man."

\section{Gendering Earth: Roots and Rot in the Anthropocene}

Allegory is known for its wordplay, and accordingly, Brodber engages a series of etymological and semantic connections between diaspora, seeds, and semen; planting and transplantation; memory, member, and dismembering; humus and human; and, as I explore in this final section, roots and rot. These relationships are essential to understanding Brodber's complex exploration of the violence of plantation modernity and its implications for naturalizing the relations between humans and place. While roots are a generative metaphor for cultural origins, decay is the material way in which we know history has passed and thus is key to the articulation of time and "nature" itself. As Benjamin would have it, nature and history are petrified in allegorical representation through the figure of the corpse, of "irresistible decay." Moreover, "If nature has always been subject to the power of death, it is also true that it has always been allegorical." ${ }^{4}$

The term "root" derives from "rot," and in Brodber's novel the ability to excavate one's maternal origins or roots is dependent on the decay of the patronymic plot, symbolized by the bodies of Woodville and Mr. Charlie. ${ }^{95}$ Benjamin argues that "the word 'history' stands written on the countenance of nature in the characters of transience," and it is this mortality that the community actively seeks to enter what they call "naturalness." 96 This is symbolized by the rotting root, Woodville, whose slow decay over the course of the novel functions as a cipher the community and reader must interpret. As the community learns about sexual desire and (heterosexual) reproduction, they discover that Woodville is their progenitor, a "stud" used on the plantation. Brodber employs the word "root" in terms of the genealogies and foodways of African heritage, as well as the symbol of the phallus, a visceral rather than verbal clue to their roots culture and the larger histories of diaspora, cultivation, and regeneration.

Although Woodville spends most of his time lying silently in bed, he is associated with tremendous power and is perhaps the most illustrated 
character of the novel. Members of the community describe him as "an old $\log$ " (30), a "rotting tree trunk" (69), a "bag of sawdust" (7I). He is an "old dried up banana tree, its fruit reaped, decapitated, its trunk disconnected from the earth, lying immobile, rotting," and yet still "powerful" (42). As is characteristic of allegory, he is called "The Enigma" (86). As an enigma, he condenses the symbolism of the community's past, as well as the process of historicism itself. Hayden White has argued that the "manner of being-inthe-world that we call 'historical' is paradoxical and cannot be apprehended by human thought except in the form of an enigma. If this enigma cannot be resolved by pure reason and scientific explanation, it can be grasped in all its complexity and multilayeredness in symbolic thought and given a real, if only provisional comprehensibility in those true allegories of temporality that we call narrative histories." 97

Woodville's presence as the living dead, an ejaculating corpse whose purpose is to teach them the "natural" cycles of regeneration and decay, suggests that he is vital to their quest to face this challenge "to be perpetually young or to grow" (57) and to embrace this "painful issue of growth" (IO5). Brodber's allegory encourages readers to move beyond Woodville's seed (roots) to excavate the history of the soil (earth), just as we learn to question Mr. Charlie and his seeding of the presumably passive earth. In her dual role as medical doctor and archeologist, a student of the body and the soil, Queenie is vital to helping the community (and readers) interpret what is uncovered after Woodville directs them to "move Charlie dirt" (36). Having been the first to witness Sallywater's death and the practice of "burying her deep in the ground" (6I), Queenie is the best prepared to interpret the earth mounds discovered in Woodville's old plot. Thus, unlike the singular corpse of Baroque allegory, Brodber guides our reading to multiple constellations of the past and gendered figures of nature-history.

Queenie comes to realize that one marks the place of a "woman named Jubbah" (75). ${ }^{98}$ Brodber has written elsewhere of the importance of "Juba's head" as a sign of the feminized cultural transfer from Africa to the Americas, and this is our first clue as to how the plot of the patriarchal root, the yam story, has suppressed the sign of both woman and earth. ${ }^{99}$ Thus, this allegorical novel foregrounds the earth and woman as the primary but invisible cultural progenitors who must be excavated by the community/reader, turning this into a larger allegory about the sign of woman and gendered reproduction narratives. The fact that this excavation happens at a grave site emphasizes the imbrication of roots and rot, history and decay. Robert Pogue Harrison writes: 
The grave marks a site in the landscape where time cannot merely pass through, or pass over. Time must now gather around the sema [sign/ grave marker] and mortalize itself. It is this mortalization of time that gives place its articulated boundaries, distinguishing it from the infinity of homogeneous space. As the sign of human mortality, the grave domesticates the inhuman transcendence of space and marks human time off from the timelessness of the gods and the eternal returns of nature. ${ }^{100}$

As people of the yam, Queenie and her cohorts have already learned that "what is under the ground is sacred" (28) because they see these as birth mounds; they have not yet entered history, which would lead to death and decay. One character, who visits a place called "the Future," teaches the astonished community about funerals: "A real non-breathing human body in a box... They put markers on these mounds too. They call them graves. A whole collection of them is called a cemetery" (II6). The community, on hearing the news, asks, "Are we to become stiff and be put into a hole in the earth; why, we were raised from it, how go back?" (I2I). This "mortalization of time," as Harrison puts it, is key to the postemancipation community's ability to render nature-history, to find their own means of planting their ancestors in the soil and to articulate their shared connection to roots and rot. This, in turn, is part of a planetary temporality about which they are instructed: "Nature changes. You are part of nature. It is natural to change" (66). Here the community naturalizes itself in the soil through earthly burial, which, as Harrison observes, "domesticates the inhuman transcendence of space" and catalyzes their entrance into history. Consequently regional access to history is rendered through an embodied engagement with localized place rather than through colonial narrative "monuments" and "battles," as Derek Walcott has written..$^{101}$

In their excavations of "Charlie dirt" they find two additional mounds, marked "Phibbah" and "Princess" (75), allegorical names likened to living members of the community ( 78 ). Associating the earth with Charlie's originary plot, some characters interpret the soil as sacred yam mounds, people who "had not yet been unearthed" (79). Yet this plot gives way to another root, of a feminized earth and maternal body, symbolized by a grave containing a mother with an infant child (IIS). ${ }^{102}$ Literalizing the effort to excavate the subterranean root, Queenie and her cohorts discover a subterranean cave in Mr. Charlie's "plot" in which these unfortunate women were 
kept, an alternative foundation for their roots. Sealed in the women's chamber they also discover Mr. Charlie’s corpse (II4), the rotting god so vital to Benjamin's thesis of allegory and historical decay. Consequently, the excavation of history leads to subterranean ancestors and roots, rendering human time in relation to the violent biopolitics of sexual labor and reproduction as integral to the plantation economy. ${ }^{103}$ This incorporates a feminized and maternal genealogy rather than the anachronism of Mr. Charlie's Eden.

In allegorical terms, the community members must dig below the patriarchal narratives of both Mr. Charlie and Woodville to recover their submerged mother/earth; only then can their corpses signal their imbrication in naturehistory and in reproductive futurity. The cave, that well-known feminized figure of Platonic allegory, is also a foundation for subterranean human development and provides a new plot for the postemancipation community. Consequently, they are "publicly forced to question the yam story and to think of death and its lifelessness" (I09), and to engage the corpse(s) that signal history as ruins. In grasping the implications of this new model of time, Brodber's community turns to the plot of the provision grounds, which foregrounds earth over property and, as they develop their own agricultural system, sustainable food cultivation over plantation monoculture. It seems that Brodber does not follow Wynter in representing death and burial as a "mystical reunion with the earth," because the former's emphasis on plantation violence and a Glissantian "prophetic vision of the past" calls into question any narratives of transcendence. Her novel shifts from the teleological plot of liberation (freedom) toward the dissolution of the subject, a narrative of decay that is figured as "naturalness." Like Benjamin's allegories, "seen from the perspective of death, life is the production of corpses" and the accumulation of ruins. ${ }^{104}$

When the community excavates the three mothers, they understand Woodville's relationship with these women; he is described as a "stud" who "seeds" these female "vessels." The stories are "dismembered," and, as in Benjamin's theory, human corpses are rendered as thinglike-yet not so that they can enter allegory, as he would have it, but so that the plantation's biopolitics of reproduction are rendered as part of historical allegoresis. Accordingly, the yam story becomes "dwindling past myth" (126). Woodville then dies, "already sawdust, waiting to increase [their] soil" (I26). The novel could have easily concluded there, making this an allegory of how humans enter "nature" and "naturalness," and thereby decay and history, demonstrating a narrative healing of the nature-culture rupture created by plantation modernity. 
However, Brodber's work expands beyond the Anthropocene's "Age of Man" and the Benjaminian "plot" of nature-history. Benjamin's theory of Baroque allegory—and, by extension, nature and history—is androcentric; the vast majority of corpses in his study of the Trauerspiel are men, their sons, and soldiers. ${ }^{105}$ In Brodber's contemporary allegory about the legacies of colonial violence, we see far more active figures of both woman and nonhuman nature. In Benjamin, the figure of nature is reduced to death and decay, a plot that is evident in Brodber's allegory of the slave community's postlapsarian "fall" into knowledge and freedom from the patronymic plot. But a new plot is uncovered by the community-this one not from a rotting corpse but, rather, from their own memories. In a bizarre plot twist, Queenie begins to use hypnosis to excavate their suppressed memories, a state they liken to death (I3I). Through that process they uncover an allegory of diaspora, of the foolishness of men who insist on movement away from the maternal, and about the "depletion of Mother's nation." In sum, they lost their way and forgot their past. In this gendered narrative of diaspora, they learn that Tayeb (Woodville) was the rainmaker who made the fatal mistake of the book's title: he called forward so much water that "Mother's body [was] swept away by the tide of [his] rains." It becomes a story of a new familial relationship to history, shifting away from the patronymic plot, generating a sense of accountability in their recognition that "he had committed matricide" (I40).

In reflecting back on Tayeb's story of the yam people, the community determines it was "Laughable. Pitiable." Yet it was a narrative that "worked. It kept [them] happy" (I43). As Brodber has written extensively about the importance of the yam to the African diaspora, it is interesting that she has chosen to displace the yam as originary root and focus our attention on the figure of the maternal, on the earth/Earth. ${ }^{106}$ This chapter has sought to foreground Brodber's allegory of the mutual imbrication between the plots of the plantation (Plantationocene) and provision grounds and how engaging these historiographies leads to a formal shift away from the realist novel in ways that suggest the postemancipation community must establish their own plot. In an obvious sense, the allegory's didactic function is to suggest one must excavate the seeds and soil of community history to recover what Brathwaite would call its "submerged mothers." 107 A new, more hopeful plot emerges that demonstrates that excavations of history can lead diasporic communities "into naturalness" (146), which in this speculative novel means both reproductive futurity and mortality. The community defines becoming 
human as to be "preserved not so much for labour," as Mr. Charlie would have it, "as for life" (I47). The shift from labor to life thus signals a movement away from the plot of plantation capitalism, and perhaps even from the plot of the provision grounds as well.

A large body of Anthropocene scholarship focuses on excavating the source of the originary split between the human (as species) and nonhuman nature. Consequently, it is an allegory of reading earth (soil) for Earth (planet). In a similar vein, Brodber's novel stages a quest in which the community is given one origin narrative, only to be repeatedly replaced by another (Mr. Charlie, Woodville, the yam, the subterranean mothers). Yet the last "plot" of the novel uncovers what is foundational to the allegory of excavation: earth. Soil is ubiquitous in the novel, appearing on the first page under Mr. Charlie's fingernails and later as a sign of the yam mounds that produce people, as well as serve as the burial mounds of their mothers. Earth becomes one of the community's first imports to their new island after emancipation, enabling a "vigorous movement between [their] present and the past" (2I) and sustaining their crops and survival. And, of course, earth or soil itself is a figure of both microbial life and sedimentary decay.

Although many would claim that "cli-fi"climate fiction is not relevant to Caribbean literary production, the key rupture in this novel is about the destruction of earth/Earth. The mistake made by the titular rainmaker was that Tayeb tried to "prove that we knew how to do great things" and thus called forward a rain that overwhelmed the planet, sweeping away "mother's body" (I4O). The rains "came and came; swept the green out to sea and left white marl, for pulverizing into noxious dust," creating a "river cutting the earth" that caused "grasslessness, treelessness" (I37). This is more than an allegory of diaspora from "mother Africa." It stages a plot of environmental crisis, what Brodber calls a "genosuicide" ( 140 ), and, given its global scale, a constellation of the Anthropocene. Rather than using the term "species suicide," which has become common in the Anthropocene's focus on the apocalyptic scale of mass extinctions, Brodber employs "genus" to invoke a larger, broader scale than race, nation, or species. ${ }^{108}$

Since their "mother's body" has been swept away, the figure of Earthand its synecdoche soil-become lost objects that signal the community's rupture from place. Brodber's allegory concludes with the need to recognize the disjunctive relationship with earth/Earth and the rupture caused by an "Age of Man." I mentioned earlier that allegory appears at moments of crisis-it uses historical figures to reflect on constellations of the present. 
Brodber upholds the metaphysical conflation of people with the soil, of the maternal with the earth. Since allegory generates disjunctions with the past and signals aporia between figures and their articulation, we might also read the novel's focus on earth (and its erosion) as a sign of a contemporary crisis of soil depletion in the Anthropocene, the loss of our greatest resource. Following Glissant and Harris, we may interpret the novel's excavation of roots as an engagement with the historiography of emancipation, as well as the representation of nonhuman others, an upholding of heterogeneous roots, foregrounding our reliance on living fossil, living history, and even fossil fuels. Reading this novel in relation to the turn to agriculture as an origin story for the Anthropocene/Plantationocene, we can see the telescoping between a planetary Earth as a figure of crisis and its localized effects in the human relation to soil as origin (root), resource (sustenance), and destination (rot).

According to the geologist David Montgomery, soil is our "most underappreciated, least valued, and yet essential natural resource." 109 In the Caribbean and elsewhere, increased hurricanes, industrial soil fertilization, and flooding associated with sea-level rise all contribute to more soil erosion than regeneration. "Considered globally," Montgomery reveals, "we are slowly running out of dirt" — as much as seventy-five billion metric tons per year. ${ }^{110}$ Soils of the tropics are especially impacted by this global problem of erosion because, contrary to the myth of fecundity, they are often nutrient poor, depending on vegetation for the recycling of minerals. Drawing from Benjamin, we can more plainly recognize the crises of the past through the constellations of the present.

Brodber's research has been deeply involved in the relationship between Jamaican rural communities, their histories, and the soil. She is therefore clearly aware of the long-term threats to Jamaica's agricultural industry over the past few decades, such as the International Monetary Fund's lending policies, North America Free Trade Agreement trading blocs, pressures of globalization and outmigration, and cadmium and other forms of soil pollution from mining that have taken an enormous toil on Jamaican ecologies. Moreover, the destruction of mangroves due to increasing (state-sponsored) tourism, the selling of conservation land to developers, deforestation, and the expansion of enormous resorts on vulnerable coastlines have become national concerns thanks to a small but growing environmental movement. ${ }^{111}$ Writing near the twentieth anniversary of the devastating Hurricane Gilbert (1988) and in the wake of Hurricane Ivan (2006), Brodber was certainly aware of the continual soil erosion from increasing numbers of hurricanes 
and threats to island sustainability. Therefore, we might read Brodber's novel as responding to a historical and current crisis of the Anthropocene, a narrative in which she posits humans-and human exceptionalism-as accountable in this degradation of an Earth that is depicted as progenitor, our "mother's body."

One of the signs of twenty-first-century modernity is that humans are no less dependent on the soil even as we are increasingly detached from place. Thus, the epigraph that frames this chapter from Michel Serres calls attention to "the disappearance of agricultural activity at the helm of human life," which has become a major challenge to Jamaica, causing tremendous urban poverty. Serres points to what is lost in the urban experience of living indoors, a separation from the experience of weather (temps) and time (temps). This is a future Brodber's characters want to avoid, as they fear a future of "sitting at desks," acquiring "soft limbs," and being attuned to "electric light" (139). It is this engagement with both the futurity of the human and the planet enabled by a "prophetic vision of the past" that brings forward the recognition of modernity, as well as alterity.

Speaking about the "human" writ large, Harrison suggests that the contemporary alienation from the soil of one's ancestors, as well as "uncertainty as to one's posthumous abode," causes a shift in the relation to the earth/Earth:

Uncertainty about the provenance of one's food and the destination of one's corpse relate to one another not accidentally but essentially. We have suffered endless hardships and indignities in the name of our obligations to the dead and the land. Haven't we paid our dues several times over? Don't we have the right to settle, once and for all, our debts with the dead, with the earth, even with God, if it comes to that? This remains to be seen.... Certainly no amount of emancipation, be it through mechanized food production, technological innovation, or genetic engineering, can absolve us from the "substance" of our humanity. ${ }^{112}$

In writing about the human at the scale of a "species," Harrison does not take into account how forced migration and slavery alter a community's relationship to the soil; nor does he consider a specifically Indigenous viewpoint of ethical obligation to the more-than-human world. Yet he raises an important question about the historical obligation of humans to the Earth that is foundational to both Brodber's novel and the planetary crisis signaled by the Anthropocene. Thus, the indignity of forced agricultural labor may encourage not necessarily a desire for a "language of landscape" but its 
opposite - a desire for alienation from the land as a kind of freedom from obligation. This poses a vital counternarrative to the pastoral nostalgia Serres demonstrates in the epigraph to this chapter. While some of Brodber's characters disappear into the urban worlds of "the Future," the novel as a whole does not quite resolve these questions about the community members' obligations to one another, their ancestors, the plot of historical narrative, and the earth/ Earth. In this allegory of ecological modernity, Brodber constructs a plot that reflects the long process of alienation from the earth/Earth and a desire to recuperate it imaginatively, even as we destroy it.

The allegorical aesthetics of The Rainmaker's Mistake encourage us to actively engage and intellectualize how "naturalness, twinned to mortality" must be "accompanied by hope, and duly tempered by responsibility" (I5O). To reflect back on Chakrabarty's query about the relation between the plotting of human freedom and the planet's ecological crisis, we might consider a poignant question raised by one of Brodber's characters: "Can Massa's blood atone for our disrespect for our own mother?" (I46). This is a question left unanswered by both Chakrabarty and the novel. On the one hand, the "sex typing" of the planet as female raises a quagmire of issues that have been engaged in feminist thought. To some extent, Brodber does uphold an allegory in which masculine figures are associated with time and women with space, a narrative that is also apparent in current scholarly discourse of what some feminists refer to as the "Manthropocene." But her use of a genealogical relationship to the Earth, imagined in networks of kinship and obligation, is also in keeping with Indigenous forms of planetary thinking that are foundational to geontological thinking.

This allegory of obligation to the earth/Earth problematizes universalizing discourses of the Anthropocene, such as Serres's admonition that we must "never forget the place from which you depart, but leave it behind and join the universal. Love the bond that unites your plot of earth with the Earth, the bond that makes kin and stranger resemble each other." ${ }^{113}$ Brodber suggests that we can never "leave it behind," but through an allegorical telescoping between earth and Earth, she provides a means by which we might recognize their disjunctive relation. Although "allegory elicits continual interpretation as its primary aesthetic effect," it remains unclear how the mutual obligations between humans and between humans and the soil will produce a more stable ground of sustainability. ${ }^{114}$ For now, we rely on that dose of hope and responsibility, a plot to access that utopian place where Brodber asks us to join her "in the free" (I5O). 


\section{Planetarity}

\section{Militarized Radiations}
The Age of Ecology began on the desert outside Alamogordo, New Mexico on July 16, 1945, with a dazzling fireball of light and a swelling mushroom cloud of radioactive gases. -DONALD WORSTER, Nature's Economy

The fully enlightened earth radiates disaster triumphant.

-THEODOR ADORNO AND MAX HORKHEIMER, Dialectic of Enlightenment

Writing over forty years ago, at a time when the idea of a nuclear winter was thought to be the Earth's biggest anticipated climate threat, the historian Donald Worster made a vital link between the rise of ecology and the $\mathrm{Nu}$ clear Age. Despite the blossoming of environmental scholarship in the past decade, particularly the debates about the origin of the Anthropocene, Worster's claims about the relationship between militarism and global ecology have been largely overlooked. For a decade, scholars attributed the invention of the steam engine as a hallmark of anthropogenic climate change; only in 2010 did scholarship begin to emerge that linked the worldwide traces of military-produced radionuclides with the Anthropocene. ${ }^{1}$ Tracing the artificial isotopes of the thousands of nuclear weapons detonated on the planet, scientists have determined that the ongoing presence of "bomb radiocarbon" and the anticipated presence of militarized plutonium-239 (for forty thousand more years) are some of the distinguishing markers of the Anthropocene. ${ }^{2}$ 
The previous chapter examined the ontological relationship between humans and the soil, in which a fragment and figure of decay, earth, is allegorized as the Earth. This chapter turns to the figure of (militarized) radiation, shifting from soil to isotope, to examine how allegories of light are utilized to represent the human on a planetary, if not cosmic, scale. Here the Anthropocene figure of the human is not a generic "species" but, rather, a "postatomic species." In this chapter, radiation allegorizes an intangible and uncanny constellation of the Anthropocene.

Dipesh Chakrabarty has argued that the Anthropocene calls for an understanding of the human in at least three registers: as the subject of human rights; as a subject of racial, gendered, or other kinds of difference; and, finally, as a "species" that acts as a geological force. Due to the planetary scale of the Anthropocene, this last category, he argues, cannot be experienced ontologically. ${ }^{3}$ The previous chapter engaged the human in the former two senses, particularly how naturalizing practices that ground people in the soil such as planting and burial facilitate ontological claims to earth/Earth. This chapter takes up the challenge of whether one can figure a nonontological relationship to the planet. I do so by examining how the relationship to radiation and its many manifestations - the sun, light, photography, nuclear weapons, fallout-might be understood through the allegorical function of the daemonic, which signals the alterity of the planet, or "planetarity."

As mentioned in the introduction, allegory is a mode that figures parallel worlds; a language of cosmologies that reflects nested structures (microand macrocosms) or spatially dispersed lower and upper realms such as Earth and outer space. To place these realms in conversation, allegory relies on what Angus Fletcher has called the "daemonic" function, which he draws from Judeo-Christian intermediary figures such as angels or demons. In contemporary narrative these may be figures who move between worlds and knowledge systems, such as travelers, soldiers, scientists, and writers. ${ }^{4}$ In religious and secular allegories, light has functioned as the emblematic daemon, as a perceived emissary between the divine and the earthly or between knowledge and recipient. In this chapter, I engage this association of the daemonic in relation to solar light and its unnatural other, militarized radiation. Building on the work of Bruce Clarke who has demonstrated the ways in which the discourse of science, particularly physics, relies on allegory, I foreground the daemonic as a figure of energy, that which moves "between the physical and spiritual [and] between the mundane and divine." In an age of secular reckoning about the Anthropocene, the daemonic is 
all the more fundamentally tied to scientific knowledge. As Clarke argues, "As a discipline for the production of the sort of knowledges that enables persons to seize powers previously reserved to the agency of the divine, science has often taken on the allegorical attributes of Luciferian [daemonic] enterprise."

This book is concerned with provincializing the Anthropocene; accordingly, my interest in the daemonic figure of light resides in its uncanniness as it registers at both the scale of the planet and in the irradiation of human bodies. Humans generally experience light as simultaneously local (in visual perception) and planetary (in a heliocentric orbit). The relational quality of light, energy, and radiation is tied up with the question of otherness, as Jacques Derrida has demonstrated. ${ }^{7}$ What is produced by the sun-light and radiation-is actually invisible. Accordingly, Derrida has called the solar trope, or heliotrope, "the father of all figures of speech," which is "the most natural" and simultaneously the most unrepresentable. ${ }^{8}$ The sun is the "essence of that which is," and yet we cannot look at it." He bases this on Aristotle's failure to find a word to describe the sun's casting forth rays of light, as sowing is to the casting forth of seed. In this failure of language, Derrida locates radiation's radical alterity. The Anthropocene offers us an opportunity to think about the ways in which the figure of nonhuman nature is anthropocentric, and thus a product of modernity. Consequently, in shifting from solar rays to those of radioactive fallout we foreground an uncanny figure of militarized nature. As I explain, the persistent use of solar metaphors for understanding nuclear weaponry have been vital to naturalizing global militarization, underlining its potential for historical erasure.

Building on Derrida, the philosopher David Grandy has argued that light is tied to alterity because it is "unfamiliar and inscrutable" and because it "enables apprehension of the other." ${ }^{10}$ Despite the remarkable discoveries of quantum physics, light is still "as fundamentally mysterious as ever," an "invisible companion who accompanies us inwardly as much as it does outwardly," and an entity that exceeds all reckonings of material space. ${ }^{11} \mathrm{We}$ never actually see light; we see only what it illuminates. Light's capacity to illuminate objects of knowledge but not itself, Grandy suggests, is "the origin of otherness." Here I build on this argument to consider radiation as an uncanny daemonic figure for the Anthropocene. To do so, I draw on Gayatri Chakravorty Spivak's concept of planetarity. Writing about the allknowing claims of globalization discourse, Spivak proposes to think of the planet as "a species of alterity." 12 If globalization is characterized by excessive 
visibility, planetarity provides a means to think through—but not necessarily to represent-that which is rendered invisible. As she explains, our relation to alterity is neither necessarily continuous nor discontinuous. It is the process by which the familiar is rendered uncanny and unhomely, similar to the ways that the apprehension of (invisible) radiation and its ecological properties destabilize our understanding of place and space. Planetarity is a method of reading that defamiliarizes "familiar space," just as our apprehension of the physics of light foregrounds its "uncanniness" as it "puts us in touch with distant, seemingly untouchable entities." 13

Tracing the figure of light helps us see how military radiation was naturalized, rendering the detonation of more than two thousand nuclear weapons since 1945 almost invisible to history. ${ }^{14}$ This was done by associating man-made radiation with its solar counterpart and by likening atomic detonations on Earth as harnessing the power of the sun. The repeated connection between a military lab product (a nuclear weapon) and its cosmic figure (the sun) naturalized atomic weapon production and helped to eclipse hundreds of nuclear detonations set off in the Pacific Islands until 1996, resulting in radioactive traces that permeated the global atmosphere and which all humans carry in our bodies today. The lack of popular recognition of our own planetary (and bodily) irradiation is due to the ways in which the master metaphor, the heliotrope, has been configured as both a natural and unrepresentable allegory for global nuclear fallout. By putting pressure on this heliotrope to examine its daemonic function, we can render these histories more legible.

Although light sustains life on our planet, most modern genealogies of radiation emphasize a destructive rather than life-sustaining trajectory. Theodor Adorno and Max Horkheimer, writing amid the state violence of World War II, argued that the instrumental rationality of the Enlightenment perpetuates its self-destruction and utilized metaphors of light to warn against the dangers of the "fully enlightened earth." Writing one year before the detonation of the first atomic weapon, they argued "what men want to learn from nature is how to use it in order wholly to dominate it and other men." ${ }^{15}$ While the start of the twentieth century witnessed Albert Einstein's rendering of the speed of light as the only universal absolute, by midcentury the new technologies of light-such as color photography, the X-ray, aerial surveillance, the motion picture, and nuclear weapons-were understood as constitutive of a heliographic modernity with frightening potential for state violence against all life forms on Earth. ${ }^{16}$ 
This "fully enlightened earth," the excess illumination Adorno and Horkheimer warn of in the epigraph to this chapter, has been a primary concern in the Pacific Islands, a region often deemed peripheral to modernity and yet the site of nearly continuous nuclear weapons testing from 1946 to 1996 (see map 2.I). Since their exploration by Enlightenment-era cartographers, painters, and naturalists, the Pacific Islands have been incorporated into an especially visual economy of colonialism in which the ethnicity of the region's peoples, the exoticism of tropical light, and the flora and fauna of the landscape were studiously mapped, painted, and inscribed for European display and distribution. ${ }^{17}$ By the mid-twentieth century, Oceania entered an entirely different economy of light when hundreds of nuclear detonations conducted by the United States, France, and the United Kingdom produced an atomic cartography and a militarized grammar of "radiation atolls" and "nuclear nomads." 18 The irradiation of the Pacific Islands marks an important era of global militarization that has largely been overlooked by the very metropoles that benefited from the economic, political, and technological products of nuclear weapons testing, such as the high-speed camera, color film, and radiotherapy. Overtly using the islands as laboratories and spaces of radiological experiment, British, American, and French militaries configured those spaces deemed by Euro-American travelers as isolated and utopian into a constitutive locus of a dystopian nuclear modernity. ${ }^{19}$

In this chapter I examine the relation between Cold War science and the Anthropocene, then turn to Indigenous Pacific Island authors to examine how they have engaged the violence and uncanniness of nuclear radiation as a daemonic device in their writing. In this particular context, nuclear annihilation is not a threat looming in the future, but an experience of the past, foregrounding the ways in which climate change and apocalypse might also be historically experienced and parochialized. I focus particularly on the novel Ocean Roads (2006) by the Māori author James George, whose mapping of the Pacific wars of light, like the claims for the Anthropocene, begins with the detonation of Trinity in 1945 and the legacies of the Cold War. The novel suggests that the primary way we understand the planet is through the vehicle of light, even if that vehicle often exceeds the limits of representation and comprehension. While my first chapter focused on the ontological claims of matter to figure the Earth, this chapter turns to radiation as a sign of planetarity-what illuminates matter but is not necessarily constituted by it. Of course, the allegory of illumination is closely tied to knowledge production. Through this daemonic device, we see, we are illuminated, we 


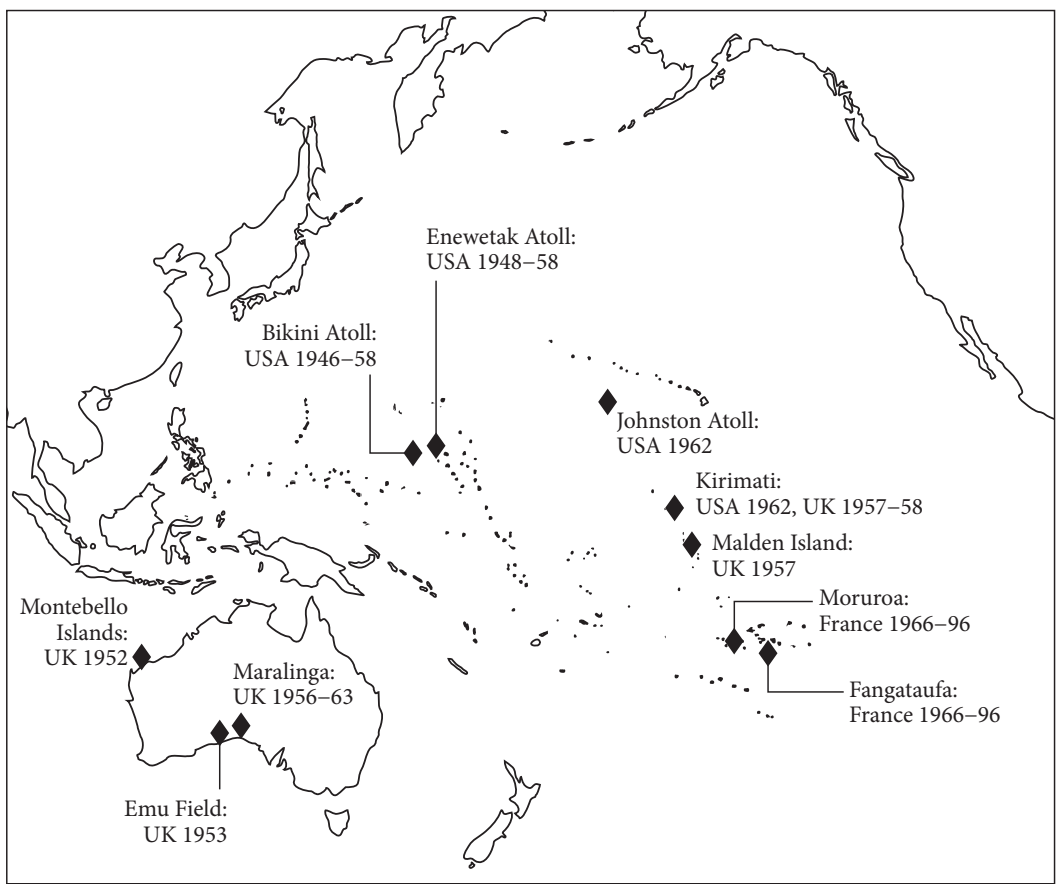

MAP 2.I. Pacific nuclear testing map, 2018.

inspect. ${ }^{20}$ Yet light itself cannot be seen; it is absent presence. Like the daemonic function of allegory, light is profoundly relational. In fact, light can only be apprehended in relation to the objects it illuminates and can only be seen-from material experience to classical and quantum physics-by its affect. It is this "revelatory otherness (the light-mediated manifestation of the other)" that I explore in this novel as a daemonic sign of the modernity of the Anthropocene. ${ }^{21}$

Light has complex attributes and forms; it is energy, electricity, heat, motion, and our medium of visual perception. But light has a uniquely complicated relation to time; the perpetual movement of light means that it is a time traveler. In physical terms, what we receive through our visual senses represents the past by the time it reaches our retina, whether we speak of the microseconds it takes for these words on the page to appear or the years it takes for extraterrestrial light to reach our planet. With Einstein's Theory of Special Relativity, the speed of light became the only universal absolute, which destabilized classical understandings of time and space and, by extension, the environment. As such, the only medium for rendering history in 
space and time became radiation and light. The relation between time and light is vital to different disciplines: physicists use the speed of light to locate coordinates in space-time; geographers use radioactive carbon dating to measure the age of the planet; and astronomers measure cosmic background radiation as the echo of the big bang, essential to the dating of our universe. Thus we might say that cosmic and militarized radiation are signs of our own planetarity, a sign of history that exceeds our capacity for measurement and perception. Read through the trope of radiation, planetarity is the recognition of our simultaneous continuity and discontinuity with light, the necessarily partial illumination of our enlightenment. I turn to that ultimate figure of alterity, light, and trace the figure of radiation to dis-figure it, to read the daemonic function of this allegory of the Anthropocene.

\section{A Cold War Anthropocene}

In his discussion about the paradoxical age of ecology, Worster observes that "the sudden acceleration of environmental damage throughout the world since World War Two has been largely the consequence of our scientific enterprises. That is the lesson of Alamogordo; no other explanation can bear as much weight." ${ }^{22}$ This was decades before geologists turned seriously to the military legacies of the Cold War in their efforts to pinpoint an origin for the Anthropocene. This is somewhat surprising because the very science that led to our understanding of the Anthropocene is directly connected to the science of nuclear weapons testing and fallout. When Jan Zalasiewicz, Mark Williams, Will Steffen, and Paul Crutzen consider an origin date for the Anthropocene and remark that "the world's strata from 1945 on contain tiny but measurable amounts of artificial radionuclides, ${ }^{23}$ they minimize both the global and atmospheric impact of nuclear weapons testing. Moreover, they overlook an enormous body of work that has measured the geological, biological, and social impact of this "tiny" but often devastating change to all bodies and spaces of the planet-from the poles to the deepest ocean. ${ }^{24}$

Militarism remains the elephant in the room when considering issues of climate change, globalization, and the Anthropocene. ${ }^{25}$ For all the debates about various national contributions to greenhouse gases, few have acknowledged that the U.S. military is the world's largest institutional consumer and producer of fossil fuels and carbon emissions. ${ }^{26}$ Connecting the Anthropocene to militarism may help bring forward the largely forgotten relationship between nuclear weapons and the rise of the discipline of ecology. Joel Bartholemew 
Hagen provides a compelling history of the "symbiosis develop[ed] between atomic energy and ecosystem ecology," ${ }^{27}$ particularly as it was organized by Eugene and Howard Odum, the founding figures of ecology in the United States. Given the rapid expansion of the nuclear industrial complex in the I950s and the subsequent radiological contamination of the planet, the Atomic Energy Commission (AEC) hired the Odums to study the ecological impacts of militarized radioactivity. Surveys of the nuclearized Bikini Atoll began in 1946, and the field of "radiation ecology" was established in the Pacific with the Odums' AEC-funded study of Enewetak Atoll in Micronesia in 1955. After the repeated nuclear bombing of Enewetak, the AEC provided the first opportunity to study a "complete ecosystem" and its "overall metabolism" through the trace of radiation. Understood as a "landmark in ecological research," the Odums' work on the radiation of $\mathrm{Pa}$ cific coral reefs provided a model of a self-regulating ecosystem and the first theorization of shared resource relationships in nature. ${ }^{28}$ This inaugurated the uncanny figure of energy as vital to the interpretation of planetary-wide ecology. In turn, AEC-funded research laboratories and programs in radiation ecology were organized in universities all over the United States and at nuclear power sites, catalyzing the institutional development of ecosystem ecology. ${ }^{29}$ Ironically, the discipline so associated with the preservation of nonhuman nature arose from its militarized destruction, and contaminants in the environment such as radioactive strontium and iodine became, for ecologists, the legible "trace" of ecosystem health.

The nuclear tests in the Pacific were foundational to the understanding of the ecology of the planet; their fallout is an uncanny residue for the Anthropocene. Turning to the fossil records of militarized radiation we can more visibly recognize that the Cold War was not simply about the explosive power of nuclear weapons (the immediate, spectacular yield) but rather its long-term radiological effects. In Braudelian terms, the shock of an eventist model of history, the nuclear explosion, should not distract our attention from the impact of a longue durée of radioactive ecologies, ${ }^{30}$ particularly when we consider that nuclear weapon byproducts such as carbon-I 4 and plutonium-239 have 5,700 and 24,000 year half-lives. ${ }^{31}$ This is a legacy of what Rob Nixon calls "slow violence," particularly when we consider that, thanks to the Odums' work, the AEC realized that radiation itself was a more powerful and insidious weapon than an explosive, short-term yield. Consequently, large amounts of militarized radiation were purposefully released into the oceans and atmosphere through hydrogen detonations, and used in 
human medical experiments. Inspired by the ecological nature of radiation, the AEC coordinated the secret release of enormous amounts of radioactive wastes and gases at their Hanford, Washington, site to measure the impact on local ecologies (including humans); the radiation far exceeded the emissions from the 1986 Chernobyl disaster and has caused an ongoing legacy of radiogenic effects on human and nonhuman bodies. ${ }^{32}$

In an effort to understand the human dimension of radioecology, the AEC also funded studies, in concert with universities across the United States, that injected or fed radioactive tracers into the bodies of thousands of uninformed people-such as poor pregnant women, orphaned and disabled children, and the terminally ill—and conducted full body radiation experiments on prisoners. In the vast majority of cases, the victims carried the cost of their illnesses (or their children's illnesses) on their own, and were not informed or compensated for their radioactive exposure. What the Department of Energy calls "human radiation experiments" were simultaneous with the studies coordinated by the AEC of the biological impact of radioactive fallout on Micronesians and experiments on other Indigenous peoples in the Americas. ${ }^{33}$ These are hardly undocumented histories; the journalist Eileen Welsome won a Pulitzer Prize in 1994 for her reportage on radiation experiments on human subjects, and her subsequent book, The Plutonium Files: America's Secret Medical Experiments in the Cold War, won a PEN award in 2000. President Clinton publicly apologized for the experiments and documentation can be found on the Department of Energy's website. ${ }^{34}$ Since the Cold War was fought through visual effects, there are also ample online resources of the tons of film footage created by an AEC film studio used to document an era of "Big Science." So while the legacies of this complex history are entirely accessible, Cold War nuclearism and its fallout continue to be peripheral to conversations about world ecology, human consciousness of the planet, and, until very recently, the Anthropocene. ${ }^{35}$

Although the connections between nuclear weapons history and the Anthropocene have not been fully examined, it is not a coincidence that the atmospheric chemist best known for his promotion of the term "Anthropocene" was the co-author of an essential Cold War text warning of the dangers of nuclear winter. ${ }^{36}$ As has been documented, "climate science and nuclear weapons testing have a long and surprisingly intimate relationship." ${ }^{37}$ Concerns about the atmosphere and its impacts on Earth were first catalyzed by the fallout from the Bravo explosion at Bikini Atoll in 1954, distributing radiation around the earth, which is carried in the bones and teeth of all 
subsequent generations. ${ }^{38}$ Operation ARGUS, a series of high-altitude hydrogen bomb detonations, combined with the hundreds of atmospheric tests conducted by the United States and Soviet Union, nearly doubled the atmospheric concentration of radiocarbon by the time the 1963 Atmospheric Test Ban Treaty was implemented. ${ }^{39}$ International public outcry about the irradiation of the planet catalyzed the Cold War sciences of energy, ecosystems, deep time, and climate. The tracking of radioactive fallout led to the discovery of radiocarbon dating, providing new and more accurate models of the deep time of the planet. Studying nuclear test-derived radioactive carbon-I 4 in the atmosphere enabled meteorologists to determine that carbon dioxide levels were uniform and consistent and that "excess" radiocarbon from the tests was global and might be tracked in parcels across the atmosphere. ${ }^{40}$

As Joseph Masco has demonstrated, teams of meteorologists followed radioactive tracers across the stratosphere to discover that many artificial isotopes such as strontium-90 were globally distributed through the food chain; this science, in addition to computer modeling, is integral to our understanding of the current climate crisis. ${ }^{41}$ Scientists involved in U.S. nuclear testing discovered that the oceans provided a carbon dioxide "sink" and that there were high levels of fossil fuel pollution of the atmosphere. ${ }^{42}$ The oceanographer Roger Revelle and the nuclear chemist Hans E. Suess are now widely cited for calling attention to the anthropogenic changes to the Earth's climate in 1957, declaring about the nuclear tests that "human beings are now carrying out a large scale geophysical experiment of a kind that could not have happened in the past nor be reproduced in the future. Within a few centuries we are returning to the atmosphere and oceans the concentrated organic carbon stored in sedimentary rocks over hundreds of millions of years." ${ }^{33}$ Anthropocene scholars have missed that these scientists were also architects of the very systems they warned of; Revelle was part of a team that helped the United States plan nuclear tests so they could use the data at the Scripps Institute for Oceanography, while Suess, a pioneer of radiocarbon dating, was a consultant for the Nazi regime's nuclear program. ${ }^{44}$

While the Apollo space voyages and their images of Earth have been associated with a rise in global consciousness, well before 1960 scientists and the public were aware about alarming anthropogenic changes to the earth's climate and had fossil evidence of the distribution of militarized radioactive isotopes. ${ }^{45}$ Denis Cosgrove has observed that "since the mid-nineteenth 
century the image of the globe has emerged as the icon for the interrelated processes of connection, communication, and control that characterize modernity; it is an image that rests primarily on the idea of the globe's visibility. " 66 Yet the invisible military irradiation of the Earth signals a new era of global consciousness. These concerns led Cold War nuclear science to create climate modeling, which, in turn, led to the discovery of the Antarctic ozone hole in 1985; within three years, the Intergovernmental Panel on Climate Change (IPCC) was founded. In fact, the Cold War relationship between global climate and nuclear weapons was so naturalized that the American public casually blamed any inclement weather on the atomic bomb. ${ }^{47}$ Reporters in the United States even suggested that the military set off nuclear weapons in the Arctic to melt the ice caps and thereby "give the entire world a moister, warmer climate. ${ }^{\not 8}$ In myriad ways, the history of worldwide military irradiation has been an important material and symbolic precursor to our current articulations of global warming.

Certainly international attention has been directed toward the planetary dangers of nuclear militarism, as evidenced by the nuclear winter scare of the I980s and the worldwide protests against French nuclear testing in the Pacific. But by and large, those histories seem to have been forgotten by those outside of the fallout zones. One of the reasons that established connections between climate change and nuclear militarism have been eclipsed from history is because the AEC used naturalizing solar metaphors to market both atomic and hydrogen weapons. The rhetoric that framed the atomic bomb through the natural power of the sun can be attributed to William Laurence, a journalist for the New York Times and reporter for the Manhattan Project, whose consistent cosmic hyperbole about the power of atomic explosions was copied, often verbatim, by countless other reporters and politicians. ${ }^{49}$ In a speech written by Laurence to announce the bombing of Hiroshima in 1945, President Harry Truman referred to the atomic bomb as "a harnessing of the basic power of the universe. The force from which the sun draws its power has been loosed against those who brought war to the Far East." ${ }^{50}$ In 1946, Laurence described atomic energy as a "promise" to "bring the sun down to earth as its gift to man," a promethean metaphor that spoke to a long history of the daemonic harnessing of light. ${ }^{51}$ When the distribution of nuclear radiation became a global concern, the AEC and its allies utilized solar analogies to conflate man-made weapons with natural energy from the sun. In 1947, AEC Chair David E. Lilienthal likened atomic energy to solar energy, arguing that nothing "was more friendly to man or more necessary 
to his being than the sun.... In its rays is the magic stuff of life itself." ${ }^{52}$ News reels from the AEC about the nuclear tests at Bikini Atoll featured the displaced Islanders singing the tune "You Are My Sunshine." 53 These metaphors invoked the sun's power in a way that deliberately "confused" the public, per President Dwight Eisenhower's orders, about different types of radiation and their risks. ${ }^{54}$

The daemonic figure of light was appropriated in Cold War discourse as an emissary of the sun to eclipse the sign of the violence of nuclearization and radiation. It is by turning to the figure of the sun and its byproduct, radiation, that I register a shift from our material reckonings of globalization to Spivak's concept of planetarity. If globalization is characterized by visuality and illumination, planetarity provides a means to think through that which is rendered invisible. Planetarity, in Spivak's definition, is the figure for alterity, generally read in terms such as the divine and nonhuman nature. ${ }^{55}$ While agencies such as the AEC argued that nuclear radiation "was a familiar part of the everyday environment" and "just one more of the hazards of contemporary living," 56 the concept of planetarity denaturalizes that familiarity. In contrast to the instrumental rationality of total illumination, it is the process by which the familiar is rendered uncanny, unhomely. It is the "defamiliarization of familiar space."

Tracing the daemonic figure of light helps us see how "nukespeak" naturalized military radiation across the planet. "Nukespeak," a revision of Orwellian "newspeak," 58 is a euphoric language of nuclearization that draws its symbolic power from the historical association between radium, the earliest form of radioactivity discovered by Pierre and Marie Curie in I898, and the life-generating rays of the sun. Medical journals once confidently declared that "radium has absolutely no toxic effects, it being accepted as harmoniously by the human system as is sunlight by the plant." ${ }^{9}$ The words "radium" and "radioactivity" derive from the Latin root term radius; these cognates are based on a synecdochical relation between the sun and its ray of light on earth, often interpreted as an emissary of natural life force or the daemonic force of the divine. Terms such as "liquid sunshine" were attributed to radium products, which were thought to be elixir vitae until the mid-r920s when female employees of the United States Radium Corporation in New Jersey began to die from their ingestion of radium-based paint and dust. ${ }^{60}$ Radium, like the isotope strontium-90, one radioactive byproduct of nuclear detonations, is chemically similar to calcium and is thus taken up by bodies, causing leukemia and other illnesses of the blood and bone. ${ }^{61}$ 
This merger between invisible radiation and human and more-than-human bodies suggests the ways in which the nuclearized atmosphere is, in fact, embodied.

Clearly, there is a long history of associating man-made radiation with its solar counterpart, and of likening atomic detonations on earth to daemonic allegories about harnessing the power of the sun. While the daemonic function of allegory renders light as the uncanny, it is the merger between the human body and the environment made possible by radiation that renders the experience of our own bodies as unhomely. This first occurred on a global scale by the fifteen-megaton thermonuclear (hydrogen) bomb Bravo detonated at Bikini Atoll in 1954, which covered the surrounding islands and eventually the planet with radioactive strontium, cesium, plutonium, and iodine. It was an ecological and political relations disaster because it exposed thousands of Marshall Islanders and U.S. soldiers to nuclear fallout, contributing to countless miscarriages, leukemia deaths, thyroid cancers, and the kind of chromosome damage that knows no temporal or genealogical limit. ${ }^{62}$ Estimated at one thousand times the force of the bombs dropped on Hiroshima and Nagasaki, Bravo has been called the worst radiological disaster in history: fallout was detected in rain over Japan, in lubricating oil of Indian aircraft, in winds over Australia, and in the sky over the United States and Europe. ${ }^{63}$ It also created a public relations disaster with Japan over the deadly exposure to the men on board the fishing ship Daigo Fukuryū Maru (Lucky Dragon), an international incident that inspired vehement antinuclear protest, Pacific fish consumption bans, and even the film Godzilla. One scientist declared that by 1954 all humans on the globe "harbor [ed] ... radioactivity from past H-bomb tests: 'hot' strontium in bones and teeth, 'hot' iodine in the thyroid glands." ${ }^{14}$

By the late 1950 s, the international outcry over nuclear fallout prompted the AEC (with the Rand Corporation) to coordinate a top-secret investigation into the increasing strontium-90 levels in humans, plants, and animals around the world. The AEC labeled this body-snatching program Operation Sunshine and collected thousands of human limbs, dead infants, human and cattle thyroids, and cadavers without consent. ${ }^{65}$ Despite other studies that were recording alarming worldwide increases in radioactive strontium in bones and teeth, as well as radioactive iodine in the thyroid glands of all mammals, journalist Robert Jungk observed dryly, the report of Operation Sunshine "beamed with purposeful optimism." ${ }^{66}$ The name of the study was derived from the analogy between the sun and nuclear radioactivity because 
after these tests, "fallout, like sunshine, covered the globe." ${ }^{67}$ This, in turn, led to new concepts of an illuminated globalization, an era in which one mapped the world through the trace of militarized radiation. As one scientist reported, "Nobody believed you could contaminate the world from one spot. It was like Columbus when no one believed the world was round." 68 This reflected a "new world" of militarized radiation, an Anthropocene epoch in which the planet became (re)written by artificial light. While the One World or None antinuclear movement of the r940s generated some of the earliest articulations of global environmentalism and planetary consciousness, ${ }^{69}$ by the 1960 s every person on the planet was in fact globally connected due to the bodily absorption of the radioactive fallout from hydrogen weapons detonated in the Pacific. We are cautioned that the Anthropocene cannot be experienced ontologically, yet the militarized radioactive isotopes carried by our bodies may suggest otherwise.

Bravo and the subsequent two thousand or so nuclear tests on this planet, Eileen Welsome observes, "split the world into 'preatomic' and 'postatomic' species." ${ }^{\prime 70}$ Radioactive elements produced by these weapons were spread through the atmosphere, deposited into water supplies and soils, and absorbed by plants and thus into the bone tissue of humans (and our nonhuman others) all over the globe. The body of every human on the planet now contains strontium-90, a man-made byproduct of nuclear detonations, ${ }^{71}$ and forensic scientists use the traces of militarized radioactive carbon in teeth to date human remains. ${ }^{72}$ Radiation is unstable matter in the continual process of transformation into something more stable. It is a register of decay, entropy, and a process of what Walter Benjamin meant by "nature-history." Although invisible to the naked eye, radioactive traces help constitute a history of light that can be interpreted on a local and planetary scale. In this way, radioactive fallout signals invisible ruins. It is the unseen wreckage of catastrophe that lies before Benjamin's Angel of History. ${ }^{73}$ It presents us with the most invisible yet pernicious form of planetarity, one directly tied to the transformation of the human body and an uncanny sign of our ontological merger with a globalized environment signaled by the Anthropocene.

\section{Heliography: Inscribing the Wars of Light}

The radioactive militarization of the globe has long been a concern for Pacific Island writers, who have engaged with this heliotrope of the "fully enlightened earth." Pacific sovereignty movements have posed legal, political, and 
philosophical challenges to what Paul Virilio refers to as "light wars," which he dates to the start of the twentieth century with the first use of the searchlight. ${ }^{74}$ Combined with technologies of surveillance such as the camera and the sniper's lens, to sight was to target, producing "a deadly harmony between the functions of the eye and the weapon." 75 Thus, the modern conquest of space is synonymous with the conquest of the image; long before nuclearization, light and militarism were constitutive. ${ }^{76} \mathrm{With}$ this shift to the technologies of optical representation, the landscape of war has been increasingly understood as the visual media used to perpetuate and represent it.

Memory of the wars of light has never diminished in the Pacific Islands; accordingly, a body of work by Indigenous authors in particular has addressed the complex legacies of nuclear radiation, all of which turn to the daemonic figure of light both as history and as a figure for writing. ${ }^{77}$ In calling attention to the ways in which solar metaphors suppress the history of violence, Teresia K. Teaiwa asks, "What does the word bikini evoke for you? A woman in a two-piece bathing suit or a site for nuclear weapons testing? A bikini-clad woman invigorated by solar radiation, or Bikini Islanders cancer-ridden from nuclear radiation?"78 In their fiction, Albert Wendt, Chantal Spitz, and others have inscribed the wars of light as a colonial reckoning with modernity and a critique of the military globalization of the region. This literary genealogy might be traced back to the work of the Māori poet Hone Tuwhare, whose earliest poems sought to denaturalize the heliocentrism of military nukespeak. His "No Ordinary Sun" (1964), a five-stanza poem written amid the British and U.S. nuclear tests throughout the Pacific Islands (1946-62) and at the advent of French nuclearization of Tahiti or Te Ao Mā'ohi (1966-96) repeatedly negates the solar metaphors accorded to the nuclear bomb that so successfully naturalized violence against the people of the Pacific. ${ }^{79}$

While we generally associate naturalizing metaphors with terrestrial matter, such as the trees and soil that are thought to "root" human relationships to the land (and thus provide ontological relations to the Earth), the discourse of military nuclearization has drawn from the extraterrestrial to naturalize the violence of cosmic universalism. Robert Oppenheimer purportedly borrowed from the Bhagavad Gita to describe the explosion of Trinity, the world's first nuclear detonation, as "the radiance of a thousand suns." ${ }^{80}$ Atomic (fission) and hydrogen (fusion) weapons are often described as harnessing the power of the sun, or of releasing the universal and generative power of the Big Bang and therefore replicating the origin of our universe. This allegory suggests that the weapon "partakes in the cosmos's 
forces of creation, that it somehow helps establish the world's conditions of existence." ${ }^{1}$

It is in this association of the sun, a "supernatural" metaphor of radiance and (nuclear) radiation that is key to understanding Tuwhare's poem, which pairs it with the tree, a "natural" metaphor of human presence on the planet. The title "No Ordinary Sun" frames the poem with the simultaneous creation and destruction of metaphor (23). As an allegory about the relation between an all-powerful sun (nuclear weapon) and tree (human), the title and opening "no" negate the ordinariness that naturalizes the bomb as the sun. The first stanza begins:

Tree let your arms fall:

raise them not sharply in supplication

to the bright enhaloed cloud.

Let your arms lack toughness and

resilience for this is no mere axe

to blunt nor fire to smother.

The unnamed speaker begins the first line of the poem with an imperative. The personification of the tree's limbs doubles the man-made military "arms" that make this metaphor possible (23). The rest of the opening stanza develops the anthropocentrism of the tree and the divinity of the sun, placing the two in unequal relation. The speaker presumes an intimacy with the tree and warns it not to raise its arms "in supplication/to the bright enhaloed cloud," creating a spatial hierarchy between earth and sky and suggesting that the raised arms that normally would link both realms should not be used to facilitate this connection, a refusal of the daemonic function of allegory.

The last stanza of the poem destroys its own metaphors and leaves the poet with no earthly landscape to transform.

$\mathrm{O}$ tree

in the shadowless mountains

the white plains and

the drab sea floor

your end at last is written.

The very process by which human language gains its meaning-through its rootedness in natural, earthly metaphor-is eradicated. The speaker turns to the mountains, usually a space of contrast and spatial depth, but finds they are now "shadowless." Similarly, the "plains" are now "white" and the 
sea floor is "drab." Here nuclearization leads to a planet determined not by darkness, a lack of light, but total light. The sea floor, representing the farthest depths of earthly existence but also the space that is completely unfathomable to human knowledge, is not "illuminated" by the atomic sun; it is simply "drab."

Given its nuclear topic, the poem's structure is oddly antiapocalyptic. Unlike almost every other visual and narrative account of nuclear detonations, which capitalize on the stunning visual effects of nuclear explosions and thus produce an optic aesthetic of violence, Tuwhare recounts a nuclear apocalypse in which the actual detonation and blast are not inscribed. This is a world of total light, but illumination does not follow. It is these very spaces that lack figurative imagery where, the poem concludes, the tree's "end at last is written" (23). Tuwhare's poem is an elegy to the globalizing impact of the Cold War and its potentially scorching implications for life on earth. As I have argued elsewhere, the power of the poem lies in its defiguration of the naturalization of light, rendering an uncanny planetarity. ${ }^{82}$

"No Ordinary Sun" has been adopted as a rallying point for the peace movement across Oceania. The poem has been reproduced in stone in the Wellington Peace Flame Garden; it has been set to music; and it has been adapted in a series of antinuclear paintings by Aotearoa New Zealand's best known visual artist, Ralph Hotere, a figure notable for his attempts to defigure the naturalizing violence of the nuclear bomb with dark and decidedly nonfigural representations of an irradiated Pacific. ${ }^{83}$ In this particular Hotere painting (figure 2.I), we see the shape of the sun and the way in which it puts pressure on the written space of Tuwhare's poem, but its light does not illuminate. Both Tuwhare and Hotere are remarkable for their defiguration of the naturalizing relationship between the nuclear bomb and solar ecologies; both resist the cosmological (including Christian) origin narratives that help normalize the tremendous anthropogenic violence of fission and fusion weapons. In doing so, they foreground the process of representation, importantly claiming the daemonic function for the writer or artist rather than for the figure of light.

As Clarke has pointed out, "The daemonic is intrinsically allegoricalit personifies the supplementary status of allegorical writing. Moreover its structural role of cosmic intermediation parallels allegory's historical role of cultural intermediation." ${ }^{\prime 4}$ This intermediary function is about the distribution of power (or its equivalent, knowledge) from one realm to another. This is why, as Clarke demonstrates, writing itself is daemonic. Tuwhare makes 


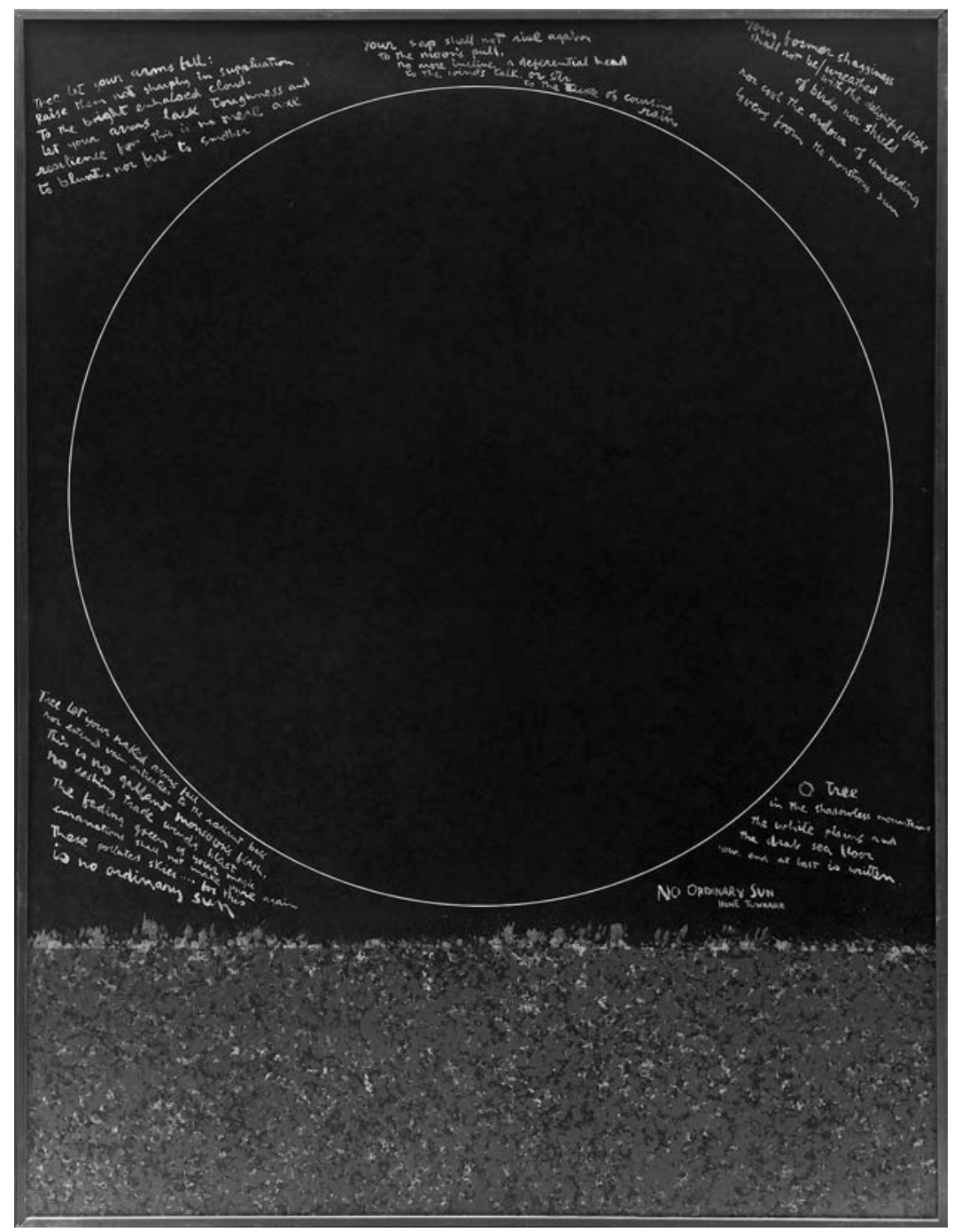

FI GU RE 2.I. Ralph Hotere, No Ordinary Sun, 1984. Enamel on board, 1,560 × 1,180 mm, Auckland Art Gallery. By permission of the Hotere Foundation Trust. 
this point in the end of his poem, concluding with an omniscient voicenot that the "end is near," but the "end is written." The insertion of the human mediator of power-through art, writing, or the bodily experience of nuclear irradiation-is integral to dis-figuring "nukespeak." This human mediation is eclipsed in the military discourse that connects the atom's latent power to the sun, even though the human body has been foundational in western philosophical systems as a daemonic allegory for measuring the relationship between the micro- and the macrocosmos. ${ }^{85}$

Allegory is known for its visual language, which helps explain the close relationship between Indigenous writers and visual artists in representing the nuclearized Pacific. The visual de-figuration of naturalizing allegories of light has inspired other Pacific authors, such as the New Zealand-based Samoan writer Albert Wendt, who uses Hotere's Black Rainbow painting as a title for his dystopian novel. Black Rainbow (1992) depicts a nuclear doomsday clock that is a continual touchstone to the protagonist and determines the apocalyptic temporality of the text and, by extension, the Pacific as a region. (In fact, this same Bulletin of Atomic Scientists' doomsday clock is now being used to warn the public about critical levels of global warming. ${ }^{86}$ The protagonist turns to Hotere's paintings about French nuclear testing in Moruroa (French Polynesia) as a critique of the totalitarian state and the potential for art in the wake of state violence against the Indigenous. ${ }^{87}$ The concept of the black rainbow in both Hotere's and Wendt's work nicely demonstrates the paradox of representing nuclear radiation in ways that challenge the daemonic allegory of solar radiation.

While Tuwhare critiqued the naturalizing of solar metaphors for nuclearization, Wendt and Hotere de-figure the daemonic allegory of nuclear light by turning to darkness, read here as an Indigenous cosmology of $\mathrm{Te}$ Pō, or originary space of creation. ${ }^{88}$ This darkness, however, is marked by a nuclear temporality that registers ruin and eventual (radioactive) decay. While to Benjamin history is "subject to nature" and thus to inevitable decay, in these nuclear allegories-and in the Anthropocene-nature is subject to history and thus reflects "a process not of eternal life but rather of irresistible decay." This is suggested in Hotere's Black Rainbow lithograph (figure 2.2), in which the rays of light appear in black rather than the full color spectrum and move downwards-like sickening fallout-rather than upwards. Moreover, the countdown clock runs vertically alongside a column that may represent a nuclear detonation, in which time is annihilated by violence. 


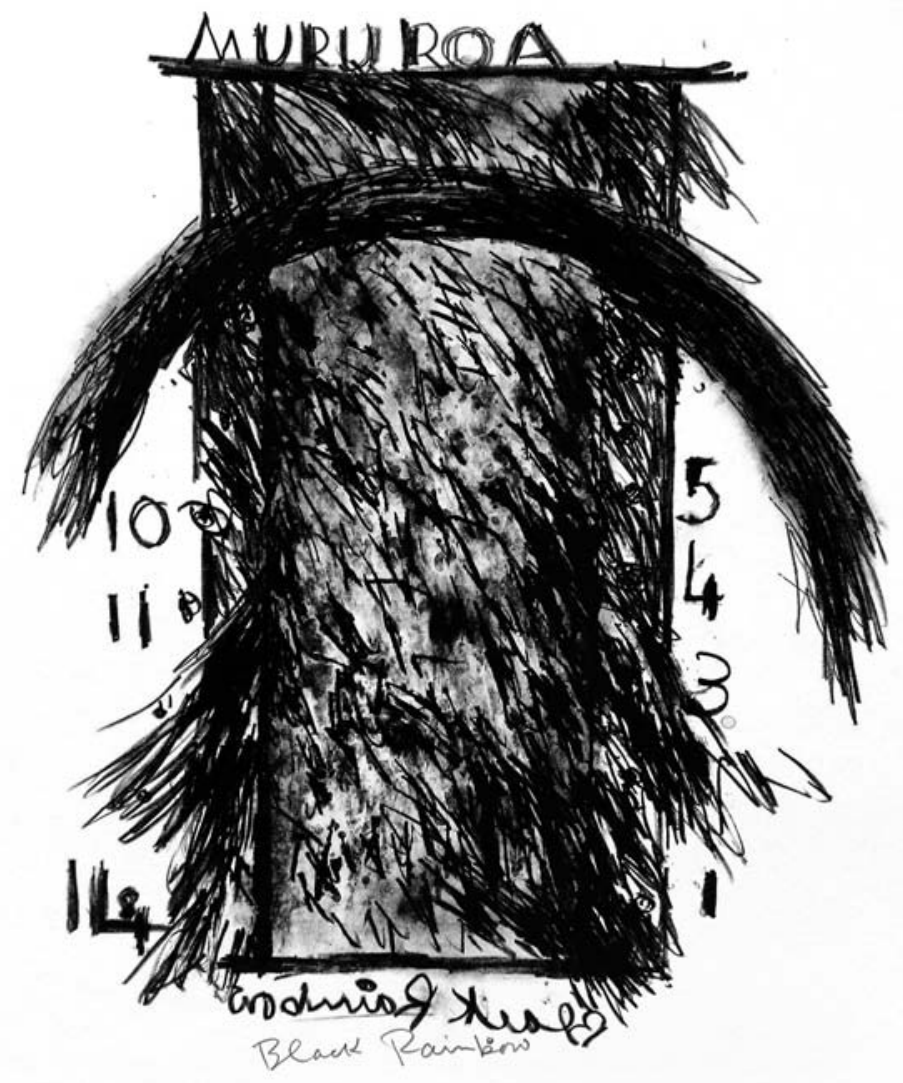

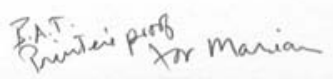

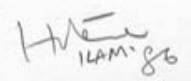

FI GURE 2.2. Ralph Hotere, Black Rainbow, Mururoa, 1986. Lithograph, $570 \times 380$ mm, P G Galleryı2. By permission of the Hotere Foundation Trust. 
Tuwhare, Hotere, and Wendt are all concerned with the daemonic allegory of light's mediation between the earthly and the divine, between nature and history. In a similar vein, the Tahitian writer Chantal Spitz opens her allegorical novel Island of Shattered Dreams (1991) by juxtaposing two cosmologies of light. The first, written in Tahitian, inscribes the separation of the earth and sky to create Te Ao Mārama, the world of light, a genealogy linking humans with the divine common to many traditions of the Polynesian Pacific. This is followed by a passage from Christian genesis of the divine creation of light and its separation from darkness, including man's decree of dominion "over all the earth." ${ }^{89}$ Like Polynesian accounts, the biblical genesis replicates the movement of formlessness to form, the construction of earthly temporality, and the association of light as a legacy of knowledge of the divine. In juxtaposing these cosmologies, Spitz highlights the remarkable difference in how this shift of form produces different ecological results. In the novel, the Mā'ohi cosmology (written in Tahitian) positions the human as a genealogical product of divine nature descended from Rumia and Ta'aora, whereas the Christian genesis (written in French) positions the natural world in terms of its distinction from the human and therefore authorizes "dominion" (IO). This rupture between divine cosmology and disenchantment is visible in the novel's narrative trajectory, which moves from an allegory of cosmogony, the world of Ra, "the majestic lord of light" (80), toward the temporal discourse of modernity and nuclear colonialism.

Recent Anthropocene scholarship has raised important questions about how to best narrate climate crisis, apocalypse, and the extinction of the human as species. Turning to the Indigenous Pacific, we see that the worldthreatening apocalypse has already occurred, whether we consider the (ongoing) history of Euro-American empire and settler colonialism in the region or twentieth-century nuclear colonialism in the Marshall Islands and French Polynesia. Thus, it is instructive to consider the ways in which Pacific authors have long engaged with apocalyptic narratives and drawn on different narrative registers to replicate the shock of the "irruption into modernity," as Glissant puts it.

Narratively, Spitz marks a major shift from the epic mode of allegory to nuclear realism once French nuclear missiles are placed in the "sacred belly" of Mā'ohi land. The novel begins with daemonic inscriptions of its characters as "children of light," but once the economy is militarized, it shifts to inscribe light as nuclear radiation. Soon modern fears plague the Tahitians about being "burned to a crisp" ( 85 ) by missiles. French physicists introduce 
the Enlightenment discourse of instrumental rationality, what Spitz refers to as "the logic of men" (I45), changing narrative and history as Tahitians are displaced from an allegory about the relationship to the divine into a neocolonial "light-filled city" (I48) that produces cancer, alienation from ancestral language, and an economic legacy of nuclear dependents. Thus, the absorption of radioactive light creates terminal cancer in her protagonist, calling attention to the daemonic function of light as well as its allegorical temporality of decay and ruin. Spitz's novel, which tracks the failed romance between a female French nuclear scientist on the island and her Tahitian lover, can be read as a "counterallegory" to the French colonial romance novel, reconfiguring the light of the tropics so central to French exoticism of Tahiti and harnessing it to a critique of its modern counterpart in nuclear radiation. ${ }^{90}$

\section{Allegories of Anthropogenesis: Trinity}

The Pacific texts I have reviewed thus far all engage the daemonic function of allegory, turning to light and radiation as a figure for the mediation between the earthly and the divine, a relationship visible in the history of U.S. nuclear discourse, which began with the naming of the first atomic detonation Trinity. In 2015, the Anthropocene Working Group (AWG) created a new narrative of anthropogenesis. They turned to the Trinity test and claimed July 16, 1945, as the origin to the Anthropocene, the same date that Worster located as inaugurating the "Age of Ecology." In Beginnings, Edward Said describes an "origin" as tied to discourse of the divine, while "beginnings" are earthly, human-produced, secular narratives. Yet these multiple claims for the detonation of Trinity as an origin story-of modernity, technology, ecology, and the Anthropocene-all suggest that secular claims to beginnings draw their power from cosmological (often Judeo-Christian) origin stories. In his work on theorizing the globe as an ecology, Timothy Ingold has argued that contemporary global thinking has replaced cosmology with technology. ${ }^{92}$ Yet here we see that allegories of the Anthropocene use cosmological narratives that are legitimated by the trace of radioactive decay. The naming of Trinity as a way to suggest that human technology emanates from the divine is a hallmark of Anthropocene discourse of the Anthropos as a "god species," yet we can also see it is part of a long history of the AEC and Manhattan Project in naturalizing state violence through daemonic allegories. ${ }^{93}$ 
In the twenty-first century, geologists must demonstrate a clear stratigraphic marker - not a daemonic allegory—for the origin of the Anthropocene. Yet interestingly, Zalasiewicz and his colleagues in the AWG admit that in choosing the Trinity test there is no actual stratigraphic spike for that precise date. They acknowledge that the "radiogenic signal became prominent worldwide a few years later than 1945," but, "nevertheless, placing the benchmark at the first nuclear test provides a clear, objective moment in time." ${ }^{94}$ This is an odd choice for many reasons, particularly because the atomic (fission) tests of the r 940 s were in fact "tiny" compared with the enormous fusion (hydrogen) weapons that followed in the Pacific and that are far more relevant to the radioisotopes evident in today's stratigraphy. My interest is not in establishing any truth claims to these anthropogenesis narratives but, rather, in highlighting the daemonic function of allegory that underlines this presumably "objective" and yet, in geological terms, unsubstantiated desire to contend that the Trinity test is the origin point for the Anthropocene.95

In this section of the chapter, I turn to how the Trinity test has become a historical marker for the entrance into a militarized modernity, an era of unprecedented ecological destruction that Worster presciently called "the lesson of Alamogordo." I explore these issues through the work of James George, a contemporary Māori novelist who has produced a remarkable trilogy of novels that examine Pacific militarization and, in his most recent work, the way in which humans have negotiated the correspondence between the micro- and the macrocosmos, a daemonic allegory that is embedded in the irradiation of the human body. Although the watery trajectories of the title, Ocean Roads, would seem to suggest otherwise, George's novel is an exceedingly complex work that, like "No Ordinary Sun," explores the repercussions of heliocentrism and offers a critique of the devastating effects of nuclear weaponry and their irradiation of the planet. ${ }^{96}$

George's novel charts the tumultuous Cold War years between 1945 and 1989, examining the implications of bringing the (nuclear) sun to humanity that, as the legends of both the Māori demigod Māui and Prometheus foretell, leads to the scorching of the earth. This daemonic allegory is told in multiple forms. The central "disciple of physics. Of light" (6I) is the JewishBritish nuclear physicist Isaac Simeon, who, over the course of his heliocentric professional life, disobeys his father's orders not to "look into the sun" (73) and becomes an architect of the plutonium weapon that was dropped on Nagasaki. In the current time of the novel, he relocates to Aotearoa New 
Zealand and, after marrying a Māori photographer, loses his sanity in realizing his responsibility in pursuing this "love of light." His stepson Troy and son Caleb struggle with this legacy of earthly irradiation, particularly as it is reformulated as napalm accelerant in their participation in and resistance to the Vietnam War. The mother of the two boys and husband to Isaac, Etta Henare, travels across the globe in an effort to capture light as a war photographer, witnessing and documenting the violence of nuclearization and the napalm fires of Vietnam. Although these characters are all to some extent destroyed by the violence of light, fire, and radiation, the novel places some regenerating hope in the character Akiko Io (and her daughter Rai), a survivor of the Nagasaki bombing who is associated with the rain needed to quench a scorched earth.

While George's novel is not allegorical in the sense of The Rainmaker's Mistake or Island of Shattered Dreams, the author explores the intermediary functions of light and radiation through the daemonic function of allegory, tracing out how the wars of light inscribe history, the planet, and the human body. Defining radiation in its broadest terms—as the energy of the sun, visible earthly light, the invisible trace of global nuclearization, and radiotherapy - the novel breaks with historical realism as a genre to restructure the chronology into one informed, ruptured, and illuminated by the presence of light. As such, it is organized around a Benjaminian constellation of past and present rendered in sudden flashes of illumination. Each of his characters engage light through different methodologies: physics, war photography, sniper fire, cinema, and radiation therapy. Beginning with the Trinity site at Alamogordo, the novel remaps the light wars of the Pacific as a U.S. military frontier of "radioactive colonization" that stretches from the nuclear landscapes of New Mexico across the irradiated Pacific Islands to postatomic Japan, extending southward into Aotearoa New Zealand and finally into the frigid deserts of Antarctica. ${ }^{97}$

The novel begins in 1989 with a chapter called "Sand," an important symbol in the text that represents the starting and end point of nuclear detonation and a larger commentary on the ruins of history, particularly the scorched deserts left in the wake of nuclear detonations. This chapter depicts Etta at the Trinity site in New Mexico, forty-four years after the detonation in 1945 , in the year in which Mikhail Gorbachev and George H. W. Bush declare the official end of the Cold War. While she has been commissioned to photograph the origin site for the nuclear era, memorialization is chal- 
lenged because the only visible ruins are sand. In this opening chapter, the text shifts between three narrative layers: the third-person omniscient narrative that describes present space-time, Etta's internal monologue in which she addresses the Isaac of the past who witnessed the detonation, and the textual descriptions of her photographs of the site, a capturing of time and space framed by a narrative-stopping "Click." This mechanical sound is "the noise of time," as Roland Barthes famously argued; as such, "cameras are clocks for seeing." ${ }^{8}$ In keeping with the "trinity" theme of the novel, there are three narrative layers and three sections representing three photographs each. The images Etta captures with her camera-a dusty water tank, an abandoned barn (3) - suggest the ruins of man-made architectures of history. In the words of Benjamin, "In the ruin history has physically merged into the setting. And in this guise history does not assume the form of the process of an eternal life, so much as that of irresistible decay." 99 Yet as a photographer capturing the setting (which in turn is captured by the author), Etta turns the background into the foreground, calling attention to history as alterity, that which is invisible to narrative.

By imagining her husband, Isaac, watching the Trinity explosion in 1945 , Etta uses personal memory to stitch together a military site with the history that it is supposed to represent. In a novel suffused with visual imagery, from paintings, photography, war surveillance, and silent film, the text immediately foregrounds the importance of other, undocumented forms of memory and history outside visual knowledge. Etta leaves the desert with a small cup of sand, explicitly against her war photographer's code to "leave no trace but your pictures" (38I), wishing that Isaac had been able to witness the site's potential for a recuperative history beyond ruins. She captures images of human reconciliation such as the visitors shaking hands, kissing, and embracing (6). Although for much of the novel she is hidden from our view behind her camera, Etta's return to Aotearoa New Zealand after the Trinity shoot and a stopover at Pearl Harbor provides the structural catalyst to events in the novel, generating a last family reunion between characters who have been devastated by the legacies of World War II.

This complicated relationship between radiation, time, and the ecology of war is explored in Ocean Roads through heliographic instruments that are essential to modernity. This includes print media such as Life magazine (Etta's employer) and other photographic magazines that commission her to document war and its aftermath, all of which share titles that signal the 
attempt to arrest time, such as Heuer (This Year) and Time (36, 71, 156). Visual media catalyze actions in the plot; Etta's wartime photographs circulate between characters and across the forty-four years of the Cold War, and televised news events including the moon landing that she watches from her Saigon hotel room affect the narrative. How these technologies of light inscribe history is one motif that troubles the novel, particularly when we consider how photography may confound rather than uphold historical context. ${ }^{100}$ As early as 1927 , Siegfried Kracauer noted the flattening of time and space caused by the rise in photographic magazines:

The flood of photos sweeps away the dams of memory. Never before has a period known so little about itself. In the hands of the ruling society, the invention of illustrated magazines is one of the most powerful means of organizing a strike against understanding. ... The contiguity of these images systematically excludes their contextual framework available to consciousness. The "image-idea" drives away the idea; the blizzard of photographs betrays an indifference toward what the things mean. ${ }^{101}$

Kracauer's critique of the knowledge production of visual economies is particularly relevant to Etta, a figure we see little of in terms of textual presence, yet her professional mobility and her photographs catalyze events and structure the narrative time of the novel. Ocean Roads is nonchronological, signaling a narrative shift away from linear historicism and highlighting how the ecologies of light trigger both continuity and discontinuity in time and memory. ${ }^{102}$ Given George's concern with the visual and subvisual manifestations of radiation and their impact on human memorialization, it is not surprising that the novel opens with the ways in which technologies of light attempt to memorialize the Trinity detonation site in 1989. The Trinity obelisk is central to this chapter, a monument engraved with the historical starting point of the novel, July I6, 1945, and a subject of Etta's photographs. As Cosgrove has observed, "The obelisk was not only a cosmographic instrument whose shadow located time and latitude; its very form denoted a beam of light" that signified divine illumination; for Christians, this divine light derived from the Holy Trinity. ${ }^{103}$ The appropriation of divine discourse, likening the nuclear weapon to the presence of the sun on earth, harnesses the daemonic function of allegory to obfuscate the origin story of this first atomic bomb as an intentional, not divinely orchestrated, \$2 billion U.S. military project. 
Conscious of how solar metaphors of the atomic bomb adopt divine rhetoric to mystify the constitutive relationship between militarism, science, and nationalism, George explores the entanglement between light and modernity through the secular temporality of photography. This is signified by Etta's camera with its terminal "Click." (5), which stops the narrative and captures what Benjamin might refer to as the "now-time" of this visit to Trinity and many other scenes. ${ }^{104}$ This time-stopping "Click." resists the naturalizing flow of narrative and calls attention to the media of historical transmission. Moreover, its signification as a moment of simultaneous continuity and discontinuity with otherness - the otherness of history, narrative, nature, and radiation-invokes the paradox of light as an absent presence and an engagement with the alterity of planetarity. This radiation-mediated relationship to planetarity is different from the way the antinuclear movement has adopted a homogenizing one-worldism, what Lisa Yoneyama calls a "nuclear universalism" that reduces the complexity of the wars of light into a homogenous nationalist or spiritualist discourse of peace. In contrast, this "now-time," the "photographic temporality" in Eduardo Cadava's gloss of Benjamin's concept of history, ${ }^{105}$ suggests an arrest in narrative that potentially opens up new insights into the past and is specifically engaged in defiguring the figure of light.

In its capturing of light, we might say that Etta's time-stopping "Click." offers a caesura to universal linear narrative. ${ }^{106} \mathrm{In}$ fact, George's protagonist in an earlier war novel describes the photograph as "a moment with no before and no after." ${ }^{107}$ Yet Ocean Roads represents an effort to engage multiple allegories of light including the arrest of time articulated by Benjamin, as well as the visual contiguity theorized by Kracauer. Other temporalities of light explored by the novel include the longue durée of the irradiated earth, evident in the radioactive "trinitite" Etta observes at the Trinity site, and how light impacts personal and political narrative. Of course, the ultimate but unseen symbol of light, time, and photography is the Trinity explosion itself. Richard Rhodes and Virilio have commented on the ways in which a nuclear explosion functions like a camera, flashing an apocalyptic snapshot of a place in which only the shadows of presence, the remnants of light remain. ${ }^{108}$ This particular use of light to foreground the complexity of time has been noted by Akira Mizuta Lippit, who demonstrates that weapons of light such as "the X-ray, photographic media, and the atomic weapon circulate in a specular economy, bound-as are all photographic events-by the logic of anniversaries. By capturing single moments in time, 
all photographs suggest future anniversaries" as an archive of the moment and the future. ${ }^{109}$

The spectral logic of anniversaries and their relationship to the archive is crucial to understanding the structure of George's novel and its destabilization of linear models of time. Accordingly, the opening of the novel positions Etta at the Trinity site at the fiftieth anniversary of the start of World War II. The current time of the novel takes place in April and May 1989, tracking Etta's movement between Trinity and Pearl Harbor and her journey home to meet with the curators at the Auckland Museum, a military monument and cenotaph, to coordinate a retrospective exhibit of her photographs. The rest of the novel occurs through flashbacks, illuminating constellations of past and present, such as August 1945, when she photographs vJ Day celebrations; April 1975, when she photographs the withdrawal of American troops from Vietnam; and July 1969, when she takes a Pulitzer Prize-winning photograph of her son Troy, whom she discovers in a river attempting to save the lives of two Vietnamese children from a napalm attack. This "triangle of blackened faces" she refers to as "an unholy trinity" (95), a dystopian familial counter to the divine national signification of the Trinity obelisk. The publication of this photograph alienates her from her younger son Caleb, whose primary experience of his traveling mother is through her photography in Time and Life (36). Yet Caleb is not a naïe reader of the sort Kracauer imaged; although he has been alienated from his maternal origin (history), the photograph of the "unholy trinity" catalyzes his antiwar activism. Moreover, the picture of this "unholy trinity" circulates in the novel between characters, generates Troy's flashbacks to the Vietnam War, is narrated from multiple perspectives, and structures the action and temporality of the novel. After a lifetime of work hoping that "every photo she has had published has scrubbed one day off the war. Off all wars" (342), Etta refuses to display this Pulitzer Prize-winning photograph in the war museum's archive of military light (298). The visual collapse signified by this picture between the soldiers she photographs and her own sons' participation in war suggests an inescapable familial inheritance of the wars of light. Moreover, tying the daemonic allegory of light to specific bodies enables the narrative to engage with nation-state violence, alterity, and accountability, the very issues that are missing in the Anthropocene's presumed origins in the explosion of Trinity. 


\section{Allegories of Postatomic Species}

Nuclear militarism has catalyzed a radical change in the age of ecology and in our perception of light, radiation, and what constitutes the visible. The hypervisuality of an atomic or hydrogen explosion renders visible the otherwise sub-visible splitting of atoms. Lippit has argued that "since 1945, the destruction of visual order by the atomic light and force" has created an "A-visuality" from the legacy of the A-bomb. ${ }^{110}$ This is reflected in scenes of the novel in which characters are repeatedly described as blinded by flashes from the Trinity test (Isaac), napalm explosions (Troy), and the Nagasaki "pika," or flash (Akiko). This postatomic shift in visual logic, Lippit argues, has led Japanese artists to explore the "total penetration of the body by light" as an "A-visual" archive. ${ }^{111}$ Thus, "The archive is inscribed on the surface of the body to render it invisible." 112 In a novel deeply concerned with modes of heliography - the writing of light through nuclearism, photography, cinema, and physics-Ocean Roads turns in its conclusion to how these ecologies of light are written in the body, and how the human body inherits the alterity of the irradiation of the earth.

George's novel draws extensively from historical accounts of the creation of the atomic bomb, but he makes an important change in his depiction of Isaac watching the Trinity explosion in the New Mexico desert. While firsthand accounts report that AEC physicist Enrico Fermi threw up pieces of paper above his head to measure the wave of the blast, ${ }^{113}$ the author has Isaac use "fragments of desiccated bone" (248), the corporeal trace of previous inhabitants of the Jornada del Muerto desert. In the same section, the novel connects this scientific excursion into the desert to witness the dawn of the atomic era with the Spanish colonization of the Americas, both masculine conquests of Indigenous lands under the banner of divine light that suggest a long history of radioactive colonization and "Age of Man." The first empire used the daemonic allegory of Christian light; the second, the secular allegory of promethean technology. George's decision to shift from paper to bone is important because bone more readily signals the ruins of human history, rendered not through technologies (such as architecture) but through the body. Again, we return to the Benjaminian corpse and the suturing of nature-history into allegories of decay. Like the practices of burial explored in the previous chapter, the placement of human bones signify a connection to the earth as ruins and mark ontological histories of place through burial. In Māori contexts, bone (not blood) is the term solidifying tribal identity, 
or iwi. And while it remains invisible to the naked eye, bone incorporates the history of planetary irradiation.

Twenty-five years after the Trinity test, Isaac's son Caleb feels "a shuddering in his bones" (200), and his oncologist informs him that he has "too many immature lymphocytes, lymphoblasts, sometimes called blast cells. They fill up the bone marrow"' (268, emphasis added). This is a particularly aggressive form of cancer, an "A-Bomb disease" associated with the radiation exposure of the hibakusha (nuclear survivors of Japan). ${ }^{114}$ This form of leukemia is a genealogical and historical inheritance from Isaac and a legacy of what Catherine Caufield terms the "industrial radiation age." 115 Previously, Caleb's brother Troy had traveled through the Jornada del Muerto, moving through the land where his stepfather Isaac developed a plutonium weapon, noting to himself that that the (plutonium) "bomb was in his stepfather's blood" (I2I). Plutonium-239, the byproduct of nuclear weapons, is a "boneseeker." 116 In a novel that uses the genealogy of radiation as a model for history, Caleb now inherits a disease of nuclear modernity, "acute lymphoblastic leukaemia," described as "spiked wheels turning in his bones" (305). After a visit to the oncologist, Caleb raises his face "to the stark sun, imagining it highlighting his dying bones" (306) like those in the Jornada del Muerto, a constellation and originary sacrificial space of empire, the Nuclear Age, and the Anthropocene.

The militarization of light has been widely acknowledged as a historical rupture that brought into being the nuclear age, but less understood is the way in which our bodies are written by these wars of light. As noted earlier, U.S. nuclear tests "split the world into 'preatomic' and 'postatomic species." 117 After seven decades of nuclear tests, radioactive isotopes of carbon, cesium, strontium, and plutonium have been absorbed by all postwar humans on the planet. ${ }^{118}$ This is a different nuclear universalism from what Yoneyama observes in the postwar script of Japanese nationalism, one found not in the "panhuman eschatology" of a hypervisual nuclear apocalypse, ${ }^{119}$ but rather in an invisible and ephemeral trace of what Nixon calls "slow violence"the nonapocalyptic threats to our survival such as depleted uranium weapons and the toxic ecologies that Rachel Carson brought to public consciousness. Radioactive fallout presents us with the most invisible yet pernicious form of the wars of light, one directly tied to the transformation of the human body and a sign of our merger with the alterity of our planetary environment.

We are, to borrow from Daniel Tiffany, a "radiant species," a phrase coined by Roger Bacon, whose work on celestial bodies and optics produced 
an influential vocabulary of "visual species" in the Enlightenment. ${ }^{120}$ Isaac Newton's work with the new technologies of the microscope led him to argue that "the changing of Bodies into Light, and Light into Bodies, is very conformable to the course of Nature, which seems delighted with Transmutations." ${ }^{121}$ Light is transformative of our bodily ecologies; the irradiation of tissue continues after the body's death. ${ }^{122}$ Although as readers we are initially led to believe that Akiko of all characters will inherit radiation sickness from her exposure to the Nagasaki flash, Caleb, the most localized of George's characters, whose ambit is limited to the greater Auckland area, is chosen by the author to signal the legacy of militarized radiation and its transmutation of the human body. As Yoneyama remarks, radiation "trespasses over geographical borders and temporal limits ... no existing borders-whether national, cultural, ideological and political—can ensure immunity." 123 The military irradiation of the earth is more than a symptom of globalization and the Anthropocene; George's novel helps us recognize the signs of planetarity, an apprehension that refuses to naturalize the military transmutation of light.

In his experience of both cancer and the radiation treatments, Caleb describes his body in planetary terms, an internalization of light in which his body is "rendered uncanny, unhomely ... a defamiliarization of familiar space." 124 When Caleb's oncologist recommends radiotherapy, the use of "high energy rays to destroy the cancer cells" (269), Caleb laughs at the irony and writes "a single word ... over and over. Radiation" (277). Cancer is often understood as a disease of modernity, metaphorically linked to the inability to limit consumption and violence in industrial society. ${ }^{125}$ The radiotherapy advised by Caleb's oncologist is part of a tradition Susan Sontag has likened to the militarization of disease treatment, the "battle" against cancer, noting that early chemotherapy was derived from chemical warfare in World War II. ${ }^{126}$ Caleb's transformation from a human body to one of metallic modernity has already been foreshadowed in earlier scenes in which he dresses as the Tin Man from The Wizard of $O z$ for children's parties, a character understood to represent the industrialization of labor and, as a former woodsman who has turned into metal, a critique of the commodification of labor and alienation from nonhuman nature.

Angus Fletcher has noted that "the perfect allegorical agent is ... a robot," a point examined by George as his character begins to become more metallic and inhuman. ${ }^{127}$ At the oncologist's, Caleb undergoes "the clicking and whirring of the machines" and imagines "sunlit doorways," where "sometimes 
the sun is so hot that it starts the tall grass burning" (274). When the "blast cells" return, Caleb refuses to "accede to radiology" and this space of total illumination where he would "spend his last days amid the metallic whir of electric motors and gauges and scopes" (3I2). Shifting away from radiotherapy to another mode of heliography, he invokes the "unholy trinity" that inspired his antiwar activism, his "binding commitment" to his brother's face "on the magazine cover" with the Vietnamese children (3I2), a photograph taken by his mother, and determines to immolate himself at an Armistice Day peace rally.

In a novel about nuclearization and the wars of light, George shifts attention from the often blinding (and totalizing) apocalyptic focus of a nuclear "war of the worlds" to addresses less visible forms of the wars of light, including the movement of radiation across space, time, and human bodies. ${ }^{128}$ Caleb's activist friends demand spectacular visibility. Heeding their antiwar strategy "to be more visible" (26I), Caleb attends the Armistice Day peace rally in 1970, held on Isaac's birthday and at the Auckland Domain where Etta will later display her archive of light. There Caleb douses himself with napalm-laced kerosene and, holding his father's army-issued Zippo lighter, delivers a speech against the global quest for total illumination (366). He echoes Virilio's critique: "Nothing is sacred anymore because nothing is now meant to be inviolable. This is the tracking down of darkness, the tragedy brought about by an exaggerated love of light." 129 The scene is narrated cinematically, with crosscuts between Akiko (a peace rally dancer), Troy (now a fireman), and the suicidal Caleb. When Caleb's actions endanger Akiko, he is shot dead by his sniper brother Troy, triggering the kerosene fire and Caleb's immolation in napalm. In turn, Troy hallucinates the return of a Vietnamese prisoner of war (POw) he had freed; when he shoots at this ghost and at the war museum, he is killed by the police. In a novel documenting forty years of the wars of light, George eschews the representation of nuclear apocalypse. He instead depicts an apocalyptic scene of fratricide, the only humanized narration of murder in a four hundred-page novel about the Cold War and its violent legacies of light.

\section{From the Wars of Light to Ocean Roads}

George's shift from the transnational violence of the wars of light to the tragic murders of Troy and Caleb refocuses our attention from excess global visibility to local familial legacies and the war's suppression of its Indigenous 
others. The circulation of pre-European or Cold War indigeneity is rendered visible in a child's fingerprint Isaac finds in the ancient forged clay vessel in the Jornada del Muerto, the ancient rock paintings found by Troy in the Vietnamese jungle, and the short but significant scenes in which Troy and Caleb's family heritage is tied to Māori history. Although we know little of Etta's background, we are told that she is from Hokianga, a name translated as "the returning place" ( $\mathrm{IO}_{4}$ ) of Kupe, the Pacific voyager who discovered Aotearoa and facilitated the earliest Māori settlement. Although there is one reference to direct racism against Etta, her relationship with Māori culture and language is not rendered visible. The only spoken Māori to appear in the text comes when Troy hallucinates the return of the Vietnamese P ow and exclaims, “E hoa ... ka whawhai tonu matou. Ake! Ake! Ake!” translated in the text as, "Friend, we shall fight on forever and ever and ever" (229). These are the famous lines attributed to Rewi Maniapoto in his resistance to the Pākehā (British settler) invasion of the Waikato in April I864 during the New Zealand Wars. Although never explained in the text, the setting of the novel in April 1989 invokes the 125 th anniversary of this event in the violent establishment of Aotearoa New Zealand through the musket wars. Through a constellation, a flash of violence, we are given insight into an earlier, invisible war of light; one of settler colonialism that was an important precursor to U.S. Cold War expansion into the Pacific.

The site of Troy's and Caleb's deaths, the Auckland Domain, is the city's largest public park and the location of the Auckland War Museum, where Etta was to display her archive of the wars of light. The volcanic crater that dominates the landscape of the Domain, Pukekawa (Bitter Hill), represents a monument to Māori presence in the region and is significant to the pantribal wars between two Māori tribes, Ngāti Whātua and Ngāpuhi; the latter is the iwi of James George. This layering of Indigenous history in the very spaces of the contemporary antiwar protest movement poses a complex and ultimately explosive model of New Zealand history. George's decision to relocate the war protests of the 1970s, which took place at U.S. embassies in Wellington, to Auckland, a space of New Zealand nation building on Armistice Day, foregrounds the long history of national violence in the construction of Indigenous and settler peoples. As such, the space of this fraternal sacrifice opens up the wars of light to its predecessors in the musket wars and the settlement of the nation, a frontier history with close connections to U.S. expansion into the west and a war, in Māori terms, against family, or whānau. In fact, this war of Pākehā settlement and Māori resistance was 
largely uncommemorated by the Auckland War Memorial Museum, which did not focus on local militarism until as late as 1996. It is only by condensing these constellations of the New Zealand Wars, the World Wars, the Cold War, and the Vietnam War that the novel demonstrates the long temporal and spatial reach of the Pacific wars of light.

It is worth asking why a writer who has consistently depicted in his previous novels the complexities of historic and present-day Māori identitycharacters visibly marked as Indigenous in terms of moko (tattoos) and by the use of Māori language, history, and cosmology—decides to alter the landscape of identity so radically in Ocean Roads. I suggest that the overwhelming discourse of these wars of light has rendered such excess visibility that the foundational Indigenous subtext must be sought in the shadows. Like Tuwhare's total illumination in "No Ordinary Sun," George's novel implies that this visual excess blinds the characters and, by extension, the modern subject to Indigenous history and ongoing presence. This history of alterity can be recognized only through an allegoresis that traces the daemonic figure light, leaving the reader to stitch together these constellations of history, made visible through flashes and flashpoints of violence.

How do these "disciples" recover from their love of light? The myriad forms of heliography explored in this novel-photography, literature, physics, cinema, and radiotherapy—suggest that modernity is constituted by excess illumination. This is what is critiqued in Spivak's shift from globalization as total illumination, to the call for recognizing alterity through "planet thought." But George demonstrates this pursuit of total illumination is gendered. In contrast to his homicidal (and suicidal) male characters, the author leaves it to his female characters to heal the scorched earth. Akiko, associated with the cooling rain to stop the fires, as well as the redemptive power of art, bears a child associated with two fathers, Troy and Caleb, and in her pregnancy her belly is "round like the first half of a rising sun" (289), suggesting a recuperative relationship to the form of radiation and light. Like the works discussed in chapter I, this novel creates a (hetero)reproductive futurity as a possible amelioration of state and masculine violence. Her daughter, Rai, a name that the author explains means "trust" in Japanese (322), also suggests a healing "ray" of light as she becomes a medical student. When Etta returns to Aotearoa New Zealand in 1989 at the end of the Cold War, Akiko continues to teach dance and perform pieces that transform the wars of light into art, she and Rai are planting new seeds in their garden, and they are tending to the family history at the house in Rangimoana. Ocean Roads 
upholds maternal love and heterosexual reproduction as the antithesis to the masculinized, excess illumination of modern science and technology, a gendered universal humanism Yoneyama has noted in the postatomic nationalism of Japan. ${ }^{130}$ Moreover, the temporal duration of the maternal and genealogy function as a constitutive contrast to the violent cataclysmic time of wartime masculinity. ${ }^{131}$

While we are expected to associate a redemptive rather than retributive future with Rai and Akiko, the novel also ends with an alternative solution in the Indigenous concept of ala moana (ocean roads), or the watery trajectory away from the excess illumination of the earth to Māori origins and afterlife. In their last ride together, Etta fulfills her promise to Isaac to take him to Te Rerenga Wairua, a place known in Māori tradition as "the leaving place of spirits" (I66) at the northernmost tip of Aotearoa New Zealand. They ride through "the breezes of decades, carrying small grains and dust and seed spores of memory" (382), figures for decay, ruin, and regeneration. Fittingly, Etta notes "the page of the immense book of ocean waves leading down onto the sand," a reference to the opening Trinity scene and the "debris of history" as Benjamin would have it. In a pact to "leave no trace but your pictures" (38I), the couple reach the cliff over the ocean, and narration is suspended. This leaving point of spirits is not an end, but rather a new beginning in Indigenous cosmology, of navigating watery roads that are no longer illuminated by the world of light, or Te Ao Mārama. We are left impressed with the image of their vehicle at the sea's edge, arrested in time by Etta's signature "Click." (383). These bodies, like those destroyed by irradiation before them, will leave no fossil traces for the Anthropocene. Instead, we must look for that flash of "now time" in the midst of constellations of daemonic allegory. 
CHAPTER THREE

\section{Accelerations \\ Globalization and States of Waste}

Allegories are, in the realm of thoughts, what ruins are in the realm of things.

-walter benjamin, The Origin of German Tragic Drama

Walter Benjamin's writing about allegory's imbrication in "nature-history" was catalyzed in a large part by the violence of modernity. While the figure of ruins made nature-history an active dialectic, Benjamin could never have anticipated that in the twenty-first century, ruins would entail inorganic objects that do not deteriorate in the temporalities of normative nature. For example, militarized radioactive isotopes will continue to mark the nuclear age for another forty thousand years, just as the persistence of petro-chemicals, synthetic fertilizers, petroleum-based plastics, and other objects that are not subject to the natural decay of biodegradation all signify an era of "technofossils" prevalent in what some geologists call the "Great Acceleration." Consequently, the anthropogenic ruin becomes a figure of history that is no longer permeable to decay and now oddly decoupled from nonhuman nature. Benjamin claimed that the "experience of allegory, which holds fast to ruins, is properly the experience of eternal transience,"2 but the material 
ways that we allegorize the transience of human history are being replaced by a seemingly eternal "realm of things."

Scholars who use the Great Acceleration as an originary marker of the Anthropocene epoch bring our attention to the rapid global consumption and regimes of disposability that characterize capital since the mid-twentieth century. Anthropogenic ruins, particularly plastics, are a marker of the excesses of globalization and of an era called by some the Capitalocene and by others the Plasticene. ${ }^{4}$ As mentioned in the introduction, the turn to the Great Acceleration helps us to see how Anthropocene discourse can be a materialist intervention in globalization studies in its stratigraphic analysis of the "technosphere." In this way, the key concepts of twentieth-century globalization such as scale, technology, politics, speed, urbanization, modernity, militarism, and time/space compression are materialized in the stratigraphic record of the Anthropocene. ${ }^{6}$ In fact, they are mutually constitutive: the liberalization of trade created by globalization contributed to the worldwide distribution of the technofossil residue of mineraloids (artificial glasses and plastics), polycarbonates (which make up compact discs), plastics such as polyethylene and polypropylene, as well as aluminum, concrete, mortar, tarmac, and electronic waste. ${ }^{7}$ Like militarized radiation, technofossils are no longer exclusively associated with the inhabited soil but permeate the oceans and outer space. In fact, the oceans are thought to hold more than five trillion tons of plastic, and recently scientists found plastic residue in sea salt all over the world. ${ }^{8}$

While the previous chapter focused on how Cold War state militarization irradiated the Earth, this chapter engages globalization and neoliberal state regimes of disposability. There are certainly historical and material continuities between these different constellations of energy and waste. Technofossils are not new to planetary history since they refer to any human-made technologies, but their distribution since the Great Acceleration and potential for long-term preservation are unprecedented. To mark epochal change, Anthropocene discourse, like the globalization discourse that preceded it, is suffused with novelty. Benjamin wryly observed that "there has never been an epoch that did not feel itself to be 'modern' ... and did not believe itself to be standing directly before an abyss." Nevertheless, the waste created by this "emerging technosphere" is changing the planet's mass and energy flows and "may represent the most fundamental revolution on Earth since the origin of the biosphere." 10 
Of course, to geologists, "revolution" is rendered in the deep time of the planet rather than human history, but a responsible ethics of the Anthropocene insists that we theorize them together. ${ }^{11}$ Therefore, the turn to anthropogenic fossils brings forward complex, disjunctive temporalities: the deep time of stratigraphic layering; the more-than-human time of the Earth; and how our present debris-our anticipated history of ruins-will create future fossils and perhaps new narratives. This has created a body of emergent work theorizing time in relationship to our fossil remains. Bronislaw Szerszynski has argued that, from a geologist's perspective, the "truth of the Anthropocene is less about what humanity is doing, than the traces that humanity will leave behind." ${ }^{12}$ In contrast, the historian Libby Robin points out that the future projections of anthropogenic impacts-over the next fifty thousand years - are what catalyzed Paul Crutzen and Eugene Stoermer to coin the term "Anthropocene," arguing that "it is an epoch that is not so much back-dated as forecast." ${ }^{13}$ Following Benjamin, I propose "the collector as allegorist" to be a figure well suited for this temporal movement between past, present, and future. ${ }^{14}$ The collector assembles the ruins of uneven human history to provide new possibilities for meaning for our present and past as well as to "augur" the future, using allegorical modes as "interpreters of fate." 15 In bringing together Anthropocene technofossils in relation to the systems that created them, such as capitalism, globalization, and the violence of neoliberal regimes, I foreground the historical and formal possibilities of what Benjamin refers to as the "refuse of history." ${ }^{16}$ Moreover, this chapter considers the ways in which certain types of technofossils, the realm of things, can substitute for the presence of the human and thus call attention to the archival impetus of Anthropocene and its attendant erasures. In this sense I am as concerned with excavating the "refuse of history" as much as uncovering the trace of what does not produce legible remains.

Accordingly, this chapter turns to Caribbean artists and writers as collectors of technofossils and narrators of waste to foreground how state violence produces the "refuse of history." I harness the Anthropocene focus on material remnants and traces to a postcolonial critique of neoliberal globalization; doing so allows us to see the human impact of regimes of disposability. It is by allegorizing the Anthropocene-which is to say, foregrounding a disjunctive telescoping between the planet as system to the scalar level of the state- that we can more clearly understand the complex and mutually constitutive connection between global and local, planet and place. 
For all the euphoria about transcending the state in globalization studies in the 1990s, scholars ultimately had to conclude that the seemingly transcendent claims of the global were almost always mediated and mitigated by state agents. In other words, the claim to a certain kind of global cosmopolitics was often made at the expense of those migrants who were the most vulnerable to state violence. ${ }^{17}$ Since Hannah Arendt's theorization of state expulsion of minorities, ${ }^{18}$ critics have engaged the nation-state as a pivotal structure for regimes of (human) disposability. My intervention here is to explore how literature and arts render the state as an essential agent in the production of more-than-human waste in an era of neoliberal globalization. Through the use of montage and the figure of the collector, the "ragpicker," the refugee, or the urban poor, the artists and writers examined here all allegorize the Anthropocene. Moreover, they employ the allegorical device of engaging the reader as participant by calling attention to our responsibility as witnesses to states of waste in the age of the Great Acceleration.

\section{States of Waste: The "Refuse of History"}

To turn to figures of waste is to examine the spatial collapse between the human and nonhuman nature, and to render visible some of the most pernicious and mystified by-products of late capitalism and regimes of state disposability. Because it suggests that nonhuman nature is thoroughly caught up in modernity, the Anthropocene signals a turn away from the western concept of wilderness, which is to say, a space outside the human. Thus, the Great Acceleration foregrounds the fact that the rise of economic regimes of disposability has created enormous plastic and chemical waste across the planet, particularly in the world's oceans. Far from rendering our atmosphere and the ocean as "natural" spaces outside the ambit of the human, turning to the figure of waste enables us to see that the global commons have become deeply anthropomorphized through the byproducts of human production. This is particularly evident in the Pacific Garbage Patch, a "plastisphere" or plastic ecosystem larger than the State of Texas, and in the leaking of Runit Island, a cemented-over dome in the Marshall Islands that was expected to temporarily contain the radioactive waste of U.S. nuclear testing and yet, due to erosion and sea-level rise, is now spreading plutonium as far as China. ${ }^{19}$

Waste is constitutive of modernity, and as we turn to irradiated landscapes, ongoing petro-disasters, spaces of environmental racism including "superfund sites," and the corporate outsourcing of risk, we might see its 
most visible affects. Although it has not factored into Anthropocene discussions, the construction and distribution of waste is also constitutive of empire. ${ }^{20}$ Infamously, Larry Summers, as the World Bank's chief economist, declared in a 199I memo that the global south was "underpolluted" and that the "World Bank [should] be encouraging more migration of the dirty industries to the LDCs [less developed countries]." While he later declared it to be a parody of current globalization thinking, the argument that "the economic logic of dumping a load of toxic waste in the least wage country is impeccable" was certainly adopted by corporations in an era of waste imperialism. ${ }^{21}$ Geologists who focus on the ubiquity of technofossils foreground the fact that a rise in human population is vital to their distribution; ${ }^{22}$ here I shift the conversation toward the density of population signaled by urbanization in the global south and raise the specter of consumption in an era often termed the Capitalocene. ${ }^{23}$ In short, Great Acceleration discourse, like its counterpart in the Anthropocene, continues to be out of step with a large body of work that examines issues of late capitalist consumption and the outsourcing of risk, particularly in those areas that are the most impacted by the conjunction of the history of empire with neoliberal globalization.

In an effort to open up Anthropocene discourse to postcolonial contexts, this chapter examines how Caribbean artists and writers have called attention to the political and formal implications of making waste visible. The anthropologist Mary Douglas has famously argued that what we conceive of as waste is merely matter out of place. Therefore, "Where there is dirt there is a system. Dirt is the byproduct of a systemic ordering... of matter in so far as ordering involves rejecting inappropriate elements." ${ }^{24}$ To follow Douglas, the rise of modernity is coterminous with the material, social, and ethical construction of waste, insofar as these elements of waste are rejected and deemed inappropriate to the development of a modern social system. In engaging the field of "garbology," ${ }^{25}$ I am defining the concept of waste in broad terms. This includes the material residue of waste from the individual as well as the social body and ranges from shit to the discarded remnants of high capitalism-including technofossils—-that fill the planet's sewers, landfills, oceans, beaches, and public spaces. Following Benjamin, I position waste as a figure of "petrified unrest," an animated symbol of the "refuse of history." 26

I place these definitions of waste in conversation with the social and ethical construction of "wasted lives," those who, according to Zygmunt Bauman, function as the negative, discarded constructions of a political body such as the poor, refugees, the stateless, and, I would add, the negatively 
racialized. ${ }^{27}$ I expand his definition by turning to a larger geopolitical problematic in which the migrant from the global south is rendered-particularly in the recent Mediterranean crisis - as expendable by the political powers of the global north. To call attention to "wasted lives" is not to relegate people to waste but to foreground the political and social systems that deem certain humans "matter out of place." Relegating human beings to waste is a dehumanizing and deeply entrenched social and political practice of capitalism, empire, and neoliberal globalization; to render this practice visible is to open up the potential for radical political critique. Thus, while the human beings who leave behind "technofossils" might be erased by the Anthropocene's emphasis on material residue, the work of the "allegorist as collector" is to reassemble those materials that portray the human lives that are relegated to waste more visibly and, through allegory, foreground the reader or viewer's accountability. The Caribbean artists and writers I turn to here-Tony Capellán (Dominican Republic), Kamau Brathwaite (Barbados), and Orlando Patterson (Jamaica) - all differently engage ecologies of waste, turning in particular to how state hierarchies contribute to the positioning of certain people as matter out of place.

One of the markers of a functioning state infrastructure is to segregate waste; this sanitation regime has social and material effects. Thus, the production of waste becomes mystified and rendered invisible by its state-sponsored regimes of segregated disposability. Gay Hawkins remarks that state regimes of ordering the public body_of sanitizing and privatizing its production of waste into sewers, private bathrooms, lower-income housing, and refugee camps-reflect biopolitical regimes in which "techniques of invisibility" are utilized that reflect "technological and aesthetic commitment to disappearance." 28 Thus, the state comes to function "as a purifying force that establishes its power through its capacity to remove filthy things to the category of the private." 29 This includes human as well as nonhuman subjects and objects. Thus, "Garbage is everywhere, yet invisible" to the social classes that benefit from regimes of state infrastructure. ${ }^{30}$ The social implications of segregating figures of waste and making them visible to the privileged classes have long been a concern of Caribbean writers.

The figure of waste is a mutable subject for reading, with temporal and scalar effects. Waste is a remainder, a remnant of history, a ruin, and might be understood as an unintended archive. As a figure of decay, waste is a signifier of planetary history, particularly when we consider entropy, the development of radiocarbon dating, and fossils. It can be understood as the 
uncanny, as deteriorating matter, as human and social excess, and, according to John Scanlan, "the detached remainder of things we value." ${ }^{11}$ Waste often exceeds our own temporal limits (particularly modern technofossils), and its morphological qualities suggest our own uncanny terminal assimilation into the earth. ${ }^{32}$ As such, organic waste, like Benjamin's ruins of allegory, functions as a sign of the merger of nature-history.

The Anthropocene might be described as an acknowledgment of the failure of history as progress, a rupture to colonial and neoliberal development narratives. As the antinomy to development, waste is "the broken knowledge that lies in the wake of (and in the way of) progress." 33 To render waste visible is to destabilize the hierarchies of social order and, at the same time, according to Slavoj Žižek, to "recreate an ... aesthetic dimension in ... trash itself." That method of reading suggests "true love of the world" through an acceptance of waste "with all its failures, stupidities, ugly points." 34

It is this recuperative element that informs a body of Caribbean literature that turns to the rendering of "wasted lives" associated with the enslaved, the poor, the folk, and the refugee. "The sigh of History rises over ruins, not landscapes," Derek Walcott declared in his Nobel Prize speech of 1992, noting that "in the Antilles there are few ruins to sigh over." ${ }^{35}$ This has jettisoned a vital conversation about "imperial ruins," to borrow from Ann Laura Stoler, but in the Caribbean it is precisely what Walcott described elsewhere as "the absence of ruins" that has catalyzed the turn to waste as more readily legible remains. ${ }^{36}$ This can be dated back to novels about the Middle Passage and is palpable in John Hearne's "smellscape" The Sure Salvation, a revision of Herman Melville's depiction of an immobile slave ship, a place where time is marked by the growing oceanic pool of human waste. ${ }^{37}$ This is also evident in the urban poverty of the gritty independence-era novels of Jamaica by authors such as Andrew Salkey and Orlando Patterson, who portrayed the despairing masses, no longer contained on slave ships but now segregated in the close quarters of the West Kingston slums. ${ }^{38}$ This chapter suggests that Caribbean writers and artists have long examined how the region, often relegated to a backyard and (often literal) junkyard of the United States, has utilized the material and discursive constructions of waste as political and formal critique. Perhaps in the absence of colonial models of monumental "History," one might excavate the history of the region's enslaved and poor subjects by turning to figures of waste as decay-as an archive of the masses and of the "refuse of history." 


\section{The Collector: Technofossil Montage}

The possibilities of this reading were inspired by the Dominican artist Tony Capellán and his persistent engagement with what we might call the "flipflopsam" of the modern state. ${ }^{39}$ The cover image of this book, Mar Caribe, is a powerful installation of hundreds of flip-flops found by the artist on the Dominican shore, collected and arranged from vibrant blues to teal green. As a visual reflection of an azure sea, the scales of a fish-or a school of fish if we look at their alignment in the same direction-our first visual register is perhaps a soothing sign of oceanic nature, of flows, and even the people's mobility writ large (figure 3.I). When we look closer, barbed wire, a U.S. invention, is embedded in the flip-flop (figure 3.2). The apprehension of the barbed wire is shocking because of the disjunction between an emblem of mobility and one of state violence. Moreover, its secondary apprehension suggests that the very discourse of flows and mobility favored by globalization studies may obscure the thorny-and violent-barbs of nation-state boundaries that segregate the stateless: refugees and the people determined to be disposable. Consequently, our primary frame of vision-the shades of blue and the organizational symmetry of the flip-flops-causes us to overlook the ways in which the sea has always been a militarized space of bordermaking and the violence of modernity.

Capellán's installation embeds a vital critique about euphoric narratives of the transoceanic imaginary and how it displaces the materiality of "wasted lives." Bauman argues that modernity is constituted by the boundaries erected between normative and disposable subjects, resulting in an enormous surveillance industry dedicated to policing borders between disposable and enduring objects, citizens and refugees. He characterizes our era of "liquid modernity" as "a civilization of excess, redundancy, waste and waste disposal," one that produces human refugees as "the waste products of globalization." ${ }^{0}$ This concept of patrolling the fluid sea is vital to interpreting representations of waste, understood as the lost lives of transoceanic subjects and recuperated here, visually, not by actual bodies but by their commodity "footprints."

In viewing Mar Caribe we are invited to visualize what national politics render invisible, to reflect on the materiality of the object as technofossil, and to consider how barbed-wire fences were integral to the process of nineteenth-century expansion across the American hemisphere. As an artist, Capellán has been strongly influenced by the arte povera movement, known 


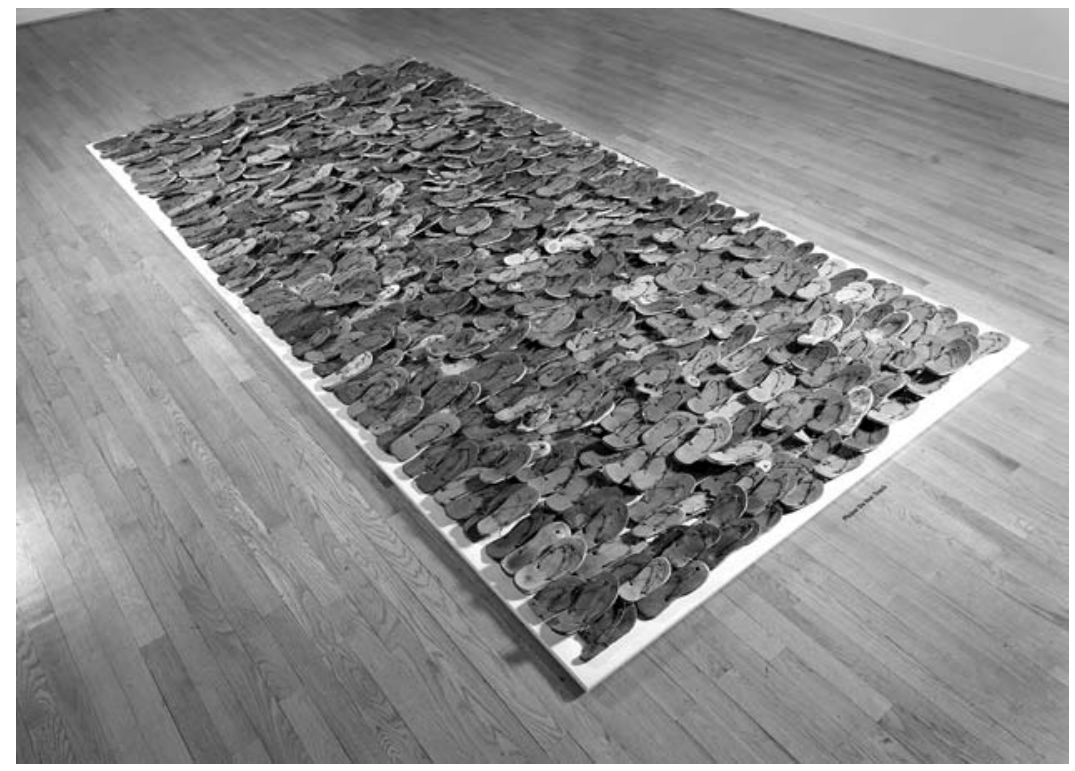

FIgure 3.r. Tony Capellán, Mar Caribe, 1995. Photo by Erik Gould. Courtesy of the Museum of Art, Rhode Island School of Design, Providence.

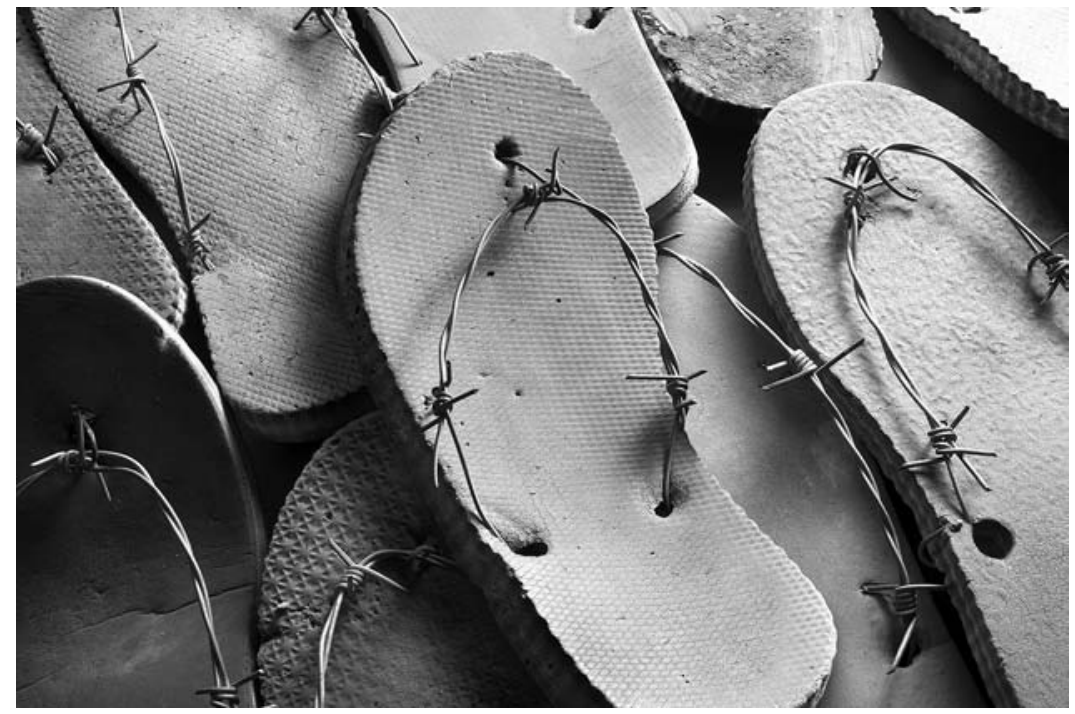

FIg URE 3.2. Tony Capellán, Mar Caribe (detail), 1995. Photo courtesy of Dennis Helmar. 
for its critique of capitalism and for its use of recycled or waste materials. ${ }^{41}$ Perhaps the most notable artwork of this movement is Marcel Duchamp's testimony to the relationship between art and waste in his porcelain urinal of 1917 entitled "Fountain." While his work invokes the British recycling sculptor Tony Cragg, Capellán is careful to point out that his materials are found rather than manufactured objects, collected where the Ozama River meets the Caribbean Sea in Santo Domingo. ${ }^{42} \mathrm{He}$ observes, "One of my strongest obsessions is the Caribbean Sea, because [it] has been the vehicle for all of the culture that we know now." ${ }^{43}$ Capellán explains that the shanties built along the Ozama River are periodically flooded, producing mounds of plastic and other kinds of technofossil waste on the beaches. ${ }^{44}$ This body of mismatched footwear exceeds individual ownership. It represents perhaps the only archive of the Dominican poor, invoking other memorials such as the shoes that stand in for those subjected to genocide in Holocaust memorials, or the display of shoes at the COP2I talks in Paris to signal the lives lost due to climate change. ${ }^{45}$ This is salvage work, a rendering of the waste of the masses that state (and corporate) politics make invisible. In an interview, Capellán remarked, "I want to speak of the lives of the people who have no voice, who have nothing; have no theme in art.... These worn out shoes, for example, show a person who was fighting for his life and for mine too, because many of these people do work that is a service for others." 46

Mar Caribe might be interpreted as a technofossil montage that memorializes those who are at the frontlines of climate change. There are hundreds of thousands of poor people living along the banks and floodplains of the Ozama River in a struggling nation with a 43 percent poverty rate. The creation of barrios pobre along the river is a modern development due to the neoliberal restructuring of agricultural policies in the 1960 s and ' 70 s and the rise of urban manufacturing. The shift from small agricultural plots into large corporate holdings caused a major displacement of rural farm workers to the cities such as Santo Domingo, which also occurred in all of the major Caribbean cities at this time. ${ }^{47}$ The World Bank recently listed Santo Domingo as one of the top five cities expected to experience catastrophic climate change by 2050 due to rising sea levels; it is even more precarious than the Haitian capital on the other side of the island, Port-au-Prince. ${ }^{48}$ The state's negligence in assisting and relocating those who are the most vulnerable to the flooding has been a long-term issue of contention in these riverside barrios. Perhaps the poorest of them all is La Ciénaga, which, as 


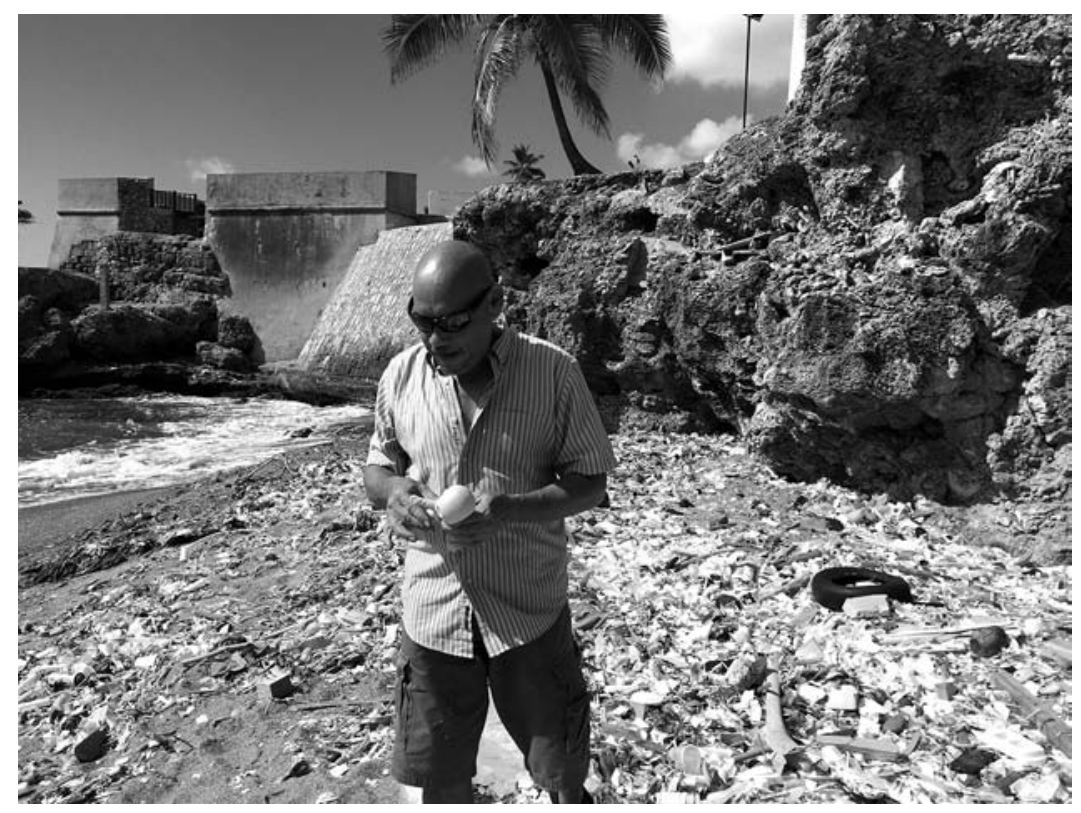

FI GURE 3.3. Tony Capellán, The Artist as Collector. Courtesy of Tatiana Flores.

the name suggests, is literally a swamp filled in with garbage. In the words of one La Ciénaga resident (who declined to be named), "Nobody mourns the poor, you know." ${ }^{49}$ Ironically, the only intervention in this crisis the state has made thus far is to clean up the beaches in the interests of tourism, removing Capellán's archive and consequently his ability to "mourn the poor." 50

In Mar Caribe, the flip-flops Capellán collected on the shore, literal flip-flotsam, are reshaped and refitted to new forms and new institutional contexts. In this case, a mass-marketed piece of plastic and rubber footwear found in every coastal community becomes a sign of the commodification and disposal of global consumption. In his theorization of the "collector as allegorist," Benjamin turned to the "broken-down matter" in the Parisian Arcades, noting the "elevation of the commodity to the status of allegory." 51 As a collector, Capellán employs the technique of montage, a collection of disparate objects that, when placed together, signify the "renunciation of the harmonious totality." 52 In other words, the montage of disparate, mismatched blue and green flip-flops speaks to both the masses and the impossibility of their representation. Moreover, their piercing by barbed wire suggests their persecution at the very moment of their formation as an al- 
legory of the masses. By using wasted commodities in large installations that fill the rooms of galleries and museums, Capellán elevates "wasted lives" through allegories that gesture toward the impossible salvation of the poor. He provides a critique of the "harmonious totality" of the Dominican state and, given the title, even the Caribbean as a region.

Mar Caribe might also be interpreted in relationship to its use of another technofossil: barbed wire. In this sense Capellán's work is prescient because it suggests that the scholarly turn to the sea-as a route away from the territorialism of the nation-state-misreads the crucial ways in which the ocean, for centuries, has been the militarized territory of the state. This is perhaps nowhere more apparent than in the Caribbean, where the United States has made various arrangements to expand its maritime borders under the aegis of the war on drugs and immigration control. The Shiprider and interdiction agreements of the past twenty-five years have allowed U.S. Coast Guard ships and law enforcement officials to intercept refugees, particularly Haitians, and, throughout the early 1990 , forcibly relocate them to Guantánamo. When Capellán produced this piece, in 1995-96, there was an international crisis over the refusal of entrance into the United States of 92 percent of all Haitian asylum seekers, a figure that does not include the thousands of Haitians intercepted at sea by the Coast Guard under the aegis of Operation Sea Signal in 1994, which redirected Haitian refugees to Guantánamo and then forcibly returned them to Haiti, at their peril. ${ }^{53}$ This prison became a central space of the control and surveillance of migrant subjects of El Mar Caribe. By 1995, the last year of this particular operation, the base held sixty thousand immigrants, including Cuban balseros, or "rafters," until the revision of the Cuban Adjustment Act in 1995 made special exceptions for these particular immigrants. ${ }^{54}$

Capellán's work urges us to reconsider the relationship between the carceral state, the construction of wasted subjects, and barbed-wire modernity in the era of neoliberal globalization. Barbed wire in this particular era invokes the U.S. incarceration of Caribbean subjects. Nikòl Payen, a Kreyòl translator on the U.S. naval base, described Guantánamo as "acres of land mines strategically plotted throughout the burned grass partitioned by steel fences with barbed-wire topping, [which] left [her] in awe of the island's intricate readiness for war." ${ }^{55}$ Although a war "on terror" was to come, for this decade its victims were the Caribbean poor. ${ }^{56}$ Barbed wire (and its successor, razor wire) is a tool of violent concentration, first used on animals in the Indigenous lands of the U.S. west and notoriously on the prisoners of 
Germany's concentration camps, and it has been emblematic of the U.S. naval detention camp of Guantánamo. As Reviel Netz has argued, "Barbed wire allows us to see a ... fundamental ecological equation, whose main protagonists are flesh and iron. Here is how modernity unfolded: as iron (and, most important, steel) became increasingly inexpensive and widespread, it was used to control motion and space, on a massive scale, exploiting its capacity." ${ }^{57}$ Barbed wire is a technofossil of the violent history of the state. It has become a sign of the policing and containment of the Caribbean Sea itself, of the border between normative and "wasted lives." Mar Caribe demonstrates how the use of barbed wire changes over time, tied, on the one hand, to prisons like Guantánamo and, on the other, to how the very symbols of mobility - the flows of the sea, the ubiquitous flip-flop-are contained by U.S. militarization and violence.

The bifurcation of Caribbean studies into language regions discourages comparative analysis, yet Capellán's work encourages us to think of both the Haitian and the Dominican side of the island of Hispaniola. While the nations have a deep history of racial violence, after the Haitian coup of I99I there was an increase in region-wide discrimination against Haitian migrants. In the Dominican Republic, that included practices such as forced labor on sugar and coffee plantations, deportation, and denial of citizenship status to Haitians and their descendants. The UN Commission on Human Rights opened an investigation in 1993 , implicating the Dominican state in this era of violence. But if we are taking up the transoceanic aspect of Mar Caribe, we might also consider the migration of Dominicans to Puerto Rico. In 1994, the Dominican Republic approved dual citizenship to institutionalize the complex diaspora and kinship networks connecting to Puerto Rico and the United States that date back to the mass exodus in 1961, after the death of President Rafael Trujillo. By 2000, the Dominican population in Puerto Rico had grown by thirty-four times. ${ }^{58}$ During the time of the collecting and making of Mar Caribe, more than thirty thousand undocumented Dominicans had relocated to Puerto Rico, most of them crossing the dangerous Mona Passage in small vessels (yolas). 59 The U.S. Coast Guard and immigration service were nearly as rigid about intercepting Dominican refugees and refusing them asylum as they were about Haitians, and hundreds of Dominicans have lost their lives in the crossing. ${ }^{60}$ Because the sea, in the words of Walcott, is a "grey vault," we have no way of ever knowing how many lives were lost in crossing the Middle Passage or El Mar Caribe. 
Caribbean art since the 1990 s has tried to memorialize "the ghosts of those thousands lost to the sea." As Lizabeth Paravisini-Gebert and Martha Daisy Kelehan point out, "Their memories remain, like the haunting presence of a revenant, unburied and unmemorialized." ${ }^{61}$

These lives are memorialized in Capellán's La Bandera de los Ahogados (The Flag of the Drowned; 1996), an installation that consists of a large wooden cross on the ground, outlined by salvaged, mismatched shoes. ${ }^{62}$ As a commemoration of those who drowned in the crossing to Puerto Rico, the piece makes an ironic comment on the cross(ing), as well as on the limited possibilities, for salvation. Like Mar Caribe, the installation uses abandoned footwear to signify the inability for these migrants to be rooted in national soil, as well as the ways in which technofossils uncannily exceed human temporality. In that way, the refusal to allow the shoes to be buried under the sea or in a landfill speaks to the insistence of memorialization, but one that is necessarily missing the lost human object, which is replaced by a commodity or technofossil.

Overall these installation pieces speak to allegory's "destructive furor," which is about "dispelling the illusion that proceeds from all 'given order'; whether of art or of life: the illusion of totality or of organic wholeness which transfigures that order and makes it seem endurable." ${ }^{63}$ This question of durability is doubled in Capellán's exhibits. Montage brings forward its simultaneous reconstructive and "destructive" materiality; once the collector assembles the materials for display, they are deconstructed and stored, unseen, in the museum or artist's archive. This question about the installation's accessibility and its invocation of accountability is a point I return to, but first I turn briefly to the work of Kamau Brathwaite to develop these intersections between the Caribbean Sea, the representation of "wasted lives," and the role of the artist/poet as collector and creator of allegories of salvage.

\section{Allegories of Salvage}

To Benjamin, the "refuse of history" is a key focus for the collector, who "makes his concern the transfiguration of things." ${ }^{64} \mathrm{He}$ explains that "collecting is a form of practical memory, and of all the profane manifestations of 'nearness' it is the most binding." 65 Yet what does it mean when the collector is gathering not objects such as technofossils but the memory of lives that do not leave a trace? Like Mar Caribe, Kamau Brathwaite's poem 
"Dream Haiti" (1995), about the interception of Haitian refugees at sea, questions the visibility of poverty in what Bauman refers to as "the waste of order-building" in the age of globalization. ${ }^{66}$ Allegory is well known for its visual bias; Brathwaite's poem draws on both the possibilities and limitations of rendering "wasted lives" visible. In taking an invisible violence out at sea and making it visible to the reader (and, by extension, to history) Brathwaite includes ample references to Haitian art and produces the poem in his "sycorax video style" typeface. His poetry calls attention to the mechanical process of print, often using enormous fonts that render words into pictures, and consistently interrupts the text with images in the middle of the text in ways that destabilize progressive and transparent reading. This foregrounds a Benjaminian "now-time" that in this particular poem freezes the violence of the "wasted lives" of the Middle Passage and contemporary Caribbean migration, placing past and present modernities into a disjunctive historical constellation. As Jenny Sharpe describes Benjamin’s approach, “The ability to read the past is contingent upon a present that transforms it into an image we can recognize. Since the past itself changes with each new present, the writing of history is never total or complete." ${ }^{67}$ Thus, the contemporary Haitian refugee crisis sheds light on the Middle Passage crossing and vice versa in a historical constellation. It is this disjunctive-and disorientingtelescoping between two historical moments of violence that is best articulated through allegory, a form that is polysemous and "cavalier with the sequential," even as it is caught up in antinomies or paradoxes that preclude meaning. ${ }^{68}$

The Latin term for ocean, vastus, is also the term for waste. By placing refugee/fugitive bodies at sea, both Capellán and Brathwaite demonstrate how waste is a constitutive byproduct of modernity in which the state regulates the vastus for those bodies associated with national refuse, a practice of border-making in a fluid space. ${ }^{69}$ The ocean in these texts is not, as in most transatlantic studies, aqua nullius, a blank space to cross en route to national territory and identity. Instead, it signifies a space to recuperate the "refuse of history."70 Since the ocean is in perpetual movement and cannot be easily localized, representations of what Gaston Bachelard has described as the "metapoetics of ... heavy water" problematize movement and render space into place as a way to memorialize histories of violence and to rupture notions of progress. ${ }^{71}$ These narratives merge the human subject of the past and the present, an intimacy Bachelard associates with the dissolving quali- 
ties of the oceanic, ${ }^{72}$ creating an allegory that stages the process in which one might attempt to "salvage" the waste of human history.

Written in what he terms "seametrics," Brathwaite fathoms the depths of the sea in "Dream Haiti" to explore "recent personal + historical ... cultural \& environmental disasters." 73 The use of dream sequences is consistent with allegory, which engages with "uncanny" spaces through which an "alien traveler" will pass and thereby experience some kind of transformation for both protagonist and reader. ${ }^{74}$ This is a disorienting sea for the first-person speaker, a space of "heavy waters" patrolled by the U.S. Coast Guard and likewise ordered by the poet. In a blurring of past and present, self and other, human and steel ship, the protagonist describes his "feet clanging restlessly up \& down the studded/metal stairs of our soft muted agony" as he moves between submarine depths, where Haitian refugees are drowning, and the deck of a U.S. Coast Guard "Gutter," a wordplay that, April Shemak observes, renders the ship as collector of human waste. ${ }^{75}$ Brathwaite merges the perspective of drowning with the witnessing of Haitian refugees drowning, suggesting that the poet is complicit in recuperating and ordering the waste of modernity even as he repeatedly insists "we was all artists ...\& not soldiers or sailors." ${ }^{76} \mathrm{He}$ problematizes the boundary between witness and spectacle, destabilizing the boundary-making that Douglas and Bauman pinpoint as constitutive of the process of segregating (human) waste. In other words, it is not actual "difference between useful products and waste" that creates a boundary; the boundary itself "literally conjures up the difference." 77

Brathwaite employs allegorical devices to destabilize the boundary between the disposable and the enduring, between "wasted lives" and their surveillance. The vessel he shares with soldiers and poets is one of the master tropes of allegory, a "ship in his head" representing the state as much as a figure of Atlantic militarization. ${ }^{78}$ To figure this allegory of both passages-the Middle Passage and Haitian diaspora-he turns to the visuality of Caribbean art. At sea, the passengers/refugees witness a large metal object moving past them, described as a "triangle made out/of tinnin" (tin) like "the work of Murat ... or Marshall." "The "triangle" literally allegorizes the "triangle trade"; Murat Brierre is the famous Haitian sculptor known for his recycling of oil drum lids, rendering the petro-waste of metallic modernity into art, while "Marshall" suggests the steel-hulled patrols of the military at sea. The passengers of Brathwaite's ship are "not goin anywhere," ${ }^{80}$ suggesting an 
ontological shift in the experience of natural and modern time and space, and a collapse between the patrolling of African bodies in the Middle Passage and the U.S. interdiction of Haitian refugees at sea. This, as Christina Sharpe points out, is the "wake" of racial violence in the Americas.

Allegory has been called a protean device; accordingly, Brathwaite depicts a shape-shifting protagonist who is traveling on a vessel named Salvages, a reference to both the potential salvaging of waste and the possibility of Sure Salvation, to invoke the titular slave ship of Hearne's novel. Salvages - and the poem-attempt to recover drowning Haitian refugees, but the sea, like Walcott's "grey vault," becomes a "dark blue dungeon." ${ }^{81}$ Although the U.S. Coast Guard "Gutter" textually dominates the poem - in font size alonewe discover that no one is trying to "salvage" the refugees. In a poem largely concerned with eye-witnessing, the refugees move out of visual range, and the narrator makes an ironic observation that the refugees did not notice "that we were their brothers \& fellow writers bound to us/by all kinds of ties $\&$ the content of their/character." ${ }^{2}$ In this last shift from the loss of an amorphous, dismembered body of Haitian refugees we see that the tragedy lies in the failure of vision, of state governance, and of the writer who is both a participant and witness.

Contemporary allegory is far less confident in the transformational telos of narratives of the voyage; thus, Brathwaite concludes that this history is "over \& over \& over again while we stood on the/soft hard deck of the Coast Guard/'Impeccable'/watching them poem." ${ }^{3}$ The narrator (and, by extension, we as audience) is caught in a tautological history in which he is not watching human beings "drown." Rather, he is watching them "poem" from the deck of a U.S. military ship called Impeccable. ${ }^{84}$ The Impeccable is a space cleansed of pollution and waste, the very concepts the poet seeks to "salvage" from these heavy waters and from a brutal oceanic history of treating human beings as the refuse of history. The slip from "drown" to "poem" suggests the impossibility of recuperating "wasted lives" and the limitations of allegory itself in the face of state regimes of disposability. "Dream Haiti" helps us think more critically about the discourse of modernity and waste, of the ongoing interdiction and drowning of migrant bodies at sea, and the vexed question of what formal and aesthetic means we might use to "mourn the poor." Moreover, by placing contemporary historical crises in disjunctive relation to those of the past, Brathwaite's use of allegory draws attention to how waste-as material and figure for loss-continually interrupts progressive models of time and poses a challenge to discourses of salvation—-for subject, author, and reader. 


\section{Waste Imperialism: Allegories of the Commodity}

Brought into a dialogue with Capellán's Mar Caribe, Brathwaite’s “Dream Haiti" helps us think more critically about the possibilities and limitations in rendering visible what Bauman terms "the flotsam and jetsam of the planetary tides of human waste." 85 While this chapter has focused specifically on the marginalized human figure of regimes of disposability, those who will not leave behind the fossils required by scholars of the Anthropocene, there are other ways to map the distribution of the neoliberal outsourcing of risk. Larry Summers's provocative call to ship toxic waste to the global south was particularly egregious when we consider that, immediately before the Caribbean refugee crisis, a trade in toxic waste had just begun that was particularly detrimental to Haiti. As Robert Stam points out, garbage is constitutive of the time/space compression of globalization in that its appearance and distribution is tied to "technologies of transportation, communication, and information." 86 This trade of waste imperialism became visible when in 1986 the ship Khian Sea sailed around the world looking to unload incinerator ash from a Philadelphia dump filled with heavy metals, arsenic, lead, and dioxins. The Bahamas, Bermuda, Dominican Republic, and Honduras all refused the ship port. The ship appeared in Haiti, offered the waste as "fertilizer," and illegally dumped four thousand tons of this toxic ash on the shore of the Bay of Gonaïve. ${ }^{87}$ The waste was left for thirteen years and leached into soil and water supplies, destroying local fishing grounds and livelihoods. ${ }^{88}$

While we consider waste the opposite of economy, the two are closely related. With the expansion of U.S. capitalism-based on product redundancy and disposability - coupled with stricter domestic regulations for the disposal of waste, North American firms began exporting it to developing nations sometimes for one-one thousandth of the cost of disposal at home. ${ }^{89}$ In the words of a Greenpeace report, "Bordered by the north by the world's most hazardous waste producing nation, the United States, the Wider Caribbean Region lies on the front lines of the international trade in toxic wastes." 90 Throughout the 1980 s and early I990s, Caribbean countries were offered toxic wastes for "recycling, fuel substitution, and housing and road construction materials" by U.S. waste traders for "development projects." 91 Thus, a new era of waste imperialism emerged in which toxic waste was circulated under the name "fertilizer" in exchange for funds desperately needed for debt relief. ${ }^{92}$ In an effort to stem the influx, Caribbean agencies, including the Caribbean Community (CARICOM), started legislating against toxic waste dumping 
as early as 1983 , with a full ban instituted in 1993 . Yet throughout the 1980 s, the Dominican Republic accepted municipal, industrial, chemical, and pharmaceutical waste, causing public outrage and protest.

The history of waste dumping in Haiti is less well documented, but according to one reporter, North American "toxic waste dumping in Haiti was ... a lucrative source of income for the Duvalier dictatorship" and reportedly caused a rise in cervical cancers. ${ }^{93}$ The U.S. government was also involved in a scheme to ship New York City's waste to Haiti in exchange for financial aid. In the words of the director of the Haiti Communications Project, "Instead of repatriating Haitian refugees to Haiti, the U.S. government should repatriate this toxic waste back to its own country." ${ }^{4}$

These examples of waste imperialism in the late twentieth century are directly attributed to the mechanism of the neoliberal state, particularly the United States as it forcibly repatriated Caribbean migrants while exporting its toxic byproducts. The body of Capellán's work speaks to all of these states of waste, rendering visible the "wasted lives" of refugees as well as the politics of waste imperialism. His installations-made out of collected materials such as discarded shoes, plastic bottles, toothbrushes, dolls' heads, children's baseball bats, baby bottles, and teething rings-bring the material, environmental, and allegorical dimensions of waste together. They foreground, on the one hand, the water's power over the poor (no one throws out baby bottles, he points out), and, on the other, the island's susceptibility to waste imperialism and the economies of disposability. ${ }^{95}$ Paravisini-Gebert argues that "through waste-based installations and wastescapes-which represent the antithesis of what Krista Thompson has called 'the Caribbean picturesque'-these projects intervene in the reimagining of 'landscape' as it has been understood in the European/colonial/tourism imaginary while giving voice to deep concerns about the health of the region's coastal environments." 96 This is visible in Capellán's installation of plastic bottles and containers called Mar Invadido (Invaded Sea; 2009).

In Mar Invadido, Capellán brings to our attention the cultural regimes of sanitizing the body, foregrounding as he does a sea of plastic laundry detergent bottles, shampoo bottles, buckets, and laundry baskets. In this installation, we are invited to walk around, examine, and engage with objects in this installation piece that initially seem to be ordinary products of consumption yet are reframed as "hyperobjects" that are nearly impermeable to decay. ${ }^{97}$ As in Mar Caribe, the blues and aquas of Mar Invadido's plastic deceive the viewer into believing it is a "natural" rendering of the oceanic. 


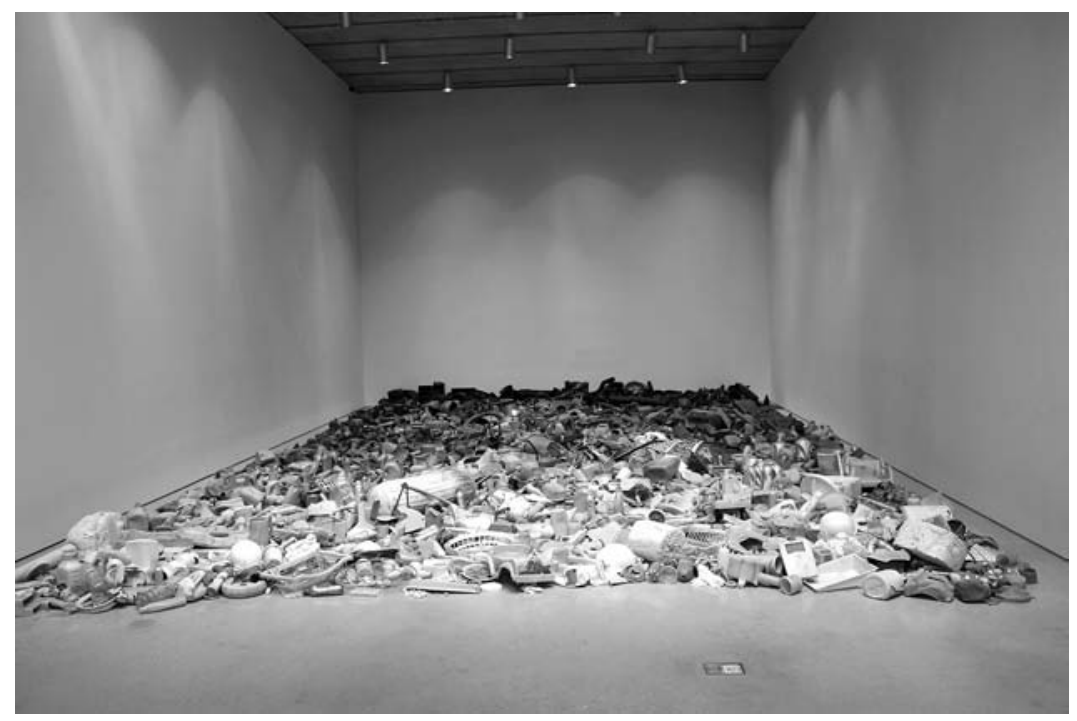

FIGURE 3.4. Tony Capellán, Mar Invadido, 2009. Courtesy of the artist.

While many writers have described Caribbean "people of the sea" due to history, proximity, and the salinity of human blood, ${ }^{98}$ Capellán suggests that, reciprocally, the sea is anthropomorphized—and industrialized-by the way it absorbs our waste. In this way, humans, including the global poor, have rendered an Anthropocene ocean. ${ }^{99}$

Benjamin observed that modern allegory is concerned with the "fetish character of the commodity." 100 Consequently, in an age of global capitalism, the emblems of allegory are no longer transcendent, sacred truths; they are replaced by profane commodities: "In allegorical terms, the profane world is both elevated and devalued." 101 In Gordon Teskey's gloss, "Benjamin's startling insight was that modern, commodity culture does not need to produce allegories in the old way, at vast expense and for a privileged few, because allegory has become incorporated in the total, economic structure of capitalist, commodity culture." 102 But for the artist as collector, there is still an imperative to render what is fundamentally profane-waste-and "elevate" it through allegory. This becomes all the more important when we consider the viewer's experience of the art of wasted commodities in state institutions, particularly in museums.

If "waste is the dark, shameful secret of all production," ${ }^{103}$ Capellán seems dedicated to exposing this secret by calling attention to the institutions that create the boundary-making that renders waste and "wasted lives" invisible. 


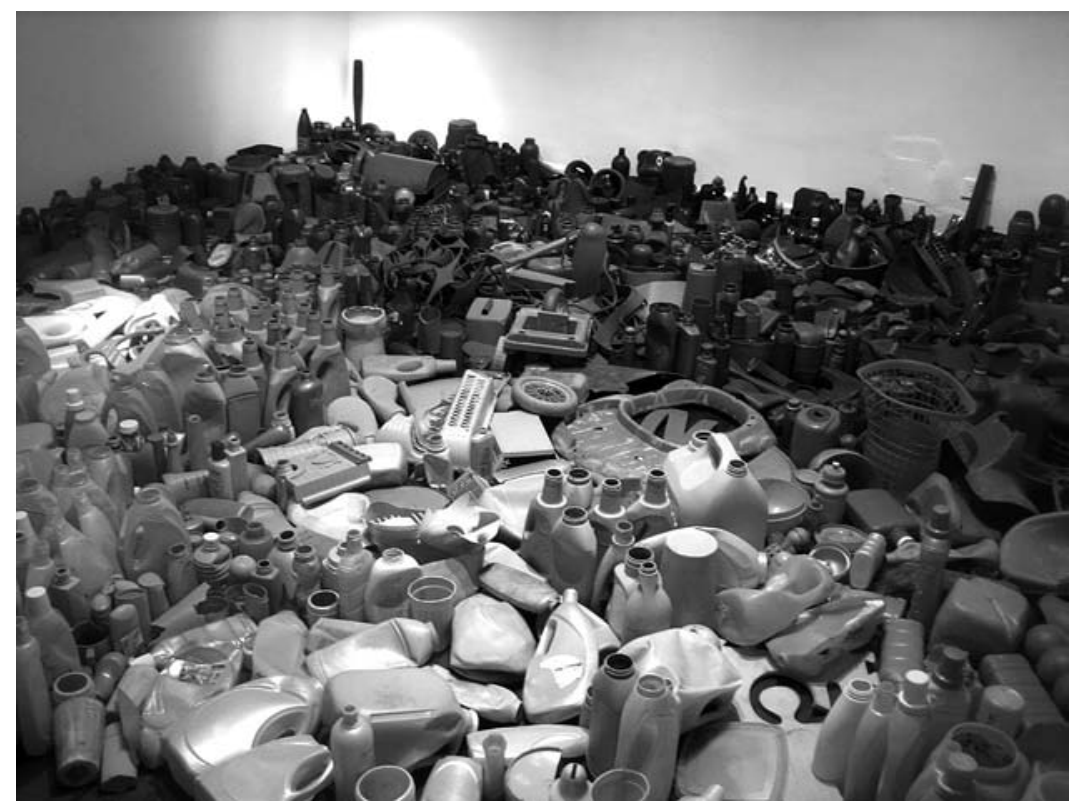

FIG URE 3.5. Tony Capellán, Mar Invadido (detail), 2009. Courtesy of the artist.

This ranges from his installations of wasted commodities such as plastic containers and footwear to powerful visual commentaries on the illicit organ trade, which disproportionately affects the poor of the global south. Capellán often uses state institutions to leverage a critique of their commodification of and abuse of vulnerable bodies. For instance, in Pequeña Esperanza (1994), from his installation Manchas (Stains; figure 3.6), Capellán sets up a dimly lit room and places in it a series of large, flat metal circles that contain men's underwear, each displaying a tell-tale stain of blood. Representing the Dominican Republic, he displayed this piece at the twenty-third Bienal Internacional de Arte de São Paulo, a bold move in that the piece represents the systemic rape of boys in a Dominican detention center, a scandal that brought an investigation from Amnesty International. ${ }^{104}$ The repetition of sixteen circularly ordered pairs of underwear suggests both the age of the boys and their entrapment in a cycle of state violence that created a major media exposé in $1993 .{ }^{105}$ The repetition of metal circles is a leitmotif in his work, invoking a later exhibit, Circulo Vicioso (Vicious Circle; 1996), suggesting what Benjamin sees in allegory as a compulsive repetition, a piling on of fragment upon fragment in an effort to create meaning. ${ }^{106}$ By fore- 


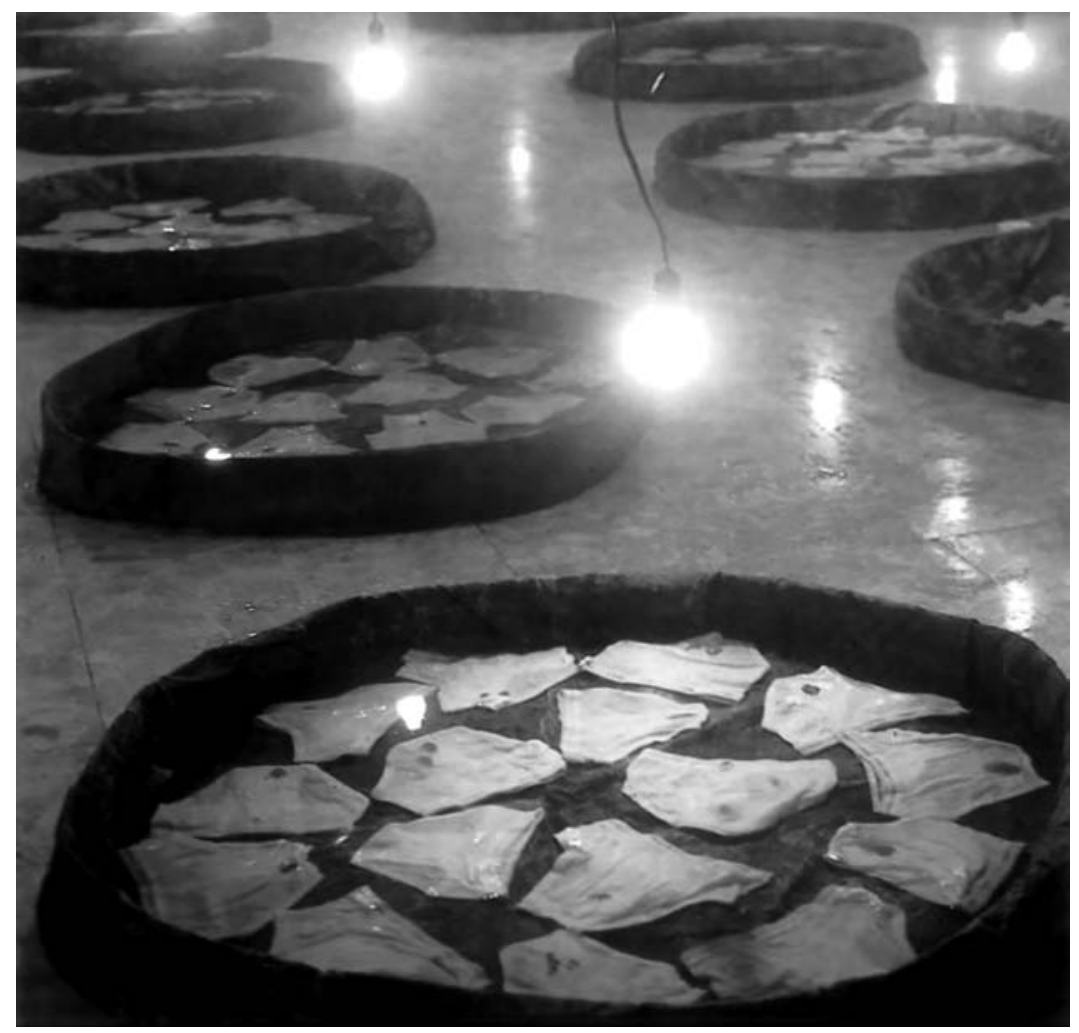

Figure 3.6. Tony Capellán, Pequeña Esperanza (Manchas), 1994. Courtesy of the artist.

grounding the fragment-flip-flops, shoes, underwear-Capellán arrests the flow of temporal progress. Through the fragment, time is "petrified," and the "false totality is extinguished." 107

As in Mar Caribe, the circles of Manchas suggest both the containment and the concentration of not the young bodies themselves but their commodity imprint, a brand of underwear repeatedly stamped "Eagle" and a stain of blood (or, from a distance, feces) representing the violent penetration of the anus by fellow prisoners and guards. The blood on the underwear shocks the viewer precisely because it has trespassed the boundaries of the body; it is matter out of place. The repetition of the brand name Eagle invokes Michel Serres's argument that corporations mark human bodies through branding with their "stain," their imprint, "which is inconspicuous because visible to all" so that branded commodities "remain dirty, hence appropriated by those who sell them." ${ }^{108}$ The brand name Eagle also suggests 
the dominance of U.S. capitalism, its exploitation of Caribbean garment workers in the "free trade zones," which were established in the 1990s. Perhaps we might even see a larger commentary on the ways in which the U.S. Central Intelligence Agency has used Dominican prisons for its own interrogation and torture practices since the start of the Cold War. ${ }^{109}$

Capellán has commented on the dual aesthetics of his works so that, for instance, in Mar Caribe one can derive aesthetic pleasure from the soothing tones of blues and greens that represent the beauty of the ocean while also, as he says, "deconstruct the myths" of tourism, by calling attention to what he calls the "painful Caribbean," the region "in struggle." ${ }^{110}$ Both Manchas and Mar Caribe signify lost and irrecoverable, "wasted lives," incarcerated subjects, and violation by the state. They also bring our attention to the commodification of bodies and the inability to recuperate the victims beyond the trace of their footprints, blood, or shit.

Robert Stam has argued that "garbage signals the return of the repressed; it is the place where used condoms, bloody tampons, infected needles and unwanted babies are left, the ultimate resting place of all that society both produces and represses, secretes and makes secret." 111 In turning to waste, we have the opportunity to see social structures "from below." Capellán's work provides this view from below, but it is more pointed in its critique of the production of "wasted lives" by the state, reminding us how the ordering of waste uses "techniques of invisibility ... and of disappearance."112 If "garbage defines and illuminates the world," 113 the lights that hang over each metal circle in Manchas mimic an interrogation room. Importantly, the lights are lowered so that we, the viewers, might walk through and visually interrogate the evidence of the "pollution," a particular concern in the r 990 s epidemic of AIDS. In the experience of the museumgoer, we are participants and perhaps even complicit in the violence, in the witnessing of defilement. As Benjamin noted about the habit of collecting, "The true method of making things present is to represent them in our space (not to represent ourselves in their space)." 114

The repetition of metal circles suggests confinement as much as the floating, ethereal pools of these disembodied traces of the waste of the incarcerated masses. Therefore, Capellán's visual allegories illuminate the state violence against young lives and our own witnessing of this process of illumination. Serres points out that the term "pollution" used to be understood as the desecration of a temple by blood, shit, or semen. Perhaps Capellán's installations might be understood as memorializing that desecration, of bear- 
ing witness to violation. ${ }^{115}$ But this raises the thorny question: what is the temple here-the museum or the state?

In his writing on the colonial archive, Achille Mbembe argues:

The status and the power of the archive derive from this entanglement of building and documents. The archive has neither status nor power without an architectural dimension, which encompasses the physical space of the site of the building ... the labyrinth of corridors, and that degree of discipline, half-light and austerity that gives the place something of the nature of a temple and a cemetery: a religious space because a set of rituals is constantly taking place there, rituals ... of a quasi-magical nature, and a cemetery in the sense that fragments of lives and pieces of time are interred there, their shadows and footprints inscribed on paper and preserved like so many relics. ${ }^{116}$

Capellán's critiques of the Dominican state, launched in museums and in public spaces, use "technofossils" to challenge the colonial archive and its legitimizing institutions. On some occasions, this has led to his arrest. ${ }^{117}$ Turning to Caribbean allegories of waste, we can interpret Capellán's installations in terms of creating not a colonial archive but rather a site of witnessing, rendering the "secret" of wasted lives visible to the more privileged classes who benefit from the labor and the sacrifices made by the undifferentiated poor. While Mbembe points out that "the best way to ensure that the dead do not stir up disorder is not only to bury them, but also to bury their 'remains,' the 'debris," 118 Capellán's installations make creative use of museum and gallery space to render the "debris" visible, to challenge those institutional "techniques of invisibility ... and of disappearance" within the institutions themselves. Capellán has utilized commodity forms, produced and consumed by the masses, to critique that which is rendered indistinguishable and without memorialization. Thus, the ruins signify an erasure from human history rather than its authorization. This is a particularly important difference from the recent Anthropocene concern with the Earth as archive, which authorizes the human through ruins and remains rather than through their absence. ${ }^{119}$

\section{Urbanization and Ruinate}

In their work on the fossil record of the Great Acceleration, geologists have pointed out that it is not only the technofossils, such as plastics and militarized isotopes, that are virtually impervious to decay. They also include the 
record of human urbanization. ${ }^{120}$ Thus, "Anthropocene rock" includes the "concrete, steel and bitumen of the planet's cities and roads." 121 In this last section, I move from the challenges posed by neoliberal globalization and its regimes of disposability back in time to the emergence of urban "wastescapes." These predate the excessive material consumption of the late twentieth century and speak to another massive social change that will not be unearthed in the Anthropocene fossil record. While the concrete may remain, its signification in terms of a "planet of slums," as Mike Davis would have it, would not register in most narratives of an Anthropocene that privileges the global north and its universalizing discourse of species. The rapid urbanization of Santo Domingo that created impoverished communities such as those at $\mathrm{La}$ Ciénaga - literally, a swamp filled with waste-were also experienced across the global south. Perhaps one of the most famous is Kingston's Dungle, a site that, like Trench Town, has inspired an enormous body of literature, reggae music, film, and art that speaks to the segregation of lives that are deemed the "refuse of history." 122 I turn to the first novel written by the sociologist Orlando Patterson, The Children of Sisyphus (1964), to read its trenchant critique of how the nascent state of Jamaica relegated the poor masses to a literal dung heap in the process of national and social order-building. As such, this chapter places together disjunctive historical constellations, moving backward from Capellán's uncanny trace of footprints on the sea toward an allegory of the earth/Earth where one can locate the burial of waste and wasted lives.

Earlier, I mentioned that the inability of hard plastics, barbed wire, and other technofossils to decay in the normative temporality of human lifespans renders an odd split in "nature-history" because the ruin that catalyzes our recognition of being in "nature" does not seem to be degenerating. In The Children of Sisyphus, Patterson deals exclusively with organic waste that is subject, in the Jamaican phrase, "to ruinate." Thus, "nature" is not the vexed term in his depiction of the residents of the urban Dungle, a creolization of the words "dump" and "jungle." Instead, it is the specter of history, particularly of the soil, that is under erasure. Thus, following the trace of waste, dirt, soil, and earth in this novel, we uncover a rupture in the Jamaican relationship between "nature-history" and its potential for representation.

The allegorist as collector, I mentioned earlier, has a particular ability to telescope between the temporalities of the remains of the past and to augur future anticipations and fate. This is demonstrated in Patterson's novel by the figure of the rag picker, who opens and concludes the novel and who, 
to Benjamin, reflects "the most provocative figure of human misery." 123 Patterson's novel, a dismal, fatalist, and naturalist account of human misery and abjection, would seem to concur. However, it is the allegorical use of the collector and dispenser of waste-stories, remnants, and garbage - that enables this particular commentary to foreground the reader-consumer's participation in the trade of waste and to excavate some of its histories. By following and recuperating the trace of waste, we are guided to read other possibilities in the text's figuring not of lifeless dirt but of live soil and Earth. ${ }^{124}$

Fitting to its title, The Children of Sisyphus, one of Jamaica's earliest philosophical novels, depicts existential despair for the poor of Kingston in the 1960s. It reflects the concerns shared by Patterson's contemporaries, Sylvia Wynter, John Hearne, and Andrew Salkey, who were also exploring either the rapid urbanization of Jamaica or the millenarianism that swept the country in the years leading up to independence (1962). In keeping with that era's body of literature, there is an almost anthropological focus on the "folk," who figure as a source of authenticity in the wake of the history of colonization and the emergence of the middle-class writer. While most novels of the folk turn to the countryside, in Patterson's novel the protagonists live in Kingston's Dungle, a literal (or littoral) dung and garbage heap located at the shore, a term etymologically and historically tied to sewer and waste. As befitting the realism of the independence-era novel, Patterson draws from his sociological observations of the West Kingston slums such as the Dungle and Trench Town. ${ }^{125}$

While Patterson's novel employs allegorical modes, it is not quite the allegorical exchange between protagonist and nation that Fredric Jameson discovered in his analysis of allegory in "Third World" texts. ${ }^{126}$ Patterson's novel does indeed uphold Jameson's observations that in postcolonial works, there is not the "radical split between the private and the public, between the poetic and the political, between ... the domain of sexuality ... and the pubic world of classes" that constitutes realist and modernist literature of the global north. The perambulations of his characters-garbage men, the poor, and prostitutes-make that abundantly clear. And Patterson's novel, written in the early years of Jamaican independence, is certainly concerned with the consolidation of a new national identity. In that respect, his first novel speaks to a concern demonstrated by other Caribbean writers at the time in which "nationalism is an urban movement which identifies with the rural areas as a source of authenticity, finding in the folk the attitudes, beliefs, customs and language to create a sense of national unity among people who 
have other loyalties." 127 But in focusing on the "refuse of history" that is left out of national citizenship and representation, Patterson marks a significant break between the coming of age as subject and as nation. Instead, his novel focuses on the ways in which the urban, dark-skinned poor are excluded from national belonging due to the rise of a brown middle class, thereby calling attention to the disjunctive function of allegorical relation between subject and nation.

There are three thwarted narratives of liberation from the Dungle, different types of progress narratives that drive the plot and that all involve, to a greater or lesser extent, what David Scott refers to as the social politics of anticipation. ${ }^{128}$ Notably, they are also gendered in terms of their objects of desire and modes of seeking earthly or spiritual redemption from the Dungle. The largest is the group of Rastafarian men who await a ship from Haile Selassie to repatriate them to Africa. When at the end of the novel their leader, Brother Solomon, admits he fabricated the story of repatriation, he hangs himself, commenting on the absurdity of life and hope. ${ }^{129}$ Patterson's interest in Rastafarians is notable in that only one previous novel-Roger Mais's Brother Man - had turned a sympathetic eye to a community understood at this time, as Patterson says, as the "dregs of humanity" and subject to violent attacks by the Kingston police. ${ }^{130}$ As such, the narrative of state violence and regimes of disposability discussed in earlier works are central here, and, similarly, the hopes for redemption are brutally crushed by agents of the state.

The second, parallel narrative of anticipation is of the Dungle resident Mary, a prostitute (the only paid labor available to the women of the Dungle) whose light-skinned daughter has won a school scholarship. Mary hopes that through marriage her daughter will give them an opportunity to advance socioeconomically. In order to raise money for her daughter's schoolbooks, Mary turns one last time to prostitution and is violently beaten by a drunken Yankee sailor and then by the police. She is left lying in a prison cell in her own feces and urine. In the subsequent scene, her daughter is taken away by the racially marked brown-skinned agents of the state (social services and the head of police), and Mary is placed in a psychiatric institution.

The narrative that concerns me here is the third and central story of Dinah, a prostitute with "ambition" who leaves her Rastafarian partner Cyrus in the Dungle to live with a policeman (also known as the "filth"). When she learns that a neighbor has "worked obeah" on her that will force her to return to the Dungle, she escapes to join a church of Zion Revival- 
ists. The church members mistakenly believe she has killed their charismatic leader, and she is violently attacked. She drags herself back to the Dungle to die, as "she knew she had to taste the filth again." ${ }^{31}$ In tracing Dinah's movement across the city, from the "wastescape" of the Dungle to the bourgeois comforts on Hope Road, where she works as a housecleaner, the novel details how different social strata produce different ecologies of waste.

The opening of The Children of Sisyphus is framed by trash collectors, figures who help us trace the movement of waste from the upper classes to the Dungle's poor. We are given a visceral image of the ambulation of three garbage men on donkey carts filled with the city's waste; their mobility establishes a theme of spatial demarcation between the human and "civilized" versus those who are trapped in, as the opening lines of the novel describe, "a worthless, lousy, dirty life" (I). Theorists of waste and garbage inevitably point out that one of its central characteristics is its "formlessness"- that it is recognizable by its lack of "distinguishing features." 132 Thus, we know waste because of the "removal of qualities" that would mark it as specific. This "comingling" with the "similarly valueless" creates a symbolic link between the social construction of waste and the masses. ${ }^{133}$ Only in the Dungle are the social hierarchies of waste comingled, and only there do they become formless, where "the mean derelict smell of human waste mingled with the more aristocratic stink of the factory chimneys" (7).

While the novel is told in third-person omniscient form, the garbage man Sammy functions as a Sisyphean witness for the "wasted lives" of the Dungle. As he unloads the waste, he is surrounded by hungry people:

The lowliness of his position weighed down upon him like a boulder. Every moment was a desperate step up hill, every movement of his shovel in the filth was a despairing surge of will, every glance of their eyes a terrifying punch of humiliation. He had to forget.... Those things. Those creatures of the Dungle. No, they weren't human. If anyone told him that they were human like himself he would tell them that they lied. (4)

Sammy, like the author (and, by extension, readers), functions as an intermediary figure, a collector who deals in the trade in wastes, whose engagement with the circulation of waste brings him into close connection with the figures whose living circumstances render them, in this description, at the threshold of the human and at the geographic boundary of the land of Kingston itself. In being beset by the impoverished masses, Sammy verbally 
demarcates the boundaries between human and nonhuman. He describes the Dungle as

a wide open field of debris which undulated from the driveway to the nearby sea. A swarm of flies ... swarmed in upon him.... The gathering herd had grown into a mob behind him.... It was a free for all. A mad, raging, screaming, laughing, angry, hungry scramble. A wolf pack at war. Men and women and children and beasts all joined in snatching and grabbing and biting one another for any new prize they found in the garbage... Gradually the turmoil died down as the garbage was ransacked of every ounce of value. (9-10)

Here the people of the Dungle are merged with the end products of production. As the fecal waste of the upper classes mingles with the "more aristocratic stink of the factory chimneys" (7), the unemployed and impoverished of the Dungle become the consumers of the end products of capitalism, "comingling" not with the "similarly valueless" but, rather, with what they attribute value. While Patterson has spoken extensively about his literary and philosophical influences, particularly Albert Camus, Guy de Maupassant, Honoré de Balzac, and Emile Zola, ${ }^{134}$ his wastescape can also be stylistically connected to the social realism of 1960 s Caribbean literature. The Children of Sisyphus speaks to an important trend in French and American naturalism of a kind of climatic determinism: the environment overdetermines human behavior in ways that uphold a telos of social Darwinism. ${ }^{135}$

Yet in the same scene, Patterson attempts to recuperate the Dungle as a sublime landscape, similar to how Capellán renders an aesthetics of waste as a critique of the violence of order building. In observing the scene, Sammy comes to depict waste as the sublime: ${ }^{136}$

There was, he imagined, a freakish infernal beauty in the oddly graceful way the mounds of filth undulated towards the unseen shore, in the way the sea murmured and sighed and lashed the shore with the breaking crack of a crocodile's tail.... Great Lucifer, what fantastic havoc was the sea playing under the cover of the towering filth? Everything seemed to flee from it. The whole atmosphere was a moment of frozen flight. And there was with the flight, yet seeming to be left behind, a wide, vacuous, lingering, yet perpetual beauty. (I2)

An unrelenting present haunts this particular novel, in which most of the characters are trapped in a moment of "frozen flight," such as the Rastafarians 
with their millenarian dreams and others who desire a social and economic mobility that ties them to whiteness and England. Both trajectories continue a pattern referred to by Édouard Glissant as an ongoing "dislocation" from the soil where "historical consciousness could not be deposited gradually and continuously like sediment." 137 In fact, no characters are given any genealogical continuity or history beyond the immediate present/place.

We might liken this emphasis on the violence of the present to the theories of Caribbean history Patterson developed that emphasized the rupture of African cultural mores by the plantocracy, resulting in historical discontinuities in diasporic family life. ${ }^{138}$ So while the Dungle and the sea function as an existentialist trope of the void or the absurdity of life, I want to bring Patterson's novel into a closer conversation with its Caribbean contexts and the vexed "quarrel with history," which I discussed in chapter I. Michael Thompson has argued that "deteriorating matter ... embodies a time that exists beyond our rational time; in this shadow world, time is always running matter down." 139 It is this model of the deep time of waste that I want to foreground as vital to Patterson's social critique.

The possibilities of this reading are generated through the central character, Dinah: her navigation of spaces of waste and the ways in which obeah, not fate, dictate the outcome of the novel. While Patterson has attributed Dinah's development to a kind of fate derived from the absurdist logic of Camus's The Myth of Sisyphus, here I want to excavate the African diasporic spiritual practices that also seem to determine the power of the Dungle. From the beginning of the novel Dinah declares that "she wasn't like the other people who sold their souls to the Dungle.... the place set a spell on them. It work obeah on them" (17). She wants to leave the "stinking filth" (13) and refuses to spend her "old days rottin and stinkin away on a load of shit" (22). While she is able to move to a slightly more respectable neighborhood, where she feels "civilized, human" (5I), she learns that the social strata of Kingston are mapped in terms of their distance from waste. Moving from the Dungle, where she literally steps in human feces, she is "astonished" when she takes a job as a housecleaner to be asked to clean an already spotless room. "No matter how hard she tried it was impossible for her to detect one speck of dirt anywhere" (IIS) in the bourgeois home, a domestic space that reinvigorates the pigmentocracy of plantation history.

Dinah is loath to let her new community know of her origins in the Dungle; one of her former neighbors lost her job as a washerwoman because a coworker identified her as "Dungle pickney," saying she could "smell" the 
Dungle on her and she had no right being in "good people place" (43). While this character is interpellated as matter out of place, Patterson also connects the comingling of waste with the denigration of the masses. Thus, when Dinah attends a gathering crowd outside the government employment office seeking work, she sees the politicians treat with "contempt ... the masses whom they had fooled," and that the people, new migrants from the countryside, "had all fallen, they were all little pieces of garbage thrown aside by their worlds" (82). This is the only reference we have in the novel to a massive migration from the agricultural districts to the growing manufacturing economy and a suggestion of a lost history of living relation to soil that is being refashioned into urban waste and dirt.

Alain Corbin has traced the ways in which bourgeois modernity constructed "the stench of the poor" in an effort to deodorize and discipline the masses. ${ }^{140}$ This history of disciplining and privatizing the waste of the body becomes apparent in Dinah's first day in her new home with the policeman, when she carries her chamber pot through the shared courtyard into the communal latrine. As she walks past her new neighbors they stop and stare, and the otherwise confident Dinah (in a mode of foreshadowing) "felt as if they had stripped her of all her being and was tearing it to pieces, searching into every last crevice of it, as if it was the muck the garbage-cart deposited in the Dungle" (55). She enters the bathroom and closes the door:

As her eyes caught the latrine bowl she came back to herself. Another luxury. Another mark of the civilized. Sure she had seen sewers before, but only in those fleeting moments behind cheap hotel rooms. Now it was hers. She could have kissed the smooth marble frame of the bowl. But she restrained herself and instead gently poured the contents of the chamber pot in and pulled the chain.... [I]t was with deep-felt pleasure, like a young boy at Christmas marveling at the ingenuity of his toys, that she heard the quick, cleansing flush, that she saw the water miraculously spring from the sides of the marble and then disappear. $(56)$

Scholars have argued that the realization of the privatized and thus individual self begins in the bathroom, a space in which waste-making is disconnected from the masses and thus privileges the state as "a purifying force that establishes its power through its capacity to remove filthy things to the category of the private." 141 Certainly, Dinah's "ambition" to leave the Dungle to some extent separates her from the "stench of the poor." But Dinah is 
exceedingly savvy of the ways in which the disciplining of the masses is at work, perhaps because in her trade as a sex worker she is already conscious of the "incommensurability of the public/private split" in which society and the state attempt to regulate and purify both sex and waste. Consequently, when she thinks about those who live in comfort outside the Dungle, she observes that "they eased themselves in privacy and sometimes had ... egg for breakfast, but she didn't see where it made them much the better" (77).

It is Dinah's return to dirt, to waste, to the masses in the Dungle that provides, on one level, the novel's violent and depressing ending, but on another, a recognition of the ecologies of waste and how, as we've seen in the work of Capellán and Brathwaite, bearing witness places us as readers into the allegory and allegoresis of waste. This shift happens when Dinah is told that one of her enemies from the Dungle has "worked obeah" on her, and she flees to the Revivalist church of Shepherd John. In his church, waste is ontological. He tells her that her "soul is clogged up with filth" (139), that she is "stink with sin" and needs a "period of cleansing" (I4I). After three ritual baths (and various animal sacrifices), Dinah is placed in an isolated room to meditate on her sins. Her only view, via a hole in the wall, is of

Earth. Little patch of bare, dry earth was all the hole permitted her vision. But there was something in the parched, plain patch that snatched her. Her being became trapped in its sear, dry nakedness. What was beyond the nothingness of the dusty patch?... Nothing but barren nothingness... The arid patch was a moment in a vast eternity. The patch itself was nothing, but the moment was real.... The more she realized the unreality of the barren patch, the more it receded into the vast eternal nothingness, unseen but implied by itself, so much more was she impressed with the certainty of the moment, with the conviction that only it was real. (143)

The passage demonstrates a tormented shift from "dry earth," a space of soil that has some generative qualities, to "her being" in time, which transforms it into "nothingness." Thus, space is rendered irrelevant because only the "moment" is real. Patterson stages a desire for transcendent meaning by turning to the soil (rendered as lowly dirt) and then suppresses the possibilities of earth-as-space in favor of the temporal "nothingness" of Camus's existentialism. Benjamin declares that "an appreciation of the transience of things, and the concern to rescue them for eternity, is one of the strongest impulses in allegory." ${ }^{42}$ While Patterson seems to employ allegory for these 
transient ends, his narrative and characters keep getting mired in the complex ontological demands of earth and dirt.

Dirt, shit, and waste are etymologically and semantically related. While Patterson may be invoking an existential epiphany between being and essence, I contend that Dinah poses the only character who does not transcend but, rather, embraces the dirt, not as ontological pollution (as the Revivalists wound contend), but as vital to the social present. It is the recognition, not of an existential transcendence of dirt, but its grounded being in the local masses that Dinah comes to realize at the end of the novel. Her resistance to transcending Jamaican dirt-and the Dungle-leads her to recognize her ambivalence about Shepherd John's initial plans to take her to England. Thus, the two millennial communities around her, the Rastafarians and the Revivalists, are both trying to transcend Jamaican dirt. When Dinah is framed for Shepherd John's murder and brutally attacked, she drags herself back to the Dungle, not due to some transcendent fate, as Patterson and critics have argued, ${ }^{143}$ but because the place "work obeah" on her and she is compelled "to taste the filth again" (I8I).

Dinah's rival Mabel attempts to send Dinah back home by mixing Dungle dirt with grave dirt and sprinkling it on her doorstep, according to the instructions of an obeah man. It is when Dinah discovers this that she flees to Shepherd John, triggering the series of events that lead to her violent death. As I mention in chapter I, grave dirt derives its power from the ancestral bodies that sanctify the human relationship to the soil; it is sacred and symbolizes the ways in which humans naturalize our bodies in a place. Dungle dirt, it turns out, is literally the shit of the masses. In the only reckoning of history in the novel, Dinah is told by the Dungle elder Rachael that the Dungle was originally a swamp until it was filled in with donkey carts of the city's feces in the days before the sewer system. Eventually the land hardened into a "land of shit." When the police raided the nearby squatters because Backra (white man) planned to build a factory, the squatters settled in the Dungle, because "you can't run a man from off of shit" (23).

Dinah never does literally "taste the filth," but the meaning should be read as symbolic of consumption of the masses and of Jamaican history. In her work on "revolutionary dirt," Lauren Derby convincingly argues that the contemporary eating of mud cakes in Haiti can be traced back to African ritual practices and positions it as a specifically feminized practice (in its marketing and its consumption). Importantly, she shifts the discourse of geophagy from Kristevan abjection to a more revolutionary "gustatory na- 
tionalism." She traces out its origins to the Minkisi (bundles of medicine) of Central Africa, magical power objects that often include cemetery dirt, as well as white clay (kaolin), materials and ritual practices that "hover on the boundary between life and death." ${ }^{144}$ Although we never meet the man who "work obeah" on Dinah, her neighbor explains that she witnessed Mabel pulling out two packets to sprinkle at Dinah's door: one was a paper bag of dirt; the other, a brown bag with a white cord string and a white powder (IO6) that, Dinah explains, she had trouble wiping away the next morning. Her neighbor concludes that the spell is composed of grave dirt and "oil-ofall-back," creating a duppy (ghost) that is set upon Dinah to ensure she will "fall back" to where she came from (I07), a prophecy rendered true by the conclusion of the novel. Mabel confides to her colleagues that the obeah also included Dungle dirt. Following Derby's reading of revolutionary dirt, we can move beyond the definition of "matter out of place" to recognize that dirt "is a medium linking the living and the dead and one that conveys the (often aggressive) powers of the ancestral spirits." 145 As such, the novel recuperates the ghost of history through living dirt, shifting the narrative from an existentialist present to a deeper history made legible by the trace of waste.

After she is beaten, Dinah drags her nearly lifeless body across Kingston, splattering blood on fancy cars as well as on donkey carts, the vehicles of the rich and poor, desperate to get back to the Dungle. While Erna Brodber imaged an ejaculating corpse in her allegory of ontological engagement with Jamaican soil (see chapter I), Patterson's character functions as the bleeding corpse. Her blood sanctifies the land and her death-a return to matter, to the dirt-represents a merger with the only landscape that is the true residue of the masses. Thus, "everything is eventually reduced to the condition of dirt," to soil, to a "time that exists beyond our rational time." 146 In Dinah's case, this deep sense of time is catalyzed by the history of the shit of the masses. In returning to the politics of anticipation, the novel takes a Rastafarian perspective in the last chapter and looks forward, as the last lines of the novel suggest, to her reunion with Cyrus "in paradise." Benjamin famously argued that in modern allegory, "Seen from the perspective of death, life is the production of corpses." In his reading, the corpse transcends not into immortality but into allegory. ${ }^{147}$ Patterson's novel thus returns us to the historically fraught merger between "nature-history" in his character's allegory of decay, rot, ruin, and return to organic soil. Unlike the ontological slippage discussed in Brodber's novel between earth and Earth, Patterson's 
characters are denied transcendence, and the novel instead turns back on our allegoresis as readers.

Patterson wrote the novel when he was twenty-three years old, in the early days of his sociological theories of the black diaspora, but even in this first novel we can see that, like Capellán and Brathwaite, he is foregrounding the role of the collector in providing a window into the world of "wasted lives," and developing an allegory about the ecologies of waste in which we as readers are implicated. Like Brathwaite's "Dream Haiti," The Children of Sisyphus is concerned about transparent middle-class access to the lives of the poor. In a concluding chapter, the novel parodies a well-meaning but clueless light-skinned reporter who plans to host a "charity ball" and publish an article about the Dungle to address this "blot on the good name of our island country" (176). While she publishes the article and gains social capital for her relationship to the Rastafari, she is unable to understand the basic tenet of their disavowal of subject-object relations in the address of one and all as "I and I."

In a similar vein, the novel concludes with the frame of the more privileged outsider providing a view of the Dungle. We hear the cries of Sammy the garbage man ringing in the air, calling for Dinah to wait for him. He loses her and sits in the gutter "overwhelmed with despair" (I8I) at his inability to help and, perhaps, at Dinah's refusal to recognize him. Sammy, who trades in waste, is an allegory for the reader and the author himself, a commentary about the representational limitations of the artist and the audience in addressing the violent implications of this view from below. Like Capellán and Brathwaite, Patterson calls attention to our limitations and even complicity, as readers, witnesses, and consumers, in the violent production of waste and "wasted lives" of the Anthropocene. Benjamin once remarked on the obsessive fascination of modern allegorists with death and the corpse as "memento mori." 148 Szerszynski likewise remarks that the Anthropocene excavation of technofossils frames itself as "a memento mori ... a reminder of our incipient minerality." 149 Yet Patterson's allegory suggests that we consider the lack of transcendence and the absence of monumentality for the majority of the Anthropos who will not be authorized by the Anthropocene archive. 
CHAPTER FOUR

\section{Oceanic Futures}

\section{Interspecies Worldings}

The most valuable thing we extract from our oceans is our existence.

$$
\text { -SYLVIA EARLE }
$$

We become who we are through multispecies aggregations.

-ANNA LOWENHAUPT TSING

In the previous chapters, I turned to the ruins of the Anthropocene as figures of what Benjamin termed "petrified unrest" to foreground the catastrophic violence of empire evident in the imaginaries of plantation agriculture (earth/Earth), militarized radiation (light), and global states of waste (debris). ${ }^{1}$ These three chapters engaged constellations of Anthropocene history, captured in the neologisms Plantationocene, Capitalocene, and Plasticene, to reflect on the human past as ruin. Building on the work of Édouard Glissant, who argued that the erasure of the postcolonial past created an "obsessive" desire on the part of the writer/artist to excavate the ruins of empire, I argued for the importance of allegory in addressing the irruption into modernity. Our allegoresis, as readers, is critical to the dialectical method to bring these constellations of the past and present into multiscalar relation. Or, given this chapter's focus on the ocean, perhaps we should more rightly term that a "tidalectic" method, following the work of Kamau Brathwaite. ${ }^{2}$ By adopting a Benjaminian "telescoping of the past 
through the present," ${ }^{3}$ these constellations parochialize the universalizing claims of the Anthropocene.

Overall, this book argues that Anthropocene discourse has invigorated a focus on fossilized ruins, a geological turn whereby anthropogenic sediment becomes a sign of deep history, evidence of human minerality where the excavation of the "geos" reveals the "bios" and a merger between the human and nonhuman nature. Because ruins represent the violence of modernity and the potential for ongoing apocalypse (rather than its latency), the Enlightenment narrative of progress is illuminated as myth. In recognizing the history, present, and future of apocalypse, universalized temporality becomes parochialized and characterized by ruptures and an experience of "now-time," a marked shift from chronology to simultaneity. While the previous chapters turned to the historical remnants of the Anthropocene, these final chapters explore allegories of our planetary futures. This shift from imagining the past to forecasting the future demands a new hermeneutics of adaptation to radical change and speculative narrative forms. As I argue, these forms emerge in a dialectical relationship to a visibly changing place. Thus, in these final chapters I turn to two of the most significant spatial constellations of the Anthropocene: ocean and island.

Our most visible sign of planetary change is sea-level rise, catalyzing a new oceanic imaginary and human relationship to the largest space on Earth. This can be seen in the increase in books, films, and photography representing the ocean (including the poles) as an active agent, as well as an expansion in technologies and sciences dedicated to both studying and mining the minerals of the seabed. This conversation draws on a recent scholarly turn toward what I have elsewhere termed a "critical ocean studies," in which the ocean is figured as agent, as embodied place, or as ontology itself. ${ }^{4}$ So while diaspora studies configured the sea, particularly the Atlantic, as a blank space, or aqua nullius, across which (male) human beings obtained their agency, this recent scholarly turn examines the materiality of the ocean itself and engages with nonhuman others. This chapter examines the tensions by which the ocean is rendered as a space that is amorphous, fluid, and a totality even as it is territorialized and mineralized by extractive technologies and desires.

The ocean is often described by westerners as a wilderness or frontier, underlining its apprehension as a foreign, extraterritorial space outside human orbits. ${ }^{5}$ The ocean is an "alien" space in the work of Stefan Helmreich and "pure nature" to Henri Lefebvre. ${ }^{6}$ Roland Barthes famously declared that 
the ocean was "a non-signifying field [that] bears no message." N Narrating an experience or ontology of the sea is exceedingly difficult because, outside shipboard (or submarine) life, it cannot be inhabited. In other words, the ability to experience the sea as an ontological place is challenged by the ways in which currents perpetually circulate the water and because of the inability to mark and monumentalize space into place. ${ }^{8}$ Thus, the world ocean, rendered as a space of "pure nature" and of the universal, presents a challenge to allegory, which in its world-making mode telescopes in scale from the universal to the particular.

Moreover, the fluidity of the sea poses a challenge to this ability to render it into embodied and fixed place, so authors and artists necessarily employ certain localizing figures such as the boat (or ship), the shore (or beach), and the body, human or otherwise. These three figures allow the spatial telescoping of allegorical narratives between local and global, place and space, and are vital to parochializing the universalizing narratives of the Anthropocene. In this way we see that allegory and allegoresis are central to theorizing ontologies of the whole. Spatial totalities such as planet and ocean, as I argue in the introduction, are often only captured by the allegorical telescoping between the part and the whole, allowing a disjunctive narrative of a partially glimpsed or illuminated figure of alterity.

This chapter builds on the body of recent work theorizing the "ontological turn" and shifts the conversation from land-based imaginaries, discourses that root the human in soil and earth/Earth, toward the oceanic. ${ }^{9}$ Generally speaking, ontological grounding is challenged by totalities (such as the ocean) and by concepts such as force (or energy). In fact, the geographer Philip E. Steinberg has argued persuasively for reading the ocean as a dynamic force rather than a place for "decentered ontologies of connection." Here I build on the work of Steinberg and others who seek to "develop an epistemology that views the ocean as continually being reconstituted by a variety of elements: the non-human and the human, the biological and the geophysical, the historic and the contemporary."11 Rendered as "wet ontologies," or placed in conversation with Indigenous, feminist, and diaspora studies, the ocean has been tied closely to human embodiment, kinship relations, and species being. ${ }^{12}$

Although it has not yet been connected to a critical ocean studies, there has been significant work in theorizing Indigenous relationships to place in the wake of neoliberalism's de-animation of matter. Building on Elizabeth A. Povinelli's work on "geontologies," I theorize the representation of 
Māori representations of the sea through the concept of what I call "sea ontologies" and turn to Indigenous reckonings of place and interspecies ontologies in an era of sea-level rise that is catalyzing new oceanic imaginaries. As such, I bring together a conversation between the "geos" as imagined in recent work on geognosy and geologics, in relationship to the "bios" of biocapital, biopolitics, and nonhuman life..$^{13}$

This chapter examines the allegorical and speculative fiction of the New Zealand Māori author Keri Hulme to argue that her transition away from the genre of realism after her Booker Prize-winning novel the bone people is suggestive in an era in which our partial understanding of global climate change produces new economies of speculation. Her work is placed in relation to Indigenous Pacific inscriptions of the ocean as both past and future in an era of climate change, complicating the "fall from nature" narrative that is embedded in western discourses of apocalypse and the Anthropocene. Indigenous-and, in particular, Māori-reckonings of genealogy complicate models of the Anthropocene that exclude nonhuman others and that relegate more-than-human entities (such as minerals) outside the sphere of life. Moreover, the use of Indigenous ontologies in relation to more-thanhuman nature, particularly the creatures of the sea, offers a vital critique of neoliberal extractivist regimes that are undermining Māori sovereignty of the foreshore and seabed. The stories I examine here help bring into relief the ontological split between human and "nature" that underpins some Anthropocene discourse (and the era of "new extractivism") and the importance of engaging an adaptive hermeneutics of reading in an era of increased planetary flux. ${ }^{14}$

\section{Oceanic Futures}

While there is considerable debate about whether to adopt the term "Anthropocene" and about the extent of climate change itself, one general point of agreement is that our planetary future is becoming more oceanic. Biogeochemists have pointed out that understanding the properties of water is central to grasping the concept of climate, as water transforms from ice to sea to atmosphere. Due to sea-level rise, the largest space on Earth is suddenly not so external and "alien" to human experience. ${ }^{15}$ While the ocean makes up 70 percent of the earth and is critical to the functioning of the global climate system, it has not featured as a direct topic in much Anthropocene discourse, which is otherwise focused on the anthropogenic fossils 
and isotopes that are stored by an oceanic "carbon sink." The "oceans were, by nature the realm of slow change," ${ }^{16}$ but that has shifted since the rise of empire and modernity. Sydney Levitus's research on a warming planetary ocean since 1948 has demonstrated that a stunning 90 percent of the added heat derives from anthropogenic greenhouse gasses. ${ }^{17}$ Due to the absorption of enormous amounts of anthropogenic $\mathrm{CO}_{2}$, the ocean is becoming more acidic, causing catastrophic damage to organisms such as coral reefs and shellfish, whose mechanisms of calcification are being destroyed.

The Intergovernmental Panel on Climate Change (IPCC) estimates that mean sea-level rise (MSL) was I.7 millimeters per year in the twentieth century, an enormous increase since preindustrial levels, and that the rate is accelerating. Although there are myriad variables to consider, the IPCC's fifth report anticipates an annual 4 millimeter rise by the end of this century-which is to say, one meter of MSL height. The NASA physicist James Hansen warns that a global warming increase of 5 degrees-which is within the predictable range formulated by the IPCC - could lead to a twenty-five meter MSL rise by the end of the century. ${ }^{18}$ This is a threat to the nearly two-thirds of the human population who live in coastal areas, with the highest risk for the poor and small island states. Climate is a nonlinear and dynamic system with both slow and abrupt changes; accordingly, measurements of the MSL are not experienced universally. Thus, speaking of the whole ocean eclipses the ways in which specific areas will see much higher sea-level rise while others will not be affected. For instance, the World Bank predicts a nearly two-meter rise this century for densely populated Bangladesh, and a loss of I6 percent of its land mass. ${ }^{19}$ Other areas, such as the western equatorial Pacific, have oceanic "bulges" due to the combined gravitational pull of the moon and weather systems, which threaten coastlines and are making some low-lying atolls uninhabitable.

Sea-level rise is caused by global warming in that increased temperatures accelerate glacial and ice-sheet melt, but the most significant and often unnoticed contributor is the thermal expansion that occurs as the sea warms. In other words, invisible thermal expansion is a larger contributor to sealevel rise than what is often spectacularly visualized, such as glacier calving and melting polar ice. Scientists warn that "the undersea storage of vast amounts of heat has serious implications for humanity's future." ${ }^{20}$ But many impacts can be seen in the present, such as the salinization of freshwater resources, acidification of the ocean, and increasing patterns of both drought and flooding, as well as increasing severity of cyclones and hurricanes. 
Moreover, pollution from oil spills (and chemical dispersants), synthetic fertilizers, and radioactive contamination from the Cold War and Fukushima tsunami are all making unprecedented chemical and isotopic changes to the world's ocean. As I mentioned in chapter 3, marine plastic debris is creating a crisis for ocean and bird life, ushering in the Plasticene and turning the ocean into a "plastisphere." ${ }^{21}$ Changes to the ocean are globally felt; the warming, acidity, and height of the sea are all contributing to weather and climate changes and to the collapse of fish stocks, ecosystems, and food supplies. Moreover, the increasing fluidity of the earth puts more pressure on tectonic faults, contributing to an uptick in earthquakes, tsunamis, and the eruption of volcanoes.

Scientific discourse has positioned the ocean as evolutionary origin for life on earth and, given the imminent threat of sea-level rising, our anticipated destiny. Sea-level rise is perhaps our greatest sign of planetary change, connecting the activity of the earth's poles with the rest of the terrestrial world, producing a new sense of planetary scale and interconnectedness through the rising of a world ocean. My work has been concerned with what I have called an "oceanic turn" in recent decades, which complicates the limits of the nationstate through recourse to the trajectories of migration, diaspora, and the global flows of empire, capital, and culture. ${ }^{22}$ While the early humanities scholarship on the transoceanic was concerned with humans, new work on the oceanic turn, alternately called critical ocean studies, the blue humanities, and the oceanic humanities, is exploring geopolitical, biopolitical, ecological, and ontological dimensions. ${ }^{23}$

As I have written elsewhere, there is a rich textual history for figuring the ocean as a space for evolutionary and ontological origins. ${ }^{24}$ Because the immensity of the ocean cannot be fathomed, allegorical figures of the microand macrocosmos become integral to representation. This can be seen in allegories that that engage the figure of the microcosmos to internalize the ocean within the human body. For instance, the conservationist JacquesYves Cousteau explains, "Our flesh is composed of myriads of cells, each one of which contains a miniature ocean ... comprising all the salts of the sea, probably the built-in heritage of our distant ancestry, when some mutating fish turned into reptiles and invaded the virgin land." ${ }^{25}$ In a similar vein, Elisabeth Mann Borgese, one of the founding members of the Club of Rome, as well as of the first United Nations Convention on the Sea in 1970, writes, "Every human ... is a good bit of planet ocean: 71 per cent of his substance consists of salty water, just as $7 \mathrm{I}$ per cent of the earth is covered by 
the oceans." 26 This "aqueous posthumanism," as Stacy Alaimo calls it, "challenges us to imagine how the 'human,' at the level of the gene, sloshes around with the rest of oceanic life." ${ }^{27}$ Other writers employ allegories of the macrocosmos, externalizing the human to planetary scale. The marine biologist "Her Deepness" Sylvia Earle describes hydrologic cycles as the earth's lungs, responsible for the "planetary respiratory rhythm," and asserts that "every breath we take is linked to the sea." In both cases, they speak of the fluidity between bodies as well as an embodied ocean. ${ }^{28}$

Allegories of the relationship between humans and the ocean provide the potential for thinking about evolutionary and ontological origins and as a shared commons and resource. This informed the integrative, interdisciplinary work of Borgese and her colleagues, such as Malta's Ambassador Arvid Pardo, as they sought to bring together cultural, economic, legislative, and ecological approaches to ocean stewardship that was called a "blue revolution." ${ }^{29}$ While those movements continue, the ocean is also rapidly becoming a renewed space of empire and territorialism. This dates back to the twentiethcentury "scramble for the oceans" catalyzed by President Harry Truman's expansion in 1946 of the U.S. Exclusive Economic Zones (EEZs) to two hundred miles at sea and his annexation of Micronesia, acts that tripled the territorial size of the United States and led to the long and contested United Nations Convention on the Law of the Sea. ${ }^{30}$ Although generally unnoticed by humanities scholars, the new EEZ cartographies are the most dramatic change to global mapping since the post-World War II era of decolonization (map 4.I).

Despite the long history of these vast territorial claims, the ocean continues to be popularly represented as "pure nature" - which is to say, as universal space. Some scholars continue to rhapsodize about the freedom of the seas, figuring the ocean as a place of fluidity without national or ethnic boundaries, or as recent work in the blue humanities suggests, a universal space of "exploration" crossed by romanticized mariners that is unmarked by masculinity, empire, slavery, and violence. ${ }^{31}$ Yet a critical ocean studies would point out that this is contrary to a long history of oceanic territorialism, empire, and militarism. Oceanography itself has been a militaryfunded science from its onset; it first emerged with the rise of U.S. naval empire in the nineteenth century and then was greatly expanded in the "Big Science" era of the Cold War. ${ }^{32}$ The mid-century scramble for the oceans was backed by utopian claims about the mineral wealth of the foreshore and seabed, particularly manganese, with the expectation of easy extraction of valuable and strategic war minerals. 


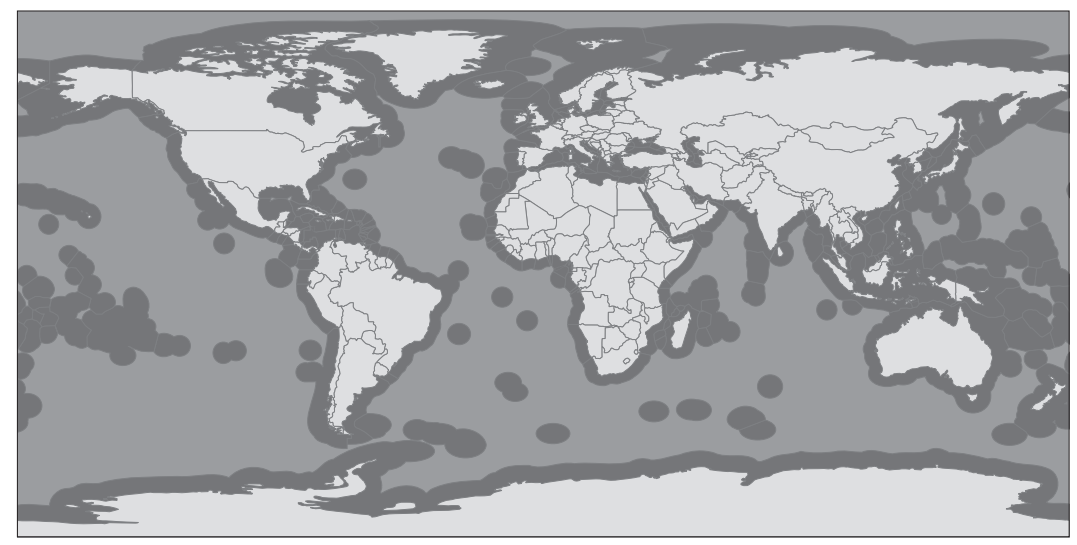

MAP 4.I. Global exclusive economic zones. Adapted from Osmar Valdebenito, "Territorial Waters."

The extractive technologies of the mid-twentieth century were not developed enough to make ocean mining feasible, and the permits languished. But in the Anthropocene, the ocean has become a new space of empire. This is apparent in the territorial claims emerging with the melting of Arctic ice, the planting of the Russian flag in the North Pole seabed, and the global expansion of submarine extractivism due to the development of mining technologies. Thirty to fifty percent of the world's oil and natural gas mining comes from submarine mining, and that proportion is expected to increase. ${ }^{33}$ At present, the Japanese have successfully completed the first large-scale, deep-sea hydrothermal mineral extraction, and commercialization of the mining site will soon follow. ${ }^{34}$ The Pacific Ocean is being termed a new "El Dorado" in the recent scramble for submarine mining rights. While this "mineral rush" began with large transnational corporations pressuring economically vulnerable countries such as Papua New Guinea, this has expanded recently to more financially secure nations, such as Aotearoa New Zealand, which is liquidating Indigenous territories to make them available for mining leases. ${ }^{35}$ Should the TransPacific Partnership be approved, states' ability to protect their foreshores and EEZs from corporate mining interests will be destabilized. As I will explain, the multiscalar shifting from the speculative logics of the horizon of our "oceanic futures" to the profoundly localizing imaginary of Indigenous ontologies is critical to understanding the complexity of our Anthropocene ocean. 


\section{From Ala Moana to Mana Moana}

There is perhaps no better place to examine competing ontologies and territorialities of the ocean than in the Pacific, or Oceania. As many have demonstrated, Pacific Island studies has long been engaged with the concept of the ocean as a space of origins and of destiny. Ala Moana, the way of the ocean, refers in many Polynesian cultures to the oceanic past in which Indigenous voyagers settled across the expanse of the Pacific, as well as the future, in which one's departing spirit joins the "ocean roads" toward Hawaiki (or Hawai i), a homeland located outside of terrestrial models of space and time. The realm of Tangaroa, the Māori deity of the ocean, is sacred and animated, unlike the passive "carbon sink" depicted in Anthropocene discourse. Inspired by Earle's blue ecology, the visionary anthropologist Epeli Hau'ofa catalyzed a move away from a colonial Pacific toward a "new Oceania," arguing that "all of us in Oceania today, whether Indigenous or otherwise, can truly assert that the sea is our common heritage." Quoting from Derek Walcott's poem "The Sea Is History," Hau'ofa determined that "our roots, our origins are embedded in the sea," which is "our pathway to each other." 36

In work that inspired a whole generation of Pacific Island scholarship (including my own), Hau' ofa inscribed the voyaging traditions of the region as producing a shared sense of origins and one of regional destiny in the wake of migration and globalization. ${ }^{37}$ Since Hau ofa established the Oceania Centre for Arts and Culture at the University of the South Pacific (USP) in 1997, an enormous body of Pacific work that includes painting, sculpture, poetry, dance, and film has been exploring the sea as ancestor, history, and destiny. More recently, climate change is spurring a new oceanic imaginary that has galvanized Indigenous scholarship, literature, arts, and film. This cultural work includes an exhibition and humanities-focused conference at USP in $2010,{ }^{38}$ as well as a dance performance written and produced by Vilsoni Hereniko called Moana: The Rising of the Sea, which toured Europe and is now a film featuring the poetry of Kathy Jetñil-Kijiner. ${ }^{39}$ The rise of an "oceanic feeling" of an Indigenous kind has inspired the rebuilding of voyaging canoes and regeneration of navigational technologies that precede European colonization, and this has recently been connecting Indigenous cultural revival to climate justice and stewardship.

For instance, the popularity of the contemporary Hawaiian voyaging canoe Hōküle'a suggests the ways in which the regeneration of traditions- 
in this case, non-instrument navigational knowledges transferred from Micronesia to Hawai $i$ - can be used to benefit new connections across the ocean. Now celebrating its fortieth anniversary, the voyaging canoe is being supported by NASA to develop scientific knowledge and raise awareness of sea-level rise. Since 2013, Hōkūle'a has been on a "Mālama Honua," or a worldwide journey "to care for our Earth," engaging pedagogies of climate change and sustainability. ${ }^{40}$ Building on this success, the Pacific Island contingent of 350.0 rg, a climate change awareness organization founded by the U.S. environmentalist Bill McKibben, has initiated a regional canoebuilding project called the Pacific Climate Warrior Campaign that in 2014 used Indigenous and allied vessels to blockade Australian coal shipping. ${ }^{41}$ The voyaging canoe is therefore a material technology, cultural heritage, and an allegory of the vessel of the people, navigating new oceanic and climate futures. ${ }^{42}$

Due to history, geography, genealogy, and anticipated sea-level rise, literature and the creative arts from the Pacific Islands engage a complex oceanic imaginary. While Aotearoa New Zealand is not facing the same challenges of sea-level rise experienced by the smaller atolls and islands of the equatorial Pacific, the ocean has been vital to Indigenous genealogies and practices there, particularly given that many Māori iwi (tribes) claim descent through a founding ancestral canoe that, in turn, connects Māori to a regional Polynesian kinship. ${ }^{43}$ Other narratives claim descent from a whale or a whale rider, made famous by Witi Ihimaera's 1987 novel (and subsequent film) of the same name. ${ }^{44}$ In all of these contexts, universalizing narratives of the ocean as "pure nature" are parochialized by Indigenous genealogical, ontological, and cosmological claims to the sea.

As I mentioned earlier, the ocean is allegorized from abstract space to local place by three key figures: the vessel (canoe, ship, or ark), the shore, and the body, particularly of submarine creatures. Keri Hulme's Stonefish (2004), an experimental collection of short stories and poetry, employs all three of these figures in her mapping of sea ontologies. Importantly, Hulme eschews the charismatic megafauna of maritime fiction such as whales and dolphins and instead incorporates profoundly mundane (and edible) sea creatures. ${ }^{45}$ Accordingly, her collection is filled with oysters, abalone, and the titular "stonefish," which is variously defined: sometimes it is the fish of the genus Synanceia, a master of blending in with the seafloor, rendering itself ordinary despite its venomous dorsal fin, but in most parts of the text the stonefish signifies the South Island of Aotearoa New Zealand, Te Wai 
Pounamu, the place (or waters) of greenstone and Hulme's ancestral home. Unlike western concepts of the fixity of land, (South) Island space here is on the move, a fish amid its kin swimming in the Pacific or, in other Māori narratives, the canoe, or waka, the demigod Māui used to fish up the North Island. In all cases, the "stonefish" signals animacy and a figure of life, history, and genealogy.

In the work of Hulme and other Māori writers, the strand, the second figure of sea ontologies, is a space of indeterminacy and flux, a space in which the borders between human and nonhuman are blurred and where one might invoke ancestral origins. ${ }^{46}$ Stonefish's cover image of the enormous coastal Moeraki boulders, thought to be the legacy of the landing of the ancestral voyaging canoe of South Island Māori (Ngāi Tahu), positions the author's whakapapa (genealogy) as a founding narrative that links knowledge, ancestry, and, borrowing from Povinelli, a "geontology" of place. ${ }^{47}$ In her work, geontology is a mutually constitutive biography and geology drawn from Indigenous contexts that destabilizes the western binary between figures of life and nonlife. ${ }^{48}$ This ontological reckoning of space and time, embedded as it is in Indigenous epistemologies, offers an alternative mode of understanding the spaces of climate change from Dipesh Chakrabarty's argument, discussed earlier in the book, that our awareness of ourselves as geological agents cannot be understood ontologically. In Māori models of epistemology, according to Mere Roberts and Peter Wills, to "know something is to be able to locate it within a whakapapa." ${ }^{49}$ "Genealogy" is not the best translation of the concept because "whakapapa" is both a noun and a verb that means "to layer." 50 Since it is a process (rather than product) of incorporating the subject into planetary networks of kinship, including to Tangaroa, knowing and being are constitutive and interrelated.

This ontological entanglement between human bodies and nonhuman figures such as the shore, stone, boulders, and the ocean all have political implications if we read this in relation to the recent nationalization of fisheries and of the seabed in Aotearoa New Zealand. Thus, the strand is not only a potent space for imagining the boundary blurring between human and nonhuman others, but it has also become a legal battleground in contemporary New Zealand politics over different ontologies of the sea. This is the context out of which Hulme's work emerges, particularly in relationship to the territorialism of New Zealand's Foreshore and Seabed Act of 2004, passed the year Stonefish was published..$^{51}$ The Foreshore and Seabed Act was an outright "sea grab" by the state that disenfranchised Māori from their 
customary title. According to the United Nations Economic and Social Council's Commission on Human Rights (UNCHR), this catalyzed an immediate "protest march (hikoi) on the country's capital, Wellington, by an estimated 30,000 to 50,000 people." 52 The act was criticized by the United Nations Committee on the Elimination of Racial Discrimination (CERD), which ruled that it was discriminatory against Māori "customary titles over the foreshore and seabed and ... fail[ed] to provide a guaranteed right of redress." 53 This is guaranteed by the Treaty of Waitangi, a document that has recognized Māori sovereignty, including the foreshore (strand) and fisheries, since $1840 .{ }^{54}$ The UNCHR investigation upheld charges of discrimination against Māori by the New Zealand state and critiqued the government for the expropriation of Indigenous property rights and the prevention of legal means by which Māori might redress the loss of the foreshore and seabed. ${ }^{55}$

Importantly, the government passed the act in the name of preserving the "common heritage of all New Zealanders," a universalizing discourse of the commons that has been used historically to alienate Indigenous people from their lands and sea. In this case, the act sought to naturalize state appropriation of the foreshore and seabed from Māori and, while it was eventually repealed and replaced by the Marine and Coastal Area Bill of 20II, the new legislation continues to pose challenges to Māori sovereignty while opening the door to transnational mining corporations. Accordingly, this territorialism has led Māori sovereignty claims that derive from "mana whenua" (power of the land) to become articulated in the more recent concept of "mana moana" (power of the sea). ${ }^{56}$ Here, mana moana might be understood as a more-than-human force, even a geological agent, but one that has ontological and cosmological ties to the first people of Aotearoa New Zealand. Unlike western models of space-as-property, the Māori relationship to the land and sea is ontological, so that one's sovereignty is formed out of a genealogical relationship to more-than-human nature.

Māori and other Indigenous people of Oceania and their allies are now at the forefront of a new scramble for the oceans in that the development of untested technologies of seabed and deep-sea mining are leading to corporate pressure on Pacific states. Since the "sea grab" by the New Zealand state, whose EEZ is the fourth largest in the world, mining companies have quickly begun to apply for prospecting and exploration permits for oil, iron, and phosphate mining. ${ }^{57}$ Fishing and mineral (especially oil) wealth are obvious motivators for this recent sea grab, but we should not neglect the importance of the microcosmos-which is to say, life at the level of the microbe. 
While territorial claims for the ocean position it as space to be crossed for military transit (especially by the U.S. Navy), and a space to be mined for minerals, increasingly the ocean has become an emergent space for bioprospecting, and, according to some Indigenous groups, for biopiracy. This commodification of life has been referred to as a different kind of "blue revolution" from the one for which Borgese and her colleagues worked. According to those working in Pacific aquaculture, this is akin to the corporate "green revolution" that industrialized and patented forms of life, such as agricultural seeds. ${ }^{58}$ This simultaneous rendering of the sea as open frontier and endless natural resource Helmreich refers to as "blue-green capitalism." 59 I suspect it is not a coincidence that the New Zealand Foreshore and Seabed Act was simultaneous with a rise in Pacific bioprospecting, which Helmreich has explored in Hawai $i .^{60}$ The microbes being chartered in Hawaiian waters that are of such great interest to venture capital (and the pharmaceutical industry) may come under the jurisdiction of the EEZ and thereby become the exclusive property of the state and not of the Indigenous peoples of Hawai'i and Aotearoa New Zealand, who have been alienated from customary title.

Whether one considers the seabed, the creatures of the sea, or its surface, the ocean has become a new frontier for capital whether we speak of transnational mining interests or utopian libertarian desires. This is probably the most apparent in the libertarian Seasteading Institute, which seeks to establish a free state on the high seas, "opening humanity's next frontier." ${ }^{1}$ Although they make a claim for humanity, their imagination of the oceanic future is predominantly white, male, and does not seem to include nonhuman others. This billionaire's project was founded by the PayPal executive Peter Thiel and Patri Friedman, a former software engineer for Google and the grandson of libertarian economist Milton Friedman. They are planning alternative communities outside state management and taxation in what they imagine to be a lawless sea (see figure 4.I). In this vision, when you are tired of the community to which you have been attached, you simply detach and sail away. In the words of Steinberg and colleagues, these "oceanborne libertarian utopias" seek to "rework... (concepts of individual and state sovereignty) by designating marine space as 'aquatory' ... [using] the liminal political, geophysical, and cultural status of the sea to construct heterotopic societies." ${ }^{2}$ They have most recently launched the corporate startup Blue Frontiers, which, according to its website, will administer their "seazone" and "build floating islands designed to adapt organically to sea-level rise." ${ }^{33}$ Interestingly, their latest "seavilization" project is in French 


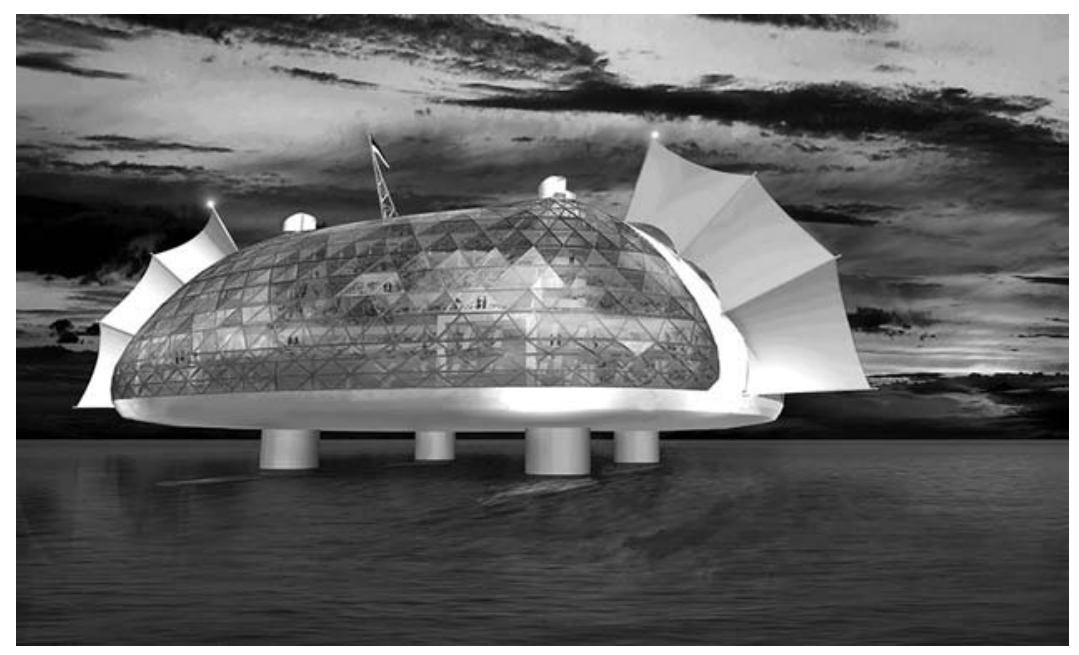

FIGURE 4.I. The aquatopia of seasteading architecture.

Polynesia, but it does not engage with Indigenous sea ontologies because to do so would challenge the universal (masculinist) law of wilderness that undergirds their vision. They promote territorial rather than ontological renderings of oceanic space because there is no cosmology, history, or epistemology of the ocean upon which the "Blue Frontiers" will be based. Perhaps this is not surprising because the ocean, as Christopher Connery has argued, is "capital's favored myth-element," creating a lacuna precisely where we should be able to trace the intersections of neoliberalism and empire, as well as their impacts on human and nonhuman sovereignty. ${ }^{64}$

\section{Aquatopia, Apocalypse, and Adaptation}

As we have seen, popular western representations of the open ocean vacillate between the utopian space of biocapital, what we might call aquatopia, and the dystopian futurity of climate change or aquadystopia. Helmreich likens this oceanic imaginary to the "swing between promise and apocalypse characteristic of American millennial culture." ${ }^{55}$ Yet, as he would point out, both of these narratives continue to mark marine space as profoundly exceptional or alien to human experience-which is to say, outside genealogy and ontology. Through experiments in form and the use of allegorical figures, Hulme's collection Stonefish offers an alternative to the history of 
aquatopian and aquadystopian visions, rendering the sea, climate change, mutation, and submarine creatures as profoundly ordinary. Her characters "get used to the fact that nothing is static, settled, or permanent" (I6), a state that she has attributed in interviews to her experience living on the shore. ${ }^{66}$ As a self-described "quintessential dweller on strands," Hulme positions her South Island town Okarito as "next to the crack between the Austronesian crust plate and the New Zealand one. It is a world of transition." ${ }^{\text {"7 }}$ As such, geological dynamism becomes translated into local scale and, by extension, informs human ontology. This geontology, being in relation to the Earth, is profoundly mutable; as one poem in the collection states, "everything changes/everything flows/nothing is exactly what it seems" (232).

Fluidity and mutability are hallmarks of the oceanic imaginary. These two concepts of transformation are also integral to allegory as a form because it is about the metamorphosis of the subject and, eventually, the reader. This is a thematic as well as a stylistic element of Hulme's collection, which is filled with dreamlike, often futuristic scenes that are permeated with fog, mist, rain, or a rising tide. Allegory is known to represent figures "poised between heaven and earth," ${ }^{\prime 8}$ which Hulme employs to blur the boundaries between earth and water, as well as an invocation of the embrace of Papatūānuku and Ranginui, Māori deities of the earth and sky who were separated to create human beings, but whose embrace becomes visible in the misty realm between. As befitting a collection dedicated to the concept of oceanic flux, Stonefish is formally innovative, mixing the genres of speculative and science fiction, allegory, and poetry. Hulme's formal experimentation has been likened to the Māori tradition of kōrero pūrākau, stories of supernatural and cosmological figures and events, but I think that overlooks her profound interest in the ordinary human and nonhuman figures that are decidedly not exceptional. In fact, the opening story, "Floating Words," is invoked later in the collection in a reference to the Japanese ukiyo, "a floating world" (73), but the hedonism that marks this courtly genre recedes to the background so that Hulme can bring to the foreground figures of the ordinary, such as workers in a fish factory.

As an island writer, Hulme makes a claim for the ordinariness of the human engagement with the sea and its nonhuman inhabitants and thus inscribes sea ontologies. This mutability and the transformative relationship between the human and the sea foreground the myth of the individuated human subject and the collapse of a linear temporality that is tied to empire and capitalism. As a "fisher-artist," Hulme depicts the sea in terms of the daily means of production, the joys and drudgery of labor, the banality and sumptuousness 
of food, a space of human violence, a space of nonhuman ontology, and a vital resource. ${ }^{69}$ Both fishing and foraging are thematics that run throughout the book, positioning Hulme, like Tony Capellán, in the activity of "collector as allegorist." ${ }^{\prime 0}$ In this sense the "ragpicker" of Benjamin's The Arcades Project becomes the beachcomber, gathering profane and often living objects and life forms. Through experiments in form, Hulme renders what would normally be understood as fantastic (such as philosophizing abalone) as profoundly ordinary. As such, she destabilizes western representation of nonhuman nature as spectacular or alien to human experience. In speaking of her craft, she has explained that she finds "distasteful" writing that is "removed from the whole of life" and "ignore $[s]$ the ordinary ... the tears and the mucous discharges." 71

This fluid, oceanic ordinary is ontologically different from the apocalyptic imagination of a threatening ocean in the (masculinist) "man versus nature" plot of many recent Hollywood climate change films. Increasingly, sensationalist accounts of sea-level rise abound in blockbuster films such as Roland Emmerich's 2012 and Darren Aronofsky's Noah, and even in scholarly books such as Brian Fagan's The Attacking Ocean, which features a menacing wave on the cover. Certainly, the crisis of climate change and the Anthropocene brings a Judeo-Christian narrative of apocalypse into a twenty-first-century environmentalist eschatology. Reading the past through the constellation of the present, we can see that Noab trades on the thin line between the biblical and secular account of the oceanic "end times" and authorizes a kind of (white) patriarchal violence as salvation. As Donna Haraway has observed, "Belief in advancing disaster is actually part of a trust in salvation, whether deliverance is expected by sacred or profane revelations, through revolutions, dramatic scientific breakthroughs, or religious rapture." ${ }^{\prime 2}$ In contrast, Hulme depicts creeping sea-level rise in terms that emphasize mutation and adaptation without a sanctifying telos brought about by normative heteromasculinity or technology, providing a welcome alternative to the spectacular tone of dominant U.S. apocalypse narratives. In fact, through a hybrid narrative style she parodies heteronormative modes of millennialist fiction, particularly nuclear disaster narratives that derive from white settler colonialism which all too often set the narrative tone for the Anthropocene.

In recent years scholars have turned a critical eye to apocalyptic discourses of climate change to raise questions about their efficacy and their suppressed histories of those who endure an ongoing apocalypse after colonialism. 
Among white environmentalists of the global north, there is a debate between "climate alarmists" and "climate realists" that has even led to environmentalists' being labeled "apocalypse abusers" and "apocaholics." 73 The ecomodernists Ted Nordhaus and Michael Shellenberger have argued that "apocalyptic global warming scenarios ... tend to create feelings of helplessness and isolation among would-be supporters." ${ }^{74}$ While there is no empirical data to back up this claim, it is worth examining our narrative production and, following Rob Nixon, thinking critically about the ways in which attention to spectacular ecocatastrophes such as tsunamis or the explosive force of nuclear weapons may detract attention from the "slow violence," or longue durée, of environmental change. A turn to nonspectacular ecological violence would demand engaging different modes of temporality, such as more-than-human models of history and deep time. Importantly, this would demand different hermeneutics - that is, new modes of reading and interpreting signs. The spectacularity of apocalyptic narratives may be less of an issue than the ways in which apocalyptic thought presumes a fall from nature, perpetuating a human-nature binary in which their encounter is inevitably rendered in ways that are both exceptional and catastrophic.

These "alter-native" hermeneutics would also foreground the ongoing critique of apocalypse narratives from the perspective of Indigenous and otherwise colonized peoples, who continue to call attention to the ways in which settler colonialism (in Aotearoa New Zealand, the United States, Canada, and Australia) is not a past "event," but rather an ongoing structure of alienation and disenfranchisement, as Patrick Wolfe has argued..$^{75}$ Indigenous scholars Kyle Powys Whyte (Potawatomi) and Zoe Todd (Métis) have both argued that settler colonial apocalypse narratives privilege a linear model of time and separate out the human from nonhuman relatives and kinship relations. Moreover, after experiencing Indigenous genocide signaled by the Orbis spike (discussed in chapter I), one cannot then forecast the future as apocalypse. As Whyte has written, "Indigenous peoples challenge linear narratives of dreadful futures of climate destabilization with their own accounts of history that highlight the reality of constant change and emphasize colonialism's role in environmental change." 76

Reading Hulme through this lens raises vital questions about the historicism and racialized contexts of apocalyptic narratives and the mutability and appropriateness of their idioms. She parochializes apocalyptic narrative, demonstrating the ways in which it is rendered as a future threat rather than 
a lived, present experience of colonized and otherwise oppressed peoples. While apocalypse has been an effective idiom in popular North American discourses, particularly as a Cold War rhetoric, it would not be an effective narrative strategy Māori might use in obtaining sovereignty over land and sea given the expropriations of the settler colonial New Zealand state. By adapting a narrative that foregrounds an appeal to mutability and kinship with the more-than-human world, Hulme is presenting what is more congruent with Indigenous ontologies. It is also a narrative that is becoming increasingly familiar to the New Zealand state, which, due to pan-tribal action by Māori, has granted sovereignty and rights to the Whanganui River. ${ }^{77}$ As Linda Te Aho explains:

Regardless of tribal affiliations, all Māori are inextricably bound to the waterways by virtue of whakapapa (genealogy), which derives from our creation stories. We see ourselves as direct descendants of our earth mother and sky father. We see ourselves as an integral part of nature-not just of the land, but as the land. In relation to water, the Whanganui people have a saying, "Ko au te awa, ko te awa ko au" (I am the river and the river is me), which is an elegant expression of this interconnectedness. ${ }^{78}$

Given this context, an Indigenous end-of-the world narrative would be far less effective than a geontology that argues for being with the world. The latter has been growing in a global "rights of nature" movement in which Eduardo Viveiros de Castro and others argue for a disciplinary move to promote the "ontological self-determination of the world's peoples." ${ }^{\text {"9 }}$

Some claim that the shift to multiple ontologies and to endow more-thanhuman nature with ontology may have some scientific basis. Hulme's inscription of oceanic mutability speaks to how, in the discourse of the Anthropocene, humans are positioned as a geological force, yet the ocean seems to be our proxy. In this sense, the ocean may function allegorically as the daemonic agent, a figure with more than natural power that moves between realms (see chapter 2). This animation of the sea is also visible in studies that suggest a rather anthropomorphic ocean-perhaps even a conscious superorganism. ${ }^{80}$ Water's mutability, measured in picoseconds, means that it changes its molecular structure about one trillion times a second and has been likened to a network. Unlike any other liquids, water molecules change in response to temperature and chemicals, blurring the distinction, the chemist Anders Nilsson believes, between chemistry and a living thing. Moreover, 
the "bacterial networking" of the ocean's microbial communities has raised new questions about whether the sea itself is ontological. ${ }^{81}$ In writing about the new knowledges catalyzed by the Anthropocene, Amitav Ghosh has asked, "Can we help but suspect that all that time that we imagined ourselves to be thinking about apparently inanimate objects, we were ourselves being 'thought' by other entities?" 82

Likewise, Hulme's narrative is constituted by the discourse of mutability and multispecies being in which her characters, human and otherwise, "become the thought." By invoking "anthropophagic oysters"; mushrooms that, when eaten, will collapse human cell walls; and sentient moonfish, abalone, and even plastic bottles, Hulme poses a fluid waterworld of queer kinship, an ontology of what Jane Bennett has called "vibrant matter," ${ }^{83}$ inscribing figures that are deeply tied to the seascape of Aotearoa New Zealand and the origins of Māori cosmologies. The emergence of what Hulme calls an "unseen neural network" (27) inscribes new morphologies for an increasingly maritime world arising from an era of climate change that, thinking allegorically, functions on the cellular and planetary scale. We might say that planetary changes in the sea level itself demand and produce different forms of narrative.

The opening story, "Floating Words" is an allegory for reading Hulme's whole collection, a parable about trading stories to an unknown audience to earn daily bread in an unpredictable era of ecological change. The narrator opens the narrative in medias res, "balanced on the end bollard" with a "sliprope in [her] hand," about to depart her terrestrial home on a homemade barge stocked with a few "sulking" fruit trees, cooking materials, clothing, English and Māori dictionaries, and a mutating bolete mushroom (5). In keeping with the master allegory, the ship, this is something of a writer's vessel, "a small-scale model of the totality of space and time" in the words of Michel Serres, and an allegory for the book itself. Serres has argued that recuperating the allegory of the ark, is necessary in an antediluvian age to "prepare for an overflow of the sea caused by some thaw in the ice caps." ${ }^{84}$ In that sense writing itself becomes the ark. But since "the sea is simultaneously in time, beyond time and in its own time ... this puts a burden on those who seek to tell stories of the sea," suggesting that it demands both a formal mutability as well as adaptive allegoresis. ${ }^{85}$

Hulme's opening sentence states, "Thinking back ... there were omens all along," (5) offering an adaptive hermeneutics for an always dynamic land and seascape. The events of the story are structured around the successful 
interpretation of omens and natural signs; correctly interpreting the fantastic mutations of the mushroom, the narrator realizes that the sea level is rising beyond a critical point, and she must leave her home. As such, reading the signs of an always dynamic nonhuman nature catalyzes the mobility of the protagonist and her narrative. As with most of the stories of the collection-and in keeping with allegorical modes-chronological narration is ruptured. In this case, it is registered by a syntactic movement between present- and past-continuous tense by a narrator who, in the first line of the story, is "thinking back" to the omens before the launch and then is interrupted by the present voice, an "I" who is "balanced on the end bollard" (5). This subject mutability continues to transform over the course of the short story. The temporal mutability is also visible in the organization of the story into short episodic structures, which are framed by figures of mobility such as the "home-made boat" (17), a "mail blimp," and floating "bubble houses" (16). Consequently, dynamic earthly change is not expressed in the grammar of the future subjunctive, as some position climate change as "if it were to be." Rather, it is being experienced in the interwoven tenses of both an immediate present and past. This highlights that climate change is a contemporaneous experience, as well as Māori temporal epistemologies that position the past in front while the future is behind.

Hulme imagines a mutable, postcapitalist "waterworld," not unlike the delightfully cheesy Kevin Costner film that would follow six years later, but her waterworld does not demonstrate an individualist competition for resources. ${ }^{86}$ Instead, she dissolves the individuated speaking subject and, by extension, human species. Allegory is about staging different worlds and placing them in conversation; thus, the narrator is a writer who creates her own watery cosmos. Her concern with writing and the mutability of interpretation derives from her role as an author who trades chapters of what she calls "The Neverending Novel" (17) to a mail blimp for food supplies. As in the science-fiction tradition, the story imagines an anonymous, centralized power structure that, in this case, establishes a trade for "processed food or drink" (8) in exchange for the narrator's words. Tracing out the layers of allegory, we recognize that we, in fact, are the readers of this narrator's "craft."

In keeping with the transformative thematics of allegory, plots begin to merge between memories of her recent past (writing a story), and the topic of her chapter (a man whose body is dissolving after drowning), blurring the boundaries between pluperfect and continuous present, as well as between self and other. This is evidenced when a menacing character appears at the 
door whom she recognizes as "an imaginary clone of herself turned real" (I2) and who promptly raids her whiskey cabinet ${ }^{87}$ Her uncanny visitor is a "leaner" and "meaner" version of herself, leading the narrator/author to comment wryly that she was "drowning in unreality" (I2). But to interpret this merger, the narrator realizes-as she pulls out a bottle of vintage champagne- "sober straight forward action will get [her] nowhere" (II). Recognizing that she "had invented too many characters [she] wouldn't want to meet" (13), she turns to a new form of narrative. In this world of (liquid) mutation and multiple selves, her mode of interpretation and of narrative must change. This is not the first time that characters she has created in The Neverending Novel appear in her home, causing her to become "very leery about who [she] fantasised: it was one thing putting people down on paper, quite another to have them lying, vomit-covered and comatose drunk on the floor" (13). In another temporal shift she looks back to comment, "When I wrote my chapters now, to earn the daily bread ... I avoided detail, intensity, realism ... it didn't seem to matter to whoever-or whatever-read them at the other end" (13).

Ghosh has noted the frequency of the connection between climate change and the concept of the "environmental uncanny," which derives from our belated recognition of our "nonhuman interlocutors." 88 The doppelgänger is an uncanny figure of allegory, a disruption of both the chronological sense of temporality and the bounded, species-limited self. In Hulme, the protagonist's double is described as "a sign of the times to come if ever there was one" (8). She is referring to the other invented characters that make appearances in her increasingly strange waking life while her dream life-which she feels should have "intimidations," "shadows," and "forebodings" about this new waterworld-is "peaceful" (8). The shifting of her fantasy world into her dayto-day reality suggests one form of mutation, in which the fantastic becomes ordinary, experiential.

The fantastic, like science fiction, is one of many allegorical modes. Tzvetan Todorov argues that by introducing elements of the extraordinary and supernatural, the fantastic suggests that a rupture has been made in the natural order of things, a shift that makes the reader hesitate (to believe) and therefore demands a different kind of reading practice than other genres. ${ }^{89}$ This rupture is often achieved through the doppelgänger, a signifier, like other elements of the uncanny, as "a collapse of the limits between matter and mind," as well as between subject and object, which triggers a profound "transformation of time and space." 90 This collapse of boundaries between Hulme's human 
subjects has broader ecological implications: it mirrors a collapse between human and nonhuman elements in a fluid era of sea-level rise. Rather than providing a rationalist explanation for the doppelgänger, Hulme insists on the reader's adaptation, a narrative strategy that Todorov locates in allegories of transformation such as The Metamorphosis, in which the author naturalizes the unnatural. ${ }^{91}$ Hulme's articulation of a mutable and mutating world demands the same kind of adaptability in terms of our reading practice, a new hermeneutics for the oceanic futures of the Anthropocene.

\section{Signs of Interspecies Worlding}

Feminist and Indigenous studies have long theorized complex interspecies and multispecies ontologies, scholarship that has recently been picked up in relationship to the Anthropocene. ${ }^{92}$ While this body of work is diverse, it shares what Kimberly TallBear explains is "an aversion to the human/ nonhuman split because of an explicit understanding that it engenders violence. ${ }^{93}$ As a complex system, what has been termed by Manuka Henare "Māori vitalism" configures "an original singular source of life ... that animates all forms and things of the cosmos. Accordingly, life itself cannot be reduced to matter or form." ${ }^{44}$ While life cannot be reduced to form itself, Hulme's story suggests that a hermeneutics of a dynamic, mutable form are necessary.

In a narrative that is retrospectively looking for "omens all along" (s) the most important is the discovery of an "odd-looking," brightly colored bolete, which frames the story. Consequently, an allegoresis of the mutations of the "strange bolete" (I7) becomes essential to the development of narrative events, and, in fact, the mushroom, along with the rising tide, are the only temporal markers of this waterworld. In other words, because the story is told retrospectively, the narrator's recollections merge together. Thus, the rising water and growing "tide bolete" mark the passing of time and the movement from narrative past to present. The bolete's hyphae over the course of time extend to cover the flax basket the narrator has woven to carry it in, the basket being associated in Māori tradition with a gift of knowledge from the progenitor of humans, Tāne. Yet this growth is "unnatural, hyphae being delicate and exceedingly vulnerable to changes in moisture or lightbut," the narrator asks, "what is natural now?" Once the fungus starts to "glow with minute blue sine waves moving up the stalk as the tide rises," 
she recognizes it as "the tide in microcosm, the whole cap becoming alight at slackwater" (17). With a pun on the omen of these "blue sine waves," she declares that she "recognizes a sign when [she] is given one so clearly" (17) and packs up her boat. ${ }^{95}$ Having already submitted the last chapter of The Neverending Novel to the mail blimp, she boards her allegorical "little boat whose only real freight is words" (I8). In adopting the allegory of the ship, she concludes the story by sending it off to her readers: "The Pirate Epistle enters your sphere" (18).

In her work on the relationship between time, space, and matter, Karen Barad has argued that spatiality is a process and that "the iterative enfolding of phenomena and the shifting of boundaries entail an iterative reworking of the domains of interiority and exteriority thereby reconfiguring space itself, changing its topology." ${ }^{\text {96 }}$ Yet "Floating Words" suggests the reverse: here we have an oceanic reconfiguring of space that demands a "reworking of the domains of interiority and exteriority" for the human and more-than-human world. Hulme's Stonefish might be read in terms of its allegorical otherworlding, an "autra mondialization" in which, to draw from Haraway, we are "siblings in nonarboreal, laterally communicating, fungal shapes of [a] queer kin group" as the narrator sails into the oceanic future with her tidal bolete, "glowing with sine" and "sign" waves, a merger of micro- and macrocosm. ${ }^{97}$

Anna Tsing might point out that Hulme's narrator is a forager, a figure that I liken to the Benjaminian collector-allegorist. The forager, unlike the agriculturist, nurtures entire "landscapes [or seascapes] with their multiple residents and visitors-rather than [a] single species." ${ }^{\prime 8}$ Arguing, like Haraway, that "human nature is an interspecies relationship," Tsing emphasizes the ways in which we might read the relationship between foragers and the symbiotic mushroom as one in which property relations are eschewed so that "territorial exclusivity" is replaced by "expansive and overlapping geog-

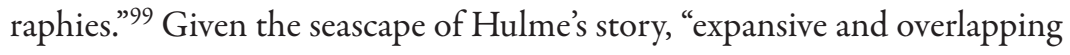
geographies"-or, perhaps more accurately, sea ontologies—are indeed necessary for a waterworld of barges and floating "bubble houses."

Hulme's work reminds us that in an era of radical ecological change, shifting hermeneutics - the very process of allegoresis-is vital for adaptation. Multispecies scholarship suggests that mushrooms are dynamic organisms that we might learn to read to understand more "about the human condition." ${ }^{100}$ Certainly, Hulme's narrator reads the tidal bolete as a sign, but not necessarily of "the human condition" or even of anthropogenic 
environmental change. It is only near the end of the story that the narrator gives us an account of climate change, which begins in the anachronistic syntax of allegory:

Once upon a time, we were a community here, ten households of people pottering through our days.... We knew-the television told us, the radio mentioned it often - that the oceans would rise, the greenhouse effect would change the weather, and there could be rumblings and distortions along the crustal plates as Gaia adjusted to a different pressure of water. And we understood it to be one more ordinary change in the everlasting cycle of life. (18)

This description of climate change raises important questions about causality and accountability. To position this as "one more ordinary change in the everlasting cycle of life" would seem to suggest that this is not humaninduced climate change and to nullify claims that we have entered the epoch of the Anthropocene. Chakrabarty's observation that "to call ourselves geological agents is to attribute to us a force on the same scale as that released at other times there has been a mass extinction of species" is relevant here. ${ }^{101} \mathrm{He}$ argues for a new form of "species thinking" that is made possible by consciousness of ourselves as globally connected and geologically determinative agents. This is not ontological because "we humans never experience ourselves as a species. We can only intellectually comprehend or infer the existence of the human species but never experience it as such." 102 Yet Indigenous and multispecies ontologies offer another mode of "species thinking" at planetary scales. "Floating Words" suggests that human exceptionalism may be embedded in a concept of "species thinking" in which the only articulated species is the human. ${ }^{103}$ Reading the signs - and sine waves - of other species becomes an important alternative to an anthropocentric narrative of modern history since the invention of the steam engine, which has characterized most of the historical work on the Anthropocene. ${ }^{104}$

An anthropocentric model of species thinking tends to overlook the ways in which human beings are constituted, even in our DNA, as interspecies creatures. ${ }^{105}$ As Haraway has observed, "Human genomes can be found in only about to percent of all the cells that occupy the mundane space I call my body; the other 90 percent of the cells are filled with the genomes of bacteria, fungi, protists, and such.... I become an adult human being in company with these tiny messmates. To be one is always to become with many." 106 
Similarly, in Māori cosmologies one claims descent from Papatūānuku and Ranginui and has kinship relationships with nonhuman beings, including minerals, mountains, and bodies of water. As Roberts and her colleagues point out, whakapapa render "no distinction between spiritual and material worlds" as everything descends from the atua, or gods. Accordingly, the "environment and its resources are both ancestors and kin." 107 This sacred model of ecology raises some complex questions about accountability and human agency. My argument is not that Hulme has explicitly woven Māori cosmologies into this particular story. What I find interesting is that "Floating Words," read as an allegory for writing, makes a specific narrative claim for adaptation and submersion, for innovative narrative strategies and the construction of new vessels to navigate the ontological and terrestrial challenges of sea-level rise and an Anthropocene ocean. ${ }^{108}$

In this sense, Hulme's allegorizing of new vessels or arks for the oceanic future is in concert with Serres's allegory of the ship, in which he invokes a "seagoing pact" in the interests of the "the collectivity." This pact is the allegorical equivalent of the "natural contract," a new relationship to the planet that would "set aside mastery and possession in favor of admiring attention, reciprocity, contemplation, and respect; where knowledge would no longer imply property, nor action mastery." ${ }^{109}$ Serres does not cite any feminist or Indigenous sources and problematically genders the dynamism of the earth as an untamable woman. Yet this precise critique has long been examined in this scholarship, which poses a counterallegory to narratives of capitalist development. Serres, like many cosmopolitan thinkers before him, argues for transcendence of place as a mode of global unity: "The ship provides a model of globality: being-there, which is local, belongs on the land," which he seeks to leave behind much like the Seasteaders. ${ }^{110}$ Yet this is precisely the logic that feminist/Indigenous ontologies critique; it is not from distancing ourselves from place but, rather, re-engaging its animation in the ordinary that provides for the navigation of oceanic futures.

Hulme's use of adaptation and transformation as an allegory eschews an apocalyptic narrative that would position humans outside the "natural" world or narrate change in nonhuman nature (such as flooding) as extraordinarywhich is to say, exceptional to human experience. If the discourse of the extraordinary asks us to activate our ecological obligations in moments of crisis, Hulme's story suggests we find our obligations in the everyday. This is a kind of "crisis ordinariness," to borrow from Lauren Berlant, or, in Mike Davis's terms, a "dialectics of ordinary disaster." ${ }^{111}$ Hulme's invocation of the ordinary, as an 
Indigenous writer, is not the rendering of bourgeois normalcy that Ghosh pinpoints as a barrier to the climate change novel. ${ }^{112}$ Instead, it is in keeping with feminist/Indigenous calls for an ethics of care and obligation, along the lines of Vandana Shiva's model of an "earth democracy," which is derived not from moments of crisis but, rather, from the everyday. She argues, "We [must] base our globalization on ecological processes and bonds of compassion and solidarity, not the movement of capital." ${ }^{113}$ This is an embodied practice, because ultimately "we are the food we eat, the water we drink, the air we breathe." 114

\section{Submersion in the "Unseen Neural Network"}

Hulme's narrator may be building an allegorical writer's ark but does so, unlike the biblical Noah, without recourse to a prelapsarian origin or to the looming exceptionalism of an aquatopian or aquadystopian future. To read Hulme's ethics of submersion and adaptation, it is necessary to consider the opening story in relation to the story that follows it. "The Pluperfect Pā-wä" imagines the bodily ways in which "we are the food we eat," foregrounding how eating, as Mary Douglas has pointed out, is perhaps the most obvious of interspecies mergers. Thus, we move from the geologics of climate change in the first story to the biologics of merger with other species. This section shifts from the allegorical figures of the shore and the boat to the engagement with nonhuman species, Hulme's third and final way to allegorize an ontological relationship to oceanic space.

Interspecies mergers, which are part of the day to day in Stonefish's stories, are often messy, uncomfortable, confusing, and violent. Moreover, their violence does not preclude the experience of pleasure. For instance, in her humorous list "Some Foods You Should Try Not to Encounter," Hulme describes animated (and often deadly) foods such as the Quiet Blue Chilli, the Extremely Pickled Onion, Exophthalmic Pie, and the Anthropophagic Oyster, which has "pinpoint black pupils" that communicate a "malevolent pale grey gaze" (37). This oyster is "very very angry about what had happened, is happening, and might happen-without its intervention-to its kin" (37). Thus, kinship and ontological relations are not limited to the human; nor are they idealized as some kind of utopian transcendence through species mergers. These mergers are often sites of violence; like Haraway, she demonstrates there is "no way to pretend innocence and transcendence or a final peace." 115 
While "Floating Words" has the narrator embark on a journey into a new waterworld, the subsequent story depicts a merger with other species by submersion into the oceanic depths. This submersion story raises foundational questions about how to represent a subject who has such porous boundaries that the concept of (human) species itself is put into question. As a result, the narrative form and voice of "The Pluperfect Pā-wä" is exceedingly complex; in fact, even determining the plot takes careful rereading. Briefly summarized, it is a story alternately narrated by husband and wife, as well as unmarked speakers (possibly abalone, possibly an omniscient narrator), about interspecies mergers. The title is an allegorical pun on the English word "power," the Māori pāua (abalone), and its homonym $p \bar{a}-w \bar{a}$, a term glossed toward the end of the story as

PLUPERFECT (TENSE) EXPRESSING ACTION COMPLETED PRIOR
TO SOME PAST POINT IN TIME SPECIFIED OR IMPLIED: PĀ (V.T/
V.I./N) TOUCH, BE STRUCK, STRIKE, HOLD PERSONAL COMMU-
NICATION WITH, AFFECT, BE CONNECTED WITH, ASSAULT, OB-
STRUCT, INHABITANTS OF A FORTIFIED PLACE, BLOW, REACH
ONE'S EARS, GROUP, CLUMP, FLOCK: WĀ (V.IN) INTERVAL, RE-
GION, DEFINITE SPACE, INDEFINITE UNENCLOSED COUNTRY,
TIME, SEASON, BE FAR ADVANCED, CONDEMN, TAKE COUNSEL,
SO-AND-SO. (33)

This merger of these English and Māori dictionary entries suggests the ways in which taxonomies of language will not necessarily assist in the act of interpretation, particularly given the fact that the story never uses the pluperfect, or completed-action tense. As with the earlier story, Hulme is consciously engaging with the multiple temporalities of the Anthropocene, foregrounding in the title of "The Pluperfect Pā-wä" our own belatedness to the scene of mutation.

Narrative form reflects the mutability of multiple speaking subjects. One voice begins the narrative, explaining that he finds it "hyperbloodyinteresting" that fifteen pāua on the beach are out of their shells, getting "superbloodyconfident now, aren't they?” (27). His narrative is interrupted by a second voice, rendered parenthetically, which provides the allegorical address to the reader. She informs the audience that "you're a ... captive listener. Reader. Whatever." Once the abalone start speaking, she is "charmed" rather than threatened (27).

We are then asked by a third, unknown voice to "picture the new cathedral. It is dense and made of bluegreen nacre: it is as fluid and ephemeral as 
a net of sounds: it is the holdfast rock... and it is the unseen neural network, and it is the tides between" (27). This is followed by a wide-ranging list of mundane, ordinary objects signifying the work of the collector; from "every ashtray made of Lucite with the chips in it" to "every cheap swinging earring" to "every haunted shell ... scattered the length and breadth of the islands." This eleven-line sentence, a list of objects without a verb, is then followed by two incomplete sentences: "Every last one of them. EVERY ONE" (28). We discover that, like the author, all nonhuman matter is experimenting with form, beginning with the pāua. The female voice remarks: "One of them said to me, quite shyly I thought, 'My first intra-generational mutation.' It was waving a chaplet of shining blue eyes, all loosely tethered to it by green filaments. The others (all sorts, I won't even try and describe them for you because the pace of change is getting hectic, and they're all experimenting madly) were giggling snidely at it" (28). The female character is depicted as one whose communication with the pāua allows for mutation; as such, language transforms material form.

"Floating Words" and "The Pluperfect Pā-wä" share millennial concerns and inscriptions of waterworlds, both depicting female characters who have merged with an oceanic realm. The latter story is narrated as a "new cathedral" of objects of everyday life, suggesting a consecration of the quotidian in which ashtrays, shells, and even a plastic beer bottle start experimenting with form. The narrator remarks that one should not be surprised at the vibrant matter of plastic, for instance, since it derives from dinosaurs, those "layers of squashed animals and plants that turned into tar and oil and coal" (29). This turn to nonapocalyptic models of climate change requires different models of temporality. As Hulme has often pointed out in interviews, in the Māori language one puts the past in front while one moves backward into the future. ${ }^{116}$ This narrative merger with fossils (and later the sea) suggests an encounter with deep planetary time that renders an interspecies relationship that is a counternarrative to the discourses of mineral extraction that drives the logic of the Foreshore and Seabed Act.

By animating fossils, Hulme provides an alternative to the neoliberal logic of extractivism, posing all beings as "walking, talking minerals," in the words of Jane Bennett. In her work on vibrant matter Bennett draws from Manuel DeLanda’s deep history of bones: "Soft tissue ... reigned supreme until 5,000 million years ago. At that point, some of the conglomerations of fleshy matter-energy that made up life underwent a sudden mineralization, and a new material for constructing living creatures emerged: bone. It is almost as 
if the mineral world that had served as a substratum for the emergence of biological creatures was reasserting itself." 117 In adopting this deep history of life, Bennett concludes that, ultimately, "all bodies are kin in the sense of inextricably enmeshed in a dense network of relation. And in a knotted world of vibrant matter, to harm one section of the web may very well be to harm oneself." 118 This is precisely the ontological ground on which Hulme bases her allegory of oceanic submersion, connecting the minerals of the earth, seawater, and pāua into a network of complex relation and accountability. In bringing together the geos and the bios of the Anthropocene, she inscribes a narrative of agency, minerality, and life. Earlier I had quoted Henare who argues that "in Māori thought life itself is independent from form." 119 This separating out of life from form is a vital allegory of the stories themselves, in which mutability between human and nonhuman figures are a central trope. Interestingly, this mutability between humans and the creatures of the sea was shown in a scientific experiment demonstrating that pāua heartbeats accelerate under the increased carbon emissions of climate change, figuring pāua as both "living fossils" and taonga (treasures). ${ }^{120}$

Hulme's stories suggest that the experience of embodied thought allows for merger with other species, raising questions as to whether the nonontological rendering of humans as a force is necessarily limited to a singular species thinking. This comes about through the primary narrator's recognition that the pāua have brains, envisioned through the allegorical mode of dream language. Then the story poses a series of philosophical questions about the first mutating abalone, such as, "How did it discover itself as a thinking being? [H]ow did it discover us?" (29). The narrator wonders, "How did they discover the interconnections between life, the universe, and everything? And time and space?" (29). She directs herself to "become the thought" and merges into the ocean with her pāua companions, shifting into the first-person plural:

(SING! SINK DOWN SLOOWWLLEEEEEEEE . . SING! SINK! SING!

AHHH! ROCK BOTTOM! THE WATER BREATHES ME AND WE

BREATHE IT! WE BREATHE WE WREATHE WE WEAVE WE SIEVE WE ARE! SING! SING! NOW CLING! CLING! DON'T EVER LET THE ROCK GO! CLING!). (29)

While Alaimo has argued that "the substance of the water itself insists on submersion, not separation," we can see in Hulme's work that this relationship to water is gendered. ${ }^{121}$ The character's husband, of course, finds 
it "fuckingbloodyannoying" that "she joined the early Sinkers after running away with the pot plant" (3I). His relationship with the pāua has been separatist and antagonistic; as his wife explains, "I told him it was Not a Good Idea to go and gut and eat sashimi style that last ordinary he found" (28). The use of the term "ordinary" here is significant, referring to one of two varieties of pāua (the other being yellow foot). The pāua is radically distant from human shape in its lack of face, skin, and limbs, yet at the same time it can resemble hyperembodied flesh. ${ }^{122}$ Hulme's experimental fiction thus does not take us outside the usual bodily ambits but, rather, brings our attention more closely to them, even submerging into them, suggesting, like Haraway, that "we learn to be worldly from grappling with, rather than generalizing from, the ordinary." 123 Haraway claims she "is a creature of the mud, not the sky," ${ }^{124}$ but we might expand this in Hulme's work to include creatures of the ocean, particularly given the submersive discourse in becoming "one of the Sinkers."

Hulme's allegory of a waterworld does not depict an aquatopian or aquadystopian totality. Rather, her characters' submersion into the ordinary oceanic raises ethical questions. Alaimo has argued that "submersing ourselves, descending rather than transcending, is essential lest our tendencies toward Human exceptionalism prevent us from recognizing that, like our hermaphroditic, aquatic evolutionary ancestor, we dwell within and as part of a dynamic, intra-active, emergent, material world that demands new forms of ethical thought and practice." She concludes, "Thinking with sea creatures may also provoke surprising affinities." 125 Hulme takes this to be reciprocal in that both sea creatures and humans "become the thought" and thus relinquish their form.

In the conclusion to the story, Hulme suggests that these affinities cannot be reached through the mainstream apocalyptic narrative of much science fiction. Her male character resists "going poetic like the fucking ex," travels to Washington, D.C., to push "the button," and then complains that he has no companions to join him in the mobile home he has equipped for the postnuclear world. He feels he is "the only real brain left, being the only real man left" and is frustrated that he cannot find a woman to create "man on top again as it always was, and always should've been" (32). Like countless Cold War films that reckon women's survival merely in terms of their reproductive futurity (including the New Zealand film The Quiet Earth), ${ }^{126}$ the male narrator positions himself in terms of violent individualist agency, having "saved" the earth (from ongoing mutation) through its nuclear destruction. In contrast, he notes, "All the sheilas had either sunk or turned 
into something else or been so fucking dumb they hadn't built themselves a mobile" home (32). In contrast to the narrator of "Floating Words," the well-prepared, solitary figure in a changing climate is a subject for critique. While he renders himself as the solitary brain, the others have "become the thought" and merged with their pāua companions or into other formations.

Thus, the "pluperfect pāua" is a species that had been; it is a creature of the past because it is in the process of ongoing change. In this story, to be a species is to always be involved in mergers, not all of them pleasant or even desirable. ${ }^{127}$ His argument of "man on top again as it always was" has ethical implications for our anthropocentric models of climate change in which humans are rendered as singular, agential, and exceptional species. It leads us to ask how anthropocentric narratives have, on the one hand, the ability to emphasize human agency (in terms of creation or cessation of climate change), yet on the other hand, continue an often masculinist framework of "man on top" of a feminized earth; a figure understood as exceptional to other species and ontologically isolated from the nonhuman world. This Manthropocene narrative renders a "fall" from an always unrecoverable "nature." This reckons back to the New Zealand state's expropriation of the foreshore and seabed as nonhuman resources to be exploited, as dead matter, versus Māori claims of custodianship through kinship relation to nonhuman life as taonga.

Haraway observes that "species is about the dance linking kin and kind," 128 a kind of queer kinship Hulme has demonstrated in her work but one that, while it may include scientific modes of understanding the more-thanhuman world, is also specifically tied to the Māori concept of whakapapa, which establishes webs of kinship and obligation with always animate others. This offers a geontological (or sea ontological) model of thinking through interspecies worldings, providing an alternative narrative history to state claims to the ocean that are influenced by corporate mining prospecting. As Teone Taare Tikao has observed, "The sea was before the land and sky, cleansing, joining, and where the sea meets the land there are obligations there that are as binding as those of whakapapa." ${ }^{129}$ These obligations and the narratives used to inscribe them are not necessarily legible to the dominant technocratic responses to climate change, highlighting the urgent need for a broad engagement with a diversity of narratives and ontologies of the Anthropocene.

This chapter has emphasized genealogy and interspecies worldings as an embedded and embodied narrative for the ordinary oceanic futures of the 
Anthropocene. We might contrast an important difference between Māori renderings of an interspecies subject and a postcolonial subject who, due to colonial history, is often decolonized through a decoupling from nonhuman nature. Yet to decouple from nature/place in Aotearoa New Zealand is to remove the very basis of Māori claims of ontology and sovereignty over land, foreshore, and seabed. The emphasis here on adaptation might also be explained in terms of the subject's ontological and political relationship to place and state. An argument for mitigation against carbon emissions is not, in Hulme's work, a viable discourse because, from an Indigenous perspective, that is the privilege of a citizen aligned with and represented by the state. In settler colonies such as the United States and Aotearoa New Zealand, the Indigenous subject is necessarily under erasure for the state to make its claims for legitimacy and foundation. Thus, an effective narrative strategy would be one that challenges the geontological ground on which the state derives its sovereignty. Although she has not addressed the "sea grab" directly, we might read Hulme's oceanic imaginary as an allegory in line with a cultural politics that destabilizes state claims of mineral extractivism, a way to imagine narratively a relationship to the oceanic through ordinary modes of merger and submersion—an adaptive, interspecies hermeneutics for the rising tides of the Anthropocene. 


\author{
CHAPTER FIVE
}

\begin{abstract}
An Island Is a World
If Pacific Islanders were whales, people would make more effort to conserve them. -Pacific delegate to 1992 climate change convention

An appreciation of the transience of things, and the concern to rescue them for eternity, is one of the strongest impulses in allegory. -walter benjamin, The Origin of German Tragic Drama
\end{abstract}

While the previous chapter explored a new oceanic imaginary for the Anthropocene, this concluding chapter turns to the island, an allegorical figure that has a long and rich history in relationship to empire, environmentalism, and the planet. Scholarship on the Anthropocene has tended to emphasize the temporal aspects of the perceived rupture with nonhuman nature, laying out various chronologies of the Anthropocene's genesis, its complex rendering of deep time and accelerated time, and its anticipation of a catastrophic future. So while the opening chapters of this book were organized around temporal constellations of the Anthropocene (plantation agriculture, radioactive militarism, the waste of globalization), these final two chapters focus on the spatial claims in Anthropocene discourse, particularly as they employ allegory to signify the disjunctive scalar relationship between island and planet. Thus, the grand narrative of the Anthropocene is parochialized by the allegory of the island as a world. As Walter Benjamin observed, modern allegory renders a universalizing, transcendent figure of "Nature" 
into a more localized "nature-history," providing a space for dialectical historicism and ontological engagement with place.

In the previous chapter I demonstrated the ways in which the totality of ocean space is necessarily rendered in its smaller allegorical parts through the ship, the shore, and the body, particularly a sea creature. Next to the ship, the island is perhaps the most essential constellation for figuring the planet. Due to the part-for-whole function of allegory the island concept of bounded space has been a popular synecdoche for our "Earth Island." This spatial allegory of finitude has become all the more relevant in an era in which Anthropocene scholars warn of humans reaching the limits of their "planetary boundaries." While it has a long colonial history, the concept of the island continues to be a useful constellation because, as Fredric Jameson observes, "in order to understand the world, ... a being of such enormous complexity that it can only be mapped and modelled indirectly," we need "a simpler object that stands as its allegorical interpretant."

Yet allegory, as I have demonstrated throughout this book, is a mutable and often paradoxical mode of representation that reflects a disjunction between part and whole and an aporia between the continuity of the self and the world. This is what Benjamin meant by the "antinomies of the allegorical." 3 For all of its engagement with history (as master narrative), allegory is also deeply anachronistic, particularly in how it participates in the erasure of the modernity of island spaces. In his work on how the world is figured by allegorical narratives of micro- and macrocosmos, Angus Fletcher argues that synecdoche assumes a "static" relation between the whole and the part, unlike metonymy, which claims a causal and therefore active relationship. ${ }^{4}$ Yet I would argue that if we engage the history of colonial discourse of islands, as I do here, we can see that this relation between island and Earth is also a metonymic one, in that ecological damage to the island is understood as staging the potential for planetary apocalypse. In that way, the island is understood not just as the Earth, but as its anticipated future, demonstrating how space is rendered into time.

The island is a trope, and for the west its spatial fetish is tropical due to the long history of European colonization of Caribbean and Pacific archipelagoes. As has been demonstrated by many scholars, western discourse has configured the tropical island in terms of vulnerability, isolation, remoteness, nonhuman nature, and historical "purity" in terms of species development and of a culture isolated from the flows of modernity. The two powerful allegorical modes that are closely tied to islands, utopia and dystopia, arose 
from a long history of European colonization. Thousands of utopian Robinsonades were written after Daniel Defoe's Robinson Crusoe (1719), and the isolated, atemporal, primitive tropical island narrative continues to inspire: the castaway plot of the U.S. reality television show Survivor was itself modelled after the Swedish program Expedition Robinson. As many have shown, utopian and dystopian island allegories are constitutive to empire as either imaginative fulfillment or critique..$^{5}$ In the words of the historian Richard H. Grove:

The isolated oceanic island, like the frail ships on the great scientific circumnavigations of the seventeenth and eighteenth centuries, directly stimulated the emergence of a detached self-consciousness and a critical view of European origins and behaviour, of the kind dramatically prefigured by Daniel Defoe in Robinson Crusoe. Thus the island easily became, in practical environmental as well as mental terms, an easily conceived allegory of a whole world. Contemporary observations of the ecological demise of islands were easily converted into premonitions of environmental destruction on a more global scale. ${ }^{6}$

Grove's research established that the earliest European conservation practices were instituted in the tropical island colonies, particularly where the islands were figured as laboratories for botanical and other kinds of experimentation. ${ }^{7}$ Yet he notes that the rise of ecological degradation ties very closely in the historical record with utopian island narratives, a "paradox" he relates to the "full flowering ... of Edenic island discourse during the midseventeenth century." ${ }^{8}$ This paradoxical relation between ecological rupture and utopia is, of course, familiar to postcolonialists, given the long history of mystifying the violence of empire through romance, sentimental travel stories, plantation georgics, and island idylls_-stories that Mary Louise Pratt has famously called "anti-conquest" narratives.?

With the turn to the crisis of climate change, these narratives have taken a visual turn, one of the primary modes of allegorical representation. Moreover, visual allegories are vital for imagining climate change, particularly sea-level rise. The boundedness of island space has been represented in the history of empire and militarism and now finds a renewed purchase in the turn to "saving the planet." This chapter examines the rise of climate change documentaries that figure the tropical island as the world in relation to a long history of Edenic island narratives that is being regenerated in the discourse of the Anthropocene, with particular attention to Benjamin's claim that 
mourning over the ruins of history is the "mother" of allegories. ${ }^{10}$ Benjamin argued that modern allegory, with its fascination with ruins, was "at home in the Fall." Similarly, the climate change documentaries I examine here adopt an Edenic discourse refitted for Anthropocene melancholia in an age of extinctions, human and otherwise.

Each chapter of this book has examined a different formal and ideological function of allegory, engaging fiction, poetry, visual arts, and in this particular chapter, film. My overall interest has been to show the great range of what Gayatri Chakravorty Spivak refers to as "allegorical tendency", ${ }^{11}$ demonstrating how, because allegory is context- and history-specific, it can be an adaptive and even subversive mode, as we have seen in its use to critique plantation slavery, nuclear militarism, and neoliberal and state violence. While allegory is polysemous, it is also well known for its imbrication in tradition, particularly when engaging master narratives such as the islandas-the-world. While Jameson argues that allegory is necessary, even inevitable, to critique, he admits that if "allegorical master narratives [are] a constant temptation, this is because such master narratives have inscribed themselves in the texts as well as in our thinking about them; such allegorical narrative signifieds are a persistent dimension of literary and cultural texts precisely because they reflect a fundamental dimension of our collective thinking and our collective fantasies about history and reality." 12

Of course, we want to complicate the "we" of both allegory and Anthropocene thinking, and the focus of this book has been to parochialize both. To that end, the climate change documentaries I discuss here speak to "collective fantasies," particularly from the global north, of a prelapsarian Eden, a space where islanders live in harmony with "nature." These pastoral fantasies are not only associated with dominant western cultures but can also be strategic critiques from Indigenous and postcolonial positionings..$^{13}$ In keeping with the allegory of the Fall, modernity and knowledge of climate change rupture the islanders' relationships to an Edenic island life that is depicted as outside capitalist relations of production and consumption. "The age of the Anthropocene is an age of grief," journalist Jeremy Hance has argued, suggesting the urgent need to create new narratives and rituals for marking an era of unprecedented precarity. ${ }^{14}$ Yet I would suggest that, in facing the great extinction narratives of the Anthropocene-or, as Justin McBrien and Ashely Dawson have argued, the Necrocene ${ }^{15}$ - these films rely on established colonial tropes of mourning. In fact, they recuperate the pernicious colonial fantasy of the "vanishing native" in which the white westerner 
tries to salvage-and mourn - the loss of what the global north has effectively destroyed. While an earlier era of anthropologists treated Indigenous cultures in terms of ethnographic allegories of extinction, a new body of climate change films frames the Indigenous island subject as an "endangered species" in the wake of anthropogenic sea-level rise. Or, as the unnamed conference delegate quoted in the epigraph suggests, if the Indigenous island subject were charismatic megafauna, perhaps a greater political response would result.

Anthropocene scholars are increasingly theorizing and modeling multiscalar relations in an effort to understand a rapidly changing planet. The eighteenth-century colonial encounter with the Pacific Islands allowed for the western circumnavigation of the globe and to render it as a finite space. The Pacific Islands were vital to European allegories of romance, utopia, dystopia, and modeling the island as the world. Fittingly, the figure of the tropical island, particularly the low-lying atolls and islands of Tokelau, Tuvalu, Kiribati, and the Marshall Islands, are now gaining attention for the ways in which the threat of sea-level rise, which disproportionately affects the tropics, anticipates a planetary future. In popular media, there has been a remarkable rise in the discourse of "sinking islands, vanishing worlds." 16 The tropical island, emblematic of "postglacial drowning," 17 is becoming a new site of visual allegories of the Anthropocene. Film documentaries are necessarily engaged in the process of world-making, ${ }^{18}$ but this model of the world signifies the politics of finitude, a recognition of spatial and inhabitable limits for both island and globe.

The process by which the Pacific Islands and Islanders are framed in visual media to represent the planetary future, I argue, is entangled with allegorical discourses of salvage ethnography: "Allegory flourishes at times of intense cultural disruption, when the most authoritative texts of the culture are subject to reevaluation and reassessment ... the whole set of sociopolitical values that these texts are to justify and propound is what is really at issue." 19 The plethora of documentaries made by westerners about a fall from a tropical garden Eden in the years immediately after $9 / \mathrm{II}$ is not coincidental in that they respond to a millennial feeling about the ending of both (western) culture and nonhuman nature due to threatening and unknown global forces. ${ }^{20}$

Allegory is about the exchange of meanings, between figures of the local and global as well between figures of tradition and the present-in other words, between space and time. These documentaries trade in historical terms with a long colonial discourse of salvage ethnography, a nineteenth- and 
early-twentieth-century movement that was concerned with capturing the "vanishing native" before colonial demise. Like many climate change discourses that frame a need for the global north to "rescue" the innocent, nature-loving Indigenous subject, these films trade in allegories of what I term "salvage environmentalism."

Similar to the ethnographic allegories examined by James Clifford, these films "present themselves as fictions of learning, the acquisition of knowledge, and finally of authority to understand and represent another culture." 21 While a generation of salvage anthropologists was focused on a "dying culture," these contemporary allegories must be reread in light of their attempt to capture a "dying nature" in an era of anthropogenic climate change called the Necrocene. In other words, they trade in the extinction narratives of the Anthropocene, using allegory as a mode of mourning to register the "appreciation of the transience of all things, and the concern to rescue them for eternity." 22 As I explain, the films' allegory of "salvage environmentalism" decouples the Pacific Islander from continental modernity and mystifies the causal links between industrialized continents and sinking islands. The final part of the chapter turns to the performance poetry of the Marshall Islander Kathy Jetñil-Kijiner to demonstrate the ways in which, by parochializing the Anthropocene and engaging the pedagogical strains of allegory, we might create new webs of obligation and responsibility.

\section{Visualizing Island Laboratories}

The tropical island was long figured by colonists as a colonial laboratory in which experiments on a small scale were extrapolated to the planet. As such, the islands were allegorized as remote and primitive yet, at the same time, at the vanguard of colonial and military science, from botanical gardens to nuclear testing. The antinomies of allegory that Benjamin brought to the foreground help us see the ways in which these island allegories are determined by paradox. Nissology, the study of islands, has long been concerned with this paradox, in which islands are depicted as isolated and remote yet seem to be under constant surveillance, visualized, studied, and visited by colonizers, militaries, anthropologists, filmmakers, and tourists. ${ }^{23}$ This paradox is made possible by many colonial epistemes, such as the reduction of complex archipelagoes into isolated islands, the denial of the history of modernity for island subjects, and the perceived threat of Indigenous cosmopolitanism associated with the "travelling native." 24 This isolated island 
trope, despite the U.S. President's claim that the island of Puerto Rico is too far across a "big ocean" to secure assistance after the devastations of Hurricane Maria, has long been critiqued in the field of island studies. ${ }^{25}$

This chapter focuses on the resurgence of the Micronesian islands in the U.S. imaginary-first, as spaces of nuclear colonialism since their annexation by President Harry Truman, and second, as visual allegories of planetary climate change. In the past and currently, these representations of the Pacific rely on the construction of the island as both laboratory and isolate, utopian and dystopian space of nature and technological modernity. The myth of the island isolate, perpetuated by the U.S. Atomic Energy Commission (AEC) and adopted by ecologist and anthropologists alike, helped to justify the detonation of hundreds of thermonuclear weapons in the Marshall Islands (Micronesia) and in French Polynesia. ${ }^{26}$ In selecting the atolls for nuclear detonations, the island was treated as an allegory of our terraqueous globe in that its decimation anticipated a nuclear planetary future. Moreover, like the Apollo space mission photos of our "Earth Island," both the planet and the island were visualized as figures of finitude in spatial and, given the threat of nuclear annihilation, temporal terms. Blowing up the island was understood in a part-for-whole relationship in which one could make predictions for the destruction and irradiation of the Earth. For instance, out of the twenty-three islands of Bikini Atoll in the Marshall Islands, three were atomized due to U.S. nuclear weapons tests, the most notorious of all being the fifteen megaton hydrogen weapon Bravo (1954). As discussed in chapter 2, the radiation from Bravo permeated the global atmosphere, creating the world's first anthropogenic "environmental refugees," and catalyzed the field of atmospheric chemistry that led to our current understanding of climate change and the Anthropocene. ${ }^{27}$

Despite their violent imbrication into modernity, Micronesian islands and people were consistently interpellated as "isolated" and "primitive" in the films of the AEC, which were part of a concerted propaganda program to gain support for the testing, despite widespread protest. ${ }^{28}$ The Cold War was largely fought on visual grounds, so picturing the Micronesian atoll as laboratory was vital to military strategy. Hundreds of Hollywood photographers and filmmakers were hired by the U.S. military during the Cold War to produce a spectral aesthetics of violence, a photographic and cinematic archive of the wars of light distributed by print media such as Life magazine. These AEC films are now ubiquitous on the Internet. For instance, Operation Crossroads at Bikini Atoll (1946) has been claimed as "the most 
photographed event in history," recorded on I.5 million feet of motion picture film (eighteen tons) and more than one million still pictures. ${ }^{29}$ In the words of the AEC, "One of the most important and dramatic elements in the dropping of the bomb is the photographic element." ${ }^{\text {"30 }}$ Displaced Bikinians were given photographs of the explosions that irradiated their home, ${ }^{31}$ an exchange of an ancestral island for a photograph of its irradiation. The U.S. military produced postcards of nuclear explosions as keepsakes for their soldiers, many of whom, like the Marshall Islanders of Bikini and neighboring Rongelap, were already carrying mementos of light in the form of radioactive strontium, carbon, and iodine.

This connection between nuclear radiation and photography is close and historical; participants in the tests were required to wear film badges that would fog when "safe" radiation levels were exceeded, replicating the behavior of the nineteenth-century photographic plates that led to the discovery of radioactivity itself. Visualizing the newly annexed Micronesian islands from a military or "aerial view" was integral to their assimilation into the U.S. imaginary (and beyond), ${ }^{32}$ and many of the images of the nuclear tests feature the red and orange light of the explosions in ways that mimic the tropicality of island sunsets. This period of island nuclearization is simultaneous with the turn of U.S. ethnography to the Pacific, a turn funded by the Navy. Consequently, at the height of the nuclear tests, anthropologists began writing articles about Pacific cultural areas as "laboratories" of "pure cultural radiation unaffected by outside contacts." 33

While eighteenth-century European empires reconfigured tropical islands as Edenic greenhouses, presumably ahistorical places for social and biological experiment, U.S. testing programs such as Operation Greenhouse, a series of four proto-hydrogen nuclear bombs detonated on Enewetak Atoll in 195I, used allegory to figure the Pacific island as a "natural" laboratory devoid of human history, subject to the "god's eye" view of the ubiquitous cameras of the AEC (figure 5.I). In a collapse of dystopian and utopian allegories, other images figure the nuclearized island as a space of tourism and leisure, creating a new logic of what Teresia K. Teaiwa, with Louis Owens, termed "militourism." 34 The second test of operation Greenhouse is known for its image of VIP spectators lounging on a patio in Adirondack chairs at the Officer's Beach Club at neighboring Parry Island, dressed in shorts and sitting back casually while their goggles capture the nuclear flash in their lenses as if they are at the cinema (figure 5.2). The image captures the aesthetics of the flash and their pleasure in the visual consumption of the islands' destruction, without recognizing what 


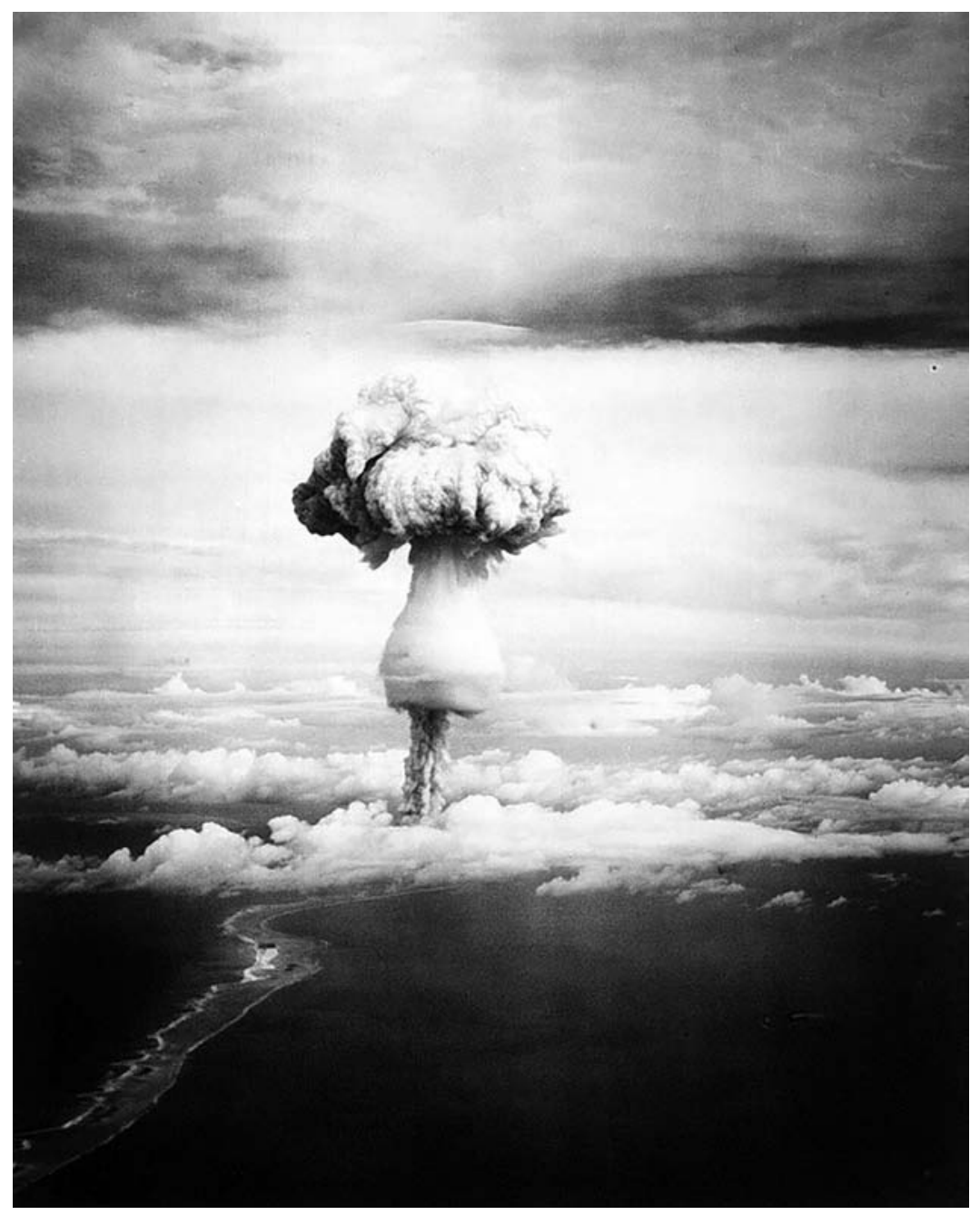

FIGURE 5.I. Nuclear test George, Operation Greenhouse, Enewetak, 1951. 


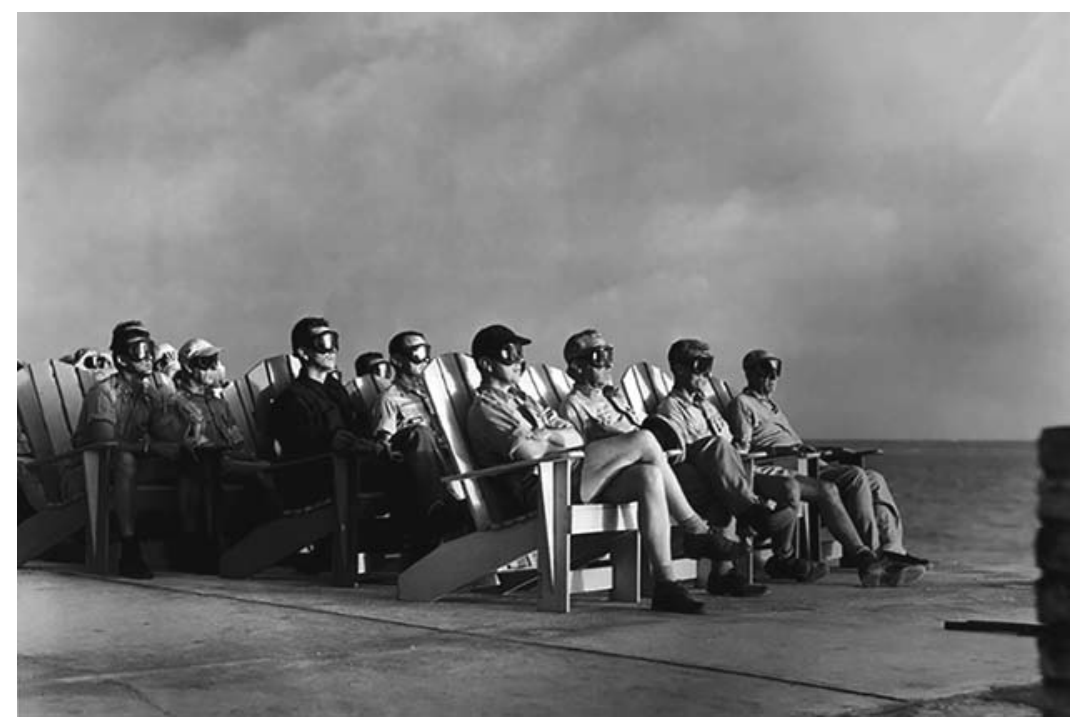

FIGURE 5.2. Nuclear test vips, Operation Greenhouse, I95I.

Rob Nixon calls the "slow violence" of nuclear militarism that U.S. servicemen and Pacific Islanders would carry in their bodies for generations. Runit Isletthe site of this explosive test as well as a 350-foot-wide crater from the Cactus test in 1958 -is currently leaking radiation from cracks in a cement dome placed over contaminated soil during the military cleanup. ${ }^{35}$ Like the presence of atmospheric carbon, militarized radiation is invisible to the naked eye and yet permeates the body in ways that uncannily exceed human temporal scales.

The U.S. military emphasized Pacific Island isolation-and even beachgoing, tropical leisure, as Teaiwa demonstrates in the transformation of the term "Bikini" from a nuclearized atoll to a sexualized bathing suit. ${ }^{36}$ But their attempt to quell fears of radiation distribution by figuring isolated islands was a complete myth when we consider that all sixty-seven nuclear tests were conducted in the complex geographies of atolls. The Marshall Islands, including Bikini and Enewetak, are in fact atolls, a series of islands, islets, and reefs formed around a sunken volcano. This relational geography was suppressed by the allegory of the (isolated) singular island as a world, which an emergent field of "archipelagraphy" is mapping. ${ }^{37}$ In nuclear discourse, islands are never understood relationally in terms of an oceanic geographyconnected to other atolls and archipelagoes through historical, familial, or political networks of relation. ${ }^{38}$ As a reductive allegory, the island in this 
way becomes reduced to pure and passive "nature," activated by visual technologies such as nuclear weapons and the documentary camera.

\section{Allegories of Scale}

The long history of colonialization in the Pacific has led to a concerted effort to remap the myth of the island isolate through a more globalized and relational allegory of an island-as-a-world. Thus, Epeli Hau'ofa's influential essay, "Our Sea of Islands," argued that the legacies of colonial belittlement that render the Pacific "islands in a far sea" need to be reinvigorated by a more accurate and world-enlarging view. ${ }^{39}$ His conceptual mapping of the "people from the sea" was visionary, ${ }^{40}$ but Hau ofa could not have foreseen the ways in which climate change, particularly sea-level rise, has transformed islands that are in fact threatened by the expansion of the sea and faced with a new era of what increasingly is being called environmental or carbon colonialism. ${ }^{41}$ The preamble to the Micronesian Constitution states, "The seas bring us together, they do not separate us. Our islands sustain us, our island nation enlarges us and makes us stronger." Yet a different oceanic imaginary is rising today due to the threats of climate change. In his address to the United Nations General Assembly in 2009, President Emanuel Mori of the Federated States of Micronesia invoked the history of Pacific voyaging and concluded that "sadly ... the ocean that has always nurtured us is becoming the very instrument of our destruction." ${ }^{42}$

A new vocabulary is developing in Oceania in which words for climate change, which did not exist in Indigenous languages, are being formed. Agencies in the Fijian government, coining the term "draki veisau" to describe global climate change, have recently produced a Fijian glossary of English words for acidification (asidetaki), carbon market (makete ni kaboni), greenhouse gases (kasirara), and sequestration (cerumi ni kaboni dokosaiti). ${ }^{43}$ At the University of the South Pacific and other educational organizations, new pedagogies, programs, and knowledges are being developed to communicate across a broad spectrum of those affected, using an archipelagic framework to encourage the circulation of information between urban island centers and the more rural satellite atolls and islands. ${ }^{44}$ Since the low-lying islands and atolls of the Marshall Islands, Kiribati, Tokelau, and Tuvalu are the first to feel the impact as the waters begin to rise, new cartographies of the Pacific are being drawn in which the smallest atolls, which never used to appear on world maps, are now attracting global attention. So recently have they 
become signifiers for the world's environmental future that the globe at the Copenhagen Climate Summit in 2009 did not include them.

Discourses of the Anthropocene and of global climate change are not synonymous. In recent years, I have attended conferences about climate change in the Pacific and about the Anthropocene in the U.S. and Europe. The conversations could not be more different and, perhaps, are mutually unintelligible. One group speaks of the salinization of staple crops and water supplies, migration, culture, the land, the ancestors, and children. The other speaks of species, history, temporality, modernity, and the west. Generally speaking, climate change discourse is concerned with embodied place and community memory; Anthropocene discourse is concerned with modalities of time and abstract space. Yet these differences are fitting — and, I would argue, necessary-because claiming to speak of an enormous system such as climate requires multiple narrative and visual registers, as well as scales. ${ }^{45}$ Bringing together Anthropocene discourse with its localizing, parochializing counterpart calls attention to the necessity for multiscalar allegorizing, including its disjunctures and antinomies.

While there are notable differences, Anthropocene and climate change discourses share an engagement with the visual and with allegory. This is evident in the veritable cottage industry of climate change documentaries about the Pacific Islands by U.S., New Zealand, Australian, and European filmmakers, which visualize sea-level rise for a global audience in which the threatened island figures as the world. Representing climate change is challenging because it is a process that can be measured only by turning to deep geological time beyond the human and because, like nuclear radiation, greenhouse gases cannot be seen by the naked eye. A quandary has been noted for metropolitan audiences of the global north in that the visual evidence for climate change is positioned at a distance, located in tropical atolls and at the Earth's poles, often favoring nonhuman species and polar "wilderness." ${ }^{46}$ These distancing effects and the emphasis on nonhuman nature have raised questions about their efficacy for western audiences and whether filling in a "knowledge deficit" is enough to inspire political action. ${ }^{47}$

Consequently, visualizing the temporal expanse and spatial depth of global climate change poses particular formal challenges. ${ }^{48}$ Barbara Adam and Julie Doyle have convincingly argued that communicating environmental risks in western contexts means relying on the visibility of materiality, an effective form yet one that may detract from what is "latent" and immanent" such as radiation damage and other forms of "slow violence." ${ }^{49}$ These challenges of 
representation are well known to visual studies. Early in the twentieth century, Siegfried Kracauer famously argued that "the 'image-idea' drives away the idea; the blizzard of photographs betrays an indifference toward what the things mean." ${ }^{50}$ This has been a concern to activists who are faced with a growing response of "green fatigue" or "climate change fatigue," particularly in relation to the question of history. Building on Kracauer, Roland Barthes has lamented that we are "no longer able to conceive of duration, effectively and symbolically; the age of the photograph is also the age of revolutions, contestations, assassinations, explosions, in short, of everything which denies ripening. ${ }^{51}$ Film privileges the immediacy of the spectacle, ${ }^{52}$ a point well understood by the AEC, which capitalized on the dramatic explosions of nuclear weapons all over the United States and Micronesia and sought actively to suppress the invisible slow violence of irradiated ecologies. The slow violence of climate change poses similar challenges to historical representation and understanding. Nevertheless, film relies on affective imagery in its ability to provide narrative and oral testimonies, graphs, emblematic images, sounds, and visceral senses of climate change that suggest that visual media can be especially influential.

Global warming is a long, cumulative effect of industrial capitalism, a slow violence that exceeds the narrative boundaries of the temporal pace of modernity. One of the contradictions pointed out by scholars of climate change is that the science, which measures the deep time of the earth's systems and makes projections far into the future, is not commensurate with the everyday experience of human communities and their observations of weather. ${ }^{53}$ This creates a bifurcation between the experience of place and time and, to go back to the opening of this chapter, a breakdown in the allegorical relationship between part and whole figured through island and earth. Sheila Jasanoff remarks, "Climate facts arise from impersonal observation whereas meanings emerge from embedded experience. ${ }^{54}$ Moreover, climate "is spatially unbounded. It is everywhere and nowhere, hence not easily accessible to imaginations rooted in specific places." 55 To bring the scales of climate and weather together cognitively, the allegorical visualization of climate change and testimonies to its bodily experience (which may produce both evidence and empathy) becomes crucial. Therefore, the distribution of images of stranded polar bears on ice floes, or Pacific Islanders wading through flooded villages, creates an imaginary for the Anthropocene and becomes the means by which those in the global north may recognize, empathize with, and perhaps become inspired to mitigate climate change. ${ }^{56}$ 
In post-9/I c climate change documentaries, the atoll nation of Tuvalu and its residents have become what Carol Farbotko and Heather Lazrus describe as the embodied figures for the "articulated stress" of climate change, as well as "ventriloquists for a western crisis of nature." 57 This allegory has ample precedent: turning to the island past as a figure for the environmental collapse of the global future creates a temporal economy of scale. Thus, through a collapse between island and world, the "premodern past" is harnessed to "our" global warming future. ${ }^{58}$ This is a common rhetorical move in environmental discourse: the environmental mistakes of the past are thought to be immanent in the present and foretell the future. This allegory has been popular in environmental determinist narratives that figure islands such as Rapa Nui (Easter Island) as spaces of "ecocide" in popular books such as Easter Island, Earth Island (1992) and Jared Diamond's bestselling Collapse (2005).59 In this case, the island is used as a cautionary tale for a planetary future that is determined by western agents in the present, erasing the presence of contemporary Rapa Nui peoples and making enormous assumptions about humans as a universally determined species. Mick Smith has turned to how this use of "environmental allegory" has become a "morality tale" but argues convincingly that there are "ethical dangers in treating places and peoples allegorically, as moralized means (lessons) to satisfy others' edificatory ends." ${ }^{60}$ Projecting late capitalist modes of unbridled consumption onto the Indigenous past, these ahistorical narratives have been debunked by the archeological record yet remain persistently popular. ${ }^{61}$ This is what in another context Anna Lowenhaupt Tsing has called a "conjuring of scale": the allegory of Earth as island has become so naturalized that its conjuring becomes invisible. ${ }^{62}$

While western environmental discourse may draw on temporally collapsed narratives to inspire activism on the part of its audience, these narratives mystify history. The scalar collapse between island (past) and world (future) bifurcates time and denies what Johannes Fabian terms "coevalness" between human societies. These narratives fall into the familiar "allochronic," or other-time, representation of a "vanishing native" who disappears at the moment of his or her incorporation into the western cinematic world. ${ }^{63}$ Hence, in the films I discuss "the Native" figures as the human past, depicted in a close relationship with nonhuman nature. This is not surprising, given the long history of colonial discourse about isolated islands and peoples who enter history only through colonialism, salvage ethnography, and now climate change. However, in the recognition of the Anthropocene, the island becomes a symbol for the planetary future in that its sinking is understood as 
the canary in the coal mine of atmospheric pollution. ${ }^{64}$ In other words, space (the island) enters the future and therefore temporality via climate change, whereas the figure of the Indigenous islander (associated with a vanishing culture) embodies the vanishing past, epitomizing the de-temporalizing logic of what Renato Rosaldo has famously termed "imperialist nostalgia." ${ }^{5}$

\section{The Water Is Rising}

Scientists have lamented their inability to galvanize the public about the importance of mitigating rather than adapting to a warming planet, and in that area literature and the arts have come to play an increasingly important role in creating a new visibility of allegorical forms that service climate change pedagogy. This has opened up a dialogue about the affective dimensions to environmental communication. Research suggests that visceral depictions of climate change are memorable to the public and presumably can have an impact. ${ }^{66} \mathrm{It}$ is on this basis of visualizing climate change, and bringing those who are the most affected by sea-level rise to one of the largest per capita greenhouse gas emitters (the United States), that inspired the "Water Is Rising" performance event in 2010, an enormous undertaking by one of my colleagues at the University of California, Los Angeles (UCLA), to employ the arts in the service of raising awareness of the ongoing U.S. "dispossession of the atmosphere." 67

The Pacific Islands' contribution to atmospheric carbon is negligible; however, many of the region's nations are at the forefront of developing new sustainable energy programs, reducing consumption, protecting millions of acres of oceanic territory, and, as active participants in the Alliance of Small Island States (AOSIS), leading the United Nations and the world in terms of legislating global climate change mitigation. ${ }^{68}$ This agency and activism, however, has not significantly featured in western visual representations about climate change, which prefer to focus on a narrative of "culture loss" outside history and politics. ${ }^{69}$ To that end, my colleague raised funds to support the recruitment of performers from Kiribati, Tokelau, and Tuvalu to share both traditional and new dance forms they had developed to raise consciousness of the ways in which the salinization of their taro beds, flooding of their schools and homes, and loss of their ancestral burial grounds were making atoll life untenable. In an era of American-style denial of climate change, the Pacific Islanders of the "Water Is Rising" event were expected to be the visible evidence of the reality of global warming. In fact, the anticipated 
embodiment of climate change was deemed threatening enough to catalyze complaints from climate change deniers against UCLA for even staging the event.

I first met the "Water Is Rising" dance troupe at UCLA, their first stop on a forty-two-day tour that would take them to universities and performance centers across the United States. As I crossed the quad to the building in which we were to host a roundtable on climate change, I could see the younger members of the troupe, dressed in T-shirts, lavalavas, jeans, and flip-flops, sitting in a large circle in the grass outside the building, playing guitars, and singing Bob Marley songs. When the preview to the performance began, they were dressed in the ceremonial garb of intricately woven pandanus; they performed in the varied styles of their homes and languages (without English translation) and were introduced as traveling from some of the most isolated and remote islands of the Pacific. The dances, which represent complex knowledge systems in the Pacific, were presented as entertainment without translation, history, or context. ${ }^{70}$ The juxtaposition of reggae-singing youth and the performance of an isolated indigeneity was striking and something I had already encountered in the UCLA marketing of the event. On the (now defunct) "Water Is Rising" website, the biography of Mikaele Maiava, the artistic director of the troupe from Tokelau, explains that he studied overseas, worked for nearly a decade for the United Nations, and has been active in various international Indigenous forums on the environment and climate change. In an article originally titled "Remote Pacific Islanders at Risk," published in UCLA's online periodical for faculty and staff, Maiava is pictured, his name is misspelled, and his ample biographical note is reduced to "a native of Tokelau." ${ }^{.11}$ Ignoring the long history of colonialism, the article states that all of the islanders cultivate traditional crops (coconut, breadfruit, taro), and that the island lacks a wage economy. It repeatedly mentions the islands' remoteness and isolation "their simple way of life," and it includes a conciliatory statement from the faculty organizer that, in regard to carbon emissions, "There is no finger-pointing or accusations that 'Americans are messing up our lives."'72

The UCLA marketing of this event got me thinking about how the majority of North American audiences were receiving Pacific Islanders as the harbingers of climate change, rendered as figures of an isolated, precapitalist and nature-loving culture that were being appropriated to share their culture and to provide, in the words of the article, "a human face of climate change." Yet that framing seemed to fall short of any critique of U.S. petrocapitalism 
and consumption, even though individual artists from the troupe have been critical of the fossil fuel industry and through Pacific Climate Warriors, participated in a canoe blockade in Australia of the largest coal port in the world. ${ }^{73}$ In fact their motto is "We are not Drowning. We are Fighting!" In contrast, the production of "salvage environmentalism" is dependent on the figure of isolated island and islander and is also constitutive to the remarkable output of documentaries that focus on the threatened atolls of the Pacific.

These documentary films have been somewhat lumped together in recent reviews, ${ }^{75}$ so in this section I would like to unpack some of their rhetorical devices, particularly in terms of their use of allegory, imperialist nostalgia, and elegy. The flurry of documentaries began with Rising Waters: Global Warming and the Fate of the Pacific Islands (2000), which, unlike the others that follow, positions climate change in terms of regional history and political activism. Directed and written by the American Andrea Torrice for P BS and featured at the United Nations Earth Summit in 2004, the film foregrounds the voices of local people in Samoa, Kiribati, and the Marshall Islands, as well as their representatives in AOSIS, an intergovernmental organization that represents nearly 30 percent of the world's developing countries and has been vital to lobbying for island interests in all the United Nations summits about climate change since 2000. It includes scenes at the Conference on the Environment and Development in Rio in 1992 and the Framework Convention on Climate Change (UNFCCC) meeting in 1997, at which island nations attempted to lobby for reduced emissions in the negotiation and signing of the Kyoto Protocol. Shifting scenes between coastal villages in Samoa and the offices of the United Nations in New York, the film stitches together connections between the Pacific Islands and industrialized centers, drawing on scientific and personal testimonies from oceanographers, geographers, and climatologists from and in the Pacific Islands such as Penehuro Lefale and Patrick Nunn rather than externalizing scientific knowledge outside the region. The documentary examines both the legacy of nuclear weapons testing in the Marshall Islands and makes a direct connection to U.S. pollution of the atmosphere. Juxtaposing footage of the relocation of the Bikinians in 1946 with that of the Rio summit in 1997, the narrator remarks, "The Marshallese, like their Pacific Neighbors, worry that in the not-too-distantfuture, they may have to leave their homes. Those fears come from a sense of history repeating itself. The United States, the country that forced them into exile half a century ago, now poses the biggest threat to their hopes 
for a better future." 76 Unlike the films that depict a white person traveling to the Pacific to articulate their nostalgia for the "vanishing native," Rising Waters has Lefale visit his fellow climatologist Vivien Gornitz in New York City, where, a decade before Hurricane Sandy, she comments on the lack of awareness that Manhattan is surrounded by water, the possibility of intensive flooding, and the loss of "connection to the land." Lefale responds to the islandness of Manhattan and contrasts that "for us in the Pacific ... the sea and the land is part of us, you know." In a film that shows concrete political steps taken in the name of colonial and neocolonial redress, it avoids the salvage environmentalism of nearly all of the films that follow.

After $9 / \mathrm{II}$, a series of films reifying the distance between the modern west of the filmmaker and the slow corruption of the South Seas idyll were produced between $200 \mathrm{r}$ and 2010 . Their timing and popularity, particularly circulating around the years 2003-2004, suggests the influence of a post- 9/II global disaster narrative that now extends to the environment in which, as Mike Hulme observes, "climate is catastrophe." 77 The films' thematic content of "[Indigenous] humans struggling with a hostile environment" to survive, ${ }^{78}$ might be tied back to an era of salvage ethnographies, evident in the U.S. films of the early twentieth century, such as the work of Robert J. Flaherty, creator of Nanook of the North (1922) and the first documentary of Samoan life, Moana (1926). Unlike the film Rising Waters, the majority of the documentaries are less concerned with the island in the world than with constructing an allegorical island as the world.

While popular lore suggests that Flaherty's Moana was not a box-office hit because the island tropics did not offer the kind of gripping "man against nature" plot featured in the Arctic Nanook, this survivalist plot is the central motif of the post 9/II climate change documentaries. In fact, these films have attracted an extraordinary number of awards, suggesting their appeal to the western audiences for which they were made. To that extent, it seems that the visual production of the figure of the "vanishing" island native is doing renewed cultural work in the twenty-first century. Certainly the funding mechanisms for documentary films encourage the production of familiar narrative tropes to render the films marketable. For example, the poster for the New Zealand documentary Paradise Drowned: Tuvalu, the Disappearing Nation (200I), by Wayne Tourell, features the caption, "See the world's most endangered country"(figure 5.3). ${ }^{79}$ All of the title images of these films feature the ocean, where waves figure prominently; some overwhelm the camera, while other shots are taken from what is depicted as a disturbing submarine view. 


\section{See the world's most endangered countrity}

\section{Paradise Drowned}
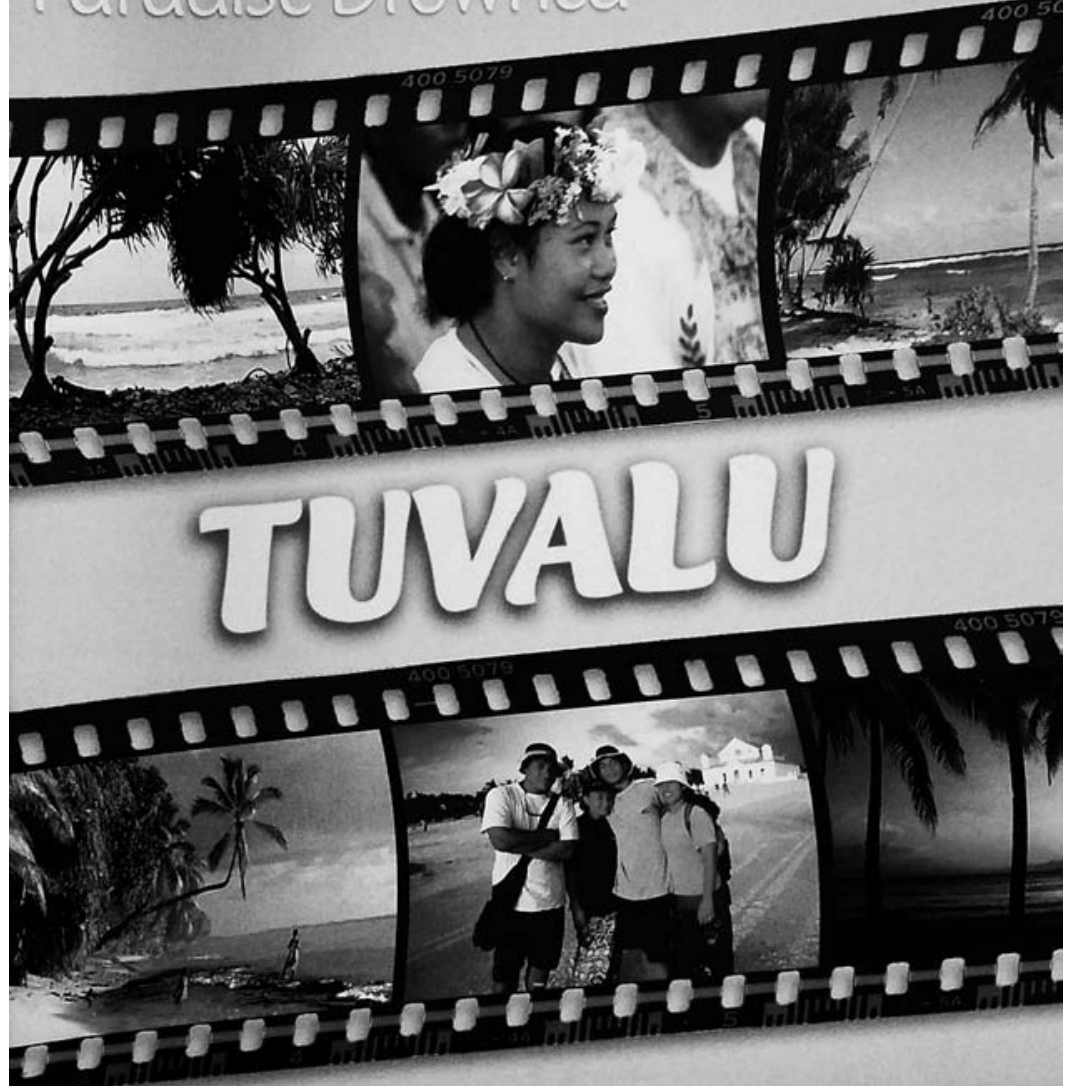

$$
\text { The Lisuppearing Waitien }
$$

FIguRE 5.3. Poster for Paradise Drowned (200I). 
Images and references to oceanic flooding both invoke past narratives of biblical catastrophe and function as a future allegory for sea-level rise.

Out of all the threatened atolls, Tuvalu seems to be the major focus because of its accessibility, an expanding tourism industry now catering to westerners interested in seeing the "world's first disappearing nation," 80 and a population well versed in the English-language discourse of global climate change. In 2004 and 2005, three films focusing on Tuvalu were released: The Disappearing of Tuvalu: Trouble in Paradise, Time and Tide, and Before the Flood. ${ }^{81}$ The Dutch film King Tide: The Sinking of Tuvalu, by Juriaan Booij, appeared in $2007 .{ }^{82}$ The films about Tuvalu take place in Funafuti, the capital, rather than the other outlying islands that are far more reliant on a subsistence economy. The anthropologist Niko Besnier has raised the question as to why Funafuti has been the sole focus when, due to food imports, a harbor, and an airport (built by the U.S. military in World War II), the atoll is far less vulnerable to sea-level rise than the other eight outlying islands. ${ }^{83}$

Although no Pacific atolls have had as much press and cinematic coverage as Tuvalu, western documentary makers in subsequent years turned to other threatened islands and atolls. The New Zealand film There Once Was an Island: Te Henua e Noho (2010), winner of eighteen awards, turned to Takuu island in Papua New Guinea, and the Australian film The Hungry Tide focused on Kiribati. ${ }^{84}$ In contrast to their North American and European counterparts, the antipodean filmmakers have focused more specifically on how sea-level rise is catalyzing the issue of migration to regional metropoles. While these films give "a human face" to the vexed political and juridical issue of "climate refugees," ${ }^{" 5}$ they harness the characters" personal mourning for their inundated islands to figure as the western audience's anticipated loss of a universal "nature." More specifically, the migration narrative engenders what in another context James Clifford has termed the "ethnographic pastoral," 86 which I adopt here as a term to indicate how the urban industrialized audience might mourn for the small-scale intimacy and seeming simplicity of a subsistence economy tied to "nature" and not dominated by neoliberal labor regimes. While this genre of salvage environmentalism documentaries was prevalent for the first decade or so of the new millennium, the filmmakers seem to have moved to projects outside the Pacific, and no new feature-length documentaries have emerged recently about these particular atolls. ${ }^{87}$

Over the decade in which these documentaries were produced, the salvage environmentalism genre began to solidify. While there was some diversity in one or two films that featured colonial history or nuclear testing or 
that incorporated political struggles at the Copenhagen Climate Summit in 2009, these documentaries tell the story in predictable ways. The films open with images of the ocean and waves, use an aerial view to locate the island on a map, depict arrival scenes by boat and plane, and focus almost exclusively on rural aspects of island life; they feature children playing on the beach, sunsets, palm trees, and men fishing, and they foreground a community culture in terms of dance performances and other celebrations. This "pacific" scene is then interrupted by testimonies of people who show beach erosion, including the loss of former homes, the threat to ancestral burial sites and taro grounds, and, in all of the Tuvalu films, a trip by boat to an islet that has lost all of its trees due to a cyclone. Allegorically, this cyclone damage stands in for climate change, just as the annual king tides, when journalists flock to the atolls, stand in for sea-level rise. Other films mourn the arrival of modernity through interviews with subjects who are considering migration to metropolitan centers. In the case of Time and Tide, Tuvaluan returnees from Aotearoa New Zealand lament, presumably like the audience, Funafuti's growing urbanization, imported food, and modern consumption culture that is contributing to a significant problem with disposable waste, which is featured in nearly all the films as an sign of the island in ruins. Benjamin claimed of Baroque allegory that "it is fallen nature which bears the imprint of the progression of history." ${ }^{88}$ Nature-history, in his work, represented the collapse of universalized transcendent "Nature" into nature, subject to history and decay. Yet in these films, history-which is to say, modernitycontinues to be bracketed out of the colonial allegory of island nature and its dehistoricized mirror, the "Native."

\section{Nature in Ruins}

In the majority of these climate change documentaries, atoll life is quite beautifully imagined in the romantic light of the setting sun over the ocean, reflecting what the film suggests is a dying culture. This dying culture is at once the death of an untouched pastoral past (and South Seas idyll) and the planet's future. The keywords of the films are paradise, disappearance, and endangerment, remarkably like the kind of extinction narratives in documentaries about the loss of nonhuman species. As the epigraph suggests, "If Pacific Islanders were whales, people would make more effort to conserve them." In recovering the "vanishing native" for the film before she or he is presumably destroyed by modernity, the filmmaker is positioned in a long 
history of salvage anthropology, using the realism of documentary film to depict a kind of mourning that we might liken to "imperialist nostalgia," to borrow from Renato Rosaldo.

This nostalgia is particular to a long history of colonial South Seas discourse in which travel narratives, novels, paintings, and later films allegorize an Edenic island lifestyle imagined outside modernity, history, empire, and labor. This trope of the island tropics is evident in testimony from Rob Bindler in the press kit on the Time and Tide website: "The heart wrenching and beautiful film TIME AND TIDE is like one of Gauguin's rare, foundobject sculptures, simultaneously celebrating a precious, edenic time and place while calling attention to the fact that it is perhaps lost forever." ${ }^{89}$ In a similar vein, in the trailer for the film King Tide: The Sinking of Tuvalu, an English-speaking narrator depicts the nation of Tuvalu as "small," "remote," endangered, and sinking. It reiterates all of the allegories of decline of these climate nostalgia films: the sea, fishing communities, children in the water, village life and flooding, testimony of increasing tides, evidence of garden flooding, traditional dance, migration narratives, a white male scientist, and a Tuvaluan testifying that they can trust in God because he already told Noah there will be no more earthly flooding. ${ }^{90}$ Benjamin has written extensively about the allegorist's obsession with melancholy, the corpse, and ruins. Accordingly, the King Tide trailer opens with haunting music and a disembodied voice speaking over the image of an empty, floating canoe: "Unless urgent actions are done against climate change in fifty years' time, the world will just come and collect our bodies from the sea."

In writing about the ways in which documentary films stage a world, Bill Nichols points to their metonymic, and thus allegorical, function:

The text presents a metonymic representation of the world as we know it (the sounds and images bear a relation of part to whole; they partake of the same order of reality as that to which they refer).... Where fiction achieves a "reality effect" by sprinkling doses of authentic historical references across the realm of its creation-costumes, tools, vehicles, known places, or prominent figures-the same references within documentary serve as tangible evidence from the historical world in support of an argument. ${ }^{91}$

Certainly, the personal experiences of the Pacific Islanders in these films function as "tangible evidence in support of an argument" for climate change, but it represents experiential evidence rather than anything drawn 
"from the historical world." This is compounded by the fact that all of these films (except for the self-reflexive Before the Flood) employ the disembodied voice of the filmmaker/narrator so that direct address to the audience "endorses the tradition of disembodied, universalized knowledge. Such speech, like the clinical gaze, requires the acceptance of a discipline that detaches knowledge from the body that produces it." ${ }^{\text {2 }}$

Documentary films are organized not by space and time but by argument, allowing them to cut from scene to scene, or edit on-screen commentary in ways that make sense only by following the oral argument depicted by expert witness, voice-over, and off-screen narration. Thus, these films, while purporting to figure the island as a world — such as the claim by Christopher Horner and Gilliane Le Gallic's film that "we are all Tuvalu"-bifurcate the experiential knowledge of Pacific Islanders from the omniscient, disembodied voice of the narration. This harks back to the division between the experience of weather versus changes in global climate, suggesting an aporia between the island and the world, foregrounding the antinomies of allegory.

It is the lack of historical engagement in these films that brings about this aporia, because the past is relegated to the short-term remembrance of extraordinary king tides or childhood memories of sandy beaches, rather than locating Tuvalu into deeper time and the larger world. This puts community memory in tension with the filmmaker's authority. ${ }^{93}$ A narrative of history is impossible because these filmmakers are committed to an allegory of mourning for a lost "nature" that figures as Indigenous culture. Most of the films lament Tuvalu's entrance into modernity in 2000, when the country leased its national internet domain ".tv" to a Californian company, bringing millions of dollars into the economy, restructuring Funafuti in particular, and making the filmmakers' arrival all the more prescient for capturing the "vanishing native" just as she or he was succumbing to capitalist development and a wage economy. "Extinction lies at the heart of capitalist accumulation," but these films bracket out the ways in which capitalism is part and parcel of the history of empire. ${ }^{94}$

In their staging of an ethnographic pastoral, an Eden before the fall, the filmmakers necessarily avoid the complex history of Tuvalu because it would challenge the narrative of the isolated tropical Eden. Yet Tuvalu is perhaps one of the most complex atoll cultures of the region in that it has experience radical change and migration, particularly since the mid-nineteenth century, when the first Samoan missionaries arrived and converted the islands to Christianity. The population was decimated by the kidnapping 
and recruitment by Peruvian slave traders in the 1860 s..$^{95}$ Up to two-thirds of the population of some of Tuvalu's atolls were lured onto Peruvian slavers that disguised themselves as missionary ships and men of the cloth. ${ }^{96}$ None of them returned. Shortly afterward, Tuvalu's relationship to land and labor was reconfigured by the expansion of German copra plantations into the region, which entailed imported labor from Rotuma, Fiji, Niue, and the Marshall Islands. This, in turn, created complex intermarriage relationships between Tuvaluans, particularly Nukulaelae, and many other island communities across the Pacific. ${ }^{97}$ Since the turn of the century, many Tuvaluans have worked in phosphate mines in Nauru and worked for the U.S. military when Funafuti was a strategic American airbase in World War II.

As I mentioned in the introduction to this book, militarism has been the elephant in the room in both climate change and Anthropocene discourses. ${ }^{98}$ Thus erasure of the wartime era of Tuvalu is particularly egregious, because one of the major studies of climate change on Funafuti suggest that sea-level rise derives from the U.S. military's dredging of the lagoon for wartime ships, permanently altering the currents and buildup of sediments and creating erosion, as well as various "earth works" projects. ${ }^{99}$ Consequently, it was not ".tv" that brought capitalism and modernity to Tuvalu. Since independence, many people have been employed by the Tuvalu Maritime Training Institute, which prepares is percent of the population for work in shipping companies all over the world. As a British and then Australian colony that achieved independence only in 1978 , Tuvalu has long been imbricated into networks of empire and the wage economy, despite the reification, in most of these films, of an isolated Indigenous culture whose biggest threat is twenty-first-century capitalism and sea-level rise.

These documentaries trade in what Susan Sontag referred to as the "imagination of disaster," but they differ in their engagement with modernity. In her critique of science-fiction films, Sontag focused on what she called "a dispassionate aesthetic view of destruction and violence-a technological view" that we might see in Hollywood-style apocalyptic climate change films such as $2012 .{ }^{100}$ In contrast, these climate change films specifically bracket out modernity and technology from island life, visibly depicting slow violence and a narrative of mourning about the loss of a subsistence mode of living in which capitalism and empire, including carbon colonialism, are only distantly implicated.

Rosaldo defines imperialist nostalgia as when "agents of colonialism long for the very forms of life they intentionally altered or destroyed." ${ }^{101}$ I quote 
from him at length because this foregrounds the return of certain allegorical forms that are rekindled in an era of carbon colonialism:

Imperialist nostalgia revolves around a paradox: A person kills somebody, and then mourns the victim. In more attenuated form, someone deliberately alters a form of life, and then regrets that things have not remained as they were prior to the intervention. At one more remove, people destroy their environment, and then they worship nature. In any of its versions, imperialist nostalgia uses a pose of "innocent yearning" both to capture people's imaginations and to conceal its complicity with often brutal domination... "We" (who believe in progress) valorize innovation, and then yearn for more stable worlds, whether these reside in our own past, in other cultures, or in the conflation of the two. ${ }^{102}$

This yearning, in western aesthetic terms, is elegy, a form that has been vital to memorializing violence. ${ }^{103}$ In the Romantic tradition, nonhuman nature figures as scenery or backdrop, "an analogue for what has been lost," as Timothy Morton points out. When the poet-or filmmaker-tries to mourn the loss of nature itself, the "sounding board ... becomes the object of lamentation" creating a shift from mourning (which can locate the lost object) to melancholia without a method of redressing loss. ${ }^{104}$

Writing about climate change, Morton notes that (European) "ecological elegy weeps for that which will have passed given a continuation of the current state of affairs"-which is to say, a future anticipation. In contrast, these films weep for a loss of culture that figures as a loss of "nature" or the planet. ${ }^{105}$ These films complicate Morton's argument; they are able to circumvent this issue of the lost object by using Pacific Islanders as the figures for nonhuman nature, reinvigorating a well-worn colonial trope. Therefore, the continental viewer mourns the loss of island culture and life-worlds as an analogue for destruction of the global environment. By bracketing out empire, capitalism, U.S. militarism, and carbon colonialism, these films trade on a "salvage environmentalism" that recuperates an ahistorical and nostalgic nonhuman nature by de-temporalizing the Pacific Islander while suppressing the issue of the viewer's complicity. ${ }^{106}$

Most of these films have fallen into the well-worn tread of Tristes Tropiques in that, like Claude Lévi-Strauss, they are mourning a loss that they never experienced, that is projected back into the time before their arrival to 
Indigenous shores. Rosaldo reminds us that "salvage work" is meant to record a culture before it disappears in the wake of modernity, and in this case, modernity is paradoxically nature and anthropogenic climate change. The salvage narrative that once helped to authorize funding for a generation of anthropologists in the Pacific under British, French, and U.S. empires is now catalyzing a new generation of journalists, filmmakers, and scholars who are often funded by state agencies, and fly across the world to descend on Kiribati, Tuvalu, and Tokelau to interrogate the residents about nothing but climate change. ${ }^{107}$ Unlike the allegorist as collector that figured in chapter 3 , the impetus to salvage in these films is not to recuperate the profane "refuse of history," as Benjamin would have it. ${ }^{108}$ Since they offer no critique of petrocapitalism or the mechanisms of consumption that create global warming, they fail as allegories to offer a pedagogy or incentive for future action. In these films, island "culture" is recuperated to catalyze a melancholic turn over the loss of a global "nature," which itself disappears because, in Anthropocene discourse, "nature is us." 109

Salvage work has the potential to "criticize destructive intrusions of imperialism" and to be used to critique the colonial center. ${ }^{110}$ Rather than dismissing these films altogether, which is tempting, I suggest that this island imaginary, as misrepresentative as it may be of the people and of history, may use an effective narrative strategy for an audience, to quote from $\mathrm{Mi}$ chel Serres, that is "indifferent to climate except during vacations when they rediscover the world in a clumsy arcadian way." 111 Salvage environmental films reflect a new idiom of a well-worn trope, appealing to those who "pollute what they don't know, which rarely hurts them and never concerns them." 12 This may seem like a conservative move, to allow for the efficacy of the way that salvage environmentalism relies on colonial narrative tropes to motivate politically unaware audiences. As anticolonial scholars, we expect some kind of representational "truth" from documentary as a genre. Yet these expectations may fall into the trap of overlooking the allegorical tendencies of realism, which, by appealing to nonfiction, erases its authorizing agents and constructions.

The coining of the term "documentary" derives from a review of Robert Flaherty's representation of a Samoan community in Moana, suggesting a long history of visual representations making truth claims about the Pacific. ${ }^{113}$ His work has been located squarely in the world of salvage ethnography; in commenting on his ethnographic films, Flaherty described his desire to "show ... the former majesty and character" of Indigenous people 
"while it is still possible-before the white man has destroyed not only their character, but the people as well." ${ }^{114}$ As Elizabeth Cowie points out, "In secular societies, truth is established through argument supported by evidence, which becomes 'fact' [through the] evidence of the filmed reality." 115 Yet documentaries, like all discourses, are caught in discursive and symbolic systems. In this case, the majority of these salvage environmental films are catering to the powers of the global north (including Australia), nations that have far more political clout to mitigate climate change. As such, if we foreground the work of these films as allegories, it may challenge "the moraland political-requirement to distinguish between the real and illusory" that constitutes "Western culture and is part of a privileging of the serious over illusion, the imagined, and fantasy, which are usually assumed to be the domain of fiction." 116 In other words, if we bring them into a discourse of the antinomies of allegory, which are always already about the disjunctive and necessarily incomplete relationship between part and whole, we elucidate the paradox rather than seek synthesis. Moreover, parochializing the Anthropocene means reflecting on the difference in not only narratives but audiences, recognizing the limits of universalizing both. It is the letting go of totalities on the side of both production and consumption, even as we necessarily employ them to tell stories of global environmental change.

\section{Weaving the Strands of Obligation}

There is a sense of déjà vu in some recent climate change discourses, a point Mike Hulme has argued in tracing out the return of climate determinism and in Kyle Powys Whyte's work on the ongoing climate apocalypse for Indigenous peoples. ${ }^{117}$ Until the early twentieth century, the colonial version of climate determinism reduced the peoples of the tropics to a torrid and languid climate, claiming they were incapable of producing civilization or modernity. The salvage environmental films I have discussed also limit Pacific Islanders to responding to or resisting the modernity of climate change. Ironically, nonhuman nature, or the weather, becomes a modern historical agent capable of producing change while the "Native," in Clifford's argument, can "either resist or yield to the new but cannot produce it." 118 The new form of climate determinism, Hulme argues, can be seen in how climate science modeling is being used as a universal determiner of political, social, and cultural futures. Climate reductionism is a scientific trend that extracts climate from a myriad of variable factors to predict migration, economics, disease, 
state infrastructural collapse, civil war, and other calamities without engaging other disciplines or studies, such as the humanities and social sciences. Oddly, in this era of what is being called "neoenvironmental determinism," climate becomes variable, but human behavior is not. As seen in the salvage environmental films, "The possibilities of human agency are relegated to footnotes, the changing cultural norms and practices made invisible, the creative potential of the human imagination ignored." 119 While not denying the very real threats posed to the inhabitants of low-lying atolls, we might call attention to the history of western constructions of vulnerability, as well as the rendering of danger, risk, and catastrophe that allows the filmmaker to "salvage" the scene for western consumption. ${ }^{120}$

While this book has focused particularly on the rise of Anthropocene and climate change discourse and its allegorical articulations, this concern with the scale of the global environmental crisis is not necessarily the immediate focus for most postcolonial and Indigenous writers and artists. ${ }^{121}$ In fact, issues of migration, sovereignty, race, sexuality, gender, decolonization, and health continue to be the primary focus for Caribbean and Pacific Island literature, arts, and film. For all of the tremendous academic production around climate change and the Anthropocene in metropolitan centers, it is not the determining discourse elsewhere. As Dipesh Chakrabarty has remarked, "Global warming is, one may be led to think, simply not as global an issue as globalization." 122 In a region facing many different challenges, climate change is not the central subject of Pacific Island literary, cultural, and visual production, ${ }^{123}$ although external funding agencies certainly encourage the shaping of community issues to be placed in this frame. ${ }^{124}$ When it is addressed, it is largely through the initiative of development and arts grants that originate from the larger carbon emitters, such as the United States and Australia, although this is rapidly changing.

I return to the performance poem "Tell Them" that opens this book because it offers a far more complex allegory figuring the local and global in a "tidalectic," to borrow again from Kamau Brathwaite. ${ }^{125}$ Kathy JetñilKijiner challenges the ethnographic pastoral by using Indigenous relations of giving that foreground the webs of obligation that connect across islands and continents, as well as between poet and audience. Moreover, it brings us back, movingly, to the disjuncture between the embodied experience of weather and the universalizing discourse of climate. The root of obligation, Serres writes, is ligare (to bond, to weave). I conclude this chapter, and the book, with the work of Jetñil-Kijiner, who has become an international 
celebrity since her moving performance at the opening ceremony of the United Nations Climate Summit in New York in 2014.

While she has recently published her critiques of U.S. nuclear testing and of climate change in the poetry collection Iep Jaltok (2017), my focus here is on the visual performance of her poetry, which is much more widely distributed by online media such as her blog and YouTube channel. ${ }^{126}$ Her gripping performance poem "Tell Them," recorded at the 2012 Olympics Poetry Parnassus, does not employ an aerial, god's-eye view of the tropical island, as the documentaries do. Instead, the camera angle places the poet high above the audience, with the cold stormy skies of London swirling behind her. Immediately we are placed in a relationship with a larger-than-life figure and a dynamic speaker and landscape. This is an allegory about the urgency of climate change for islands, but it does not employ the familiar tropes of Edenic idylls, ahistorical utopias, or dystopian mourning and melancholia. Her poem invokes some of the same tropical island imagery that we see in the documentaries: "fine white sand," "sweet harmonies ... of songs," and "papaya golden sunsets," but they are intertwined with everyday modernities such as an island "clogged with chugging cars" and Styrofoam cups of Kool-Aid. The focus on the ordinary in this narrative of climate change, as discussed in the previous chapter in relation to the work of Keri Hulme, foregrounds the ways in which the human is not exceptional to nature and deflates the Cold War narratives that render the meeting of the human and nonhuman as inevitably apocalyptic. Moreover, it also speaks to an argument made by Amitav Ghosh about the limitations of rendering ecological change in the bourgeois narrative tradition and the illustrative possibilities of poetry in the anthropocene. Ghosh demonstrates that anglophone poetry "has had a long and intimate relationship with climatic events" and intimacy-precisely in the moment of exchange-is the idiom that drives the structure of Jetñil-Kijiner's poetry. ${ }^{127}$

Jetñil-Kijiner's blog site and poetry are structured around the basket, "Iep Jeltok," which she translates as a "basket of poetry and writing" given to the reader/audience. ${ }^{128}$ Importantly, this basket metaphor is gendered and about relation: in Marshallese tradition, "iep jeltok" signifies a basket facing toward the speaker, foregrounding material and cultural exchange in a matrilineal society. ${ }^{129}$ The basket is also a major figure for Indigenous women's artistic labor and about weaving together connections and obligations across the Pacific. These bonds are legally established with the "compact of free association" Micronesian states have with the United States. This grew out 
of the U.S. annexation of Micronesia in 1946 to develop a base for its military and to conduct three decades of nuclear testing, which irradiated and displaced thousands of Marshallese, a history that Jetñil-Kijiner describes in her earlier poem "History Project." ${ }^{130}$ In a shift from invisible irradiation to the visibility of sea-level rise, this colonial relationship between the United States and the Republic of the Marshall Islands is producing a new generation of ecological effects. In speaking about the imminent threat of losing the islands to the sea and framing it as a matter of national security to the United Nations Security Council in 2013, the former Marshallese Senator and Minister of Foreign Affairs Tony deBrum observed that "the people of the Marshall Islands are not strangers to being moved around in the name of somebody else's peace and security. Displacement as a means to take land for military activities is not something new to us." ${ }^{131}$

In "Tell Them," Jetñil-Kijiner offers her "friends in the States" a gift: handcrafted jewels from the sea, "black pearls" and "cowry shell" earrings, placed in hand-woven baskets, products of women's love and labor. ${ }^{132}$ Inside this basket is a message, which is an allegory for the poem that we are asked to pass on. Scholars of allegory have long observed its uneven methods of exchange between scales, between figures, and between narrative and audience. Smith suggests that we might shift from "the moral economy of allegory" as a mode of unequal exchange (in which the allegorical lesson from "ecological morality tales" benefits the global north) and consider allegory in terms of the openness of the gift. ${ }^{133}$ Thus, Jetñil-Kijiner's presentation of the basket to her reader/audience calls attention to the obligations woven into this relationship. We must not just receive but "tell them" about the complexity and history of the Marshall Islands, as well as its threats from climate change and sea-level rise. Her use of the basket as gift is in keeping with Indigenous socialities in Oceania in which, as Marilyn Strathern and others have demonstrated, the center of the social network is not the individual but the relation itself. ${ }^{134}$

Allegory often incites action and stages a transformative lesson for the reader/viewer, which this poem invokes through the repeated imperative "tell them." Here the author is both weaver of earrings, a gendered gift, and writer of "a message" that appears nestled within the poem just as the letter appears in the basket. Her command to the reader is to "wear these earrings" to ordinary, everyday spaces of exchange and mobility such as "the grocery store, the corner store/and while riding the bus"; this may inspire others to ask from where the gift derives, and the reader will then name "the Marshall Islands" 
and "show them where it is on a map." After the process of naming and mapping, the reader is asked to "tell them" about the Marshall Islanders whom she then describes. Unlike the homogenous representation in the salvage environmental films, her human figures are exceedingly complex, modern, contradictory, and ordinary. The universals claimed by the Anthropocene detract from questions about obligation and accountability. As such the allegorical telescoping of the poem between the specificity of local, ordinary place and planetary change are staged in a "tidalectic" that insists on their connection. ${ }^{135}$

"Tell Them" produces an allegory of Marshallese history, reciting the origin stories of the islands, which "were dropped/from a basket/carried by a giant" and mentions the histories of voyaging canoes and the "finest navigators," then turns to the artistic production of women, the "sweet harmonies/of grandmothers mothers aunties and sisters." The Marshallese are both humans and nonhuman; they are "skies uncluttered/majestic in their sweeping landscape" and "dusty rubber slippers/swiped/from concrete doorsteps." The people are "hot nights" as much as "shards of broken beer bottles/burrowed beneath fine sand." Influenced by Hau'ofa's work on Pacific voyaging cultures and networks of trade and kinship, Jetñil-Kijiner declares an embodied relationship in that "we are the ocean," borrowing the title of his essay collection.

Whereas the climate change documentaries reduce Pacific Islanders to a kind of climate determinism, Jetñil-Kijiner stages an allegory of Marshallese history that turns to climate change only after a long history that ranges from creation stories to urban modernity. Only after reciting these constellations, as the camera angle switches between frontal and side perspectives, does she then declare, "after all this / tell them about the water." She concludes with the imperative, "but most importantly tell them/we don't want to leave [we] are nothing without our islands." Most of the salvage environmental films I discuss stage migration as the central story to Pacific Island futures; here Jetñil-Kijiner refuses to entertain that plot. There are multiple reasons for this. Journalists of the white settler cultures of Australia and New Zealand have been framing climate change in terms of its inevitable fate and xenophobic fears of the invading masses, two narratives the poet refuses to accept. ${ }^{136}$ Ending the poem with the defiant "we don't," "we've never," and "we are nothing without our islands," Jetñil-Kijiner refuses to accede to discourses of extinction and migration, and in that refusal she places the obligation on the reader to determine an alternative plot. Emphasizing the ways in which the earrings and the basket she has made for her audience travel, like her words, the poet creates new webs of obligation in which we are held accountable. 
Anthropocene narratives of extinction, like modern allegory, arrest the concept of history as progress and bring forward the (re)discovery of nature as history, and the human as geological agent. To Benjamin, "Death digs most deeply the jagged line of demarcation between physical nature and significance," suggesting that nature is both allegory and death. ${ }^{137}$ This is not an allegory of redemption from death (or extinction), because there is "no guaranteed ... salvation." 138 This is why the ragpicker, the beachcomber, and the allegorist (discussed in previous chapters) are all so critical to deciphering and making visible the animated ruins and their associated narratives. As allegorists and interpreters of allegory, collectors and storytellers, we are left with an archive of petrified ruins, corpses, "irresistible decay," technofossils, and the refuse of history to which we are both related and obligated.

The Anthropocene suggests that death is not simple cessation but a transformation from one state to another, in an exchange, as Jetñil-Kijiner suggests, that entails obligation and accountability. "Tell Them" is a narrative of the ways in which culture is produced through women's labor, their material and literary craft, as well as an imperative to a global audience to continue the story. It shifts the Anthropocene discourse from spectatorship to participation and active engagement. As in the follow-up poem she delivered at the un Climate Summit in 2014, Jetñil-Kijiner's use of gerunds emphasizes the people "marching," "petitions blooming from teenage fingertips," as well as:

families biking, recycling, reusing,

engineers dreaming, designing, building,

artists painting, dancing, writing,

and we are spreading the word. ${ }^{139}$

In this way she renders not only the island-in-the-world, but a vital imperative for the kind of cultural, political, and intergenerational labor required in "taking care of the future." 140 Indigenous "politics of care," as Mishuana Goeman has demonstrated, derive from narrative practice, from the sharing of "storied place" between human and nonhuman others. This caretaking, particularly its feminized and Indigenous constellations, is the untold story of the Manthropocene, Capitalocene, Necrocene, and Plantationocene streams in the academic contest for the historical primacy of the Anthropocene. ${ }^{141}$ "It is past time to practice better care" in an era that Donna Haraway terms the "Chthulucene," a tentacular and complex call for cultivating relations with our multispecies others. ${ }^{142}$ An ethics of care is constitutive to our being of (and on) earth/ Earth, and to our embodied relation to our futures, human and otherwise. 
NOTES

\section{INTRODUCTION}

Epigraph: Kathy Jetñil-Kijiner, “Tell Them,” Iep Jältok (Tucson: University of Arizona Press, 2017), 64-67.

All relevant material is on Kathy Jetñil-Kijiner's website at https://jkijiner .wordpress.com.

2 The term was first published in Paul J. Crutzen and Eugene F. Stoermer, "The 'Anthropocene,'” Global Change Newsletter, no. 4I (2000): 17-18. See also Jan A. Zalasiewicz, The Earth after Us (Oxford: Oxford University Press, 2008). On tidalectics, Kamau Brathwaite's use of island geography to break up the synthesizing European dialectic, see Nathaniel Mackay, "An Interview with Edward Kamau Brathwaite," Hambone, no. 9 (Winter 1991): 42-59.

$4 \mathrm{He}$, in turn, borrowed the phrase from Hans-Georg Gadamer: see Dipesh Chakrabarty, Provincializing Europe (Princeton, NJ: Princeton University Press, 2000). Chakrabarty, Provincializing Europe, 4.

6 Chakrabarty troubles the universalist narratives of the Anthropocene and makes a compelling claim for a different, species-based universalism that is not ontological: Dipesh Chakrabarty, "The Climate of History: Four Theses," Critical Inquiry, no. 35 (2009): 197-222. I have benefited from many conversations with Dipesh about this particular point. For early postcolonial responses to his provocation, see Ian Baucom, "The Human Shore: Postcolonial Studies in an Age of Natural Science," History of the Present 2, no. I (2OI2): I-23, particularly his arguments about species-being. See also Dipesh Chakrabarty, "Foreword," in Global Ecologies and the Environmental Humanities: Postcolonial Approaches, ed. Elizabeth DeLoughrey, Jill Didur, and Anthony Carrigan (New York: Routledge, 2015), xii-xv, and the discussion of the implications of his arguments for postcolonial ecologies in the introduction, II-I2.

7 "The Anthropocene represents, according to those who initially put it forward, a dangerous shift, and a radical rupture in Earth history. This rupture means that the Holocene can be no guide to the Anthropocene geologically or intellectually": 
Clive Hamilton and Jacques Grinevald, "Was the Anthropocene Anticipated?" Anthropocene Review 2, no. I (2015): 62.

8 Édouard Glissant, Caribbean Discourse: Selected Essays, trans. J. Michael Dash (Charlottesville: University of Virginia Press, 1989), I44. Following postcolonial methods, I disagree with Bonneuil and Fressoz, who argue against the rupture model because it "depoliticizes the long history of the Anthropocene": Christophe Bonneuil and Jean-Baptiste Fressoz, The Shock of the Anthropocene: The Earth, History, and Us (New York: Verso, 2016), xii. On the contrary, incorporating rupture as an analytic helps foreground the history of empire and violence.

9 This is discussed in more detail in chapter 5. See Michel Serres, The Natural Contract, trans. Elizabeth MacArthur and William Paulson (Ann Arbor: University of Michigan Press, 1995); Chakrabarty, "The Climate of History”; Sheila Jasanoff, "A New Climate for Society," Theory, Culture and Society 27 (2010): 233-50.

IO "Tell Them" is transcribed on her website and published in Iep Jältok (Tucson: University of Arizona Press, 2017), 64-67, but it is best seen in performance at https://www.youtube.com/watch?v=w9D88ST 9 qbw. The poem is discussed in more detail in chapter 5 .

II Former Foreign Minister of the Marshall Islands Tony deBrum has savvily reframed Marshallese climate threats as a "security issue" to the United States, explaining that the "displacement of populations and destruction of cultural language and tradition is equivalent in our minds to genocide": "Marshalls Likens Climate Change Migration to Cultural Genocide," RNZ News, October 6, 2015, accessed October 24, 2018, https://www.radionz.co.nz/news/pacific /286139/marshalls-likens-climate-change-migration-to-cultural-genocide. DeBrum is discussed in more detail in chapter 5 . For her commentary on the two degrees, see Jetñil-Kijiner's poem, commissioned by CNN: “Two Degrees," Iep Jāltok (Tucson: University of Arizona Press, 2017), 76-79.

I2 See Angus Fletcher, Allegory: The Theory of a Symbolic Mode (Princeton, NJ: Princeton University Press, 2012).

I3 Zalasiewicz, The Earth after $U_{s}$; Chakrabarty, "The Climate of History"; Nigel Clark, Inhuman Nature: Sociable Life on a Dynamic Planet (Thousand Oaks, CA: Sage. 20II); Kathryn Yusoff, "Geologic Life: Prehistory, Climate, Futures in the Anthropocene," Environment and Planning D: Society and Space 31, no. 5 (2013): 779-95.

I4 The Stratigraphy Commission of the Geological Society of London initiated an inquiry into determining evidence for an Anthropocene epoch in 2008, and that was taken up by the Anthropocene Working Group, which is examining evidence of visible, chemical, biological, and radiogenic markers: Jan A. Zalasiewicz, Mark Williams, Will Steffen, and Paul J. Crutzen, “The New World of the Anthropocene," Environmental Science and Technology Viewpoint 44, no. 7 (2010): 2228-31. On locating a "golden spike," see Simon L. Lewis and Mark A. Maslin, "Defining the Anthropocene," Nature 519, no. 7542 (2015): 
171-80. On the future retrospection of the Anthropocene, see Jan A. Zalasiewicz, Paul J. Crutzen, and Will Steffen, "Anthropocene," in A Geological Time Scale, ed. Felix M. Gradstein, James G. Ogg, Mark D. Schmitz, and Gabi M. Ogg (London: Elsevier, 2012), I033-40; Zalasiewicz, The Earth after Us. Kathryn Yusoff and Jennifer Gabrys, "Climate Change and the Imagination," WIREs Climate Change 2 (2011): 518; Zalasiewicz, The Earth after Us. Crutzen acknowledged this in his early work, arguing that these effects had largely been caused by only 25 percent of the world's population: Paul J. Crutzen, "Geology of Mankind," Nature 4I5 (2002): 23. Malm and Hornborg argue that it is "sociogenic" rather than anthropogenic: Andreas Malm and Alf Hornborg, "The Geology of Mankind? A Critique of the Anthropocene Narrative," Anthropocene Review I, no. I (2014): 62-69.

Sylvia Wynter, "Unsettling the Coloniality of Being/Power/Truth/Freedom: Towards the Human, After Man, Its Overrepresentation-An Argument," CR: The New Centennial Review 3, no. 3 (2003): 257-331, 260.

Joni Adamson, "We Have Never Been Anthropos: From Environmental Justice to Cosmopolitics," in Environmental Humanities: Voices from the Anthropocene, ed. Serpil Oppermann and Serenella Iovino (New York: Rowman and Littlefield, 2016), I55-73. See also Sylvia Wynter and Katherine McKittrick, "Unparalleled Catastrophe for Our Species? Or to Give Humanness a Different Future: Conversations," in Sylvia Wynter: On Being Human as Praxis, ed. Katherine McKittrick (Durham, NC: Duke University Press, 2015); Stacy Alaimo, Exposed: Environmental Politics and Pleasures in Posthuman Times (Minneapolis: University of Minnesota Press, 2016); Heather Davis and Zoe Todd, "On the Importance of a Date, or, Decolonizing the Anthropocene," ACME: An International Journal for Critical Geographies 16, no. 4 (2017): 76I-80; Kyle Powys Whyte, "Indigenous Science (Fiction) for the Anthropocene: Ancestral Dystopias and Fantasies of Climate Change Crises," Environment and Planning E: Nature and Space I, no. I-2 (2018): I-18.

I9 Walter Benjamin, The Origin of German Tragic Drama, trans. John Osborne (New York: Verso, 1998), 166.

20 Benjamin, The Origin of German Tragic Drama, 166-67.

2I Bruce Clarke, "Allegory and Science," in Energy Forms: Allegory and Science in the Era of Classical Thermodynamics (Ann Arbor: University of Michigan Press, 2001), 28. See also Fletcher, Allegory.

22 The foundation of this argument on islands is laid out in my introduction to Routes and Roots: Navigating Caribbean and Pacific Island Literatures (Honolulu: University of Hawai'i Press, 2007).

23 See Ursula K. Heise, Imagining Extinction: The Cultural Meanings of Endangered Species (Chicago: University of Chicago Press, 2016); Ashley Dawson, Extinction: A Radical History (New York: OR Books, 2016).

24 On empire as a process, not an event see Patrick Wolfe, "Settler Colonialism and the Elimination of the Native," Journal of Genocide Research 8, no. 4 (2006):387-409. On ongoing apocalypse see Joni Adamson, "Collected 
Things with Names Like Mother Corn: Native North American Speculative Fiction and Film," in The Routledge Companion to the Environmental Humanities, ed. Ursula K. Heise, Jon Christensen, and Michelle Niemann (New York: Routledge, 2017) and Kyle Powys Whyte, "Indigenous Climate Change Studies: Indigenizing Futures, Decolonizing the Anthropocene," English Language Notes 55 (March 2017): 153-62.

Bill McKibben, The End of Nature (New York: Random House, 1989).

26 Davis and Todd, "On the Importance of a Date," 774. See also Whyte, "Indigenous Science (Fiction) for the Anthropocene."

Tsing, quoted in Donna Haraway, "Anthropocene, Capitalocene, Plantationocene, Chthulucene: Making Kin," Environmental Humanities 6 (2015): 160.

28 See the dialogue in Elizabeth Johnson, Harlan Morehouse, Simon Dalby, Jessi Lehman, Sara Nelson, Rory Rowan, Stephanie Wakefield, and Kathryn Yusoff, "After the Anthropocene: Politics and Geographic Inquiry for a New Epoch," Progress in Human Geography 38, no. 3 (2014): 439-55. See also Yusoff's critique of the Anthropocene's "grandiose nature-culture divisions, the gendering of 'man' as the subject of this epoch, the imperial basis of western science, climate racism, uncritical social figures such as "humanity"': Kathryn Yusoff, "Anthropogenesis: Origins and Endings in the Anthropocene," Theory, Culture, and Society 33, no. 2 (2016): 8.

29 See William F. Ruddiman, "The Anthropogenic Greenhouse Era Began Thousands of Years Ago," Climatic Change 6I (2003): 26I-93; Lewis and Maslin, "Defining the Anthropocene"; Malm and Hornborg, "The Geology of Mankind?”; Jason W. Moore, "Anthropocene or Capitalocene?, accessed October I8, 2018, http://jasonwmoore.wordpress.com/2013/05/13/anthropocene -or-capitalocene; Jan A. Zalasiewicz, Colin N. Waters, Mark Williams, and Anthony D. Barnosky et al., "When Did the Anthropocene Begin? A MidTwentieth Century Boundary Level Is Stratigraphically Optimal," Quaternary International (20I4): I-8; Will Steffen, Paul J. Crutzen, and John R. McNeill, "The Anthropocene: Are Humans Now Overwhelming the Great Forces of Nature?," Ambio 36, no. 8 (2007): 6r4-21; Will Steffen, Åsa Persson, Lisa Deutsch, and Jan Zalasiewicz et al., "The Anthropocene: From Global Change to Planetary Stewardship," Ambio 40, no. 7 (2011): 739-6r; John R. McNeill and Peter Engelke, The Great Acceleration: An Environmental History of the Anthropocene since 1945 (Cambridge, MA: Harvard University Press, 2016). Walter Benjamin, in Susan Buck-Morss, The Dialectics of Seeing: Walter Benjamin and the Arcades Project (Cambridge, MA: MIT Press, 1997), 219. Compare this with Amitav Ghosh's meditation on climate change, which draws on the concept of the flash as a one if many "instances of recognition" of the relationship to nonhuman energies and presences: Amitav Ghosh, The Great Derangement (Chicago: University of Chicago Press, 2016), 5.

Chakrabarty, quoted in Ian Baucom, "History 4: Postcolonial Method and Anthropocene Time," Cambridge Journal of Postcolonial Literary Inquiry I, no. I (2014): 138 . 

(1972): 332 .

33 See Fredric Jameson, The Political Unconscious: Narrative as a Socially Symbolic Act (Ithaca, NY: Cornell University Press, 198I). See also Northrop Frye, Anatomy of Criticism: Four Essays (Princeton, NJ: Princeton University Press), 195.

34 Johannes Fabian, Time and the Other: How Anthropology Makes Its Object (New York: Columbia University Press, 1983).

35 Spivak, "Thoughts on the Principle of Allegory," 335.

36 As a postcolonialist and comparativist, work on the "planetary" scale has been especially influential to my scholarship and includes Denis Cosgrove, Apollo's Eye: A Cartographic Genealogy of the Earth in the Western Imagination (Baltimore: Johns Hopkins University Press, 200I) and Gayatri Chakravorty Spivak, Death of a Discipline (New York: Columbia University Press, 2003).

37 See John McCole, Walter Benjamin and the Antinomies of Tradition (Ithaca, NY: Cornell University Press, 1993), I40.

38 See Paul de Man's introduction in Hans Robert Jauss, Toward an Aesthetic of Reception (Minneapolis: University of Minnesota Press, 1982). See also Deborah L. Madsen, Rereading Allegory: A Narrative Approach to Genre (New York: St. Martin's, 1994); Gordon Teskey, Allegory and Violence (Ithaca, NY: Cornell University Press, 1996). Fredric Jameson, "From Metaphor to Allegory," in Anything, ed. Cynthia C. Davidson (Cambridge, MA: MIT Press, 200I), 25.

40 Chakrabarty, "The Climate of History," 220.

4I This is precisely the quandary addressed by Spivak's theory of planetarity, which I discuss in chapter 2.

42 Zalasiewicz, The Earth after Us; Tim Flannery, The Weather Makers (New York: Grove, 2007); Clive Hamilton, Earth Masters (Crows Nest, New South Wales: Allen and Unwin, 2013).

43 See the series of comments under Paul Crutzen and Christian Schwägerl's online article about the "Age of Man" and their shocking response that the term "man" is gender-neutral: Paul J. Crutzen and Christian Schwägerl, "Living in the Anthropocene: Towards a New Global Ethos," Yale Environment 360 , January 24, 20II, accessed October I8, 2018, http://e360.yale.edu/feature/living _in_the_anthropocene_toward_a_new_global_ethos/236.

44 Chakrabarty, "Foreword," xv.

45 See Kate Raworth, "Must the Anthropocene Be a Manthropocene?, The Guardian, October 20, 2014; Alaimo, Exposed; Giovanni Di Chiro, "Welcome to the White (M)Anthropocene? A Feminist-Environmentalist Critique," in The Routledge Handbook of Gender and the Environment, ed. Sherilyn MacGregor (New York: Routledge, 2017), 497-505. For a wide range of feminist responses, see Richard Grusin, ed., Anthropocene Feminism (Minneapolis: University of Minnesota Press, 2017).

46 Alaimo, Exposed, 143.

47 Chakrabarty, "The Climate of History," 198. 
48 I agree with Chakrabarty, who argues that "we need to think beyond the socalled 'climate justice' position”: Dipesh Chakrabarty, "Brute Force," Eurozone, October 7, 2010, accessed October I8, 2018, http://www.eurozine.com/articles /2010-10-07-chakrabarty-en.html. See also Chakrabarty's forthcoming Tanner Lectures: The Human Condition in the Anthropocene, Tanner Lectures in Human Values, Yale University, February i8-19, 2015.

49 There is a large body of work in history. For environmental humanities, see DeLoughrey et al., Global Ecologies and the Environmental Humanities. On postcolonial literary approaches to ecology, see Elizabeth DeLoughrey and George B. Handley, eds., Postcolonial Ecologies: Literatures of the Environment (New York: Oxford University Press, 2011); Rob Nixon, Slow Violence and the Environmentalism of the Poor (Cambridge, MA: Harvard University Press, 20II); Graham Huggan and Helen Tiffin, Postcolonial Ecocriticism: Literature, Animals, Environment (New York: Routledge, 2010); Elizabeth M. DeLoughrey, Renée K. Gosson, and George B. Handley, eds., Caribbean Literature and the Environment: Between Nature and Culture (Charlottesville: University of Virginia Press, 2005); Upamanyu Pablo Mukherjee, Postcolonial Environments: Nature, Culture and the Contemporary Indian Novel in English (Basingstoke, UK: Palgrave Macmillan, 2010); Byron Caminero-Santangelo and Garth Myers, eds., Environment at the Margins: Literary and Environmental Studies in Africa (Athens: Ohio University Press, 2011).

so Madsen, Rereading Allegory, ro9.

5I Madsen, Rereading Allegory, I23.

52 My colleague Chris Chrism informs me that this division between the human and the divine is politicized and that it is a fabrication designed to bifurcate the modern from the premodern. This is a point argued in Kathleen Davis, Periodization and Sovereignty: How Ideas of Feudalism and Secularization Govern the Politics of Time (Philadelphia: University of Pennsylvania Press, 2008).

53 See, e.g., Hans-Georg Gadamer, Truth and Method, 2 d rev. ed., trans. Joel Weinsheimer and Donald G. Marshall (London: Continuum, 2004); Fletcher, Allegory; Madsen, Rereading Allegory.

54 There is an enormous body of work on empire and modernity, more than can be cited here. My work has been particularly influenced by C. L. R. James, The Black Jacobins: Toussaint L'Ouverture and the San Domingo Revolution (New York: Vintage, 1963); Sidney Mintz, Sweetness and Power: The Place of Sugar in Modern History (New York: Viking, 1985); Glissant, Caribbean Discourse; Paul Gilroy, The Black Atlantic: Modernity and Double-Consciousness (Cambridge, MA: Harvard University Press, 1993); Michel-Rolph Trouillot, “The Perspective of the World: Globalization Then and Now," in Beyond Dichotomies: Histories, Identities, Cultures, and the Challenge of Globalization, ed. Elizabeth Mudimbe-Boyi (New York: State University of New York, 2002); Michel-Rolph Trouillot, "The Otherwise Modern: Caribbean Lessons from the Savage Slot," in Critically Modern: Alternatives, Alterities, Anthropologies, ed. Bruce M. Knauft (Bloomington: Indiana University Press, 2002), 220-37. 

of Pittsburgh Press, 2009).

56 See Fletcher, Allegory, 409.

57 Jenny Sharpe, Allegories of Empire: The Figure of Woman in Colonial Text (Minneapolis: University of Minnesota Press, 1993), I3.

58 Glissant, Caribbean Discourse, I44.

59 On scale, see Timothy Clark, "What on World Is the Earth? The Anthropocene and Fictions of the World," Oxford Literary Review 35, no. I (2013): 5-24; Timothy Clark, "Scale," in Telemorphosis Theory in the Era of Climate Change, vol. I, ed. Tom Cohen (Ann Arbor: Open Humanities, 2012), I48-66. On planetarity, see Spivak, Death of a Discipline. On enormities and hyperobjects, see Timothy Morton, Hyperobjects: Philosophy and Ecology after the End of the World (Minneapolis: University of Minnesota Press, 2013).

60 Bruno Latour, "A Plea for Earthly Sciences," keynote address at the Annual Meeting of the British Sociological Association, East London, April 22, 2007, http://www.bruno-latour.fr/node/158.

6I See, e.g., the critique of force as a universalizing discourse in Ato Quayson, "The Sighs of History: Postcolonial Debris and the Question of (Literary) History," New Literary History 43, no. 2 (2012): 359-70. Elizabeth Grosz's work continues to be the most nuanced in terms of theorizing force: see especially Elizabeth Grosz, Time Travels: Feminism, Nature, Power (Durham, NC: Duke University Press, 2005), chapter I2.

62 Sylvia Wynter and Katherine McKittrick, "Unparalleled Catastrophe for Our Species? Or, to Give Humanness a Different Future: Conversations," in Sylvia Wynter: On Being Human as Praxis, ed. Katherine McKittrick (Durham, NC: Duke University Press, 2015): 9-89; Donna Haraway, When Species Meet (Minneapolis: University of Minnesota Press, 2008); and Donna Haraway, Staying with the Trouble: Making Kin in the Chthulucene, (Durham, NC: Duke University Press, 2016).

63 Fredric Jameson, The Geopolitical Aesthetic: Cinema and Space in the World System (Bloomington: Indiana University Press, 1992), 169.

64 Jameson, The Geopolitical Aesthetic, 4.

65 Bruno Latour, "Agency at the Time of the Anthropocene," New Literary History 45, no. I (2014): I-I8; Kathryn Yusoff, "Geologic Life: Prehistory, Climate, Futures in the Anthropocene," Environment and Planning D: Society and Space 31, no. 5 (2013): 779-95; Elizabeth A. Povinelli, Geontologies: A Requiem to Late Liberalism (Durham, NC: Duke University Press, 2016).

66 Jameson, The Geopolitical Aesthetic, ro.

67 Mark Lynas, The God Species: Saving the Planet in the Age of Humans (Washington, DC: National Geographic, 20II). In a similar vein, Michael Shellenberger and Ted Nordhaus preach the gospel of "modernization theology" in "Evolve," Orion, 20II, accessed October I8, 20I8, https://orionmagazine.org/article/evolve.

68 It is Anthropocene discourse that is secular, not the epoch, as there are many cosmological systems that are vital to "world-making," not the least of which is 
poetry: see George Handley, "Climate Change, Cosmology, and Poetry: The Case of Derek Walcott's Omeros," in DeLoughrey et al., Global Ecologies and the Environmental Humanities, 333-51.

69 Fredric Jameson, "Third-World Literature in the Era of Multinational Capitalism," Social Text, no. Is (Autumn 1986): 65-88. See Sara Suleri, The Rhetoric of English India (Chicago: University of Chicago Press, 1992); Rosemary George, Politics of Home: Postcolonial Relocations and Twentieth-Century Fiction (Cambridge: Cambridge University Press, 1996); Geeta Kapur, "Globalisation and Culture," Third Text 39 (1997): 2I-38. Note that others use it: see Stephen Slemon, "Post-Colonial Allegory and the Transformation of History," Journal of Commonwealth Literature 23 (1988): 157-68; Imre Szeman, Zones of Instability: Literature, Postcolonialism, and the Nation (Baltimore: Johns Hopkins University Press, 2003); Imre Szeman, "Who's Afraid of National Allegory? Jameson, Literary Criticism, Globalization," South Atlantic Quarterly I00, no. 3 (2001): 803-27. For Latin America, see Idelbar Avelar, The Untimely Present (Durham, NC: Duke University Press 1999); Katherine Sugg, Gender and Allegory in Transamerican Fiction and Performance (New York: Palgrave Macmillan, 2008). Also notable is the critique of allegory in Coetzee by Derek Attridge, who argues that it turns otherness to sameness: Derek Attridge, "Against Allegory: Waiting for the Barbarians, Life and Times of Michael K, and the Question of Literary Reading," in J. M. Coetzee and the Idea of the Public Intellectual, ed. Jane Poyner (Athens: Ohio University Press, 2006).

70 Szeman, "Who's Afraid of National Allegory?", 805.

7 I Chakrabarty nuanced his position by posing three models of the human: as subject of rights, as subject of difference, and as nonontological force. This is discussed in chapter 4. See Dipesh Chakrabarty, "Postcolonial Studies and the Challenge of Climate Change," New Literary History 43 (2012): I-18. There have been some interesting theorizations of the human in this debate: see Baucom, "The Human Shore."

72 See discussion in Bronislaw Szerszynski, "The End of the End of Nature: The Anthropocene and the Fate of the Human," Oxford Literary Review 34 (2012): I65-84.

73 Szeman, "Who's Afraid of National Allegory?," 805. See also Martin Jay, Marxism and Totality (Berkeley: University of California Press, 1984).

74 Benjamin, quoted in Buck-Morss, The Dialectics of Seeing, 80.

75 This is what Benjamin called an "unbroken chain of deduction": Benjamin, quoted in McCole, Walter Benjamin and the Antimonies of Tradition, 153.

76 I diverge from Jameson's claims about allegory by resisting a totalizing narrative of a "Third World," which in his reading sidesteps the legacies of European empires to collapse China with postcolonies such as Senegal. In that sense, Jameson's claims about allegory, a historicizing mode, are oddly ahistorical. My work also differs from Jameson and other writers on allegory in that it rejects the often unstated claim that there is a universal narrative termed "allegory" (often thought to derive from medieval Christian Europe) that can be applied 
to every postcolonial island context, and that allegory's only modern innovation is that it figures the individual in terms of the nation rather than a higher power such as the divine.

Abdul R. JanMohamed, "The Economy of Manichean Allegory: The Function of Racial Difference in Colonialist Literature," Critical Inquiry I2, no. I (1985): 68.

78 Sharpe, Allegories of Empire, 13.

79 Sharpe, Allegories of Empire, 23.

80 See Sangeeta Ray, En-Gendering India: Woman and Nation in Colonial and Postcolonial Narratives (Durham, NC: Duke University Press, 2000). Doris Sommer has examined interracial romance as constitutive to national allegory in Latin America, while others have demonstrated that postdictatorship fiction has employed allegorical codes of "other speaking" to tell the stories of state violence: Doris Sommer, Foundational Fictions (Berkeley: University of California Press, 1991). See also Avelar, The Untimely Present; Sugg, Gender and Allegory in Transamerican Fiction and Performance.

8I In addition to Szeman, "Who's Afraid of National Allegory?", see Slemon, "Post-Colonial Allegory and the Transformation of History"; Bill Ashcroft, Post-Colonial Transformation (London: Routledge, 200I).

82 Jameson, "Third-World Literature in the Era of Multinational Capitalism," 88.

83 Marlene Nourbese Philip, "A Piece of Land Surrounded," Orion I4, no. 2 (I995): 4I-47.

84 Wilson Harris, Selected Essays of Wilson Harris: The Unfinished Genesis of the Imagination 1999, ed. Andrew Bundy (New York: Routledge, 1999), 85.

85 Benjamin, The Origin of German Tragic Drama, 179.

86 Ann Laura Stoler, "Imperial Debris: Reflections on Ruins and Ruinations," Cultural Anthropology 23, no. 2 (2008): 191-219.

87 Zygmunt Bauman, Wasted Lives: Modernity and Its Outcasts (Oxford: Polity, 2004).

88 Mick Smith, "Hermeneutics and the Culture of Birds: The Environmental Allegory of 'Easter Island," Ethics, Place and Environment 8, no. I (2005): 22.

89 Benjamin, The Origin of German Tragic Drama, 178.

90 William L. Thomas Jr., ed., Man's Role in Changing the Face of the Earth (Chicago: University of Chicago Press, 1956).

91 Lewis and Maslin, "Defining the Anthropocene," 172.

92 See Will Steffen, Jacques Grinevald, Paul Crutzen, and John McNeill, “The Anthropocene: Conceptual and Historical Perspectives," Philosophical Transactions of the Royal Society $A 369$ (2011): 842-67; Lewis and Maslin, "Defining the Anthropocene," I7I-80; Nigel Clark, "Geo-politics and the Disaster of the Anthropocene," in Disasters and Politics: Materials, Experiments, Preparedness, ed. Manuel Tironi, Israel Rodriguez-Giralt, and Michael Guggenheim (Hoboken, NJ: Wiley-Blackwell, 2014), 19-37.

93 See Lewis and Maslin, "Defining the Anthropocene," 172. They also include Reverend Haughton's Manual of Geology from 1865 and the U.S. geologist James Dwight Dana’s manual from 1863. 
94 Lewis and Maslin suggest that nineteenth-century reckonings of the Holocene had a theological bent in that the human was understood to be the apex of life forms on Earth: Lewis and Maslin, "Defining the Anthropocene," 173. These origin stories have been placed into an intellectual trajectory that includes the Russian geologist Vladimir Vernadsky's work on the human relation to the geosphere, the biosphere, and the noosphere (a plane of human consciousness), with Pierre Teilhard de Chardin in particular: see Paul R. Samson and David Pitt, eds., The Biosphere and Noosphere Reader: Global Environment, Society, and Change (London: Routledge, 1999); Steffen et al., "The Anthropocene: Conceptual and Historical Perspectives." Moving against this tide, Hamilton and Grinevald argue that because the epoch is entirely unprecedented, there are no intellectual forebears: Hamilton and Grinevald, "Was the Anthropocene Anticipated?"

McCole, Walter Benjamin and the Antimonies of Tradition, I35.

96 Benjamin, The Origin of German Tragic Drama, 180.

97 Edward Said, Beginnings: Intention and Method (London: Granta, 2012), 5.

98 Said, Beginnings, 372.

99 Crutzen and Stoermer, "The "Anthropocene." See also the discussion of the fossil fuel basis for this claim in Colin N. Waters, Jan A. Zalasiewicz, Mark Williams, Michael A. Elis, and Andrea M. Snelling, A Stratigraphical Basis for the Anthropocene?, Special Publication no. 395 (London: Geological Society, 20I4), I-2I.

I00 Jonathan Dean, Melanie Leng, and Anson Mackay, "Is There an Isotopic Signature of the Anthropocene?", Anthropocene Review I, no. I3 (2014): 276-87.

IOI See also Malm and Hornborg, "The Geology of Mankind?"

IO2 Malm and Hornborg, "The Geology of Mankind?," 63-64. See also the work of Jason W. Moore, who has theorized the Capitalocene in great detail.

Io3 Waters et al., A Stratigraphical Basis for the Anthropocene?, 4.

104 In his argument for the "Necrocene," McBrien argues that "the 'Anthropocene' displaces the origins of the contemporary crisis onto the human being as species rather than as capital. It reinforces what capital wants to believe of itself: that human "nature," not capital, has precipitated today's planetary instability": Justin McBrien, "Accumulating Extinction: Planetary Catastrophism in the Necrocene," in Anthropocene or Capitalocene? Nature, History, and the Crisis of Capitalism, ed. Jason W. Moore (Oakland, CA: PM Press, 2016), i19. On the Plasticene, see Christina Reed, "Dawn of the Plasticene Age," New Scientist 225, no. 3006 (January 2015): 28-32. On the cthulucene, see Haraway, Staying with the Trouble.

Ios Libby Robin, "Histories for Changing Times: Entering the Anthropocene?", Australian Historical Studies 44, no. 3 (2013): 332.

Io6 Johnson et al., "After the Anthropocene"; Yusoff, "Geologic Life," 453.

107 For discussion of the "Paleoanthropocene" and of the Early, Middle and Late Anthropocene, see Andrew Glikson, "Fire and Human Evolution: The DeepTime Blueprints of the Anthropocene," Anthropocene 3 (2013): 89-92. 
On the "Early Anthropogenic Hypothesis," see Ruddiman, "The Anthropogenic Greenhouse Era Began Thousands of Years Ago”; William F. Ruddiman, Plows, Plagues, and Petroleum (Princeton, NJ: Princeton University Press, 2005); Stephen F. Foley, Detlef Gronenborn, Meinrat O. Andreae, and Joachim W. Kadereit et al., "The Palaeoanthropocene-The Beginnings of Anthropogenic Environmental Change," Anthropocene 3 (2013): 83-88. See also the discussion in Wolfgang Behringer, A Cultural History of Climate (Cambridge, MA: Polity, 2010), 210-15.

I09 Steffen et al., "The Anthropocene: Conceptual and Historical Perspectives."

in William F. Ruddiman, "How Did Humans First Alter Global Climate?," Scientific American 292, no. 3 (2005): 46-53.

III On the genocide, see Charles C. Mann, I493: How the Ecological Collision of Europe and the Americas Gave Rise to the Modern World (London: Granta, 2011).

II2 Lewis and Maslin, "Defining the Anthropocene," 175.

II3 Lewis and Maslin, "Defining the Anthropocene," 177.

II Lewis and Maslin, "Defining the Anthropocene," 177.

IIs Donna Haraway traces the origins of the term to 20I4: Haraway, "Anthropocene, Capitalocene, Plantationocene, Chthulucene."

II6 Alfred W. Crosby, The Columbian Exchange: Biological and Cultural Consequences of ${ }_{492}$ (Westport CT: Praeger, 2003). See also Alfred W. Crosby, Ecological Imperialism: The Biological Expansion of Europe goo-Igoo (Cambridge: Cambridge University Press, 2004).

I17 Lewis and Maslin, "Defining the Anthropocene," 172.

II 8 Lewis and Maslin, "Defining the Anthropocene," 174. As an early marker of the globalization of agriculture, Charles Mann has referred to this as the "homogenocene": "The Dawn of the Homogenocene," Orion 30, no. 3 (2011): 16-25.

II Benjamin, The Origin of German Tragic Drama, 166.

I20 Crutzen, "Geology of Mankind"; Paul J. Crutzen and John W. Birks, "The Atmosphere after a Nuclear War: Twilight at Noon," Ambio II (1982): II4-25.

I2I Paul N. Edwards, "Entangled Histories: Climate Science and Nuclear Weapons Research," Bulletin of the Atomic Scientists 68, no. 4 (2012): 30-31. See also Joseph Masco, "Bad Weather: On Planetary Crisis," Social Studies of Science 40, no. I (2010): 7-40; Ronald Doel, "Constituting the Postwar Earth Sciences: The Military's Influence on the Environmental Sciences in the USA after 1945," Social Studies of Science 33, no. 5 (2003): 635-66.

I22 Waters et al., A Stratigraphical Basis for the Anthropocene? In the words of the ecologist Julio Figueroa-Colon, "Discussing the rationale (or lack thereof) and effects of the tests without exploring the relationship between scientists and governments in matters of militarization and colonialism is like counting calories just to practice your multiplication tables" (personal communication, email, June 4, 2015).

I23 Masco, "Bad Weather"; Joseph Masco, "The End of Ends," Anthropological Quarterly 85, no. 4 (2012): I107-24; Doel, "Constituting the Postwar Earth Sciences"; Edwards, "Entangled Histories." 
I24 Eleanor Randolph, "Experts Find Possible Climatic 'Bomb," Los Angeles Times, August 9, 1981. James Hansen published the "time bomb" warning later, in 2003: James Hansen, "Can We Defuse the Global Warming Time Bomb?”, naturalScience, August I, 2003, https://pubs.giss.nasa.gov/abs/ha07900q.html.

"The Doomsday Clock: A Timeline of Conflict, Culture, and Change."

Bulletin of the Atomic Scientists (blog), accessed October I8, 2018, https:// thebulletin.org/timeline.

I26 Zalasiewicz et al., "When Did the Anthropocene Begin?," 177. See also Quan Hua, Mike Barbetti, and Andrzej Z. Rakowski, "Atmospheric Radiocarbon for the Period 1950-2010," Radiocarbon 55, no. 4 (2013): 2059-72; Dean et al., "Is There an Isotopic Signature of the Anthropocene?"

Waters et. al, A Stratigraphical Basis for the Anthropocene?

Lewis and Maslin, "Defining the Anthropocene."

Fletcher, Allegory; Jacques Derrida and F. C. T. Moore, "White Mythology: Metaphor in the Text of Philosophy," New Literary History 6, no. I (1974): 5-74. Steffen et al., "The Anthropocene: Are Humans Now Overwhelming the Great Forces of Nature?"; Steffen et al., "The Anthropocene: From Global Change to Planetary Stewardship." See also Zalasiewicz et al., "When Did the Anthropocene Begin?", and, more recently, McNeill and Engelke, The Great Acceleration. Anthony Giddens, The Consequences of Modernity (Stanford, CA: Stanford University Press, 1990).

Note also that the time/space compression of globalization has been critiqued as a shock only to the colonizing west, in the sense that the experience of the rupture of modernity would have taken place much earlier in the colonies themselves: see Doreen Massey, Space, Place, and Gender (Minneapolis: University of Minnesota Press, 1994), 147.

See Massey, Space, Place, and Gender, 249.

Lewis and Maslin, "Defining the Anthropocene," 17 I.

Nixon, Slow Violence and the Environmentalism of the Poor, $12-13$.

Lewis and Maslin, "Defining the Anthropocene," 176.

Zalasiewicz et. al, "When Did the Anthropocene Begin?” 5.

Jan A. Zalasiewicz, Mark Williams, Colin N. Waters, Anthony D. Barnosky, and Peter Haff, "The Technofossil Record of Humans," Anthropocene Review I (2014): 34-43.

Jan A. Zalasiewicz and Mark Williams, "The Anthropocene Ocean in Its Deep Time Context," in The World Ocean in Globalisation: Climate Change, Sustainable Fisheries, Biodiversity, Shipping, Regional Issues, ed. Davor Vidas and Peter Johan Schei (Leiden: Martinus Nijhoff, 20II), 19-35; Jacob Darwin Hamblin, Oceanographers and the Cold War (Seattle: University of Washington Press, 2005). Elizabeth DeLoughrey, "Submarine Futures of the Anthropocene," Comparative Literature Journal 69, no. I (2017): 32-44.

Lewis and Maslin, "Defining the Anthropocene," 172.

Clark, Inhuman Nature; Lynn Margulis and Dorion Sagan, Dazzle Gradually: Reflections on the Nature of Nature (White River Junction, VT: Chelsea Green, 
2007). See also Jamie Lorimer, "Multinatural Geographies for the Anthropocene," Progress in Human Geography 36, no. 5 (2012): 593-611; Myra J. Hird, The Origins of Sociable Life: Evolution after Science Studies (Basingstoke, UK: Palgrave Macmillan, 2009); Alaimo, Exposed; Whyte, "Indigenous Science (Fiction)"; Davis and Todd, "On the Importance of a Date"; and Haraway, Staying with the Trouble.

I43 Crutzen and Schwägerl, "Living in the Anthropocene."

I44 Sarah Whatmore, Hybrid Geographies: Natures, Cultures, Spaces (London: Sage, 2002).

I45 Ghosh, The Great Derangement, 33.

I46 Johan Rockström, Will Steffen, Kevin Noone, and Åsa Persson et al., "A Safe Operating Space for Humanity," Nature 461, no. 7263 (2009): 474. This rate is projected to increase tenfold: see Zalasiewicz et al., "The New World of the Anthropocene."

I47 Latour, "Agency at the Time of the Anthropocene," I3.

\section{GENDERING EARTH}

Epigraphs: David Montgomery, Dirt: The Erosion of Civilizations (Berkeley: University of California, 2007), I5; Michel Serres, The Natural Contract, trans. Elizabeth MacArthur and William Paulson (Ann Arbor: University of Michigan, 1995), 28.

I Elizabeth M. DeLoughrey, Renée K. Gosson, and George B. Handley, eds., Caribbean Literature and the Environment: Between Nature and Culture (Charlottesville: University of Virginia Press, 2005).

2 Simon L. Lewis and Mark A. Maslin, "Defining the Anthropocene," Nature 519, no. $7542(2015): 175$.

3 Walter Benjamin, quoted in Susan Buck-Morss, The Dialectics of Seeing: Walter Benjamin and the Arcades Project (Cambridge, MA: MI T Press, 1989), 24; Walter Benjamin, The Arcades Project, ed. Rolf Tiedemann, trans. Howard Eiland and Kevin McLaughlin (Cambridge, MA: Harvard University Press, I999), 47I.

4 Alfred W. Crosby, The Columbian Exchange: Biological and Cultural Consequences of 1492 (Westport, CT: Praeger, 2003); Alfred W. Crosby, Ecological Imperialism: The Biological Expansion of Europe 9oo-19oo, 2nd ed. (Cambridge: Cambridge University Press, 2004).

$5 \quad$ William McNeill, "American Food Crops in the Old World," in Seeds of Change, ed. Herman J. Viola and Carolyn Margolis (Washington, DC: Smithsonian Institution Press, 1991), 52.

6 There is an enormous body of work on transatlantic modernity and slavery. Books influential to my thinking include Sidney Mintz, Sweetness and Power: The Place of Sugar in Modern History (New York: Viking, 1985); C. L. R. James, The Black Jacobins: Toussaint L'Ouverture and the San Domingo Revolution (New York: Vintage, 1963); Paul Gilroy, The Black Atlantic and the 
Countercultures of Modernity (Cambridge, MA: Harvard University Press, 1993); David Scott, Conscripts of Modernity (Durham, NC: Duke University Press, 2004); David Scott, Omens of Adversity: Tragedy, Time, Memory, Justice (Durham, NC: Duke University Press, 2014).

7 Jason W. Moore, "Introduction," in Anthropocene or Capitalocene? Nature, History, and the Crisis of Capitalism, ed. Jason W. Moore (Oakland, CA: PM Press, 2016), 7.

8 See Donna Haraway, "Anthropocene, Capitalocene, Plantationocene, Chthulucene: Making Kin," Environmental Humanities 6 (2015): 159-65. See also the discussion in Moore, Anthropocene or Capitalocene?

9 On narrative and the environmental humanities, see Elizabeth DeLoughrey, Jill Didur, and Anthony Carrigan, "Introduction: A Postcolonial Environmental Humanities," in Global Ecologies and the Environmental Humanities: Postcolonial Approaches, ed. Elizabeth DeLoughrey, Jill Didur, and Anthony Carrigan (New York: Routledge, 2015), I-32.

Io See José Rabasa, "Allegories of Atlas," in The Post-Colonial Studies Reader, ed. Bill Ashcroft, Gareth Griffiths, and Helen Tiffin (London: Routledge, 1995), 319-24; Peter Hulme, Colonial Encounters: Europe and the Native Caribbean, 1492-I797 (London: Routledge, 1992).

II Edmundo O'Gorman, The Invention of America: An Inquiry into the Historical Nature of the New World and the Meaning of Its History (Bloomington: Indiana University Press, 1961).

I2 Antonello Gerbi, Nature in the New World: From Christopher Columbus to Gonzalo Fernández de Oviedo, trans. Jeremy Moyle (Pittsburgh: University of Pittsburgh Press, 1985).

I3 Richard H. Grove, Green Imperialism: Colonial Expansion, Tropical Island Edens, and the Origins of Environmentalism, I600-1860 (Cambridge: Cambridge University Press, 1995), 9.

I4 See also Tom Griffiths and Libby Robin, Ecology and Empire: Environmental History of Settler Societies (Victoria, Australia: Melbourne University Press, 1997); Peder Anker, Imperial Ecology: Environmental Order in the British Empire, 1895-1945 (Cambridge, MA: Harvard University Press, 2001).

I5 Grove, Green Imperialism, 240.

16 As quoted in Gerbi, Nature in the New World, 28-29. The argument in this paragraph and the following is drawn from the introduction to DeLoughrey et al., Caribbean Literature and the Environment.

I7 The West Indies, David Lowenthal argues, with "their infertile, dry, or poorly drained soils, precipitous slopes, and long history of soil erosion and depletion contrast sharply with the stereotype of lush tropical gardens that will bear fruit if one just pokes a stick in the ground": David Lowenthal, West Indian Societies (New York: Oxford University Press, 1972), i5. See also David Watts, The West Indies: Patterns of Development, Culture and Environmental Change since 1492 (Cambridge: Cambridge University Press, 1987).

I8 James Grainger, "The Sugar Cane: A Poem, In Four Books," in Caribbeana: An Anthology of English Literature of the West Indies 1657-1777, ed. Thomas W. 
Krise, 166-260 (Chicago: University of Chicago Press, 1999), part III, lines 538-39.

I9 Ian Gregory Strachan, Paradise and Plantation: Tourism and Culture in the Anglophone Caribbean (Charlottesville: University of Virginia Press, 2002). On West Indian adoption of the pastoral genre, see Elizabeth DeLoughrey, "Ecocriticism: The Politics of Place," in The Routledge Companion to Anglophone Caribbean Literature, ed. Michael Bucknor and Alison Donnell (New York: Routledge, 2011), 265-75.

20 On the island garden in anglophone Caribbean literature, see Jill Casid, Sowing Empire: Landscape and Colonization (Minneapolis: University of Minnesota Press, 2005); DeLoughrey et al., Caribbean Literature and the Environment; Sarah Phillips Casteel, Second Arrivals: Landscape and Belonging in Contemporary Writing of the Americas (Charlottesville: University of Virginia Press, 2007); George B. Handley, New World Poetics: Nature and the Adamic Imagination of Whitman, Neruda, and Walcott (Athens: University of Georgia Press, 2007); Elizabeth M. DeLoughrey, Routes and Roots: Navigating Caribbean and Pacific Island Literatures (Honolulu: University of Hawai'i Press, 2007).

2I Édouard Glissant, Caribbean Discourse: Selected Essays, trans. J. Michael Dash (Charlottesville: University of Virginia Press, 1989), 64.

22 "Where we perceive a chain of events, he sees one single catastrophe which keeps piling wreckage upon wreckage and hurls it in front of his feet. The angel would like to stay, awaken the dead, and make whole what has been smashed. But a storm is blowing from Paradise; it has got caught in his wings with such violence that the angel can no longer close them. The storm irresistibly propels him into the future to which his back is turned, while the pile of debris before him grows skyward. This storm is what we call progress": Walter Benjamin, "Theses on the Philosophy of History," in Illuminations: Essays and Reflections (New York: Schocken Books, 1968), 257-58. Baucom makes a convincing argument that the Anthropocene compels us, as species, to consider the wreckage of this past called progress: Ian Baucom, "The Human Shore: Postcolonial Studies in an Age of Natural Science," History of the Present 2, no. I (2012): IO.

23 Glissant, Caribbean Discourse, 61-62.

24 Glissant, Caribbean Discourse, 63.

25 Erna Brodber, The Rainmaker's Mistake (London: New Beacon, 2007), I49. Hereafter, page numbers are cited in parentheses in the text.

26 See the introduction in DeLoughrey et al., Caribbean Literature and the Environment; DeLoughrey, Routes and Roots.

27 George Lamming, The Pleasures of Exile (Ann Arbor: University of Michigan Press, 1992), 46.

28 See, e.g., Fernando Ortiz, Cuban Counterpoint: Tobacco and Sugar, trans. Harriet de Onís (New York: Alfred A. Knopf, 1947); Kamau Brathwaite, History of the Voice: The Development of Nation Language in Anglophone Caribbean Poetry (London: New Beacon, 1984). 
John Parry, "Plantation and Provision Ground: An Historical Sketch of the Introduction of Food Crops into Jamaica," Revista de Historia de America 39 (1955): I.

Sylvia Wynter, "Novel and History, Plot and Plantation," Savacou 5 (June 1971): 95-102.

3I On Plantationocene, see Haraway, "Anthropocene, Capitalocene, Plantationocene, Chthulucene."

32 David Montgomery, Dirt: The Erosion of Civilizations (Berkeley: University of California Press, 2007), 27.

33 See also Wynter, "Novel and History," 99. This division is used as a foundational point in the essays in DeLoughrey et al., Caribbean Literature and the Environment.

34 Glissant, Caribbean Discourse, 105-6. See also the introduction in DeLoughrey et al., Caribbean Literature and the Environment.

35 Glissant, Caribbean Discourse, I46.

36 Wynter, "Novel and History," 99. See also Lizabeth Paravisini-Gebert, "'He of the Trees," in DeLoughrey et al., Caribbean Literature and the Environment, 182-96. Wynter, "Novel and History," 99-100. On conceptual systems and space, see also Barry Higman, Jamaica Surveyed: Plantation Maps and Plans of the Eighteenth and Nineteenth Centuries (Kingston, Jamaica: University of the West Indies Press, 200I). See Anthony Bogues, "Writing Caribbean Intellectual History," Small Axe 12, no. 2 (June 2008): 168-78.

38 William Ed Grimé, Ethno-Botany of the Black Americans (Algonac, MI: Reference, 1979), 23.

39 Barry Higman, Jamaican Food: History, Biology, Culture (Mona, Jamaica: University of the West Indies Press, 2008), 58. A correction to Higman's meticulous account: Joseph Banks did request transplantation of the Tahitian plantain and yam because he felt they were superior to the West Indian varieties. See the letter to James Wiles dated June 25, I791, in Neil Chambers, ed., The Letters of Sir Joseph Banks: A Selection $1768-1820$ (London: Imperial College Press, 2000). See also Alan Frost, Sir Joseph Banks and the Transfer of Plants to and from the South Pacific, 1786-1798 (Melbourne: Colony, 1993), 53.

40 See Hans Sloane, A Voyage to the Islands Madera, Barbadoes, Nieves, St. Christophers, and Jamaica, 2 vols. (London: B. M., 1707-25). See also Judith A. Carney and Richard N. Rosomoff, In the Shadow of Slavery: Africa's Botanical Legacy in the Atlantic World (Berkeley: University of California Press, 2009).

4I Carney and Rosomoff, In the Shadow of Slavery, iI3.

42 Higman, Jamaican Food, 55.

43 Higman, Jamaican Food, 60.

44 Michel-Rolph Trouillot, Silencing the Past: Power and the Production of History (Boston: Beacon Press, 1995).

45 Higman, Jamaican Food, 73.

46 Kamau Brathwaite, Mother Poem (Oxford: Oxford University Press, 1977), I2 I. 
Edward Kamau Brathwaite, "Afternoon of the Status Crow," lecture delivered at the University of Bremen, June 1980; Edward Kamau Brathwaite, Afternoon of the Status Crow, Savacou Working Paper no. I (Mona, Jamaica: n.p., 1982), I4b.

48 Brathwaite, Mother Poem, I2I. In bell hooks, Sisters of the Yam: Black Women and Self-Recovery (Boston: South End, 1994). hooks defines "root" as "a lifesustaining symbol of black kinship and community ... and diasporic connections": hooks, Sisters of the Yam, i3. Paule Marshall comments on African transplants such as the terms yam and nyam (to eat) in "Poets in the Kitchen," in Reena and Other Stories (Old Westbury, NY: Feminist Press, 1983), 21. On the yam as a prestige food in West Africa, see William Bascom, "Yoruba Food," Africa 21, no. I (195I): 4I-53.

49 In the Caribbean, the yam has signified the primary roots culture of West Africa, even though the tuber has both American and African origins. Glissant has warned against privileging a "totalitarian drive of a single, unique root-rather than [a] fundamental relationship with the Other”: Édouard Glissant, Poetics of Relation, trans. Betsy Wing (Ann Arbor: University of Michigan Press, 1997), I4. Interestingly, the yam is not, botanically, a root but a rhizome, suggesting a more lateral series of relationships.

so Higman, Jamaican Food, 58.

5I Nalo Hopkinson, Whispers from the Cotton Tree Root: Caribbean Fabulist Fiction (Montpelier, VT: Invisible Cities, 200I), I.

52 See Jenny Sharpe, Allegories of Empire: The Figure of Woman in the Colonial Text (Minneapolis: University of Minnesota Press, 1993).

53 Ira Berlin and Philip D. Morgan, "Introduction," in The Slaves'Economy: Independent Production by Slaves in the Americas, ed. Ira Berlin and Philip D. Morgan (London: Frank Cass, I99I), I2, I4.

54 Berlin and Morgan, "Introduction," 9. See also Parry, "Plantation and Provision Ground”; Dale Tomich, "Une petite Guinée: Provision Ground and Plantation in Martinique, I830-1848," in Berlin and Morgan, The Slaves' Economy, 68-69; Ira Berlin and Philip D. Morgan, Cultivation and Culture: Labor and the Shaping of Slave Life in the Americas (Toronto: Scholarly Book Services, 2002).

55 Higman, Jamaica Surveyed, 263.

56 Kamau Brathwaite, "Caribbean Culture: Two Paradigms," in Missile and Capsule, ed. Jürgen Martini (Bremen: Universität Bremen, I983), 25.

57 Hilary McD. Beckles, "An Economic Life of Their Own: Slaves as Commodity Producers and Distributors in Barbados," in Berlin and Morgan, The Slaves' Economy, 33 .

58 See Sidney Mintz, "Caribbean Marketplaces and Caribbean History," Radical History Review 27 (1983): 110-20. Other sources include Sidney Mintz and Douglas Hall, "The Origins of the Jamaican Internal Marketing System," Yale University Publications in Anthropology 57 (1960): 3-26; Verene Shepherd and Hilary McD. Beckles, eds., Caribbean Slavery in the Atlantic World (Kingston, Jamaica: Ian Randle, 2000). 
60 Wynter, "Novel and History," 95, 97, 99.

6I Wynter, "Novel and History," IoI.

62 Sylvia Wynter, "Unsettling the Coloniality of Being/Power/Truth/Freedom:

Towards the Human, After Man, Its Overrepresentation-An Argument." CR:

New Centennial Review 3, no. 3 (Fall 2003): 267. I take up this argument in relation to Wynter's only published novel in Elizabeth DeLoughrey, "Provision Grounds and Cultural Roots: Towards Ontological Sovereignty," in The Caribbean Woman Writer as Scholar, ed. Carole Boyce Davies (Pompano Beach, FL: Caribbean Studies Press, 2009), 205-24.

63 Wynter's essay was published in the 197I issue of Savacou, followed by Kenneth Ramchand's "History and the Novel: A Literary Critic's Approach," expanding on the role of Morant Bay and revolution in general. Derek Walcott's "Muse of History" was first published in 1974 (in Is Massa Day Dead? Black Moods in the Caribbean, ed. Orde Coombs [New York: Anchor-Doubleday, 1974], I-27), and Edward Baugh's "The West Indian Writer and His Quarrel with History" was published shortly after (Tapia, February 20, 1977, 6-7; February 27, 1977, 6-7, II).

64 Kamau Brathwaite, "Caribbean Man in Space and Time" Savacou, no. 2 (September 1974): 4 .

65 Wynter, "Novel and History," 99.

66 Wilson Harris, History, Fable, and Myth in the Caribbean and Guianas (Georgetown: National History and Arts Council, 1970), 17.

67 Higman has traced a "golden age" constructed by Caribbean historians using these same criteria: see Barry Higman, Writing West Indian Histories (London: Macmillan, 1999), I55-6I.

68 Wilson Harris, "The Fabric of the Imagination," in The Radical Imagination: Lectures and Talks, ed. Alan Riach and Mark Williams (Liège, Belgium: Liège Language and Literature, 1992), 72.

69 Wilson Harris, Explorations: A Selection of Talks and Articles, 1966-198I, ed. Hena Maes-Jelinek (Mundelstrup, Denmark: Dangaroo, I98I), 90.

70 See Bronislaw Szerszynski, "The Anthropocene and the Memory of the Earth," paper presented at the The Thousand Names of Gaia: From the Anthropocene to the Age of the Earth colloquium, Casa de Rui Barbosa, Rio de Janeiro, Brazil, Septemberis-19, 2014.

7 I Harris, "The Fabric of the Imagination," 78.

72 Anticipating Glissant's critique of the "totalitarian drive of a single, unique root," Harris laments the "lack of imagination daring to probe the nature of roots of community beyond fixed or static boundaries" and laments how the "homogenous imperative" prevents the "imaginative daring" needed to see the "contrasting spaces" that make up the "heterogeneous roots of a community": Harris, Explorations, 57.

73 Harris, The Radical Imagination, 21. On the vexed question of allegory and history, see the introduction in this volume. Notable contributors include Paul 
de Man, "The Rhetoric of Temporality," in Blindness and Insight: Essays in the Rhetoric of Contemporary Criticism (Minneapolis: University of Minnesota Press, 1983); Fredric Jameson, "Third World Literature in an Age of Multinational Capitalism," in The Current in Criticism: Essays on the Present and Future of Literary Theory, ed. Clayton Koelb and Virgil Lokke (West Lafayette, IN: Purdue University Press, 1987); Aijaz Ahmad, "Jameson's Rhetoric of Otherness and the "National Allegory," Social Text, no. 17 (Autumn 1987):3-25; Madhava Prasad, "On the Question of a Theory of (Third World) Literature," Social Text, nos. 31-32 (Spring 1992): 57-83; Stephen Slemon, "Post-Colonial Allegory and the Transformation of History," Journal of Commonwealth Literature 23, no. I (1988): 157-68; Imre Szeman, "Who's Afraid of National Allegory? Jameson, Literary Criticism, Globalization," South Atlantic Quarterly Ioo, no. 3 (2001): $803-27$.

74 See Gay Clifford, The Transformation of Allegory (London: Routledge and Kegan Paul, 1974), 97-ıог.

75 Mary Hanna, "Masterful Historical Discourse," Gleaner, June 3, 2007, accessed August 5, 2010, http://www.jamaica-gleaner.com/gleaner/20070603/arts/arts3 .html. Carolyn Cooper observes, "[The novel] does not have a main character. It doesn't even have a main narrator.... Why have one narrator when she could have seven? Some chapters have two narrators. And why the narrators should have one identity and one name when they can have two?... In Erna's emancipated world view, everything is possible": Cooper, quoted in Mel Cooke, "Erna Brodber Presents Her Freedom Song," Gleaner, May I8, 2007, accessed July 5, 20I5, http://old.jamaica-gleaner.com/gleaner/20070518/ent/entr.html.

76 Brodber, The Rainmaker's Mistake, back cover.

77 Dipesh Chakrabarty, "The Climate of History: Four Theses," Critical Inquiry 35 (Winter 2009): 208.

78 On tidalectics see Kamau Brathwaite, "Caribbean Culture: Two Paradigms," in Missile and Capsule, ed. Jurgen Martini, 9-54 (Bremen, Germany: Universität Bremen, 1983), as well as my exploration of the idea in the introduction to DeLoughrey, Routes and Roots.

79 On allegory and Harris's influence on Brodber, see Heather Smyth, "Roots beyond Roots: Heteroglossia and Feminist Creolization in Myal and Crossing the Mangrove," Small Axe 6, no. 2 (September 2002): I-24.

80 See John McCole, Walter Benjamin and the Antinomies of Tradition (Ithaca, NY: Cornell University Press, 1993), I35; Walter Benjamin, The Origin of German Tragic Drama, trans. John Osborne (London: Verso, 1998), 178.

8I Cooper, quoted in Cooke, "Erna Brodber Presents Her Freedom Song."

82 Sylvia Wynter, "Unsettling the Coloniality of Being/Power/Truth/Freedom: Towards the Human, After Man, Its Overrepresentation-An Argument." CR: New Centennial Review 3, no. 3 (Fall 2003): 267.

83 See Maureen Quilligan, The Language of Allegory: Defining the Genre (Ithaca, NY: Cornell University Press, 1992), 28; James J. Paxson, The Poetics of Personification (London: Cambridge University Press, 1994), II; Gordon Teskey, Allegory and 
Violence (Ithaca, NY: Cornell University Press, 1996), 3; Quilligan, The Language of Allegory, 3 I.

84 See Quilligan, The Language of Allegory, 26-27; Angus Fletcher, Allegory: Theory of a Symbolic Mode (Ithaca, NY: Cornell University Press, 1964), 2.

85 Quilligan, The Language of Allegory, 26.

86 See Teskey, Allegory and Violence, I2; Hans Robert Jauss, Towards an Aesthetics of Reception, trans. Timothy Bahti (Brighton, UK: Harvester, 1982); Paul de Man, Allegories of Reading: Figural Language in Rousseau, Nietzsche, Rilke, and Proust (New Haven, CT: Yale University Press, 1979).

87 Slemon, "Post-Colonial Allegory and the Transformation of History," I5 8; Paul de Man, Blindness and Insight: Essays in the Rhetoric of Contemporary Criticism (New York: Oxford University Press, 1971).

88 Deborah L. Madsen, Rereading Allegory: A Narrative Approach to Genre (New York: St. Martin's, 1994), 109, I36.

89 See Annie Paul, "Black Rain: Annie Paul on The Rainmaker's Mistake, by Erna Brodber," Caribbean Review of Books is (February 2008), para. I4, accessed August 5, 2010, http://caribbeanreviewofbooks.com/crb-archive/I5-february -2008 /black-rain.

90 Colonial representations of islands are discussed in more detail in the introduction to DeLoughrey, Routes and Roots; see also Rod Edmond and Vanessa Smith, eds., Islands in History and Representation (London: Routledge, 2003). On the garden and allegory see Clifford, The Transformation of Allegory, iо .

9I Samuel Durrant, Postcolonial Narrative and the Work of Mourning: J. M. Coetzee, Wilson Harris, and Toni Morrison (Albany: State University of New York Press, 2004).

92 Hayden White, The Content of the Form: Narrative Discourse and Historical Representation (Baltimore: Johns Hopkins University Press, 1987).

93 See Benjamin, The Origin of German Tragic Drama, 166.

94 Benjamin, The Origin of German Tragic Drama, 166.

95 Charles Morrow Wilson, Roots: Miracles Below (Garden City, NY: Doubleday, 1967), 2.

96 See Benjamin, The Origin of German Tragic Drama, 166.

97 White, The Content of the Form, I8I. All of the metaphors used to describe him are associated with trees and their death. This encodes a different temporality of the novel that is measured by human endeavor but not necessarily in human time.

98 Brodber draws names significant to Thomas Thistlewood's diary: see Douglas Hall, ed., In Miserable Slavery: Thomas Thistlewood in Jamaica I750-I786 (Mona, Jamaica: University of the West Indies Press, 1998).

99 See Erna Brodber, The Continent of Black Consciousness: On the History of the African Diaspora from Slavery to the Present Day (London: New Beacon, 2003).

Ioo Robert Pogue Harrison, "Hic Jacet," Critical Inquiry 27, no. 3 (2001): 398. 
Derek Walcott, “The Sea Is History," in Collected Poems, 1948-1984 (New York: Farrar, Straus and Giroux, 1986), 364-67.

IO2 Robert Pogue Harrison notes that "the surest way to take possession of a place and secure it as one's own is to bury one's dead in it": Harrison, "Hic Jacet," 398 .

103 See Nancy Leys Stepan, The Hour of Eugenics (Ithaca, NY: Cornell University Press, 1992); Mimi Sheller, Citizenship from Below: Erotic Agency and Caribbean Freedom (Durham, NC: Duke University Press, 2012); Juanita De Barros, Reproducing the British Caribbean: Sex, Gender, and Population Politics after Slavery (Chapel Hill: University of North Carolina Press, 2014)

I04 McCole, Walter Benjamin and the Antimonies of Tradition, 136.

IO5 As Jenny Sharpe remarks in Allegories of Empire, the Baroque mourning play was caught up in discourses of modernity that were produced through the violence of colonialism. See the discussion in the introduction to this book.

Io6 Erna Brodber, "Afro-Jamaican Women at the Turn of the Century," Social and Economic Studies 35, no. 3 (1986): 23-50.

Io7 Edward Kamau Brathwaite, “Submerged Mothers," Jamaica Journal 9, nos. 2-3 (1975): 48-49.

I08 "Extinction names not just private deaths of finite individuals but the irreversible disappearance of kinds - much more than many little deaths. Humanity orchestrates the peril of mass extinction through species suicide, ecological devastation, and planetary obliteration": Srinivas Aravamudan, "The Catachronism of Climate Change," Diacritics 4I, no. 3 (2013): 6-30. Many conversations with Kristen Cardon about species suicide brought this to my attention; see her forthcoming dissertation, "Narrative Suicidology: Suicide Notes In Fact, Fiction, and Species." (Geno- may also be derived etymologically from genetics.)

I09 Montgomery, Dirt, 3.

IIO Montgomery, Dirt, 3, 174.

II Work focusing on the environment in Jamaica is still limited. See the important documentary films by Esther Figueroa-Jamaica for Sale (2008-2009), Cockpit Country: Voices from Jamaica's Heart (2007), and Massa God Fish Can Done (2009) - and her short videos on YouTube. Her novel Limbo fictionalizes some devastating ecological threats to the island nation: Esther Figueroa, Limbo: A Novel about Jamaica (New York: Arcade, 2014). Stephanie Black's film Life and Debt (200I) remains one of the more important investigations into the collapse of Jamaican agriculture due to neoliberal regimes of globalization. Jean Binta Breeze has also critiqued the International Monetary Fund's decimation of rural Jamaica: see Jenny Sharpe, "Dub and Difference: A Conversation with Jean 'Binta' Breeze," Callaloo 26, no. 3 (2003): 607-I3.

II2 Harrison, "Hic Jacet," 404.

II3 Serres, The Natural Contract, 50.

II 4 Teskey, Allegory and Violence, 4. 


\section{PLANETARITY}

Epigraphs: Donald Worster, Nature's Economy: A History of Ecological Ideas, 2nd ed. (Cambridge: Cambridge University Press, 1994), 342; Theodor Adorno and Max Horkheimer, Dialectic of Enlightenment, trans. John Cumming (New York: Continuum, 1976), 3. Jan A. Zalasiewicz, Mark Williams, Will Steffen, and Paul Crutzen, "The New World of the Anthropocene," Environmental Science and Technology Viewpoint 44, no. 7 (2010): 2228-3I.

2 Quan Hua, Mike Barbetti, and Andrzej Z. Rakowski, "Atmospheric Radiocarbon for the Period I950-2010," Radiocarbon 55, no. 4 (2013): 2059-72; Gary J. Hancock, Stephen G. Tims, Keith Fifield, and Ian T. Webster, "The Release and Persistence of Radioactive Anthropogenic Nuclides," Geological Society 395 (2014), doi: I0.1144/SP395.I5; Jonathan Dean, Melanie Leng, and Anson Mackay, "Is There an Isotopic Signature of the Anthropocene?" Anthropocene Review I, no. I3 (2014): 276-87; Colin N. Waters, James P. M. Syvitski, Agnieszka Gałuszka, and Gary J. Hancock et al., "Can Nuclear Weapons Fallout Mark the Beginning of the Anthropocene Epoch?” Bulletin of Atomic Scientists 7I, no. 3 (2015): I-I2.

Dipesh Chakrabarty, "Postcolonial Studies and the Challenge of Climate History," New Literary History 43 (2012): I-2.

Angus Fletcher, "Chapter I: The Daemonic Agent," in Allegory: The Theory of a Symbolic Mode (Princeton, NJ: Princeton University Press, 2012), 24-68. See also Bruce Clarke, "Allegory and Science," in Energy Forms: Allegory and Science in the Era of Classical Thermodynamics (Ann Arbor: University of Michigan Press, 200I), 17-34. Clarke, "Allegory and Science," 2 I.

6 Clarke, "Allegory and Science," 22.

7 See Jacques Derrida, "White Mythology: Metaphor in the Text of Philosophy," in Margins of Philosophy, trans. Alan Bass (Chicago: University of Chicago Press, 1982); Emmanuel Levinas, Totality and Infinity (Pittsburgh: Duquesne University Press, 1969); the discussions in David-Michael Kleinberg Levin, The Philosopher's Gaze: Modernity in the Shadows of Enlightenment (Berkeley: University of California Press, 1999); David Grandy, "The Otherness of Light: Einstein and Levinas," Postmodern Culture I2, no. I (200I): 7; Hans Blumenberg, "Light as a Metaphor for Truth: At the Preliminary Stage of Philosophical Concept Formation," in Modernity and the Hegemony of Vision, ed. David Michael Levin (Berkeley: University of California Pres, 1993), $30-86$.

8 Derrida, "White Mythology," 44.

9 Derrida, "White Mythology," 43. He argues that we are unwillingly drawn "by the movement which turns the sun into metaphor or attracted by that which turns philosophical metaphor towards the sun": Derrida, "White Mythology," 5I. The sun, which is "always turning, thus appearing and hiding itself," is, in 
Derrida’s words, a "bad metaphor which gives only improper knowledge": Derrida, "White Mythology," 52.

Io Grandy, "The Otherness of Light."

II Arthur Zajonc, Catching the Light: The Entwined History of Light and Mind (Oxford: Oxford University Press, 1995), 7, 9.

Gayatri Chakravorty Spivak, Death of a Discipline (New York: Columbia University Press, 2003), 72. Spivak's emphasis is ethical and spatial. For a temporal approach to literature, see Wai Chee Dimock, Through Other Continents: American Literature across Deep Time (Princeton, NJ: Princeton University Press, 2006). Spivak, Death of a Discipline, 77; Grandy, "The Otherness of Light."

I4 A list, current through 1996, is compiled by the Oklahoma Geological Survey Observatory and is available at http://nuclearweaponarchive.org/Library/Catalog. Theodor Adorno and Max Horkheimer, Dialectic of Enlightenment, trans. John Cumming (New York: Continuum International, 1976), 3 .

On Cold War technologies and their impact on modernity, see Lisa Cartwright, Screening the Body: Tracing Medicine's Visual Culture (Minneapolis: University of Minnesota Press, 1995); Paul Virilio, The Vision Machine (Bloomington: Indiana University Press, 1994); Joseph Masco, The Nuclear Borderlands: The Manhattan Project in Post-Cold War New Mexico (Princeton, NJ: Princeton University Press, 2006).

I7 See Bernard Smith, European Vision and the South Pacific (New Haven: Yale University Press, 1985).

I8 See Stewart Firth, Nuclear Playground (Honolulu: Pacific Islands Studies Program, Center for Asian and Pacific Studies, University of Hawai'i, 1987); Stewart Firth and Karin von Strokirch, "A Nuclear Pacific," in The Cambridge History of the Pacific Islanders, ed. Donald Denoon, Malama Meleisea, Stewart Firth, Jocelyn Linnekin, and Karen Nero (Cambridge: Cambridge University Press, 1997), 324-58.

I9 The nuclear history of the island laboratory is explored in Elizabeth M. DeLoughrey, "The Myth of Isolates: Ecosystem Ecologies in the Nuclear Pacific," Cultural Geographies 20, no. 2 (April 2013), 167-84.

20 Martin Jay, Downcast Eyes: The Denigration of Vision in Twentieth-Century French Thought (Berkeley: University of California Press, 1993), 2.

2I Grandy, “The Otherness of Light."

22 Donald Worster, Nature's Economy, 343.

23 Zalasiewicz et al., "The New World of the Anthropocene," 28.

24 The work on nuclearism and its fallout is immense, but sources that were particularly influential to my thinking include Holly M. Barker, Bravo for the Marshallese: Regaining Control in a Post-Nuclear, Post-Colonial World (Belmont, CA: Wadsworth, 2004); Paul Boyer, By the Bomb's Early Light: American Thought and Culture at the Dawn of the Atomic Age (Chapel Hill: University of North Carolina Press, 1994); Catherine Caufield, Multiple Exposures: Chronicles of the Radiation Age (New York: Harper and Row, 1990); Robert Jungk, Brighter Than a 
Thousand Suns: A Personal History of the Atomic Scientists (New York: Harcourt Brace, 1958); Firth, Nuclear Playground; Masco, The Nuclear Borderlands; Richard Rhodes, The Making of the Atomic Bomb (New York: Simon and Schuster, 1990); Teresia K. Teaiwa, "bikinis and other s/pacific n/oceans," in Voyaging through the Contemporary Pacific, ed. David L. Hanlon and Geoffrey Miles White (Lanham, MD: Rowman and Littlefield, 2000), 91-II2; Spencer R. Weart, Nuclear Fear: $A$ History of Images (Cambridge, MA: Harvard University Press, 1988); Eileen Welsome, The Plutonium Files: America's Secret Medical Experiments in the Cold War (New York: Dial, 1999); Jonathan M. Weisgall, Operation Crossroads: The Atomic Tests at Bikini Atoll (Annapolis: Naval Institute Press, 1994).

25 This is the argument made in Victor Bascara, Keith L. Camacho, and Elizabeth DeLoughrey, "Gender and Sexual Politics in the Pacific Islands: A Call for Critical Militarisation Studies," Intersections: Gender and Sexuality in Asia and the Pacific 37 (March 2015). http://intersections.anu.edu.au/issue37/bascara_camacho_de loughrey.html. See also Robert P. Marzec, Militarizing the Environment: Climate Change and the Security State (Minneapolis: University of Minnesota Press, 2015).

26 See "The U.S. Military and Oil," Union of Concerned Scientists, n.d., accessed October 16, 2018, http://www.ucsusa.org/clean_vehicles/smart-transportation -solutions/us-military-oil-use.html\#.Wcv6kbKGOpo. See also Marzec, Militarizing the Environment; and Elizabeth DeLoughrey, "Towards a Critical Ocean Studies for the Anthropocene," ELN 57, no. I (April 2019): 21-36. Joel Bartholemew Hagen, An Entangled Bank: The Origins of Ecosystem Ecology (New Brunswick, NJ: Rutgers University Press, 1992), IOI.

28 Hagen, An Entangled Bank, I02, I03, I05.

29 Hagen, An Entangled Bank, II2.

30 Fernand Braudel, On History, trans. Sarah Matthews (Chicago: University of Chicago Press, 1980). See also Masco, The Nuclear Borderlands, 4. Michael Stephenson and John Weal, Nuclear Dictionary (London: Longman, I985), 70.

32 Caufield, Multiple Exposures, 136.

33 See Welsome, The Plutonium Files; Barker, Bravo for the Marshallese; Barbara Rose Johnston, Half-Lives and Half-Truths: Confronting the Radioactive Legacies of the Cold War (Santa Fe, NM: School for Advanced Research Press, 2007).

34 See U.S. Department of Energy, Office of Scientific and Technical Information, OpenNet database, http://www.osti.gov/opennet/.

35 See the examination of fallout as a concept in Joseph Masco, "Terraforming Planet Earth," in Global Ecologies and the Environmental Humanities: Postcolonial Approaches, ed. DeLoughrey, Didur, and Carrigan (New York: Routledge, 2015).

36 Paul J. Crutzen, "Geology of Mankind," Nature 4I5 (2002): 23; Paul J. Crutzen and John W. Birks, "The Atmosphere after a Nuclear War: Twilight at Noon," Ambio II (1982): II4-25.

37 Paul N. Edwards, "Entangled Histories: Climate Science and Nuclear Weapons Research," Bulletin of the Atomic Scientists 68, no.4 (2012): 28-40, 28; also 
discussed in Elizabeth DeLoughrey, "Satellite Planetarity and the Ends of the Earth," Public Culture 26, no. 2 (Spring 2014): 257-80.

38 Caufield, Multiple Exposures.

39 Edwards, "Entangled Histories," 30.

40 Edwards, "Entangled Histories," 30-3 1 .

4I Joseph Masco, "Bad Weather: On Planetary Crisis," Social Studies of Science 40, no. I (2010): 7-40.

42 Edwards, "Entangled Histories"; Spencer R. Weart, The Discovery of Global Warming: A Hypertext History of How Scientists Came to (Partly) Understand What Humans Are Doing to the Earth's Climate (College Park, MD: Center for the History of Physics, American Institute of Physics, 2007), http://www.aip .org/history/climate.

43 Rodger Revelle and Hans E. Suess, "Carbon Dioxide Exchange between the Atmosphere and Ocean and the Question of an Increase of Atmospheric $\mathrm{CO}_{2}$ during the Past Decades," Tellus 9 (1957): 19.

44 "Deciphering Climate Messages via the Heart of the Atom," June 15, 2013, accessed October 16, 2018, https://simpleclimate.wordpress.com/2013/06/15 /deciphering-climate-messages-via-the-heart-of-the-atom.

45 The Apollo images are discussed thoroughly in Denis Cosgrove, Apollo's Eye: $A$ Cartographic Genealogy of the Earth in the Western Imagination (Baltimore: Johns Hopkins University Press, 200r), and Ursula Heise, Sense of Place and Sense of Planet (Oxford: Oxford University Press, 2008). Their relevance to planetary climate change is addressed in DeLoughrey, "Satellite Planetarity and the Ends of the Earth."

46 Cosgrove, Apollo's Eye, 206.

47 See H. Alley Smith, "Where's That Crazy Weather Coming From?" Saturday Evening Post, August I, 1953, 30, 89-90.

48 Others argued that atomic weapons could be used to "tidy up the awkward parts of the world": quoted in Boyer, By the Bomb's Early Light, II3.

49 Weart, Nuclear Fear, 104.

so Weart, Nuclear Fear, I03. Laurence later described the first Bikini tests as "like the birth and death of a star," "a gigantic white sun, ten times larger than natural," and the "awe of a new cosmic force": William Laurence, Dawn over Zero: The Story of the Atomic Bomb (New York: Alfred A. Knopf, 1946), 276, 280,284 .

5I Laurence, "Is Atomic Energy the Key to Our Dreams?" Saturday Evening Post, April I3, 1946, 9-10, 36-4I, 90. See also Laurence, Dawn over Zero. Truman announced the bombing of Hiroshima "as a harnessing of the basic power of the universe. The force from which the sun draws its power has been loosed against those who brought war to the Far East": quoted in Weart, Nuclear Fear, 103.

52 "From the sun you and I get ... the energy that gives life and sustains life, the energy that builds skyscrapers and churches, that writes poems and symphonies": David E. Lilienthal, "Atomic Energy Is Your Business" Bulletin of Atomic Scientists 3, no. II (November 1947): 335-36. 
Weisgall, Operation Crossroads, I76; Robert Stone, dir., Radio Bikini, documentary film, New Video Group, 1987.

54 See Boyer, By the Bomb's Early Light, i88.

55 Spivak, Death of a Discipline, 73.

56 Boyer, By the Bomb's Early Light; Ralph Eugene Lapp, Must We Hide? (Cambridge: Addison-Wesley, 1949), III, 314.

57 Spivak, Death of a Discipline, 77.

58 Stephen Hilgartner, Rory O'Connor, and Richard C. Bell, Nukespeak: The Selling of Nuclear Technology in America (Harmondsworth, UK: Penguin, 1982). Paul Chilton used the term the same year: see Paul Chilton, "Nukespeak: Nuclear Language, Culture, and Propaganda" in Nukespeak: The Media and the Bomb, ed. Crispin Aubrey (London: Comedia, 1982).

59 Quoted in Caufield, Multiple Exposures, 26.

60 Hilgartner et al., Nukespeak, 4, 9.

6I The recognition of radium's lethal qualities did not diminish the practice through the first half of the twentieth century to treat cancers and other diseases, particularly those associated with women's reproductive systems, with radium (Weart, The Discovery of Global Warming, 48). In fact, so embedded were the semantic connections between radiation, radium, and rays of sunlight with longevity and health that knowledge of Marie Curie's death from radiuminduced leukemia in 1934 did little to minimize the American production of and desire for radium-illuminated watches and dials, contraceptive jellies, skin-lightening creams, and whitening toothpaste, even through the I970s: Caufield, Multiple Exposures, 27-28; Weart, The Discovery of Global Warming, 50; S. G. Hutchison and F. I. Hutchison, "Radioactivity in Everyday Life," Journal of Chemical Education 74, no. 5 (May 1997): 503.

62 See Jane Dibblin, Day of Two Suns: U.S. Nuclear Testing and the Pacific Islanders (London: Virago, 1988); Barker, Bravo for the Marshallese; Barbara Rose Johnston and Holly Barker, Consequential Damages of Nuclear War: The Rongelap Report (Walnut Creek, CA: West Coast Press 2008).

63 Jungk, Brighter Than a Thousand Suns, 3 IO.

64 Quoted in Jungk, Brighter Than a Thousand Suns, 3 II.

65 Children who drank milk between the years 1955 and 1965 demonstrate higher levels of strontium-90 in their bones due to the atmospheric nuclear tests of that era: Stephenson and Weal, Nuclear Dictionary, I3I.

66 Jungk, Brighter Than a Thousand Suns, 312.

67 Welsome, The Plutonium Files, 299.

68 Quoted in Welsome, The Plutonium Files, 303. In 1958, the United States, United Kingdom, and Soviet Union exploded nearly one hundred nuclear weapons, leading to record levels of strontium-9o in American soil, wheat, and milk. Only later would an AEC officer admit that "civilized man would have been in trouble" if the atmospheric testing program had continued: Caufield, Multiple Exposures, I29.

69 Boyer, By the Bomb's Early Light, 76.

70 Welsome, The Plutonium Files. 
72 See K. L. Spalding, B. A. Buchholz, L. E. Bergman, H, Druid, and J. Frisen, "Forensics: Age Written in Teeth by Nuclear Tests," Nature 437 (2005): 333-34. Interestingly, Benjamin allegorized his methodology in The Arcades Project to atomic physics, writing, "I set forth how this project—as in the method of smashing an atom-releases the enormous energy of history that lies bound in the 'once upon a time' of classical historical narrative": quoted in Susan Buck-Morss, The Dialectics of Seeing: Walter Benjamin and the Arcades Project (Cambridge, MA: MIT Press, I99I), 250.

74 Paul Virilio, War and Cinema: The Logistics of Perception (London: Verso, 1989), 68.

75 Virilio, War and Cinema, 69.

76 Virilio, War and Cinema, 88.

77 See Witi Ihimaera, The Whale Rider (Orlando, FL: Harcourt, 2003); Robert Barclay, Melal: A Novel of the Pacific (Honolulu: University of Hawai'i Press, 2002); Kiana Davenport, House of Many Gods (New York: Ballantine, 2006); Ambury Hall, ed., Below the Surface: Words and Images in Protest at French Nuclear Testing on Moruroa (Auckland, New Zealand: Vintage, 1995).

78 Teaiwa, "bikinis and other s/pacific n/oceans," 91.

79 Hone Tuwhare, No Ordinary Sun (Auckland, New Zealand: Blackwood and Janet Paul, 1964). Hereafter, page numbers are cited in parentheses in the text.

80 Quoted in Jungk, Brighter Than a Thousand Suns, 20I. It is questionable whether this was his initial response to Trinity or if, as his brother reported, he simply exclaimed, "it worked." (See Rhodes, The Making of the Atomic Bomb).

8I Jeff Smith, Unthinking the Unthinkable: Nuclear Weapons and Western Culture (Bloomington: Indiana University Press, 1989).

82 Elizabeth DeLoughrey, "Heliotropes: Solar Ecologies and Pacific Radiations," in Postcolonial Ecologies: Literatures of the Environment, ed. Elizabeth DeLoughrey and George B. Handley (Oxford: Oxford University Press, 20II), 235-53.

83 In fact, this poem sparked a close political and artistic collaboration between Hotere and Tuwhare. Hotere's "Moruroa Sunrise," a visual protest against French nuclear testing, became the cover for subsequent printings of No Ordinary Sun. Hotere has also provided the cover images for many of Tuwhare's subsequent poetry collections: see Ralph Hotere, Black Light: Major Works (Wellington, New Zealand: Te Papa Press, 2000); Gregory O’Brien, Hotere: Out the Black Window: Ralph Hotere's Work with New Zealand Poets (Auckland, New Zealand: Godwit in Association with City Gallery, Wellington, 1997).

84 Bruce Clarke, Allegories of Writing: The Subject of Metamorphosis (Albany, NY: State University of New York Press, 1995), I3.

85 Arthur Eddington, the physicist best known for his photographs of the solar eclipse in 1919 that validated Albert Einstein's Theory of General Relativity, imagined the human body as the midway point between the atom and the sun. He wrote, "From his central position man can survey the grandest works of Nature with the astrono- 
mer, or the minutest works with the physicist.... [T] he road to a knowledge of the stars leads through the atom; and important knowledge of the atom has been reached through the stars": Arthur Eddington, Stars and Atoms (New Haven, CT: Yale University Press, 1927), 9-10. Although he was referring to twentieth-century developments in physics, the microcosmos concept is perhaps the most ubiquitous in western history, spanning biblical, hermetic, and Christian discourse through to present-day assertions that humans (like all earthly matter) are made of stardust. The very term "microcosm" historically refers not to the atom but to the human body, understood as a "little universe" in which, according to the Oxford English Dictionary online, human experience represents a "miniature of divine or universal nature." The microcosmos has also been defined historically as the philosopher's stone (also known as the philosopher's fire), a figure of transmutation that changes metal into gold, mortal into immortal, and earthly into divine. Thus, the human, the microcosmos or philosopher's stone, is the figure of daemonic transmutation as poet, philosopher, physicist, or seeker of divine illumination.

86 The clock can be found at "Timeline," Bulletin of Atomic Scientists, http:// thebulletin.org/timeline.

87 I explore this novel in detail in Routes and Roots: Navigating Caribbean and Pacific Island Literatures (Honolulu: University of Hawai'i Press, 2007). For more literature of the nuclear Pacific, see Hall, Below the Surface. Barclay's Melal explores the legacy of radiogenic illness in the Marshall Islands and the American militarization of Kwajalein in particular. At the time of writing, this novel is being made into a film by Vilsoni Hereniko called Fallout.

88 I do not have space here to explore the Indigenous subtexts of the rainbow and darkness (as Te Pō, a generative space of becoming in Polynesian cosmologies). For more on its implications for Pacific literature, see Joyce Lindsay Pualani Warren's dissertation: Theorizing Pō: Embodied Cosmogony and Polynesian National Narratives, Ph.D. dissertation, University of California, Los Angeles, 2017.

89 Chantal Spitz, Island of Shattered Dreams, trans. Jean Anderson (Wellington, New Zealand: Huia, 2007), ro. Hereafter, page numbers are cited in parentheses in the text. The novel was first published as Chantal Spitz, L'île des reves écrasés (Papeete, French Polynesia: Au Vent des Iles, I991). For more on the novel and its context, see Dina El Dessouky, "Activating Voice, Body, and Place: Kanaka Maoli and Ma'ohi Writings for Kaho'olawe and Moruroa" in DeLoughrey and Handley, Postcolonial Ecologies, 254-72.

90 On counterallegory, see Jenny Sharpe, Allegories of Empire (Minneapolis: University of Minnesota Press, 1993). See also Paul Sharrad, "Island of Shattered Dreams (Review)," Contemporary Pacific 21, no. I (Spring 2009): 190-92, which discusses allegory and romance.

9I Jan A. Zalasiewicz, Colin N. Waters, Mark Williams, and Anthony D. Barnosky et. al, "When Did the Anthropocene Begin?" Quaternary International I, no. I (20I5): I-8. 
"Cosmology provides the guiding principles for human action within the world; technology provides the principles for human action upon it. Thus, as cosmology gives way to technology, the relation between people and the world is turned inside out ..., so that what was a cosmos or lifeworld becomes a world—a solid globe-externally presented to life": Tim Ingold, "Globes and Spheres: The Topology of Environmentalism," in Environmentalism: The View from Anthropology, ed. Kay Milton (London: Routledge, 1993): 4I.

93 Mark Lynas, The God Species: Saving the Planet in the Age of Humans (Washington, DC: National Geographic, 20II). For discussion see Bronislaw Szerszynski, "The End of the End of Nature: The Anthropocene and the Fate of the Human," Oxford Literary Review 34 (2012): 165-84.

94 Zalasiewicz et al., "When Did the Anthropocene Begin?" 5.

95 For a critique of origin stories of the Anthropocene, see the introduction to this book and Kathryn Yusoff, "Anthropogenesis: Origins and Endings in the Anthropocene," Theory, Culture and Society 33, no. 2 (2015): 3-28.

96 James George, Ocean Roads (Wellington, New Zealand: Huia, 2006). Hereafter, page numbers from the novel are cited in parentheses in the text.

97 Ward Churchill, "Geographies of Sacrifice: The Radioactive Colonization of Native North America," in Struggle for the Land: Native North American Resistance to Genocide, Ecocide, and Colonization, ed. Ward Churchill (San Francisco: City Lights, 2002), 239.

98 Roland Barthes, Camera Lucida: Reflections on Photography (New York: Hill and Wang, 1981), i5.

99 Walter Benjamin, The Origin of German Tragic Drama, trans. John Osborne (New York: Verso, 1998), 177-78.

Ioo Building on Siegfried Kracauer's work, Susan Sontag has called for an "ecology of images" that would correct this relationship among time, the image, and the real. She writes, "Just because [images] are an unlimited resource, one that cannot be exhausted by consumerist waste, there is all the more reason to apply the conservationist remedy. If there can be a better way for the real world to include the one of images, it will require an ecology not only of real things but of images as well”: Susan Sontag, "On Photography," in A Susan Sontag Reader, introduction by Elizabeth Hardwick (New York: Farrar, Straus, Giroux, 1982), I80. Although she later abandoned this hope because there are no "guardians" to conserve the visual onslaught of war images or the lives that are represented, this question about the distribution and consumption of images, forms of light, and radiation are a key concern to Ocean Roads: see Susan Sontag, "Looking at War: Photography's View of Devastation and Death," New Yorker 78, no. 38, December 9, $2002,97$.

IOI Siegfried Kracauer and Thomas Y. Levin, "Photography," Critical Inquiry 19, no. 3 (1993): 432 . 
IO2 See Nancy Armstrong, Fiction in the Age of Photography: The Legacy of British Realism (Cambridge, MA: Harvard University Press, 2000).

I03 Cosgrove, Apollo's Eye, I59-60. On this mystification, see Peggy Rosenthal, "The Nuclear Mushroom Cloud as Cultural Image," American Literary History 3 (1991): 63-92; Smith, Unthinking the Unthinkable; Weart, Nuclear Fear.

I04 See Walter Benjamin, Illuminations, ed. Hannah Arendt, trans. Harry Zohn (New York: Schocken, 1968).

IO5 Eduardo Cadava, Words of Light: Theses on the Photography of History (Princeton, NJ: Princeton University Press, 1997), 64.

106 On caesura, see Cadava, Words of Light, xx; Benjamin, Illuminations.

107 James George, Hummingbird (Wellington, New Zealand: Huia, 2003), 70.

Io8 They seem to have reached this observation independently: Rhodes, The Making of the Atomic Bomb; Virilio, War and Cinema, 68, 715.

I09 Akira Mizuta Lippit, Atomic Light (Shadow Optics) (Minneapolis: University of Minnesota Press, 2005), 48.

IIO Lippit, Atomic Light, 4, 8I.

II I Lippit, Atomic Light, I20.

II2 Lippit, Atomic Light, II9.

II3 Rhodes, The Making of the Atomic Bomb, 674.

II4 George's acknowledgments cite Masamoto Nasu's Children of the Paper Crane, which documents the death of one young girl from this form of cancer: Masamoto Nasu, Children of the Paper Crane: The Story of Sadako Sasaki and Her Struggle with the A-Bomb Disease (New York: M. E. Sharpe, I99i).

in Caufield, Multiple Exposures, 200.

II6 Weisgall, Operation Crossroads, 238.

i17 Welsome, The Plutonium Files, 299.

i18 Welsome, The Plutonium Files, 489.

I19 Lisa Yoneyama, Hiroshima Traces: Time, Space, and the Dialectics of Memory (Berkeley: University of California Press, 1999), i5.

I20 Daniel Tiffany, Toy Medium: Materialism and Modern Lyric (Berkeley: University of California Press, 1998), 202.

I2I Quoted in Tiffany, Toy Medium, I99.

I22 Caufield, Multiple Exposures, 53.

I23 Yoneyama, Hiroshima Traces, i5.

I24 Spivak, Death of a Discipline, 77.

I25 Susan Sontag, Illness as a Metaphor (New York: Farrar, Straus, and Giroux, 1977), 87 .

I26 Sontag, Illness as a Metaphor, 65.

I27 Fletcher, Allegory, 53.

I28 Jacques Derrida, "No Apocalypse, Not Now (Full Speed Ahead, Seven Missiles, Seven Missives)," Diacritics I4, no. 2 (1984): 20-3I.

Virilio, The Vision Machine, 35.

130 Yoneyama, Hiroshima Traces, 196.

I3I Yoneyama, Hiroshima Traces, 210. 
Epigraph: Walter Benjamin, The Origin of German Tragic Drama, trans. John Osborne (New York: Verso, 1998), 179. This chapter was first presented in 2010 and has gone through multiple reiterations, including at the universities of Warwick (20II), Florida (2013), and Sydney (20I4), as well as the 2012 ACLA annual meeting. My thanks to my interlocutors for their valuable feedback. Will Steffen, Paul J. Crutzen, and John R. McNeill, “The Anthropocene: Are Humans Now Overwhelming the Great Forces of Nature?” Ambio 36, no. 8 (2007): 614-21; Will Steffen, Åsa Persson, Lisa Deutsch, and Jan A. Zalasiewicz et al., "The Anthropocene: From Global Change to Planetary Stewardship," Ambio 40, no. 7 (2011): 739-6r. See also Jan A. Zalasiewicz, Colin N. Waters, Mark Williams, and Anthony D. Barnosky et al., "When Did the Anthropocene Begin?" Quaternary International (2014): I-8.

Walter Benjamin, The Arcades Project, ed. Rolf Tiedemann, trans. Howard Eiland and Kevin McLaughlin (Cambridge, MA: Harvard University Press, 1999), 348. Note that Benjamin's work on allegory in the The Arcades Project, focuses on nineteenth-century commodity forms and is therefore different from his analysis of the sixteenth-century Trauerspiel.

See Timothy Morton, Hyperobjects: Philosophy and Ecology after the End of the World (Minneapolis: University of Minnesota Press, 2013).

4 See Jason W. Moore, ed., Anthropocene or Capitalocene? Nature, History, and the Crisis of Capitalism (Oakland, CA: P M Press, 2016); and Christina Reed, "Dawn of the Plasticene Age," New Scientist 225, no. 3006 (January 2015): 28-32. Peter K. Haff, “Technology as a Geological Phenomenon: Implications for Human Well-Being," in A Stratigraphical Basis for the Anthropocene, ed. Colin N. Waters, Jan A. Zalasiewicz, Mark Williams, Michael A. Elis, and Andrea M. Snelling (London: Geological Society, 2014).

The literature on globalization is enormous, but works that have influenced my thinking include Arjun Appadurai, Modernity at Large: Cultural Dimensions of Globalization (Minneapolis: University of Minnesota Press, 1996); Ali Behdad, "On Globalization, Again," in Postcolonialism and Beyond, ed. Suvir Kaul and Ania Lumba (Durham, NC: Duke University Press, 2005); James Clifford, Routes: Travel and Translation in the Late 2oth Century (Cambridge, MA: Harvard University Press, 1997); Carla Freeman, "Is Local : Global as Feminine : Masculine? Rethinking the Gender of Globalization," Signs 26, no. 4 (2001): 1007-37; Anthony Giddens, The Consequences of Modernity (Stanford, CA: Stanford University Press, 1990); Simon Gikandi, "Globalization and the Claims of Postcoloniality," South Atlantic Quarterly 100, no. 3 (Summer 2001): 627-58; David Harvey, The Condition of Postmodernity (London: Basil Blackwell, 1989); Mary Louise Pratt, "Modernity and Periphery: Towards a Global and Relational Analysis," in Beyond Dichotomies: Histories, Identities, Cultures, and the Challenge of Globalization, ed. Elisabeth Mudimbe-Boyi (Albany: State University of 
New York Press, 2002), 2I-48; Michel-Rolph Trouillot, "The Perspective of the World: Globalization Then and Now," in Mudimbe-Boyi, Beyond Dichotomies, 3-20.

7 Jan A. Zalasiewicz, Mark Williams, Colin N. Waters, Anthony D. Barnosky, and Peter K. Haff, "The Technofossil Record of Humans," Anthropocene Review I, no. I (2014): 35 .

8 Marcus Eriksen, Laurent C. M. Lebreton, Henry S. Carson, and Martin Thiel et al., "Plastic Pollution in the World's Oceans: More Than 5 Trillion Plastic Pieces Weighing over 250,000 Tons Afloat at Sea," PLOS One, December Io, 2014, http://journals.plos.org/plosone/article?id=I0.1371/journal.pone .orir913; Charles Moore, "Choking the Oceans with Plastic," New York Times, August 25, 2014; Jessica Glenza, "Sea Salt around the World Is Contaminated by Plastic, Studies Show," The Guardian, September 8, 2017, https:// www.theguardian.com/environment/2017/sep/o8/sea-salt-around-world -contaminated-by-plastic-studies.

9 Benjamin, The Arcades Project, 545.

io Zalasiewicz et al., "The Technofossil Record of Humans," 4r.

II I am trying to offer an alternative reading of the Anthropocene from that of Clive Hamilton and his colleagues, who argue, "Talk of ethics renders banal a transition that belongs to deep time, one that is literally Earth-shattering. In deep time, there are no ethics": Clive Hamilton, Christophe Bonneuil, and François Gemenne, "Thinking the Anthropocene," in The Anthropocene and the Global Environmental Crisis: Rethinking Modernity in a New Epoch, ed. Clive Hamilton, François Gemenne, and Christophe Bonneuil (London: Routledge, 2015), 8. Bronislaw Szerszynski, "The End of the End of Nature: The Anthropocene and the Fate of the Human," Oxford Literary Review 34 (2012): 169.

I3 Libby Robin, "Histories for Changing Times: Entering the Anthropocene?" Australian Historical Studies 44, no. 3 (2013), accessed May 26, 2014, doi: 10.1080/1031461X.2013.817455.329-340.331,334.

I4 Benjamin, The Arcades Project, 206.

I5 Benjamin, The Arcades Project, 207.

I6 Benjamin, The Arcades Project, 461.

I7 See, e.g., Gikandi, "Globalization and the Claims of Postcoloniality."

I8 Hannah Arendt, The Origins of Totalitarianism (New York: Harcourt, Brace and World, 1966). See also Judith Butler and Gayatri Chakrabarty Spivak, Who Sings the Nation-State? Language, Politics, Belonging (London: Seagull, 2007).

19 See "This Dome in the Pacific Houses Tons of Radioactive Wasteand It's Leaking," The Guardian, July 3, 2015, accessed October 18, 2018, http://www.theguardian.com/world/2015/jul/o3/runit-dome-pacific -radioactive-waste. As this book was in press Kathy Jetñil-Kijiner released her video-poem about the island, called "Anointed." See http://www .kathyjetnilkijiner.com/blog/.

20 See, e.g., Chakrabarty's essay on waste and the British empire in India: Dipesh Chakrabarty, "Of Garbage, Modernity and the Citizen's Gaze," Economic and 
Political Weekly 27, nos. I0-II (March 7-14, 1992): 54I-47; William Cohen and Ryan Johnson, Filth: Dirt, Disgust, and Modern Life (Minneapolis: University of Minnesota Press, 2004); Kenneth Harrow, Trash: African Cinema from Below (Bloomington: Indiana University Press, 2013). Lawrence Summers, "Let Them Eat Pollution," The Economist, February 8, 1992, 66.

22 Zalasiewicz et al., "The Technofossil Record of Humans," 35.

23 Jason W. Moore, “Anthropocene or Capitalocene?”, http://jasonwmoore .wordpress.com/2013/05/13/anthropocene-or-capitalocene. This webpage is an excerpt from Jason W. Moore, Capitalism in the Web of Life: Ecology and the Accumulation of Capital (New York: Verso, 2015), 173-95.

24 Mary Douglas, Purity and Danger: An Analysis of Concept of Pollution and Taboo (New York: Praeger, 1966).

25 Robert Stam, "Beyond Third Cinema: The Aesthetics of Hybridity," in Rethinking Third Cinema, ed. Anthony R. Guneratne and Wimal Dissanayake (New York: Routledge, 2003), 4I. See also John Scanlan, On Garbage (London: Reaktion, 2005), 136.

26 Benjamin, The Arcades Project, 366.

27 Zygmunt Bauman, Wasted Lives: Modernity and Its Outcasts (Cambridge, MA: Polity, 2003).

28 Gay Hawkins, The Ethics of Waste: How We Relate to Rubbish (Lanham, MD: Rowman and Littlefield, 2005), 56.

29 Hawkins, The Ethics of Waste, 52.

30 Scanlan, On Garbage, I2.

3I Scanlan, On Garbage, 8.

32 Scanlan, On Garbage, 16.

33 Scanlan, On Garbage, 16.

34 Slavoj Žižek, in Astra Taylor, dir., Examined Life, documentary film, Zeitgeist, 20I0. The field of garbology has been rapidly expanding since I first presented this paper in 2010: see Carl A. Zimring and William L. Rathje, Encyclopedia of Consumption and Waste: The Social Science of Garbage (Thousand Oaks, CA: Sage, 2012); Harrow, Trash.

35 Derek Walcott, What the Twilight Says (New York: Farrar, Straus and Giroux, 1998), 68.

36 George Handley, Renée Gosson, and I discuss Walcott's theory of history and place and Caribbean literature's turn to nonhuman nature in the introduction to Elizabeth M. DeLoughrey, Renée K. Gosson, and George B. Handley, eds., Caribbean Literature and the Environment: Between Nature and Culture (Charlottesville: University of Virginia Press, 2005). See also Ann Laura Stoler, "Imperial Debris: Reflections on Ruins and Ruinations," Cultural Anthropology 23, no. 2 (2008): 191-219. Derek Walcott, "The Royal Palms ... an Absence of Ruins," London Magazine, vol. I, no. I1, I962, I2-13. Orlando Patterson's second novel, Absence of Ruins, derives its title from Walcott's poem: Orlando Patterson, An Absence of Ruins (Leeds, UK: Peepal Tree, 2012). 
John Hearne, The Sure Salvation (London: Faber and Faber), 1985. "Smellscape" is taken from Brian J. Hudson, "The Landscapes of Cayuna: Jamaica through the Senses of John Hearne," Caribbean Geography 3, no.3 (1992): 175-86. This novel is discussed at length in Elizabeth M. DeLoughrey, Routes and Roots: Navigating Caribbean and Pacific Island Literatures (Honolulu: University of Hawai' i Press, 2007).

38 See Andrew Salkey, The Late Emancipation of Jerry Stover (London: Hutchinson, 1968). Patterson's novel is discussed later in this chapter. See Nicole A. Waligora-Davis's Sanctuary: African Americans and Empire (New York: Oxford University Press, 20II) and Christina Sharpe's In the Wake: On Blackness and Being (Durham, NC: Duke University Press, 2016), which both draw compelling parallels between the hold of the slave ship, the ghettoization of the racialized poor, and U.S. state regimes of incarceration.

39 See also the video and his commentary in "Tony Capellán—Entrevista— Cielonaranja," October 27, 2010, accessed October I8, 2018, http://www .youtube.com/watch?v=dmNTitTP $3 \mathrm{D}_{4}$.

40 Zygmunt Bauman, Liquid Modernity (Cambridge, MA: Polity, 2000), 66, 97.

4I The movement has radically changed contemporary art. I thank Judith Bettelheim for her guidance in this period of art. Arte Povera might be placed in relation to Ngugi's "poor theory" and globalization: see Ngugi wa Thiong'o, Globalectics: Theory and the Politics of Knowing (New York: Columbia University Press, 2012).

42 He points out that his materials are not artificially colored for display: Tony Capellán, personal correspondence with the author, November 2012.

43 Erling Borgen, Hispaniola fantastiske kunst/The Fantastic Art of Hispaniola, trans. Sophia Lykke, DVD, 2003.

44 Capellán, personal correspondence.

45 See John D. Sutter, "The Shoes Are Marching for Us," CNN, November 29, 2015, accessed October 18, 2018, https://www.cnn.com/2015/11/29/opinions /sutter-climate-demonstration-paris-cop2r/index.html.

46 "Es una de mis obsessións más fuertes, el mar caribe, porque el mar caribe ha sido el vehículo por que ha venido toda la cultura que conocemos ahora. Nuestra cultura aborigen fue extinguida. Entonces, estos zapatos y todas de las más materiales que uso ahora los traien el mar porque vienen por el río Ozama, y la gente vive alrededor del río, cuando sube el agua, entra a las casas, se lo lleva, y yo los recogo en todas las playas de litoral de Santo Domingo": Borgen, Hispaniola fantastiske kunst.

47 See Erin B. Taylor, Materializing Poverty: How the Poor Transform Their Lives (Lanham, MD: Rowman and Littlefield, 2013), 27-3I.

48 "Santo Domingo Is among the Cities with the Biggest Risk of Being Affected by Climate Change," International Business Times, February 8, 2013, accessed October 18, 2018, http://www.ibtimes.com/santo-domingo-among-cities -biggest-risk-being-affected-climate-change-I46I 488. 
"Climate Change and Poverty, a Deadly Cocktail for Dominicans," Inter Press Service, July 26, 2012, accessed October 18, 2018, http://www .ipsnews.net/2012/07/climate-change-and-poverty-a-deadly-cocktail-for -dominicans.

50 Capellán, personal correspondence. In February 2015, the government began to allocate funds: see "Agencia ortoga préstamo de 210 MM de dólares para ordenamiento urbano SDE," Hoy, February 4, 2015, accessed October I8, 2018, http://hoy.com.do/agencia-otorga-prestamo-de-210-mm-de-dolares-para -ordenamiento-urbano-sde. Benjamin, The Arcades Project, 207.

52 Benjamin, The Arcades Project, 330.

53 Naomi Paik, "Carceral Quarantine at Guantánamo Legacies of U.S. Imprisonment of Haitian Refugees, 1991-1994," Radical History Review II5 (2013): 142-68.

54 On the visual representation of this history, see the important article by Lizabeth Paravisini-Gebert and Martha Daisy Kelehan, "The 'Children of the Sea': Uncovering Images of the Botpippel Experience in Caribbean Art and Literature," in Displacements and Transformations in Caribbean Cultures, ed. Lizabeth Paravisini-Gebert and Ivette Robero-Cesareo (Gainesville: University Press of Florida, 2008), I27-6I.

55 Nikòl Payen, "Something in the Water," in The Butterfly's Way: Voices from the Haitian Dyaspora in the United States, ed. Edwidge Danticat (New York: Soho, 2001), 66-82.

56 For an astute analysis of Payen's translation work, see April Shemak, Asylum Speakers: Caribbean Refugees and Testimonial Discourse (Bronx, NY: Fordham University Press, 2010).

57 Reviel Netz, Barbed Wire: An Ecology of Modernity (Middleton, CT: Wesleyan University Press, 2004), xii.

58 Jorge Duany, "Dominican Migration to Puerto Rico: A Transnational Perspective," Centro Journal I7, no. I (2005): 246.

59 See the ironic commentary by Colectivo Shampoo, who create a "Mona Mall" as a place to stop for commercial goods in the dangerous passage: Tumelo Mosaka, Annie Paul, and Nicollette Ramirez, Infinite Island: Contemporary Caribbean Art (New York: Brooklyn Museum in Association with Philip Wilson, 2007). I thank Robin Derby and Judith Bettleheim for bringing this to my attention.

60 Duany, "Dominican Migration to Puerto Rico," 249. See Ben Bowling, Policing the Caribbean: Transnational Security Cooperation in Practice (Oxford: Oxford University Press, 2010).

6I Lizabeth Paravisini-Gebert and Martha Daisy Kelehan, "The 'Children of the Sea," 128.

62 See Laurie Ann Farrell, "Island Thresholds: Contemporary Art from the Caribbean," NKA: Journal of Contemporary African Art 21 (2007): I29.

63 Benjamin, The Arcades Project, 33 I. 
64 Benjamin, The Arcades Project, 9.

65 Benjamin, The Arcades Project, 205.

66 Bauman, Wasted Lives, 9.

67 Jenny Sharpe, Allegories of Empire: The Figure of Woman in Colonial Text (Minneapolis: University of Minnesota Press, 1993), I4.

68 On allegory, see Gay Clifford, The Transformation of Allegory (London: Routledge and Kegan Paul, 1974), 97. See John McCole, Walter Benjamin and the Antinomies of Tradition (Ithaca, NY: Cornell University Press, 1993), I40. This is discussed in detail in the introduction to this book.

69 On the rise of hygienic modernity and its associated effluvia, see Alain Corbin, The Foul and the Fragrant (Cambridge, MA: Harvard University Press, 1988). On boundary surveillance the discourse of purity and pollution, see Douglas, Purity and Danger.

70 For more on aqua nullius see DeLoughrey, Routes and Roots, 22-30.

7I Gaston Bachelard, Water and Dreams: An Essay on the Imagination of Matter, trans. Edith Farrell (Dallas: Pegasus Foundation, 1983) II, 56. I build on his idea in Elizabeth DeLoughrey, "Heavy Waters: Waste and Atlantic Modernity," PMLA I25, no. 3 (2010): 703-12. This idea is elaborated in DeLoughrey, Routes and Roots, chapter I.

72 Bachelard, Water and Dreams, 6.

73 Cynthia James, "The Unknown Text," World Literature Today 68, no. 4 (1994): 758; Kamau Brathwaite, "Haltering the Landscapes of the Wind," World Literature Today 68, no. 4 (1994): 654. A longer discussion of "Dream Haiti" that examines the ocean as a space of metallic modernity appears in DeLoughrey, "Heavy Waters," 708-ir. See also Sharpe, In the Wake.

74 Clifford, The Transformation of Allegory, 3, 11, 25.

75 Kamau Brathwaite, "Dream Haiti," in Dream Stories (Harlow, UK: Longman, 1994), 97; Shemak, Asylum Speakers, 83.

76 Brathwaite, Dream Stories, Io I.

77 Bauman, Wasted Lives, 28.

78 Brathwaite, Dream Stories, ino.

79 Brathwaite, Dream Stories, IO2. I thank LeGrace Benson and Judith Bettelheim for their helpful discussions about Brierre's work.

80 Brathwaite, Dream Stories, 96.

8I Brathwaite, Dream Stories, 108. Brathwaite breaks from the Romantic narrative of salvation and redemption that David Scott has noted of early postcolonial historicism, particularly C. L. R. James's initial history of the Haitian revolutionary Touissant Louverture: David Scott, Conscripts of Modernity (Durham, NC: Duke University Press, 2004), 134. Instead, Brathwaite's dream voyage focuses on Toussaint's containment in Napoleon's jail, highlighting how the border making of liquid modernity expands to the land, depicting "the glacial seas of the/Jura" mountains where Touissant perished: see Brathwaite, Dream Stories, 9.

82 Brathwaite, Dream Stories, ino. 
84 Marie-José Nzengou-Tayo, "Kamau Brathwaite and the Haitian Boat People: Dream Haiti or the Nightmare of the Caribbean Intellectual," in Caribbean Culture: Soundings on Kamau Brathwaite, ed. Annie Paul (Kingston, Jamaica: University of West Indies Press, 2006), 184; Brathwaite, Dream Stories, 49. See also Christina Sharpe's In the Wake: On Blackness and Being for her engagement with Brathwaite's work.

85 Bauman, Wasted Lives, 57.

86 Stam, "Beyond Third Cinema," 40.

87 Emily Brownell, "Negotiating the New Economic Order of Waste," Environmental History I6, no. 2 (2011): 276.

88 “U.S. Refuses to Remove Philadelphia’s Toxic Ash from Gonaives," International Liaison Office for President Jean-Bertrand Aristide, Haiti Update, November 8, 1995, accessed October 18, 2018, http://www.hartford-hwp .com/archives/ $43 \mathrm{a} / 259 . \mathrm{html}$. The Bay of Gonaïve dumping is described as an invasion of toxic wastes in a recent Haitian noir by Rodney Saint-Éloi, whose short story "The Blue Hill" describes the dumping, its poisoning of the local community, and its hallucinatory effects on the mind of the detective narrator: Rodney Saint-Eloi, “The Blue Hill," in Haiti Noir, ed. Edwidge Danticat (Brooklyn, NY: Akashic, 2010).

89 Brownell, "Negotiating the New Economic Order of Waste," 278.

90 Greenpeace International, "The Transboundary Movement of Hazardous and Nuclear Wastes in the Wider Caribbean Region-A Call for a Legal Instrument within the Cartagena Convention," CEP Technical Report no. 7, Caribbean Environment Programme, Kingston, Jamaica, I991, 2.

91 Greenpeace International, "The Transboundary Movement of Hazardous and Nuclear Wastes in the Wider Caribbean Region," 2.

92 Brownell, "Negotiating the New Economic Order of Waste," 276.

93 Mitchel Cohen, "Haiti and Toxic Waste," Counter Punch, January 22, 2010, accessed October I8, 2018, http://www.counterpunch.org/2010/or/22/haiti-and -toxic-waste.

94 Cohen, "Haiti and Toxic Waste."

95 Capellán, personal correspondence.

96 Krista Thompson, “The Debris of Caribbean History: Literature, Art, and Archipelagic Plastic." Keynote at 37th Annual West Indian Literature Conference, Miami, Florida, October 4-6, 2018. See also Krista Thompson, An Eye for the Tropics (Durham, NC: Duke University Press, 2007).

97 Morton, Hyperobjects.

98 Antonio Benítez-Rojo, The Repeating Island: The Caribbean and the Postmodern Perspective (Durham, NC: Duke University Press, 1997).

99 See Jan A. Zalasiewicz and Mark Williams, "The Anthropocene Ocean in Its Deep Time Context," in The World Ocean in Globalisation: Climate Change, Sustainable Fisheries, Biodiversity, Shipping, Regional Issues, ed. Davor Vidas and Peter Johan Schei (Leiden: Martinus Nijhoff, 20II), I9-35. 
Benjamin, The Arcades Project, 207.

Walter Benjamin, The Origin of German Tragic Drama, trans. John Osborne (New York: Verso, 1998), I75.

Gordon Teskey, "Colonial Allegories in Paris: The Ideology of Primitive Art," in Thinking Allegory Otherwise, ed. Brenda Machosky (Stanford, CA: Stanford University Press, 2010), I25.

Bauman, Wasted Lives, 27.

4 Marianne de Tolentino, "An Artist Who Reflects and Questions," May i8, 2013, accessed October 18, 2018, http://www.latinartmuseum.com/ capellan.htm.

U.S. Department of State, Dominican Republic Human Rights Practices, 1993, http://dosfan.lib.uic.edu/ERC/democracy/1993_hrp_report/93hrp_report _ara/DominicanRepublic.html.

Benjamin, The Origin of German Tragic Drama, 178.

Benjamin, The Origin of German Tragic Drama, 166. See also McCole, Walter Benjamin and the Antimonies of Tradition, I4I.

8 Michel Serres, Malfeasance: Appropriation through Pollution?, trans. Anne-Marie Feenberg-Dibon (Palo Alto, CA: Stanford University Press, 201I), 25.

William Blum, Killing Hope: U.S. Military and CIA Interventions since World War II (Monroe, ME: Common Courage, 1995).

"Tony Capellán-Entrevista-Cielonaranja."

Stam, "Beyond Third Cinema," 4I.

Hawkins, The Ethics of Waste, 56.

Stam, "Beyond Third Cinema," 45.

Benjamin, The Arcades Project, 206.

Serres, Malfeasance, 16.

6 Achille Mbembe, "The Power of the Archive and Its Limits," in Refiguring the Archive, ed. Carolyn Hamilton, Verne Harris, Jane Taylor, and Michele Pickover et al. (Dordrecht: Kluwer Academic, 2002), i9.

Capellán, personal correspondence.

Mbembe, "The Power of the Archive," 22. On installation art and allegory, see Craig Owens, "The Allegorical Impulse: Toward a Theory of Postmodernism," October I2 (Spring 1980): 67-86.

9 See, e.g., Claire Colebrook, “The Anthropocene and the Archive," Memory Network, January 26, 20I4, accessed October I8, 2018, http://thememorynetwork .net/the-anthropocene-and-the-archive.

Jan A. Zalasiewicz, Mark Williams, Will Steffen, and Paul Crutzen, "The New World of the Anthropocene," Environmental Science and Technology Viewpoint 44, no. 7 (2010): 2230.

Zalasiewicz et al., "The New World of the Anthropocene."

See, e.g., Perry Henzell, dir., The Harder They Come, International Films, 1972; Michelle Cliff, No Telephone to Heaven (New York: E. P. Dutton, 1987). 
I2 4 Timothy Reiss, Sisyphus and Eldorado: Magical and Other Realisms in Caribbean Literature (Trenton, NJ: Africa World Press, 2002).

I25 See David Scott, "The Paradox of Freedom: An Interview with Orlando Patterson," Small Axe 40 (2013): 96-242. In later years, the Dungle was bulldozed and replaced by a government housing project called Tivoli Gardens.

I26 Fredric Jameson, "Third-World Literature in the Era of Multinational Capitalism," Social Text, no. Is (Autumn 1986): 65-88

I27 Bruce King, The New English Literatures (London: MacMillan, 1980), 42.

I28 Scott, "The Paradox of Freedom," I45.

I29 The possibility of suicide is dismissed in Camus's Myth of Sisyphus, so Patterson's intervention is a critique of both Camus and Rastafarian millenarianism: Albert Camus, The Myth of Sisyphus, trans. Justin O'Brien (London: Hamish Hamilton, 1955). The promised ship is based on the notorious Claudius Henry affair. Patterson witnessed the despair of the Rastafari who had sold all their worldly possessions and waited for repatriation: see Scott, "The Paradox of Freedom," $142-43$.

130 Scott, "The Paradox of Freedom," I 44. See M. G. Smith, Roy Augier, and Rex Nettleford, The Rastafari Movement in Kingston, Jamaica (Mona, Jamaica: Institute of Social and Economic Research, University College of the West Indies, 1960). See also the debate in Orlando Patterson, "Ras Tafari: Cult of Outcasts," New Society 12 (November 1964): 15-17; Rex Nettleford, "African Redemption: The Rastafari and the Wider Society, 1959-1969," in Mirror, Mirror: Identity, Race, and Protest in Jamaica (Kingston, Jamaica: Sangster and Collins, 1970), 42-43.

I3 I Orlando Patterson, The Children of Sisyphus (Boston: Houghton Mifflin Harcourt, 1964), I81. Hereafter, page numbers are cited in parentheses in the text.

I32 Scanlan, On Garbage, I4.

133 Scanlan, On Garbage, 14.

I34 Scott, "The Paradox of Freedom," 139.

I35 See Daryl Cumber Dance's critique of his representation of the impoverished masses as animal-like and Patterson's response about social violence in Jamaica: Daryl Cumber Dance, New World Adams: Conversations with Contemporary West Indian Writers (Leeds, UK: Peepal Tree, 1992).

I36 See Bauman, Wasted Lives, 22.

I37 Édouard Glissant, Caribbean Discourse: Selected Essays, trans. J. Michael Dash (Charlottesville: University of Virginia Press, 1989), 6I-62.

I38 On his linking of discontinuities and continuities, see Scott, "The Paradox of Freedom," 165 , 170. See also his discussion about his falling out with Brathwaite in this regard, who emphasized continuities and remnants: Scott, "The Paradox of Freedom," I60-6I.

139 Michael Thompson, Rubbish Theory: The Creation and Destruction of Value (Oxford: Oxford University Press, 1979), 34. 
I40 See Corbin, The Foul and the Fragrant, I42.

I4I See Dominique LaPorte, History of Shit, trans. Rodolphe el-Khoury

(Cambridge, MA: MIt Press, 2000); Hawkins, The Ethics of Waste, 52.

I42 Benjamin, The Origin of German Tragic Drama, 223.

143 Scott, "The Paradox of Freedom," I47.

I44 Lauren Derby, "On Revolutionary Dirt in Haiti," in Wild Things: Nature and the Social Imagination, ed. William Beinart, Karen Middleton, and Simon Pooley (Cambridge: White Horse, 2013), 240, 247.

I45 Derby, "On Revolutionary Dirt in Haiti," 248.

I46 Thompson, Rubbish Theory, 34, 43.

I47 Benjamin, The Origin of German Tragic Drama, 217.

${ }_{148}$ Benjamin, The Origin of German Tragic Drama, 218.

I49 Szerszynski, "The End of the End of Nature," I8I.

\section{OCEANIC FUTURES}

Epigraphs: Sylvia Earle, quoted in Tom Clarke, "Sylvia Earle: America's Female 'Aquanaut," Channel 4 News, accessed October 18, 2018, https://www .channel4.com/news/sylvia-earle-americas-female-aquanaut/; Anna Lowenhaupt Tsing, "Strathern beyond the Human: Testimony of a Spore," Theory, Culture, and Society 3I, no. 2-3 (2014): 230.

I Walter Benjamin, The Arcades Project, ed. Rolf Tiedemann, trans. Howard Eiland and Kevin McLaughlin (Cambridge, MA: Harvard University Press, 1999), 366.

2 Kamau Brathwaite, in Nathaniel Mackey, "An Interview with Edward Kamau Brathwaite," Hambone 9 (199I): 44. I used this concept to structure my first book, Routes and Roots.

3 Benjamin, The Arcades Project, 47 I.

4 On critical ocean studies, see Elizabeth DeLoughrey "Submarine Futures of the Anthropocene," Comparative Literature Journal 69, no. I (2017): 32-44.

5 I develop this point in relation to outer space and the poles in Elizabeth DeLoughrey, "Satellite Planetarity and the Ends of the Earth," Public Culture 26, no. 2 (2014): 257-80. See also Stefan Helmreich, Alien Ocean: Anthropological Voyages in Microbial Seas (Berkeley: University of California Press, 2009).

6 Helmreich, Alien Ocean, 137.

7 Roland Barthes, Mythologies, trans. Annette Lavers (New York: Farrar, Straus, and Giroux, 1991), I60.

8 This builds on the argument in Elizabeth M. DeLoughrey, Routes and Roots: Navigating Caribbean and Pacific Island Literatures (Honolulu: University of Hawai' i Press, 2007). For visual narration, see Philip E. Steinberg, "NonLinearity in the Ocean Documentary" in Documenting World Politics: A Critical Companion to IR and Non-Fiction Film, ed. Rens van Munster and Casper Sylvest (New York: Routledge 2014), 78-94. 
This turn has been specifically associated with anthropology, but the work in philosophy and multispecies ethnography are also vibrant. In addition to work cited later in this chapter, see Tim Ingold, The Perception of the Environment Essays on Livelihood, Dwelling and Skill (London: Routledge, 2000); Eduardo Viveiros de Castro, "Perspectival Anthropology and the Method of Controlled Equivocation," Tipiti 2, no. I (2004): 3-22; Philippe Descola, The Ecology of Others (Chicago: Prickly Paradigm, 2013); Eduardo Kohn, How Forests Think: Toward an Anthropology beyond the Human (Berkeley: University of California Press, 2013). For a critique of its appropriation, see Zoe Todd, "An Indigenous Feminist's Take on the Ontological Turn: 'Ontology' Is Just Another Word for Colonialism," Journal of Historical Sociology 29, no. I (March 2016): 4-22. Philip E. Steinberg, "Of Other Seas," Atlantic Studies Io, no. 2 (2013): I6I. Steinberg, "Of Other Seas," 157. Philip E. Steinberg and Kimberley Peters, "Wet Ontologies, Fluid Spaces: Giving Depth to Volume through Oceanic Thinking," Environment and Planning D: Society and Space 33(2015): 247-64; Astrida Neimanis, "Hydrofeminism: Or, On Becoming a Body of Water," in Undutiful Daughters: New Directions in Feminist Thought and Practice, ed. Henriette Gunkel, Chrysanthi Nigianni, and Fanny Söderbäck (New York: Palgrave Macmillan, 2012), 85-99; and Bodies of Water: Feminist Posthuman Phenomenology. (London: Bloomsbury, 2017). See also Stefan Helmreich, “The Genders of Waves," Women's Studies Quarterly 45, nos. I-2 (Spring-Summer 2017): 29-5I.

I3 On the "geo-," I am thinking in particular of Bronislaw Szerszynski, "The End of the End of Nature: The Anthropocene and the Fate of the Human," Oxford Literary Review 34 (2012): 165-84; Kathryn Yusoff, "Geologic Life: Prehistory, Climate, Futures in the Anthropocene," Environment and Planning D: Society and Space 31, no. 5 (2013): 779-95.

I4 Scholarship on the "new extractivism" has focused on the Americas but has overlooked similar pressures in the Pacific: see Henry Veltmeyer, James Petras, and Verónica Albuja, The New Extractivism: A Post-Neoliberal Development Model or Imperialism of the Twenty-First Century? (London: Zed, 2014).

is Helmreich, Alien Ocean.

I6 Jérôme Bindé, "What Future for the Oceans?" Making Peace with the Earth: What Future for the Human Species and the Planet? (Paris: United Nations Educational, Scientific, and Cultural Organization, 2009), 75. Robert Henson and Duncan Clark, The Rough Guide to Climate Change (London: Rough Guides, 2011), in6.

Henson and Clark, The Rough Guide to Climate Change, 127. See the 2018 report: Intergovernmental Panel on Climate Change, "Global Warming of $\mathrm{I} .5^{\circ} \mathrm{C}$," http://report.ipcc.ch/sris/pdf/sris_chapter3.pdf.

"Warming Climate to Hit Bangladesh Hard with Sea Level Rise, More Floods and Cyclones, World Bank Report Says," press release, World Bank, June i9, 2013, accessed October I8, 20I8, http://www.worldbank.org/en/news/press 
-release/2013/06/19/warming-climate-to-hit-bangladesh-hard-with-sea-level -rise-more-floods-and-cyclones-world-bank-report-says.

On the Plastisphere, see Eril R. Zettler, Tracy J. Mincer, and Linda A. AmaralZettler, "Life in the 'Plastisphere': Microbial Communities on Plastic Marine Debris," Environmental Science and Technology 47, no. 13 (2013): 713I-46. On the Plastic Age, see Andrés Cozár, Fidel Echevarria, J. Ignacio GonzálezGordillo, and Zabier Irigoien et al., "Plastic Debris in the Open Ocean," Proceedings of the National Academy of Sciences of the United States of America, III, no. 28 (2014): I-6. See also Anthony L. Andrady, "Microplastics in the Marine Environment," Marine Pollution Bulletin 62 (2011): 1596-1605.

See DeLoughrey, "Submarine Futures of the Anthropocene." Influential texts in postcolonial studies include Paul Gilroy, The Black Atlantic: Modernity and DoubleConsciousness (Cambridge, MA: Harvard University Press, 1993); Epeli Hau'ofa, We Are the Ocean (Honololu: University of Hawai i Press, 2007); Gaurav Desai, Commerce with the Universe (New York: Columbia University Press, 2013).

See "Wet Matter," a special issue of Harvard Design Magazine, 39, (Fall-Winter 2014). See also Kerry Bystrom and Isabel Hofmeyr, "Oceanic Routes: (Post-It) Notes on Hydro-Colonialism," Comparative Literature 69, no. I (March 2017): I-6.

24 The argument in this paragraph is developed in DeLoughrey, Routes and Roots.

25 Jacques-Yves Cousteau, "The Perils and Potentials of a Watery Planet," in Oceans: Our Continuing Frontier, ed. H. William Menard and Jane L. Scheiber (Del Mar, CA: Publisher's Inc., 1976), I3. See also Sylvia Earle who writes “our origins are there, reflected in the briny solution coursing through our veins" (I5).

26 Elisabeth Mann Borgese, The Oceanic Circle (New York: Brookings Institution Press, 1998$), 46$.

27 Stacy Alaimo, "Oceanic Origins, Plastic Activism, and New Materialism at Sea," in Material Ecocriticism, ed. Serenella Iovino and Serpil Oppermann (Bloomington: Indiana University Press, 2014), 191. Alaimo warns that "such origin stories, even as they attempt to provoke concern for the sea as our original home or for sea creatures as kin, revel in a prelapsarian innocence, as they skip over a wide swath of human history in which humans slaughtered ocean creatures and destroyed ocean ecologies"(192). See also Stacy Alaimo, Exposed: Environmental Politics and Pleasures in Posthuman Times (Minneapolis: University of Minnesota Press, 2016).

28 Sylvia Earle, Sea Change: A Message of the Oceans (New York: Fawcett, 1995), xiv. See also Neimanis, Bodies of Water.

29 Borgese, The Oceanic Circle, I4.

30 On the "scramble for the oceans," see DeLoughrey, Routes and Roots; Arvid Pardo, Common Heritage: Selected Papers on Oceans and World Order 19671974, ed. Elisabeth Mann Borgese (Malta: Malta University Press, 1975). Map 4.I is adapted from Osmar Valdebenito, "Territorial Waters," https://commons. wikimedia.org/wiki/File:Territorial_waters_-_World.svg. 
John R. Gillis, “The Blue Humanities," Humanities 34, no. 3 (June 2013), http://www.neh.gov/humanities/2013/mayjune/feature/the-blue-humanities.

Naomi Oresekes, "A Context of Motivation: U.S. Navy Oceanographic

Research and the Discovery of Sea-Floor Hydrothermal Vents," Social Studies of Science 33, no. 5 (2003): 697-742; Jacob Hamblin, Oceanographers and the Cold War: Disciples of Marine Science (Seattle: University of Washington Press, 2005). Bindé, "What Future for the Oceans?" 80.

34 "Japan Successfully Undertakes Large-Scale Deep-Sea Mineral Extraction," Japan Times, September 26, 2017, accessed October 18, 2018, https://www .japantimes.co.jp/news/2017/09/26/national/japan-successfully-undertakes -large-scale-deep-sea-mineral-extraction.

See, e.g., the struggle over mining rights in Papua New Guinea, in Karen Abplanalp, "PNG Faces Criticism over Plan for Deep Sea Mining 'El Dorado' in Pacific," Pacific Scoop, accessed August 29, 2012, http://pacific.scoop.co.nz/2012 /o8/png-faces-criticism-over-plan-for-deep-sea-mining-el-dorado-in-pacific. See Anne Salmond's Tears of Rangi: Experiments across Worlds (Auckland: University of Auckland Press, 2017) on seabed mineral prospecting in Aotearoa New Zealand, and Teresa Shewry, "Going Fishing: Activism against Deep Ocean Mining," The South Atlantic Quarterly II6, no. I (2017): 207-17.

36 Hau'ofa, We Are the Ocean, I42.

37 Hau'ofa, We Are the Ocean; DeLoughrey, Routes and Roots.

38 The proceedings of the conference are collected in a special issue of the University of the South Pacific's journal Dreadlocks: see Mohit Prasad, ed., Dreadlocks: Oceans, Islands and Skies: Proceedings from Oceans, Islands and Skies-Oceanic Conference on Creativity and Climate Change 6-7 (2010-11).

39 Vilsoni Hereniko, dir., Moana: The Rising of the Sea, European Consortium for Pacific Studies and the Oceania Centre, University of the South Pacific, accessed October I8, 20I8, https://search.alexanderstreet.com/view/work /bibliographic_entity\% 7 Cvideo_work\%7C2657493/moana-rising-sea. Documentaries on climate change are discussed in the next chapter. Also of note is the work of Chamorro writer Craig Santos Perez, particularly his moving "eco-poem-film" called "Praise Song for Oceania": http://craigsantosperez.com /praise-song-oceania/.

40 See the Polynesian Voyaging Society's website at http://www.hokulea.com /malamahonua/.

4I See "We're Building Canoes," 350.org, at http://350.org/were-building-canoes.

42 This argument is developed in DeLoughrey, Routes and Roots. See esp. Robert Sullivan's use of the "vessel” in Star Waka (Auckland, New Zealand: Auckland University Press, 2000).

43 There are limitations to this model of an oceanic imaginary articulated by Margaret Jolly that have to do with geography (not all Pacific Islanders are coastal dwellers) and ethnicity (not all are Polynesian): see Margaret Jolly, "Imagining Oceania: Indigenous and Foreign Representations of a Sea of Islands," in Framing the Pacific in the 2Ist Century: Co-existence and Friction, ed. Daizaburo Yui 
and Yasua Endo (Tokyo: Center for Pacific and American Studies, University of Tokyo, 200I), 29-48. On the oceanic turn and its lack of engagement with Indigenous Pacific studies, see Alice Te Punga Somerville, "Where Oceans Come From," Comparative Literature 69, no. I (2017): 25-31.

44 Witi Ihimaera, The Whale Rider (Auckland: Heinemann, 1987); Niki Caro, dir., Whale Rider, Columbia TriStar Home Entertainment, 2002.

45 Keri Hulme, Stonefish (Wellington, New Zealand: Huia, 2004).

46 See Hulme's poetry collections: Keri Hulme, The Silences Between: (Moeraki Conversations) (Auckland, New Zealand: Auckland University Press, 1982); Keri Hulme, Strands (Oxford: Oxford University Press, 1992). See also Keri Hulme, "Okarito and Moeraki," in Te Whenua, Te Iwi: The Land and the People, ed. Jock Phillips, I-9 (Wellington, New Zealand: Allen and Unwin, 1987). See also Patricia Grace, Potiki (Honolulu: University of Hawai'i Press, 1995). June Mitchell, Amokura (Harlow, UK: Longman Paul, 1978), engages the strand in terms of Māori cosmologies.

47 See Hulme, "Okarito and Moeraki."

48 See Elizabeth A. Povinelli, Geontologies: A Requiem to Late Liberalism (Durham, NC: Duke University Press, 2016); Yusoff, "Geologic Life."

49 Mere Roberts and Peter Wills, "Understanding Māori Epistemology: A Scientific Perspective," in Tribal Epistemologies: Essays in the Philosophy of Anthropology, ed. Helmut Wautischer (Sydney: Ashgate, 1998), 43-77. See also Mere Roberts, Bradford Haami, Richard Anthony Benton, and Terre Satterfield et al. "Whakapapa as a Māori Mental Construct: Some Implications for the Debate over Genetic Modification of Organisms," Contemporary Pacific i6, no. I (Spring 2004): I-28.

50 Whakapapa is exceedingly complex; it's discussed in more detail as a literary method in DeLoughrey, Routes and Roots, 16I-74, building upon the works of Anne Salmond, "Maori Epistemologies," in Reason and Morality, ed. Joanna Overing, (London: Tavistock, 1985), 240-63; Charles Te Ahukaramū Royal, "Nga Kawa e hangaia ai he Matauranga Maori: Whakapapa as a Research Methodology," in Proceedings of Te Oru Rangahau Maori Research and Development Center (Palmerston North, New Zealand: Massey University, 1999), 78-87.

5I Foreshore and Seabed Act 2004, Public Act 2004 no. 93, November 24, 2004, Wellington, New Zealand, accessed October I8, 2018, http://www .legislation.govt.nz/act/public/2004/0093/latest/whole.html?search=ts_act _foreshore+and+seabed_noresel\#DLM319839. Almost all of the stories in Stonefish had been published previous to the collection.

52 Rodolfo Stavenhagen, "Indigenous Issues," report of the Special Rapporteur on the Situation of Human Rights and Fundamental Freedoms of Indigenous People, United Nations Economic and Social Council, Commission on Human Rights, 62d sess., 2006, Mission to New Zealand addendum, accessed October I8, 20I8, https://documents-dds-ny.un.org/doc/UNDOC/GEN /Go6/118/36/PDF/Go611836.pdf ?OpenElement, I4. 
See the United Nations' review of New Zealand's compliance with the International Convention on the Elimination of All Forms of Racial Discrimination: Committee on the Elimination of Racial Discrimination, "Decision I (66): New Zealand Foreshore and Seabed Act 2004), 66th sess., February 2IMarch II, 2005, accessed October I8, 20I8, http://www2.ohchr.org/english /bodies/cerd/docs/CERD.C.66.NZL.Dec.r.pdf.

54 The treaty has recently been argued to include the wind, because, like the water, it is a resource: Dan Satherley, "Treaty Gives Us the Wind-Ngapuhi Leader," 3 News, accessed September 5, 20I2, https://www.newshub.co.nz/politics/treaty -gives-us-the-wind--ngapuhi-leader-2012090509.

55 Stavenhagen, "Indigenous Issues," 6-7.

56 Abby Suszko, "Māori Perspectives on the Foreshore and Seabed Debate: A Dunedin Case Study," bachelor of arts (honors) diss., University of Otago, Dunedin, New Zealand, accessed October I8, 2018, 2005, https://ourarchive.otago .ac.nz/bitstream/handle/10523/5152/Abby_490.pdf ?sequence=4\&isAllowed =y, 3; Fiona Cram, Te Ari Prendergast, Katrina Taupo, Hazel Phillips, and Murra Parsons, "Traditional Knowledge and Decision-Making: Māori Involvement in Aquaculture and Biotechnology," in Proceedings of the Traditional Knowledge Conference 2008. Te Tatau Pounamu: The Greenstone Door, ed. J. S. Te Rito and S. M. Healy (Auckland: Ngā Pae o te Māramatanga, 2010), I52.

57 On the Neptune and Nautilus mineral companies, see "Seabed MiningThe Unplumbed Riches of the Deep," The Economist, May I4, 2009, 32; Meghan Miner, "Will Deep Sea Mining Yield Another Gold Rush?” National Geographic, February I, 2013, accessed October I8, 2018, http://news .nationalgeographic.com/news/2013/13/13020I-underwater-mining-gold -precious-metals-oceans-environment. On the New Zealand context, see Phil McCabe, "Strip-Mining or Marine Life?" Dominion Post, March II, 20I4, accessed October 18, 2018, http://www.stuff.co.nz/dominion-post/comment /columnists/9812846/Strip-mining-or-marine-life; and Anne Salmond, "Tears of Rangi: Water, Power, and People in New Zealand," HAU: Journal of Ethnographic Theory 4, no. 8 (2014): 285-309.

58 Cram et al., "Traditional Knowledge and Decision-Making," 153.

59 Helmreich, Alien Ocean, 26.

60 Helmreich, Alien Ocean.

6I See the Seasteading Institute's website at https://www.seasteading.org. For a smart analysis, see Philip E. Steinberg, Elizabeth Nyam, and Mauro J. Caraccioli, "Atlas Swam: Freedom, Capital, and Floating Sovereignties in the Seasteading Vision," Antipode 44, no. 4 (2011): 1532-50.

62 Steinberg et al., "Atlas Swam," Iо.

63 See the Seasteading Institute, http://www.seasteading.org.

64 Christopher Connery, "The Oceanic Feeling and the Regional Imaginary," in Global/Local: Cultural Production and the Transnational Imaginary, ed. Rob Wilson and Wimal Dissanayake (Durham, NC: Duke University Press, 1996), 289. 
65 Helmreich, Alien Ocean, in4-I5.

66 Hulme, Stonefish, I6. Hereafter, page numbers are cited in parentheses in the text.

67 Rima Alicia Bartlett, "The Wonder of Words Winds through All Worlds" (interview with Keri Hulme), Wasafiri I2 (1997): 83. See also Hulme, "Okarito and Moeraki."

68 Bruce Clarke, Allegories of Writing: The Subject of Metamorphosis (Albany: State University of New York Press, I995), ir.

69 John Bryson, "Keri Hulme in Conversation with John Bryson," Antipodes 8, no. 2 (1994): I3I-35.

70 Benjamin, The Arcades Project, 206.

71 Bryson, "Keri Hulme in Conversation with John Bryson," I32

72 Donna Haraway, Modest_Witness@Second_Millennium.FemaleMan@_Meets_ OncoMouse ${ }^{T M}$ : Feminism and Technoscience (New York: Routledge, 1997), 16-22.

73 Peter Kareiva, "Conservation for Our World of Nine Billion People: The End of Nostalgia and Apocaholism," lecture presented at the Oppenheim Lecture Series, Institute of the Environment and Sustainability, University of California, Los Angeles, February I2, 2013.

74 Ted Nordhaus and Michael Shellenberg, "The Death of Environmentalism: Global Warming Politics in a Post-Environmental World," Grist, January I4, 2004, accessed October I8, 2018, http://grist.org/article /doe-reprint.

75 Patrick Wolfe, "Settler Colonialism and the Elimination of the Native," Journal of Genocide Research 8, no. 4 (2006): 387-409.

76 Kyle Powys Whyte, "Indigenous Science (Fiction) for the Anthropocene: Ancestral Dystopias and Fantasies of Climate Change Crises," Environment and Planning E: Nature and Space I, no. I-2 (2018): I-I8. See also Zoe Todd, "An Indigenous Feminist's Take on the Ontological Turn: 'Ontology' Is Just Another Word for Colonialism,' Journal of Historical Sociology 29, no. I (2016): 4-22. On the Orbis Spike, see Simon L. Lewis and Mark A. Maslin, "Defining the Anthropocene," Nature 519, no. 7542 (2015): $17 \mathrm{I}-80$.

77 There is a large body of "rights of nature" work that I do not have space to explore here. For the Aotearoa New Zealand context, see Elaine Hsiao, "Whanganui River Agreement: Indigenous Rights and Rights of Nature," Environmental Policy and Law 42, no. 6 (December 2012): 371-75; Anne Salmond, "Tears of Rangi: Water, Power, and People in New Zealand," HAU: Journal of Ethnographic Theory 4, no. 8 (2014): 285-309.

78 Linda Te Aho, "Attempting to Integrate Indigenous Traditional Knowledge of Waterways with Western Science: To Restore and Protect the Health and Well-Being of an Ancestral River," in Proceedings of the Fourth International Traditional Knowledge Conference 20Io. Kei Muri I Te Kapara He Tangata Ke: Recognizing, Engaging, Understanding Difference, ed. J. S. Te Rito and S. M. 
Healy (Auckland, New Zealand: Ngā Pae o te Māramatanga/Māori Centre of Research Excellence, 2010), 332.

79 Eduardo Viveiros de Castro, “The Relative Native," trans. Julia Sauma and Martin Holbraad, HAU: Journal of Ethnographic Theory 3, no. 3 (2013): 473-502. See the discussion in Martin Holbraad, Morten Axel Pedersen, and Eduardo Viveiros de Castro, "The Politics of Ontology: Anthropological Positions," Cultural Anthropology, accessed October 18, 2018, http://culanth .org/fieldsights/462-the-politics-of-ontology-anthropological-positions. For the application of Viveiros de Castro to Māori contexts, see Salmond, Tears of Rangi, 2018.

80 Catherine Brahic, "The Real Avatar: Ocean Bacteria Act as 'Superorganism," New Scientist, February 24, 2010, accessed October 18, 2018, https://www .newscientist.com/article/mg20527493-800-the-real-avatar-ocean-bacteria-act -as-superorganism.

8I Lars Peter Nielsen, Nils Risgaard-Petersen, Henrik Fossing, Peter Bondo Christensen, and Mikio Sayama, "Electric Currents Couple Spatially Separated Biogeochemical Processes in Marine Sediment," Nature 463, no. 25 (February 2010): I074; and Myra J. Hird, "Meeting with the Microcosmos," Environment and Planning D: Society and Space 28, no. I (2010): 36.

82 Amitav Ghosh, The Great Derangement: Climate Change and the Unthinkable (Chicago, IL: University of Chicago Press), 3 I.

83 Jane Bennett, Vibrant Matter: A Political Ecology of Things (Durham, NC: Duke University Press, 2010).

84 Michel Serres, The Natural Contract, trans. Elizabeth MacArthur and William Paulson (Ann Arbor: University of Michigan Press, 1995), 3 I.

85 Philip E. Steinberg, "Non-Linearity in the Ocean Documentary," in Documenting World Politics: A Critical Companion to IR and Non-Fiction Film, Ist ed. (New York: Routledge, 2014), 8I.

86 Hulme's short story "Floating Words" was originally published in 1989 . See Prize Writing: An Original Collection of Writings by Past Winners to Celebrate $2 I$ Years of the Booker Prize, ed. Martyn Goff (London: Hodder \& Stoughton, 1989).

87 On Hulme's fear of characters taking over the plot and self, see Antonella Sarti, Spiritcarvers: Interviews with Eighteen Writers from New Zealand (Amsterdam: Rodopi, 1998).

88 Ghosh, Great Derangement, 30.

89 Tzvetan Todorov, The Fantastic: A Structural Approach to a Literary Genre, trans. Richard Howard (Ithaca, NY: Cornell University Press, 1975), 26, 32.

90 Todorov, The Fantastic, II5-16.

91 Todorov, The Fantastic, $17 \mathrm{I}$.

92 See Mette Bryld and Nina Lykke, Cosmodolphins: Feminist Cultural Studies of Technology, Animals, and the Sacred (London: Zed, 2000); Donna Haraway, When Species Meet (Minneapolis: University of Minnesota Press, 2008); Eben S. Kirksey and Stefan Helmreich, “The Emergence of Multispecies 
Ethnography," Cultural Anthropology 25, no. 4 (2010): 545-76; Vine Deloria Jr., "American Indian Metaphysics," in Power and Place: Indian Education in America, ed. Vine Deloria Jr. and Daniel R. Wildcat (Golden, CO: Fulcrum, 200I), I-6; Kimberly TallBear, "Why Interspecies Thinking Needs Indigenous Standpoints," Cultural Anthropology, April 24, 2011, accessed October 18, 2018, http://www.culanth.org/fieldsights/260-why-interspecies-thinking-needs -indigenous-standpoints; Anna Lowenhaupt Tsing, "Unruly Edges: Mushrooms as Companion Species," Environmental Humanities I (2012): I4I-54; Mel Y. Chen, Animacies: Biopolitics, Racial Mattering, and Queer Affect (Durham, NC: Duke University Press, 2012); Stacy Alaimo, Exposed: Environmental Politics and Pleasures in Posthuman Times (Minneapolis: University of Minnesota Press, 2016); Whyte, "Indigenous Science (Fiction) for the Anthropocene"; Heather Davis and Zoe Todd, "On the Importance of a Date, Or, Decolonizing the Anthropocene," ACME: An International Journal for Critical Geographies 16, no. 4 (2017): 761-80.

93 TallBear, "Why Interspecies Thinking Needs Indigenous Standpoints," 7.

94 Manuka Henare, “Tapu, Mana, Mauri, Hau, Wairua: A Māori Philosophy of Vitalism and the Cosmos," in Indigenous Traditions and Ecology: The Interbeing of Cosmology and Community, ed. John A. Grim (Cambridge, MA: Harvard University Press, 200I), 204.

95 Hulme has written about the importance of reading omens and natural signs to Māori epistemology: Keri Hulme, "Myth, Omen, Ghost, and Dream," in Te Ao Marama: Regaining Aotearoa: Maori Writers Speak Out, ed. Witi Ihimaera (Auckland, New Zealand: Reed, 1993).

96 Karen Barad, "Re(con)figuring Space, Time and Matter," in Feminist Locations: Global and Local, Theory and Practice, ed. Marianne DeKoven, 75-109 (New Brunswick, NJ: Rutgers University Press, 2001), 92.

97 Haraway, When Species Meet, ro.

98 Tsing, "Unruly Edges," I 42.

99 Tsing, "Unruly Edges," 142.

Io० Tsing, "Unruly Edges," 152 . The adaptability of the mushroom, Tsing points out, means that mushrooms register the signs of human modernity such as radiation (in the Chernobyl fallout zone), air pollution, and acid rain: Tsing, "Unruly Edges," I 42.

IoI Dipesh Chakrabarty, "The Climate of History: Four Theses," Critical Inquiry 35 (2009): 207. Chakrabarty's argument is expanded in Dipesh Chakrabarty, "Postcolonial Studies and the Challenge of Climate Change," New Literary History 43 (2012): I-18, as well as in his forthcoming Tanner lectures.

IO2 Chakrabarty, "The Climate of History," 220.

IO3 Chakrabarty's later essays begin to acknowledge the complexity of nonhuman species in the Anthropocene: see Dipesh Chakrabarty, "The Politics of Climate Change Is More Than the Politics of Capitalism," Theory, Culture and Society (February 8, 2017): I-I3. Since I first wrote this argument in 2012 there have 
been ample critiques of Chakrabarty's initial language about species. For the most recent in relation to the oceanic, see Alaimo, Exposed.

Io4 See Paul J. Crutzen and Eugene F. Stoermer, "The 'Anthropocene," Global Change Newsletter, no. 4I (2000): 17-18; Will Steffen, Jacques Grinevald, Paul J. Crutzen, and John R. McNeill, “The Anthropocene: Conceptual and Historical Perspectives," Philosophical Transactions of the Royal Society A 369 (2011): 842-67; Jan A. Zalasiewicz, Mark Williams, Alan Haywood, and Michael Ellis, "The Anthropocene: A New Epoch of Geological Time?", Philosophical Transactions of the Royal Society A 369 (2011): $835-4 \mathrm{I}$.

IO5 Neanderthals and Denisovans, for instance: see Rosie Mestel, "Genome of Ancient Denisovans May Help Clarify Human Evolution,” Los Angeles Times, August 30, 20I2, accessed October I8, 2018, http://articles.latimes.com/2012 /aug/30/science/la-sci-denisovan-genome-20120828.

106 Haraway When Species Meet, 4.

I07 Roberts et al., "Whakapapa as a Maori Mental Construct," 4.

I08 Hulme's story does not evade questions of ethical responsibility, as the narrator herself adapts when the characters she has created come home to roost, raising important questions about issues of representation and reciprocity (utu).

I09 Serres, The Natural Contract, 31, 40.

IIO Serres, The Natural Contract, 4I. Note also that he figures the ark in terms of a Christian fall from "nature," which Hulme destabilizes. "Have we lost the memory of the antediluvian age when a patriarch, from whom we're doubtless descended, had to construct an ark, a small-scale model of the totality of space and time, to prepare for an overflow of the sea caused by some thaw in the ice caps?": Serres, The Natural Contract, 3 I.

III See Lauren Berlant, Cruel Optimism (Durham, NC: Duke University Press, 20II); Mike Davis, "Los Angeles after the Storm: The Dialectic of Ordinary Disaster," Antipode 27, no. 3 (1995): 221-4I

II2 Ghosh, The Great Derangement, i9.

II3 Vandana Shiva, Earth Democracy (Boston: South End, 2005), 5.

II 4 Shiva, Earth Democracy, 5.

IIs Haraway, When Species Meet, 295.

II 6 Sarti, Spiritcarvers, 66.

I17 Manuel DeLanda, A Thousand Years of Nonlinear History (New York: Zone, 1997), quoted in Bennett, Vibrant Matter, II.

II 8 Bennett, Vibrant Matter, II.

II Manuka Henare, “Tapu, Mana, Mauri, Hau, Wairua: A Māori Philosophy of Vitalism and Cosmos," 204.

I20 "Pāua Hearts Beat to Climate Change's Tune," Radio New Zealand, August 24, 2018, accessed October I8, 20I8, http://www.radionz.co.nz/news/national /337954/paua-hearts-beat-to-climate-change-s-tune.

I2I Alaimo, Exposed, I6I. 
Rebecca Stott, Oyster (London: Reaktion, 2004).

Haraway, When Species Meet, 3.

Haraway, When Species Meet, 3.

Stacy Alaimo, "New Materialisms, Old Humanisms, or, Following the Submersible," Nordic Journal of Feminist and Gender Research 19 (2011): 283.

Geoff Murphy, dir., The Quiet Earth, film, Anchor Bay Entertainment, I985.

Scientists debate what the term "species" even means, because species are always evolutionary and changing: see John Dupré, "Species: Theoretical Contexts," in Keywords in Evolutionary Biology, ed. Evelyn Fox Keller and Elisabeth A. Lloyd (Cambridge, MA: Harvard University Press, 1992), 312-17.

Haraway, When Species Meet, 17.

Moana Jackson, “'There Are Obligations There': A Consideration of Maori Responsibilities and Obligations to the Seabed and Foreshore," in Te Takutai Moana: Economics, Politics, and Colonisation (Tamaki Makaurau, New Zealand: IRI, 2003), 29.

\section{AN ISLAND IS A WORLD}

Epigraphs: Unnamed conference delegate, quoted in Keith S. Chambers and Anne F. Chambers, Unity of Heart: Culture and Change in a Polynesian Atoll Society (Prospect Heights, IL: Waveland, 200I), 225; Walter Benjamin, The Origin of German Tragic Drama, trans. John Osborne (New York: Verso, 1998), 223.

Will Steffan et al., "Planetary Boundaries: Guiding Human Development on a Changing Planet," Science 347, no. 6223 (2015), accessed October 18, 2018, http://precaution.org/lib/steffen_planetary_boundaries(incl_supplemental) .150213.pdf

Fredric Jameson, The Geopolitical Aesthetic: Cinema and Space in the World System (Bloomington: Indiana University Press, 1992), 169.

Walter Benjamin, The Origin of German Tragic Drama, trans. John Osborne (New York: Verso, 1998), 174.

Angus Fletcher, Allegory: The Theory of a Symbolic Mode (Princeton, NJ: Princeton University Press, 2012), 84-87.

5 This is the argument of the introduction to Elizabeth M. DeLoughrey, Routes and Roots: Navigating Caribbean and Pacific Island Literatures (Honolulu: University of Hawai'i Press, 2007).

6 Richard H. Grove, Green Imperialism: Colonial Expansion, Tropical Island Edens, and the Origins of Environmentalism, I60o-I860 (Cambridge: Cambridge University Press, 1995), 8-9.

7 For more on the island as laboratory for social and scientific experiment, see Rod Edmond and Vanessa Smith, eds., Islands in History and Representation (London: Routledge, 2003). Grove, Green Imperialism, 5 . 
Mary Louise Pratt, Imperial Eyes: Travel and Transculturation (London: Routledge, 1992).

IO Benjamin, The Origin of German Tragic Drama, 230, 234.

II Gayatri Chakravorty Spivak, "Thoughts on the Principle of Allegory," Genre 5 (1972): 335 .

Fredric Jameson, The Political Unconscious: Narrative as a Socially Symbolic Act (London: Routledge, 1983), 19.

I3 This is a point argued in DeLoughrey and Handley's introduction to Postcolonial Ecologies, (London: Oxford University Press, 2011), 3-39.

I4 Jeremy Hance, "Why Don't We Grieve for Extinct Species?," The Guardian, November 19, 2016, accessed October 18, 2018, https://www.theguardian.com /environment/radical-conservation/2016/nov/19/extinction-remembrance -day-theatre-ritual-thylacine-grief\#img-I.

I5 The term "Necrocene" was coined by Justin McBrien in "Accumulating Extinction: Planetary Catastrophism in the Necrocene," in Anthropocene or Capitalocene? Nature, History, and the Crisis of Capitalism, ed. Jason W. Moore (Oakland, CA: PM Press, 2016), i16-37. See Ashley Dawson, Extinction: A Radical History (New York: OR, 2016) and Jason W. Moore's post “The Myth of the 'Human Enterprise': The Anthropos and Capitalogenic Change," accessed October 18, 2018, https://jasonwmoore.wordpress.com/2016/10/30/the -myth-of-the-human-enterprise-the-anthropos-and-capitalogenic-change/.

I6 Tomari i Tutangata, "Sinking Islands, Vanishing Worlds," Earth Island Journal I5, no. 2 (2000); A. C. Walsh, "Subsistence Agriculture and the Communication of Innovations: Some Niuean Examples," in The Subsistence Sector in the South Pacific, ed. J. B. Hardaker (Suva, Fiji: University of the South Pacific, 1975). See also John Connell, "Losing Ground? Tuvalu, the Greenhouse Effect and the Garbage Can," Asia Pacific Viewpoint 44, no. 2 (2003): 89-107; Elaine Stratford, Carol Farbotko, and Heather Lazrus, "Tuvalu, Sovereignty and Climate Change: Considering Fenua, the Archipelago and Emigration," Island Studies Journal 8, no. I (2013): 67-83.

I7 Patrick D. Nunn, "The End of the Pacific? Effects of Sea Level Rise on Pacific Island Livelihoods," Singapore Journal of Tropical Geography 34 (2013): 165. See also Patrick D. Nunn, Vanished Islands and Hidden Continents in the Pacific (Honolulu: University of Hawai'i Press, 2012).

I8 Bill Nichols, Representing Reality: Issues and Concepts in Documentary (Bloomington: Indiana University Press, 1991).

I9 Deborah L. Madsen, Rereading Allegory: A Narrative Approach to Genre (Houndmills, UK: Palgrave Macmillan, 1995), 135.

20 In fact, while the threat to the islands is increasing, the documentaries about it have tapered off since 2004 .

2I James Clifford, "On Ethnographic Allegory," in Writing Culture: The Poetics and Politics of Ethnography (Berkeley: University of California Press, 1986), Io8; James Clifford and George E. Marcus, eds., The Work of Film in the Age of Video (Berkeley: University of California Press, 1986). 
23 See Grove, Green Imperialism; Ilan Kelman, James Lewis, and J. C. Gaillard, "Participatory Action Research for Dealing with Disasters on Islands," Island Studies Journal 6, no. I, (2011): 59-86; Godfrey Baldacchino, "Studying Islands: On Whose Terms? Some Epistemological and Methodological Challenges to the Pursuit of Island Studies," Island Studies Journal 3, no. I (2008): 37-56; DeLoughrey, Routes and Roots; Edmond and Smith, Islands in History and Representation; Elizabeth DeLoughrey, "The Litany of Islands, the Rosary of Archipelagoes': Caribbean and Pacific Archipelagraphy," Ariel 32, no. I (200I): 2I-5I.

24 Johannes Fabian, Time and the Other: How Anthropology Makes Its Object (New York: Columbia University Press, 1983); James Clifford, Routes: Travel and Translation in the Late 2oth Century (Cambridge, MA: Harvard University Press, 1997). Turning to geology, oceanography, and histories of voyaging, Vincente Diaz and J. Kēhaulani Kauanui have argued against colonial models of island isolation to demonstrate that the "Pacific is on the move," understood in terms of tectonics, human migration, and a growing field of scholarship in Vincente M. Diaz and J. Kēhaulani Kauanui, "Native Pacific Cultural Studies on the Edge," Contemporary Pacific I3, no. 2 (200I): 317.

25 This argument is expanded in Elizabeth DeLoughrey, "Revisiting Tidalectics: Irma/José/Maria." In Tidalectics: Imagining an Oceanic Worldview through Art and Science, ed. Stefanie Hessler (Boston: Mit Press, 20I8), 93-IOI.

26 Elizabeth DeLoughrey, "The Myth of Isolates: Ecosystem Ecologies in the Nuclear Pacific," Cultural Geographies 20, no. 2 (April 2013): 167-84. Joseph Masco, "Bad Weather: On Planetary Crisis," Social Studies of Science 40, no. I (2010): 7-40.

28 DeLoughrey, "The Myth of Isolates."

29 See Robert Stone, dir., Radio Bikini, documentary film, New Video Group, 1987. Accordingly, most popular films about nuclearization are about media itself: see also Robert Jungk, Brighter Than a Thousand Suns: A Personal History of the Atomic Scientists (New York: Harcourt Brace, 1958), 279.

30 See Stone, Radio Bikini.

3I Jonathan M. Weisgall, Operation Crossroads: The Atomic Tests at Bikini Atoll (Annapolis: Naval Institute Press, 1994), 207.

32 See Peter Adey, Aerial Life: Spaces, Mobilities, Affects (Oxford: WileyBlackwell, 20IO); Caren Kaplan, "Mobility and War: The Cosmic View of US 'Air Power," Environment and Planning A: Economy and Space 38 (2006): 395-407; Caren Kaplan, Aerial Aftermaths (Durham, NC: Duke University Press, 2018).

33 Ward Goodenough, quoted in DeLoughrey, Routes and Roots, 106.

34 See Teresia K. Teaiwa, "Reading Paul Gauguin's Noa Noa with Epeli Hau'ofa's Kisses in the Nederends: Militourism, Feminism, and the 'Polynesian' Body," in Inside Out: Literature, Cultural Politics and Identity in the New Pacific, ed. 
Vilsoni Hereniko and Rob Wilson (Lanham, MD: Rowman and Littlefield, 2001), 249-63.

35 As this book was going to press, Kathy Jetñil-Kijiner released on her blog a powerful three-part video poem about the destruction of Runit entitled "Dome": http://www.kathyjetnilkijiner.com/blog/, accessed October i 8, 2018.

36 This is discussed in chapter 2. See Teresia K. Teaiwa, "Reading Paul Gauguin's Noa Noa with Epeli Hau'ofa's Kisses in the Nederends."

My earlier work focused on the reduction of the archipelago to an isolated island in DeLoughrey, “The Litany of Islands, The Rosary of Archipelagoes': Caribbean and Pacific Archipelagraphy." ARIEL: A Review of International English Literature 32, no. I (200I): 21-51. This concept has been developed with much greater range in Brian Russell Roberts and Michelle A. Stephens, eds., Archipelagic American Studies (Durham, NC: Duke University Press, 2017); Jonathan Pugh, "Island Movements: Thinking with the Archipelago," Island Studies Journal 8, no. I (2013): 9-24; Elaine Stratford, Godfrey Baldacchino, Elizabeth McMahon, Carol Farbotko, and Andrew Harwood, "Envisioning the Archipelago," Island Studies Journal 6, no. 2 (2011): 113-30.

38 See also the discussion of the term "aquapelago" in Helen Dawson, "Archaeology, Aquapelagos and Island Studies," Shima 6, no. I (2012): 17-24; Philip Hayward, "Aquapelagos and Aquapelagic Assemblages," Shima 6, no. I (2OI2): I-II; Stratford et al., "Tuvalu, Sovereignty and Climate Change."

39 Epeli Hau'ofa, "Our Sea of Islands," in A New Oceania: Rediscovering Our Sea of Islands, ed. Eric Waddell, Vijay Naidu, and Epeli Hau'ofa (Suva, Fiji: Beake House, 1993), 2-16.

40 Hau'ofa, "Our Sea of Islands," 8.

4I Anil Agarwal and Sunita Narain, Global Warming in an Unequal World: A Case of Environmental Colonialism (New Delhi: Centre for Science and the Environment, 1991).

42 Quoted in Joakim Peter, "Matauen ese Pwipwi, Mataauen ese Nounou: 'Disruptive Oceans' and Waves of Moving Island(er)s," paper presented at the Waves of Change Conference, University of Hawai' $\mathrm{i}$, Manoa, April 4-6, 2013.

43 "Vosa Qali ni Draki Veisau—iTaukei Glossary of Climate Change Terms," Pacific Climate Change Portal, September II, 2013, accessed October I8, 2018, https://www.pacificclimatechange.net/sites/default/files/documents /CCCPIR-Fiji_iTaukei\%2oGlossary\%20of\%2oClimate\%2oChange\%2oTerms .pdf.

44 Nunn, "The End of the Pacific?" See, e.g., the University of the South Pacific's Pacific Centre for Environment and Sustainable Development and its Global Climate Change Alliance Project, funded by the European Union. The ocean is increasingly perceived as a shared vulnerability, evident in the Moana (Ocean) Declaration of 2009, an initiative from Pacific church leaders to promote environmental justice in response to how sea-level rise is threating food and water sovereignty as well as human rights: "Pacific Church Leaders' Statement," 
World Council of Churches, April 24, 2009, accessed I8 October 2018, http:// www.oikoumene.org/en/resources/documents/wcc-programmes/justice -diakonia-and-responsibility-for-creation/climate-change-water/pacific-church -leaders-statement. See also Halapua’s (also Christian) Moana methodology: Winston Halapua, "Moana Methodology: A Way of Promoting Dynamic Leadership," Talanoa Oceania, accessed I8 October 2018, https://sites.google .com/a/nomoa.com/talanoa/Home/papers-presentations/halapua--moana.

45 See Joakim Peter's method of engaging climate change in the Pacific through the model of "disruptive oceans": Peter, "Matauen ese Pwipwi, Mataauen ese Nounou."

46 See Rachel Slocum, "Polar Bears and Energy-Efficient Lightbulbs: Strategies to Bring Climate Change Home," Environment and Planning D: Society and Space 22, no. 3 (2004): 413-38; Kate Manzo, "Imaging Vulnerability: The Iconography of Climate Change," Royal Geographical Society 42, no. I (2009): I-I2; Anthony Leiserowitz, "Climate Change Risk Perception and Policy Preferences: The Role of Affect, Imagery, and Values," Climatic Change 77 (2006): 52.

47 Leiserowitz, "Climate Change Risk Perception and Policy Preferences"; Jane M. Gaines, "Political Mimesis," in Collecting Visible Evidence, ed. Jane M. Gaines and Michael Renov (Minneapolis: University of Minnesota Press, 1999), 84IO2; Manzo, "Imaging Vulnerability"; Sophie A. Nicholson-Cole, "Representing Climate Change Futures: A Critique on the Use of Images for Visual Communication," Computers, Environment and Urban Systems 29 (2005): 255-73.

48 Felicity Mellor, "The Politics of Accuracy in Judging Global Warming Films," Environmental Communication 3 (2009): 134-50; Julie Doyle, "Seeing the Climate? The Problematic Status of Visual Evidence in Climate Change Campaigning," in Ecosee: Image, Rhetoric, Nature, ed. Sidney I. Dobrin and Sean Morey (Albany: State University of New York Press, 2009); Saffron J. O'Neill and Nicholas Smith, "Climate Change and Visual Imagery," WIREs Climate Change 5, no. I (2013): 73-87; Sidney I. Dobrin and Sean Morey, "Ecosee: A First Glimpse," in Dobrin and Morey, Ecosee, I-22; Heather Dawkins, "Ecology, Images, and Scripto-Visual Rhetoric," in Dobrin and Morey, Ecosee, 79-94.

49 Barbara Adam, Timescapes of Modernity: The Environment and Invisible Hazards (New York: Routledge, 2005), I2. See also Julie Doyle, "Picturing the Climactic: Greenpeace and the Representational Politics of Climate Change Communication," Science as Culture 16, no. 2 (2007): 129-50; Rob Nixon, Slow Violence and the Environmentalism of the Poor (Cambridge, MA: Harvard University Press, 2011).

50 Siegfried Kracauer, "Photography," trans. Thomas Y. Levin, Critical Inquiry 19, no. 3 (Spring, 1993): 432.

5I Roland Barthes, Reflections on Photography (New York: Hill and Wang, 198I), 93-94.

52 Elizabeth Cowie, Recording Reality, Desiring the Real (Minneapolis: University of Minnesota Press, 2011).

53 See Michel Serres, The Natural Contract, trans. Elizabeth MacArthur and William Paulson (Ann Arbor: University of Michigan Press, 1995); Dipesh 
Chakrabarty, "The Climate of History: Four Theses," Critical Inquiry 35 (Winter 2009): 197-222.

54 Sheila Jasanoff, "A New Climate for Society," Theory, Culture and Society 27 (2010): 233 .

55 Jasanoff, "A New Climate for Society," 237.

56 Doyle, "Picturing the Climactic"; Dobrin and Morey, "Ecosee"; O’Neill and Smith, "Climate Change and Visual Imagery."

57 Carol Farbotko and Heather Lazrus, "The First Climate Refugees? Contesting Global Narratives of Climate Change in Tuvalu," Global Environment Change 22 (2012): 383 .

58 This collapses linear temporality while, paradoxically, upholding a teleology: Rom Harré, Jens Brockmeier, and Peter Muhlhausler, Greenspeak: A Study of Environmental Discourse (Thousand Oaks, CA: Sage, 1999), 7. See also Doyle, "Picturing the Climactic"; Kathryn Yusoff and Jennifer Gabrys, "Climate Change and the Imagination," Wiley Interdisciplinary Reviews: Climate Change 2, no. 4 (201I): 522 .

59 Paul G. Bahn and John Flenley, Easter Island, Earth Island (New York: Thames and Hudson, 1992); Jared M. Diamond, Collapse: How Societies Choose to Fail or Succeed (New York: Viking, 2005).

60 Mick Smith, "Hermeneutics and the Culture of Birds: The Environmental Allegory of 'Easter Island," Ethics, Place and Environment 8, no. I (2005): 21.

6I See, e.g., Terry L. Hunt and Carl P. Lipo, The Statues That Walked: Unraveling the Mystery of Easter Island (New York: Free Press, 20II). See also the critique of Diamond in Terry L. Hunt and Carl P. Lipo, "Late Colonization of Easter Island," Science, March 9, 2006, 1603-6.

62 Anna Lowenhaupt Tsing, "Inside the Economy of Appearances," Public Culture I2, no. I (2000): I19, I33.

63 Fabian, Time and the Other, 37. See Clifford, "On Ethnographic Allegory," III.

64 On the canary analogy, see Anne F. Chambers and Keith S. Chambers, "Five Takes on Climate and Cultural Change in Tuvalu," Contemporary Pacific 19, no. I (Spring 2007): 294-306; Carol Farbotko, "Tuvalu and Climate Change: Constructions of Environmental Displacement in the 'Sydney Morning Herald," Geografiska Annaler, Series B Human Geography 87, no. 4 (2005): 279-93.

65 Renato Rosaldo, "Imperialist Nostalgia," in Culture and Truth: The Remaking of Social Analysis (Boston: Beacon, 1989), 68-87.

66 Leiserowitz, "Climate Change Risk Perception and Policy Preferences."

67 Diana M. Liverman, "Conventions of Climate Change: Constructions of Danger and the Dispossession of the Atmosphere," Journal of Historical Geography 35 (2009): 279-96.

68 Jon Barnett and John Campbell, Climate Change and Small Island States: Power, Knowledge, and the South Pacific (London: Earthscan, 2010).

69 For an interesting examination of how the narrative of "culture loss" can be used by anthropologists to both support and undermine Indigenous Pacific claims against the devastation of nuclear testing in the Marshall Islands, see 
Stuart Kirsch, "Lost Worlds, Environmental Disaster, Culture Loss, and the Law," Current Anthropology 42 (2001): 167-98.

70 See Katerina Martina Teaiwa, "Saltwater Feet: The Flow of Dance in Oceania," in Deep Blue: Critical Reflections on Nature, Religion and Water, ed. Sylvie Shaw and Andrew Francis (London: Routledge, 2008), 107-25.

7I Cynthia Lee, "Pacific Islanders Reflect 'Human Face' of Climate Change," UCLA Today, October 5, 20II, accessed October 18, 2018, http://newsroom.ucla .edu/stories/remote-pacific-islanders-at-risk-216825.

72 On the issue of blame in the Pacific context, see Peter Rudiak-Gould, "Climate Change and Accusation: Global Warming and Local Blame in a Small Island State," Current Anthropology 55, no. 4 (2014): 365-86.

73 "Pacific Climate Warriors Will Block the World's Largest Coal Port," 350.org, accessed October 18, 2018, http://350.org/pacific-climate-warriors-will-block -the-worlds-largest-coal-port.

74 See “The Pacific Climate Warriors," 35o.org, accessed October 18, 2018. http:// world.350.org/pacificwarriors.

75 Chambers and Chambers, "Five Takes on Climate and Cultural Change in Tuvalu"; Niko Besnier, Gossip and the Everyday Production of Politics (Honolulu: University of Hawai'i Press, 2009); Carol Farbotko, “'The Global Warming Clock Is Ticking So See These Places While You Can': Voyeuristic Tourism and Model Environmental Citizens on Tuvalu’s Disappearing Islands," Singapore Journal of Tropical Geography 31, no. 2 (2010): 224-38.

76 Andrea Torrice, dir., Rising Waters: Global Warming and the Fate of the Pacific Islands, documentary film, Bullfrog Films, 2000.

77 Mike Hulme, "The Conquering of Climate: Discourses of Fear and Their Dissolution," Geographical Journal 174, no. I (March 2008): Io.

78 Jay Ruby, Picturing Culture: Explorations of Film and Anthropology (Chicago: University of Chicago Press, 2000), II.

79 Mike O'Connor, Savana Jones-Middleton, and Wayne Tourell, dirs., Paradise Drowned: Tuvalu, The Disappearing Nation, documentary film, Natural History New Zealand, 200 I.

8० Farbotko, “'The Global Warming Clock Is Ticking So See These Places While You Can.”

8I Christopher Horner, dir., and Gilliane Le Gallic, prod., The Disappearing of Tuvalu: Trouble in Paradise, documentary film, European Television Center, Planète \& Planète Future, Documentary Educational Resources, 2004; Julie Bayer and Josh Salzman, dirs., Time and Tide, documentary film, Wavecrest Film, 2005; Paul Lindsay, dir., Before the Flood, documentary film, Stampede, 2005. Tuvalu: That Sinking Feeling, by the U.S. director Elizabeth Pollock, was released in 2005; it is still a sixteen-minute "rough cut," so is not included in this review.

82 Juriaan Booij, dir., King Tide: The Sinking of Tuvalu, documentary film, Clap FilmSales, 2007.

83 Besnier, Gossip and the Everyday Production of Politics, 62. 
84 Briar March, dir., There Once Was an Island: Te Henua e Noho, documentary film, On the Level Productions, 2010; Tom Zubrycki, dir., The Hungry Tide, documentary film, Jotz Productions, 20I2. For an overview of the films on Tuvalu, see Chambers and Chambers, "Five Takes on Climate and Cultural Change in Tuvalu." See also Farbotko and Lazrus, "The First Climate Refugees?" While most films are produced in the anglophone regions, the Japanese filmmaker Kana Tomoko produced Beautiful Islands, Memoirs of Sinking Islands (Horizon Features, 2009), and the relocation of Carteret Islanders of Papua New Guinea was featured in Jennifer Redfearn, dir., Sun Come Up, documentary film, New Day Films, 2010.

85 Carol Farbotko, "Wishful Sinking," Asia Pacific Viewpoint 51, no. I (2010): 47-60; Farbotko and Lazrus, "The First Climate Refugees?"

86 Clifford, "On Ethnographic Allegory," ııо.

87 Note that the Alofa Tuvalu site at http://www.alofatuvalu.tv, created by Christopher Horner and Gilliane Le Gallic, was inspired by the "small is beautiful" movement, but posts and activities seem to have dwindled after 2010.

88 Benjamin, The Origin of German Tragic Drama, 180.

89 See the Wavecrest Films website at http://www.wavecrestfilms.com/i /Time\&TidePK.pdf.

90 The King Tide trailer is posted at https://www.youtube.com/watch?v $=$ BNql8BiAijw.

91 Nichols, Representing Reality, 28.

92 Nichols, Representing Reality, 89.

93 "The documentary is both a memory machine, making available present events for a future spectator's time of re-viewing, and a present tense-'speaking about the past' - in a 'now time.' But remembering is not simply the recall of past events; it is also the reencountering of emotions attached to those past events and their losses, and in this, it carries out a work of memorializing that is also a process of mourning and forgetting. Remembering is a space of time that is also a placing of the pastness of the past and of dwelling in the places of the past. It is the time of memory that enables the art of documentary": Cowie, Recording Reality, Desiring the Real, 6.

94 McBrien, "Accumulating Extinction," ir6.

95 Harry E. Maude, Slavers in Paradise: The Peruvian Labour Trade in Polynesia, 1862-64 (Canberra: Australian National University Press, 198I); Doug Munro, "The Peruvian Slavers in Tuvalu, i863: How Many Did They Kidnap?" Journal de la Société des Océanistes 90 (1981): 43-52.

96 Munro, "The Peruvian Slavers in Tuvalu, I863," 44.

97 Besnier, Gossip and the Everyday Production of Politics, 48.

98 This is the argument made in Victor Bascara, Keith L. Camacho, and Elizabeth DeLoughrey, "Gender and Sexual Politics in the Pacific Islands: A Call for Critical Militarisation Studies," Intersections: Gender and Sexuality in Asia and the Pacific 37 (March 2015). http://intersections.anu.edu.au/issue37/bascara _camacho_deloughrey.html. 
99 Barnett and Campbell draw upon Webb to suggest that "the two most careful studies of coastal change and flooding in Funafuti show that the major driver of change has been the construction of the airstrip and a large wharf by the United States military, which established a base there during the Second World War": Barnett and Campbell, Climate Change and Small Island States, I43; Arthur Webb, (2006) Tuvalu Technical Report: Coastal Change Analysis Using MultiTemporal Image Comparisons, Funafuti Atoll, SOPAC Project Report 54, April 2006, http://docs.tuvaluislands.com/2006_Funafuti_Coastal _Change_Report_ERoos4.pdf.

Susan Sontag, "The Imagination of Disaster," in Against Interpretation: And Other Essays (New York: Farrar, Straus, and Giroux, 1966), 45.

Rosaldo, "Imperialist Nostalgia."

IO2 Rosaldo, "Imperialist Nostalgia," 69-70.

I03 See Jahan Ramazani, Poetry of Mourning: Modern Elegy from Hardy to Heaney (Chicago: University of Chicago Press, 1994).

I04 Timothy Morton, "Dark Ecology of Elegy," in The Oxford Handbook of the Elegy, ed. Karen Weisman (Oxford: Oxford University Press, 2012), 251, 253. Morton, "Dark Ecology of Elegy," 251, 254.

On the lost garden myth in U.S. culture, see Leo Marx, The Machine in the Garden: Technology and the Pastoral Ideal in America (New York: Oxford University Press, 1964).

I07 Farbotko, "Tuvalu and Climate Change"; Besnier, Gossip and the Everyday Production of Politics; Farbotko, “'The Global Warming Clock Is Ticking So See These Places While You Can.”

Io8 Walter Benjamin, The Arcades Project, ed. Rolf Tiedemann, trans. Howard Eiland and Kevin McLaughlin (Cambridge, MA: Harvard University Press, 1999), 46I.

I09 See Ben Dibley, "Nature Is Us: The Anthropocene and Species-Being," Transformations 2I (2012): n.p. Dibley builds on Paul Crutzen and Christian Schwägerl's claim that now that the human is rendered at a geological scale, "nature is us": Paul J. Crutzen and Christian Schwägerl, "Living in the Anthropocene: Toward a New Global Ethos," Yale Environment 360, January 24, 20II, accessed January 25, 20II, http://e360.yale.edu/feature/living_in_the _anthropocene_toward_a_new_global_ethos $/ 2363$. Rosaldo, "Imperialist Nostalgia," 82.

III Serres, The Natural Contract, 28.

II2 Serres, The Natural Contract.

II3 Cowie, Recording Reality, Desiring the Real, 190. The review was written by John Grierson. See also Jeffrey Geiger, Facing the Pacific: Polynesia and the U.S. Imperial Imagination (Honolulu: University of Hawai'i Press, 2007), I2I.

II 4 Ruby, Picturing Culture, 89.

II5 Cowie, Recording Reality, Desiring the Real, 26.

II6 Cowie, Recording Reality, Desiring the Real, 21.

II 7 Mike Hulme, "Reducing the Future to Climate: A Story of Climate Determinism and Reductionism," Klima 26, no. I (201I): 245-66; Kyle Powys Whyte, 
"Is it Colonial Déjà Vu? Indigenous Peoples and Climate Injustice," Humanities for the Environment: Integrating Knowledges, Forging New Constellations of Practice, ed. Joni Adamson, Michael Davis, and Hsinya Huang (New York: Routledge, 2017), 88-104.

II 8 James Clifford, "The Politics of Representation," in Discussions in Contemporary Culture, ed. Hal Foster (Seattle: Bay, 1987), 122, emphasis added.

in Hulme, "Reducing the Future to Climate," 256. He based this term on Andrew Sluyter, "Neo-Environmental Determinism, Intellectual Damage Control and Nature/Society Science," Antipode 35 (2003): 813-17.

I20 Gregory Bankoff, "Rendering the World Unsafe: 'Vulnerability' as Western Discourse," Disasters 25, no. I (200I): 19-35; Hulme, “The Conquering of Climate”; Manzo, "Imaging Vulnerability," 4; Ilan Kelman, "Hearing Local Voices from Small Island Developing States for Climate Change," Local Environment I5, no. 7 (2010): 605-19; Ilan Kelman, "No Change from Climate Change: Vulnerability and Small Island Developing States," Geographical Journal I80 (2014): 120-29.

I2I This has been changing since I first wrote this in 20I4. See the special issue of the journal The Missing Slate on Pacific Islander climate change poetry (October I, 2017): https://themissingslate.com/2017/Io/oI/pacific-islander-climatechange-poetry/. See also the blog of poet Craig Santos Perez on ecopoetics: http://craigsantosperez.com/eco-poetics/. See also Kathy Jetñil-Kijiner's blog about being pigeonholed as a "climate change poet": https://www.kathyjet nilkijiner.com/a-few-thoughts-on-pacific-literature/.

I22 Dipesh Chakrabarty, "The Human Condition in the Anthropocene," Tanner Lectures in Human Values delivered at Yale University, New Haven, February 18-19, 2015. Amitav Ghosh makes the same observation in The Great Derangement (Chicago: University of Chicago Press, 2016).

I23 See Nunn, "The End of the Pacific?"

I24 "Not all Tuvaluan politicians are united in this discourse, as some argue that Tuvalu has more pressing concerns, including sanitation, nutrition, and access to labor markets in the industrial world": Besnier, Gossip and the Everyday Production of Politics, 63.

I25 On tidalectics see Kamau Brathwaite, "Caribbean Culture: Two Paradigms," in Missile and Capsule, ed. Jürgen Martini, 9-54 (Bremen, Germany: Universität Bremen, 1983).

I26 Jetñil-Kijiner's work can be accessed on her website at https://jkijiner .wordpress.com. See also her discussion of climate activism here: accessed October 18, 2018 at https://jkijiner.wordpress.com/2015/11/22/a-moment-of -clarity-why-im-going-to-paris-cop21/. For the performance discussed below see Kathy Jetñil-Kijiner, “Tell Them," video recording, https://www.youtube .com/watch?v=w9D88ST 9 qbw.

I27 Ghosh, The Great Derangement, 26.

I28 Kathy Jetñil-Kijiner, "Iep Jeltok: A Basket of Poetry and Writing from Kathy Jetñil-Kijiner," accessed October I8, 2018, http://jkijiner.wordpress.com; Kathy Jetñil-Kijiner, Iep Jāltok (Tucson: University of Arizona Press, 2017). 
I29 See the explication at Jetñil-Kijiner's blog, at https://jkijiner.wordpress.com /tag/marshall-islands.

I30 See Kathy Jetñil-Kijiner, "History Project," accessed October I8, 2018, https:// www.youtube.com/watch?v=DIIrrPyKoeU. Note that the poem ends in terms of failure of the part/whole "benefit of mankind." For a discussion of the history of the tests, see chapter 2 in this volume.

I3I Tony DeBrum, "Climate Change in the Pacific Islands: Implications for Hawai i," Waves of Change conference, The Center for Pacific Islands Studies at the University of Hawai' i, Mānoa, April 4-6, 2013. See also Torrice, Rising Waters, the only climate change film that integrates this nuclear history. For a rich analysis of the complexity of Marshallese attitudes to climate change, see Peter Rudiak-Gould, Climate Change and Tradition in a Small Island State: The Rising Tide (London: Routledge, 2013).

132 See Mick Smith, "Environmental Anamnesis," Environmental Ethics 23, no. 4 (200I): 359-76; Smith, "Hermeneutics and the Culture of Birds."

133 Smith, "Hermeneutics and the Culture of Birds," 22.

134 See Marilyn Strathern, The Gender of the Gift: Problems with Women and Problems with Society in Melanesia (Berkeley: University of California Press, 1988). See also Nicholas Thomas, Entangled Objects: Exchange, Material Culture, and Colonialism in the Pacific (Cambridge, MA: Harvard University Press, 1999I), which builds on this argument to include the circulation of commodities.

I35 See in Nathaniel Mackey, "An Interview with Edward Kamau Brathwaite," Hambone 9 (1991): 44.

136 Farbotko and Lazrus, “The First Climate Refugees?” See also Christian Parenti's alarmist Tropic of Chaos: Climate Change and the New Geography of Violence (New York: Nation, 2011).

137 Benjamin, The Origin of German Tragic Drama, 166. See also Bainard Cowen, "Walter Benjamin's Theory of Allegory," New German Critique, no. 22 (Winter I98I): II7.

138 See Cowen, "Walter Benjamin's Theory of Allegory," II9.

139 "Dear Matafele Peinam," in Jetñil-Kijiner, Iep Jaltok, 72.

I40 Deborah Bird Rose, "Anthropocene Noir," paper presented at the People and the Planet 2013 conference: Transforming the Future, R MIT University, Melbourne, Australia (July 2013): 8. http://global-cities.info/wp-content/up loads/2014/o5/Anthropocene-Noir.pdf. Rose is writing about the Australian Aboriginal practice of "taking care of country." See also Haraway, Staying with the Trouble.

I4I Mishuana Goeman, Mark My Words: Native Women Mapping Our Nations (Minneapolis: University of Minnesota Press, 2013), 36, 7.

I42 Haraway, Staying with the Trouble, I03. 


\section{N D E X}

abalone (pāua), I42, I48, I5I, I59-63

Adam, Barbara, 176

Adamson, Joni, 5

adaptation, 7, 9, 30, 79, I34, I36, I45, I48, I50-51, I54-58, 164, 168, 179

Adorno, Theodor, 63, 66-67

"Age of Man," 3, II-I3, 25, 50, 54, 58-59, 91. See also Manthropocene agriculture. See plantation Ahmad, Aijaz, 47

Alaimo, Stacy, II, 139, I6I-62

Alamogordo, New Mexico, 26, 63, 69, $85-86,91$. See also Trinity atomic test allegory, 4; allegoresis, 6, 9, 16-19, 25, 32, 49-50, 57, 96, I29, I32-33, I35, I5I, I54-55; allegorical act, 9; allegoric tendency, 9, I68; ambivalence of, 9, I7, 45-47, 51; Baroque allegory, I0, 13-14, 55, 58, I85; antinomies of, IO-II, 17, 45, II2, 166, 170, 176, 187, I91; Christian and Judeo-Christian allegory, 17 , $36,64,79,83-84,88$, 91, I 48, I58, I84, I87; of collector, I00-IO8, III, II7, I20-25, I32, I48, I55, I60, I90, I96; counterallegories, 17, 31, 44, 84, I57; environmental allegory, 178 ; ethnographic allegory, 31, I69-70; etymology of, 50; and gender, 17, 37, $47,49-62$; of island as a world, $\mathrm{I}-2,6$, 9-10, 17-18, 29-32, 35-36, 165-96; of light (daemonic allegory), 27, 64-69,
73-91, 96-97; "Manichean allegory," 17; and master narratives, 36, 45, 53, 166, I68; of micro- and macrocosmos, I 8, 64, 8I, 85, I38-39, I44, I55, I66; modes of, 5-13, $17-18,28,35,47-48$, $64,83,100,123,135,143,152-53,156$, I6I, I65-70, I94; national allegory, $15-17,47,123-24$; of the ocean, $133-35$, I39, I 42, I 46-47, I50-64; pastoral allegory, 36, 168; and pedagogy, 48, 58, 179; political allegory, I6; postcolonial allegory, 53; of roots and rhizomes, $40-43,46,49-62$; and salvation, 17 , 45, I04, I09, III, II 4, I48, I96; by scientists, 6, 23, 64, 138-39, I69, I78; and social crisis, 29, 59; and space/place, 5-6, 9, II, I7-I8, 27-28, 34, 42, 45-50, $56,64,78,134-35$, I 42, I5 I, I55-57, 165-66, 169-71, 179; "Third World allegory," $15-17,47,123$; and time, 5, 9, I7, 27-28, 34, 42, 46, 48, 5I, 54, 56, 8I, 84, 87, II2, II4, I22, I33, I5I, I66, I7 I, 178-79; tropes of, I, 5-6, I8, 21, 32-33, 37, 65, I13, I27, I6I, I66, I68, I7 I, I82, 186, 189-90, I93; of waste, I13-17, I21, I29, I3I-32; of writing, 157-58. See also Benjamin, Walter; daemonic allegory Alliance of Small Island States (AOSIS), I79, I8I

Angel of History, 37, 76. See also Benjamin, Walter 
Anthropocene: and alienation, 20, 6I-62; ambivalence of, II; vs. climate change discourse, 176; and Cold War, 25, 67-73; and the Columbian exchange, 24, 34; as discourse, 2 , $6-7,16,20,25,30,33-34,38-40,46$, $84,99,102,134-36,141,166,176$, I88-92, I96; and empire, I-2, I2, 22, 3I, 33-62, 83, 92, IO2, I04, I33, I40, 165-94; and fire, 2, 23, 63, 78, 86, 94, 96; futurity of, 100, 134, I40, I54, I59, I63-64, I69, 178-79, I85, 196; and gender, 39, 50, 59-62, 163, 195-96; and globalization, 27, 98-132; grounding of, 7, 44, 135; and human history, 46, $48,52,59,100,103, \mathrm{I} 2 \mathrm{I}-22, \mathrm{I} 33-34$, 16I; interdisciplinary study of, 23; and islands, $165-96$; and militarism, 63-97, I88; and multispecies studies, I54; narratives of, 38, 64-65, 83, I04, I36, I48-49, I63, I65, I68, I70, I90, 196; and the ocean, 29, $117,140-41$, I50, 157, 163-65; and ontology, 64, 76, I35, I5I; origins of, 19-26, 33-35, 60, $63,69,84-90,99,156$; parochializing of, 2-3, 10, 20-21, 34, 65, 67, 133-35, 165, 170, 176, 191; and the plantation, $8,18,22-25,33-62$; and radiation, 63-67, 7I, 76, 81, 84, 92-93, 97, 17I; and representation, 3-6, 18, 177; scale of, I4-I5; spatial, 2, I8-19, 22, 27-28, I34-35, 165-69; and technosphere, 99, IOI-2, I32. See also Capitalocene; Chthulucene; Econocene; Eurocene; Manthropocene; Necrocene; Nuclearocene; Paleoanthropocene; Plantationocene; Plasticene Anthropocene Working Group (AWG), $26,84-85$

anthropocentrism, I5, 27, 65, 78, I56, I63 anthropogenesis, 8, 16, 2I-22, 30, 34; of carbon, 29, 137; of fossils, 8, 20, 32, 42, $46,60,70,72,100,103$, II,$~ I 21-22$, I34, I36, I60-6I; of nuclear weapons,
$72,79,84-85$; of ruin, $98-99$; and sea-level rise, 169-70; of soils, $23,134$. See also technofossil

Anthropos, 5, II, I5, 22, 84, 132

anticipatory logics, 4, 29; social politics of, 124, г31. See also Anthropocene antinomies, IO-II, I7, 45, II2, I66, 170, 176, I87, I9I

Aotearoa New Zealand, 27, 79, 85-87, 95-97, 136, I40-51, 162-64, 176, I82-85; Foreshore and Seabed Act, I43, I 45, I60; North Island, I43; South Island (Te Wai Pounamu), I42-43, 147. See also Oceania; Pacific Islands apocalypse, 5, 7, 15, 19, 26-31, 59, 67, 79, 81, 83, 89, 92, 94, 134, 136, 146, I48-50, I57, I62, I66, I88, I9I, I93; "end of nature," 7; nonapocalyptic models, 160, 163. See also Benjamin, Walter; extinction Apollo space voyages, 72, I7I aquadystopia, 3I; and aquatopia, I46, 158, I62. See also dystopia; utopia aqua nullius, II2, 134 archipelagraphy, 174

Arctic, 73, I40, I82; the poles, 69, 86, I34, I38-40, 176 Arendt, Hannah, IoI Aristotle, 65 Aronofsky, Darren, 5, I48 Atomic Energy Commission (AEC), 26, 70-75, 84, 91, I7I-72, I77 Australia, 2, 75, I42, I49, 176, I81, I84, I88, 191-92

Bachelard, Gaston, II2

Balzac, Honoré de, 126

Barad, Karen, I55

Barbados, 36, 103. See also Caribbean Islands

Barthes, Roland, 87, I34, I77

Bauman, Zygmunt, IO2, IO5, II2-I5

Before the Flood (Paul Lindsay documentary), I 84, I 87 
Benjamin, Walter, 5-28, 34, 37, 59-60, 86-90, 97-99, 108, 117-32, 134, I48, I55, I66-70, I85-86; and antinomies, IO-II, I7, 45, II2, I66, I70, I76, I87, I9I; "irresistible decay," I9-20, 48, 54, 8I, 87, 91, 196; nature-history, 6, 48, $53-58,76,91,98$, I04, I22, I3I, I66, I85; "refuse of history", 32, 100-104, III-I4, I22-24, I90. See also allegory; Angel of History; apocalypse; ruin

Bennett, Jane, 151, 160-6I

Berlant, Lauren, 157

Besnier, Niko, 184

Bikini Atoll, 68, 70-71, 74-77, 17I-74, I8I. See also Bravo explosion; Marshall Islands; Oceania; Pacific Islands

Bindler, Rob, 186

Black Rainbow (Albert Wendt novel), 8I-82

Black Rainbow, Mururoa (Ralph Hotere painting), $8 \mathrm{I}$; pictured, 82

blue humanities, $138-39$

blue revolution, 145

Booij, Juriaan, I84

Borgese, Elisabeth Mann, I38-39, I45

Brathwaite, Kamau, 29, 42-46, 58, 103, I29, I33; "Dream Haiti," III-I5, I32

Bravo explosion, 71, 75-76, 171. See also Bikini Atoll

Brierre, Murat, II3

Brodber, Erna, 24, 37-40, 43, 46-62, I3I-32. See also Rainmaker's Mistake, The

Buffon, Comte de, 19-20

Bush, George H. W., 86

Cadava, Eduardo, 89

Camus, Albert, 126-29

Capellán, Tony, 28, 103, I05-I2, II5-22, I26, I29, I32, I48; La Bandera de los Ahogados (The Flag of the Drowned), III; Mar Caribe, IO5-II, II5-I6, II9-20; Mar Invadido (Invaded Sea), I16-18; Pequeña Esperanza (Manchas), II8-20 capitalism, 7-8, I2, 15-16, 2I-24, 27; and commodities, II7, II9-2I; and islands, I68, I77, I80, I87-88; late capitalism, IOI-2, I78; and the ocean, $\mathrm{I}_{3} 8, \mathrm{I} 44-47$, I52, I57-58; people as creators and products of, 45; and waste, 99-107, II5, II7, I26. See also Capitalocene; petro-capitalism; plantation

Capitalocene, 22, 35, 40, 44, 99, 102, 133, 196. See also Anthropocene; capitalism

Caribbean Islands, 8, 18, 24-25, 28, 3I, 34-37, 44, 48, IOO, $102-4$, IO7, I09-17, I20-21; Caribbean Community (CARICOM), II5; history of, $38-40,52-53,56,60,123,126-27,130$, 166. See also individual island nations

cartography, I5, 35-36, 67, 139, 175

Chakrabarty, Dipesh, 2-3, II-I2, I5-I6, $48,62,64$, I 43, I56, I92

Chernobyl, 7 I

Children of Sisyphus, The (Orlando Patterson novel), 122-32; as allegory, I22-23, I25, I29, I3I-32; and the collector, $122-23, \mathrm{I25}-26, \mathrm{I} 32$; nationalism in, I23-24, I3I; obeah in, I24, I27, I29-3I; and social politics of anticipation, I24, I3I; urbanization in, $122-23$, I2 8

Chthulucene, 22. See also Anthropocene Clarke, Bruce, 6, 64-65, 79

Clifford, James, 32, 170, I84 "cli-fi" (climate fiction, or climate film), $7,22,24,59,165-96$

climate change: vs. Anthropocene discourse, 176; and anthropogenesis, 5, 32, 63, 72, I55, 170, 190; and climate justice, I, 19, 137, I41; and Cold War science, 25-26, 67-73; and cultural genocide, 4; definition of, 6-7, 33-34; denial of, 179-80; as discourse, 170, 176, I9I-92; and empire, 25, 33, 48, I67, I75, I90; erosion, 40, 60, IOI, I85, I88; flooding, I-2, 25, 40, 60, 88, I07, I37, I57, I77-82, I84, I86-87; 
climate change (continued)

and freedom, 48; greenhouse gas, 69, 137, 175-76, 179; and islands, 165-96, 188-89, 192-96; mitigation of, 7, 9,

I8, I64, I77, I79, I9I; narration of, 83, I36, I48-49, I53, I57-58, I63, I68, I70, I76-78; and the ocean, $138, \mathrm{I}_{4} \mathrm{I}-42$, I46-47, I5I-52, I56; as rupture, 3-4, 7; summits, I, 4, I76, I8I, I85, I93, I96; visualization of, $5,8-9,18,22,28,74$, 77, 79, 81, 87-93, 96, I05, II2-14, I20, 137, 167-85, 190, 193. See also militarism; sea-level rise

climate determinism, 191, I95

climate reductionism, 191-92

Clinton, Bill, 7 I

Cold War, 8, 18-19, 27-29, 74, 79, 86-88, 94-95, 99, I20, 138-39, I50, 162, 171, 193; and Anthropocene, 25, 67-73; and climate change science, 25-26, 67-73; and ecology, 26, 34-35, 70-73; and militarism, 67-73, 85, 96. See also radiation; U.S. military

Collins, Merle, 36-37

colonization, 7-8, I2, I8, 23-24, 28, 34-35, 4I, 5I-53, 77, 86, 9I, I23, I39, I4I, I49-50, I66-70, I92; carbon colonialism, 175, I88-89. See also empire Columbian exchange, 24, 34

Connery, Christopher, 146

Copenhagen Climate Summit, 176, I85

Corbin, Alain, I28

Cosgrove, Denis, 72, 88

Cousteau, Jacques-Yves, 138

Cowie, Elizabeth, I9I

Cragg, Tony, 107

creolization, 37, 39, 43-44, 46, 50, 122

critical ocean studies, 29, 134-35, I38-39

Crosby, Alfred, 24, 34

Crutzen, Paul J., 21, 30, 35, 69, 100

Curie, Marie, 74

daemonic allegory, 27, 64-69, 73-91, 96-97, 150
Davis, Heather, 7

Davis, Mike, I22, 157

DeLanda, Manuel, I6o

de Man, Paul, I0, 13, 25

Defoe, Daniel, 6, I67

Derby, Lauren, 130-3I

Derrida, Jacques, 65

diaspora, $13,24,33,36-43,47,49,54,58-59$, IIO, II3, I27, I32-38. See also migration

Disappearing of Tuvalu: Trouble in Paradise, The (Christopher Horner and Gilliane Le Gallic documentary), I84, I87 disposability, 22, 27-28, 99-105, I08, I13-16, I22, I24, I85. See also waste documentary film, 9, I8, 3I-32, I67-69, I75-78, I8I-95; and (non)fictionality, I90-91

Dominican Republic, 28, IO3-IO, II5-2I. See also Caribbean Islands

Douglas, Mary, 28, 102, 158

Doyle, Julie, 176

"Dream Haiti" (Kamau Brathwaite story), III-I5, I32

Duchamp, Marcel, I07

Dungle (Kingston, Jamaica), 28-29, I22-32

dystopia, 6, 31, 67, 81, 90, 146, 166-72, 193. See also aquadystopia; utopia

Earle, Sylvia, I33, I39, I4I

earth. See soil

Earth, I-2, 3, 6, I2, I5, I7-30, 33-67, 7I-73, 77, 99-100, I21-23, I29, I32-36, I42, I 47, I66, I7 I, I76, I78, I96

"Earth Island," 8, 19, I66, 17 I, 178. See also island

Easter Island (Rapa Nui), 6, 178 ecology, 32-34; Age of Ecology, 63, 69, 84, 91; and Cold War, 26, 70-73; and crisis, I-3, 7, I5-20, 35, 62; and ecocide, I78; ecological change, 22, I49, I5 I, I55-56, I9I, I93; ecological imperialism, 8-IO, I8, 24, 33-34; ecological modernity, 6, 8, 50, 62; ecosystems, 24, 
70-72, IOI, I38; and empire, I2, 36, 83, I66; of islands, 35-36, 166-67, 171, I89, 194; and the ocean, 139, 157-58; and radiation, 70-71, 75-76, 79, 84-85, I77; and rupture, 33-35, 38, 167; of war, 87; of waste, I03, I25, I29, 132

Econocene, 22. See also Anthropocene Eden (Judeo-Christian cosmology), 36 , $44,49-52,57,167-69,172,186-87,193$

Einstein, Albert, 66, 68

elegy, 20, 79, I8I, I89

Emmerich, Roland, 5, I48, I88

empire: and alienation, $13,38,40-4 \mathrm{I}, 45$, 49, 6I-62, 84, 90, 93, I44-45, I49; and allegory, 38; in Americas, 21, 23-24, 34-37, 4I-45, 55-58, 7I, 9I, I05, II6; and Anthropocene, I-2, 12, 22, 31, 33-34, 58-62; and construction of the human, 45, I03; European, 8, I2-I3, 2I-24, 26, 34-36, 4I, 5I, 67, II6, I4I, I66-67, I72, I90; and islands, 166-70, 178, I89; and the novel, 45, 83-84; and the ocean, I38-39, I46-48; in Pacific, 67, 77, 83-85, 95-96, I39-4I, 175, I80, I84-90; and radiation, 77, 91-92; settler colonial, I49-50, I64; and waste, I02, I33. See also colonization; U.S. military

Enewetak Atoll, 68, 70, 172, 174. See also Marshall Islands; Oceania; Pacific Islands Enlightenment, 16, 21, 66-69, 84, 93, I34 environmental humanities, 6, 35 ethnography, 172; ethnographic allegory, 3I, I69-70; ethnographic pastoral, I84, I87, I92; salvage ethnography, I69-70, I78, I82, I90

Eurocene, 22. See also Anthropocene Exclusive Economic Zones (EEZs), I39-40, I44-45; pictured, I40 extinction, 2-6, 18-19, 31, 36, 59, 83, 156, 168-70, 185-87, 195-96. See also apocalypse

Fabian, Johannes, 178

Fagan, Brian, 148
Farbotko, Carol, 178

feminist studies, 5, 7, II-I2, 25, 30, 32, $39,49,55-57,62,130,135,154,157-58$, 163, 196

Fiji, 175,188

film. See documentary film

Flaherty, Robert J., I82, 190

Fletcher, Angus, 64, 93, 166

Foreshore and Seabed Act (New Zealand), I43, I45, 160

French Polynesia, 81-83, I46, I7 I. See also Tahiti

Friedman, Patri, I45

garbage, I03, I08, II5, I2O, I23-28, I32; garbology, I02; Pacific Garbage Patch, ıо . See also waste

genealogy (whakapapa), 136, I42-43, I46, I50, I57, I63

genocide, $8,13,23,33,36,42$, I07, I49;

cultural, 4

geohumanities, 42

geologics, 42, 158

geontologies (Elizabeth A. Povinelli term), I5, 30, I35, I43, I47, I50, I63-64 geopolitics, $15,19,103,138$ George, James, 27, 67, 85-96

George nuclear test: pictured, 173 geostory, 15,32

Gerbi, Antonello, 35, 210ni6

Ghosh, Amitav, 31, I5I-53, I58, 193

Glissant, Édouard, 37-39, 43, 57, 60, 127, 214n72; "irruption into modernity," 3, I4, 83, I33; "language of landscape," $40,52,62$

globalization, 2, 8-9, I2, I7-I8, 22, 24, $27-28,34,40,60,65,69,74-77,93$, 96, 98-105, I00, IO2, I09, II2, II5, I22, I4I, I58, I65, I92, 230n4I; and the state, I01, I03, 105, 108. See also Great Acceleration; neoliberalism; waste Goeman, Mishuana, 196

Goldmann, Lucien, 45

Goodison, Lorna, 36 
Gorbachev, Mikhail, 86

Gornitz, Vivien, 182

Grainger, James, 36

Grandy, David, 65

Great Acceleration, 8, 27-28, 98-102, I21. See also globalization; waste

green revolution, 145

Grove, Richard H., 35-36, 167

Guantánamo, I09-10

Hagen, Joel Bartholomew, 69-70

Haiti, I3, I07-I6, I30, I32. See also Caribbean Islands

Haitian Revolution, I3, 232n8I

Hance, Jeremy, 168

Hansen, James, 26, I37

Haraway, Donna J., I5, I48, I55-58, I62-63

Harris, Wilson, $18,45-48,60$

Harrison, Robert Pogue, 55-56, 6I

Hau'ofa, Epeli, I4I, 175, 195

Hawai' i, I 4I-42, I45. See also Oceania; Pacific Islands

Hawkins, Gay, I03

Hayy ibn Yaqdhan (Ibn Tufayl novel), 6

Hearne, John, I04, II 4, 123

heliotrope, 26, 65-66, 76

Helmreich, Stefan, 134, 145-46

Henare, Manuka, I54, I6I

Hereniko, Vilsoni, I4I

Hiroshima, 73, 75

"History Project" (Kathy Jetñil-Kijiner poem), 194

Hōkūléa (Hawaiian voyaging canoe), I $4 \mathrm{I}-42$

Hopkinson, Nalo, 43

Horkheimer, Max, 63, 66-67

Horner, Christopher, 187

Hotere, Ralph, 79-83

Hulme, Keri, 3I, I36, I42-43, I46-64, 193

Hulme, Mike, I9I

Hungry Tide, The (Tom Zubrycki documentary), I 84 hyperobjects (Timothy Morton term), 9, $14,28,116$

Iep Jāltok (Kathy Jetñil-Kijiner collection), 193

Ihimaera, Witi, I42

imperialist nostalgia (Renato Rosaldo term), I79, I81, I86, I88-89. See also "vanishing native"

Indigenous, 2-9, I2, I7-I8, 23-24, 27, $31-32$; in Caribbean, 44; decimation of peoples, 34-35, 42, I69, I88-89; and fallout, 71, 77; and more-thanhuman world, 61-62, 136, I44, I49-50, I54, I57-58, I63, I68-70, I87, 191-92, 195-96; ontologies, 22, 30, 8I, 9I, I35-36, I40, I43, I50, I56-57, I64; in Pacific, 83, 94-96, 136, I41-45, I75, 178-96; in United States, IIo. See also Māori; nonhuman others; Tahiti Ingold, Timothy, 84

Intergovernmental Panel on Climate Change (IPCC), 73, 137 intimacy, 31, 78, II2, I84, 193 island: and garden, 37-38, 44, 49, 51, 169; island studies, I4I, 170-7I; and isolation, 171, 175; as laboratory, 67, 170-72; and spatial effects, 3I, 38, 42, I7 I; as a world, allegorical, I-2, 6, 9-10, 17-18, 29-32, 35-36, 165-96. See also archipelagraphy; "Earth Island"; scale Island of Shattered Dreams (Chantal Spitz novel), $83-84,86$

Jamaica, I8, 28, 36-37, 4I-44, IO3-4, I22-23, I30-3I; environmentalism in, 60-6I. See also Caribbean Islands James, C. L. R., I3 Jameson, Fredric, I0, I5-17, 47, I23, I66-68

JanMohamed, Abdul, 17 Japan, 92, 96-97, I40, I47; Fukushima, 138; Hiroshima, 73, 75; Nagasaki, 75, $85-86,91$ 
Jasanoff, Sheila, I77

Jauss, Hans Robert, IO, I3

Jenkyn, Thomas, 19-20

Jetñil-Kijiner, Kathy, 32, I4I, I70; "His-

tory Project," 194; Iep Jāltok, 193; "Tell

Them," I, 3-4, II, I92-96

Jungk, Robert, 75

Kelehan, Martha Daisy, II

Kincaid, Jamaica, 36

King Tide: The Sinking of Tuvalu (Juriaan Booij documentary), I84, I86

Kiribati, 169, 175, 179, I81, I84, 190. See also Oceania; Pacific Islands

Kracauer, Siegfried, 88-90, 177

La Bandera de los Ahogados (The Flag of the Drowned; Tony Capellán art installation), III

Latour, Bruno, I5, 32

Laurence, William, 73

Lazarus, Heather, 178

Lefale, Penehuro, I8I-82

Lefebvre, Henri, 134

Le Gallic, Gilliane, I87

Lévi-Strauss, Claude, I89

Levitus, Sydney, 137

Lewis, Simon, 21, 23, 26, 34

Lilienthal, David E., 73-74

Lippit, Akira Mizuta, 89-9I

longue durée, 4, 10, 70, 89, I49. See also slow violence

Lord of the Flies (William Golding novel), 6

Lyotard, Jean-François, I3

Madsen, Deborah, I3, 5 I

Maiava, Mikaele, I8०

Mais, Roger, 124

Malm, Andreas, 21, 35

Malta, 139

Manhattan Project, 73, 84

Manthropocene, II, 22, 62, 163, 196. See also "Age of Man," Anthropocene
Māori, 30, 67, 77, 85-86, 91, 95-97, I36, I 42-43, I47, I50-54, I57-64; Treaty of Waitangi, 144. See also Indigenous

Mar Caribe (Tony Capellán art installation), I05-II, II5-16, I19-20; pictured, 106

Mar Invadido (Invaded sea; Tony Capellán art installation), I16-18; pictured, II7-I8

Marsh, George Perkins, 19-20

Marshall Islands, 4, 6, 75, 83, IOI, I69-75, I8I, I88, 193-95. See also Bikini Atoll; Enewetak Atoll; Pacific Islands; Runit Island

Masco, Joseph, 72

Maslin, Mark, 2I, 23, 26, 34

Māui, 85, I43

Maupassant, Guy de, 126

Mbembe, Achille, I2I

McCole, John, Io

McKibben, Bill, I42

Melville, Herman, IO4

Micronesia, 70-7I, I39, I42, 171-72, I77, 193; Micronesian Constitution, 175. See also Oceania; Pacific Islands

Middle Passage. See slavery

migration, 28, 40, 60-61, IOI-3, I09-16, I28, I38, I4I, I76, I84-87, I9I-92, I95. See also diaspora

militarism, 8, 22, 27, 83-93, 96, 105, I09-IO, II3, I33, I39, I65-70, I88-89; and allegory, 88; and climate change, 63-64, 69-73, 76, 190; and Cold War, 67-73, 85, 96; economic, 83; and empire, 95-96, I67; and light, 77, 79, 86, 91-94, 96; militarized radiation, 2I, 25-26, 63-66, 69-72, 76, 93, 98-99, I2I, I33, I74; militourism, I72; and modernity, 85, 87; of the ocean, I05, I09-IO, II3, I39; and science, 89, 93, 97; and Vietnam War, 86, 90, 94-96. See also climate change; nuclearization; radiation; U.S. military; World War II 
Mintz, Sidney, I3

Moana (Robert J. Flaherty documentary), I82, 190

Moana: The Rising of the Sea (Vilsoni Hereniko film), I 4 I modernity, I6; and anthropocentrism, 65; and borders, 105, 109-10, I12; and Earth imagery, 73, I7I; and empire, I2-I 4, 2I, 28, 33-34, 40, 43, 45, 54, $57,83,137,166$; vs. indigeneity, 32, 168 , 170-7I, 185-91, 195; "irruption into modernity," 3, I4, 83, I33; and light, 89; and nuclearization, 67, 77, 83-84, $87,92-93$; and "revelatory otherness," 68; and urbanity, 61-62, 102; and violence, 24, 35, 43, 98, 105, 177; and waste, 99, IOI-2, I12-14, I28. See also antinomies; Benjamin, Walter; globalization

Montgomery, David, 33, 60

Moore, Jason W., 35, 229n23

Mootoo, Shani, 36

Mori, Emanuel, 175

Morton, Timothy, 28, I89

mourning, 4, 10, 32, 42-43, 46, 53, I $67-70,184, I 86-89,193$

multispecies, I5, I8, 30-3I, I33, I36, I5I, I54, I55-64, 176, I85. See also nonhuman others

Nagasaki, 75, 85-86, 91

Nanook of the North (Robert J. Flaherty documentary), 182

Necrocene, 22, 168-70, 196. See also Anthropocene neoliberalism, I2, 28, 99-109, 115-16, I22, 135-36, 160, 168, 184; neoliberal displacement, 40. See also globalization; Great Acceleration

Netz, Reviel, IIo

New Mexico. See Alamogordo, New Mexico; Trinity atomic test New Zealand. See Aotearoa New Zealand
Nichols, Bill, I86

Nilsson, Anders, I50

9/II (September II, 200I), I9, I69, I78, I82

Nixon, Rob, I0, 28, 70, 92, I49, I71-74, 176-77, 188. See also slow violence Noah (Darren Aronofsky film), 5, I48 nonhuman others, I5, I8, 30-31, I33, I5I, I54, I55-56. See also Indigenous; multispecies

"No Ordinary Sun" (Hone Tuwhare poem), 77-8I, 85, 96

No Ordinary Sun (Ralph Hotere painting), 79; pictured, 80

Nordhaus, Ted, I49

Nuclear Age, 63, 92, 98. See also ecology nuclearization, 7, 27, 74, 77-8I, 86, 94, 162, 172; and Anthropocene dating, $63,69-73$; (de)naturalization of, 73-74, 77, 79, 81, 84, 89, 93; and ecosystems, 70-72; and empire, 83, 86; and fallout, 64-66, 69-72, 75-76, 8I, 92; and literature, 67, 76-97, I48-49; and Marshall Islands, 66-7I, 75, 77, 83, 171-74, I81, 194; Nuclear Age, 63, 92, 98; weapons testing, 25-26, 67-77, 91, I72, I8I, I84-85, 193. See also Anthropocene; militarism; radiation; U.S. military

Nuclearocene, 27. See also Anthropocene nuclear universalism, 89, 92 nukespeak (Stephen Hilgartner et al. and Paul Chilton term), 74, 77, 8I Nunn, Patrick, I8I

ocean, 133-64; acidification of (as "carbon sink"), 2, 29-30, 72, 137-38, I4I, I75; agency of, 134, 16I; critical ocean studies, 29, 134-35, 138-39; mutability of, $147-48$, I50, I53-54; and natureculture, 30; oceanic imaginary, I05, I34, I4I-42, I46-47, I64-65, I75; "oceanic turn," I09, I38-39; oceanography, 72; and planetary change, I36-39, I43, I47, I5I; and seabed 
mining, I34, I36, I39-40, I43-45,

I60, I63-64; sea-level rise, I-2, 7-8, I8, 29-3I, 40, 60, IOI, I34-38, I42, I45, I48, I5 I, I54, I56-57, I64, I67, I69, I75-76, I79, I82-85, I88, I94; sea ontology, 22, 31, 134-36, I42-43, I46-48, I5I, I55, I59-63; and waste, 99, IOI, IO4-5, II2, I26, I38

Oceania, 67, I4I, I44, I75. See also Pacific Islands

oceanic imaginary, $105, \mathrm{I} 34, \mathrm{I} 4 \mathrm{I}-42$, I 46-47, I64-65, I75

Ocean Roads (James George novel), 67, 85-97; as allegory, 86, 88-91, 96; and effects of radiation, 85-86, 91-94, 97; and empire, 95; form of, 86-88, 90; and gender, 96-97; and heliography, 87, 91, 94, 96; and nuclear weapons, 85-89, 91; and photography, 86-90, 96. See also planetarity

Odum, Eugene and Howard, 70 ontology, 3, 6, 22, 25, 31, 40, 49, 52, $64,67,76-77,91,114,129-64,166$; geontologies (Elizabeth A. Povinelli term), I5, 30, I35, I43, I47, I50, I63-64; Indigenous ontologies, 22, 30, 136, I40, I50, I57; ontological turn, 30, I35; sea ontology, 22, 31, I34-36, I42-43, I 46-48, I5 I, I55, I59-63

Oppenheimer, Robert, 77

Orbis hypothesis (Simon L. Lewis and Mark A. Maslin term), 24; Orbis spike, 26, I49

orientalism, I4

Pacific Islands, 8, 18, 27, 31, 66-70, 73, 75-86, 95, 139-43, 152, 165-66, 169-96. See also Oceania; and individual island nations

Pacific nuclear testing map, 68

Paleoanthropocene, 34, 206nio7. See also Anthropocene

Papatūānuku and Ranginui (of Māori cosmology), I47, I57
Papua New Guinea, I40, 184. See also Oceania; Pacific Islands

Paradise Drowned: Tuvalu, the Disappearing Nation (Wayne Tourell documentary), I82; pictured, I83

Paravisini-Gebert, Lizabeth, III, II 6 Pardo, Arvid, 139

parochializing narratives, $2-3,10,20-2 \mathrm{I}$, $34,65,67,133-35,165,170,176$, I9I. See also Chakrabarty, Dipesh

Patterson, Orlando, 29, 103-4, 122-32. See also Children of Sisyphus, The pāua (abalone), I42, I48, I5 I, I59-63 Paul, Annie, $5 \mathrm{I}$

Payen, Nikòl, ı०9

Pequeña Esperanza (Manchas) (Tony Capellán art installation), II8-20; pictured, II9

petro-capitalism, I80, 190; petrochemicals, 98; petro-disasters, IOI, I38; petro-waste, in 3 . See also capitalism Philip, M. NourbeSe, I7-I8 planetarity (Gayatri Chakravorty Spivak term), 9, I4, 25, 27, 63-69, 74-76, 79, 89, 93, 96, 20In41. See also Ocean Roads (James George novel); scale; uncanny planetary consciousness (Mary Louise Pratt term), 24, 76 plantation, 7-8, 18, 22-25, 33-62, I10, $\mathrm{I} 27, \mathrm{I} 33, \mathrm{I} 65-68, \mathrm{I} 88, \mathrm{I} 96$; and provision grounds, 39-47, 50-53, 57-58. See also Anthropocene; capitalism; Plantationocene; slavery

Plantationocene, 22, 24-25, 35, 39-42, 44, 52, 58, 60, 133, 196. See also Anthropocene; slavery

Plasticene, 22, 99, I33; plastisphere, IOI, I38. See also Anthropocene; technofossil; waste

Polynesia, 83, I4I-42. See also Oceania; Pacific Islands

postatomic species, 64, 76, 91-92.

See also radiation; scale 
postcolonial studies, 2-I8, 22, 32-34, $47-48,53,100-102, \mathrm{I} 23, \mathrm{I} 33, \mathrm{I} 67-68$, 192; and nature vs. human, 34, 38-40, 43, 98, IOI, I34, I36, I43, I49, I54, I64; postcolonial allegory, 53

Povinelli, Elizabeth A., I5, 30, I35, I43

Pratt, Mary Louise, 24, 167

Puerto Rico, iı--ir. See also Caribbean Islands

queer kinship, 30, I5 I, I55, I63

radiation, 8, 18, 25-27, 63-103, I34, I38, 165, 171-76, 194; and Anthropocene origins, 63, 7I-73; and cancer, 93-94; and embodiment, 75-76, 81, 91-93; and human experimentation, 71, 75; and (in)visibility, 65-68, 73-74, 87, 91-92, 174, 176-77; of light, 64-69, 77, 84-88; in Pacific, 66-67, 79-84, 172-74, 194; of photography, 64, 66, 86-96, 171-72, 177; radiation ecology, 70-75; of the sun (esp. as metaphor), 65-66, 73-79, 85-86, 88, 96. See also Cold War; militarism; nuclearization; Nuclearocene; postatomic species radiocarbon, 6, 63, 72, 103

Rainmaker's Mistake, The (Erna Brodber novel), 24-25, 33-62, 86; as allegory, 37-62; and Caribbean historiography, 37-39, 46, 53; and chronology/ history, 48-49, 52-58; and climate change, 33, 40, 48, 59; and founding myth, 49-50, 59; and gender, 37, 47, 49-62; genosuicide, 59; and "naturalness," 38, 48, 53-54, 57-58, 62; and plot (narrative and physical), 25, 37, 39-62; and provision grounds, 39-47, $50-53,57-58$; and roots/rhizomes, 40-43, 46, 49-62; and soil, 37-62

Ranginui and Papatūānuku (of Māori cosmology), I47, I57

Rapa Nui (Easter Island), 6, 178. See also Oceania; Pacific Islands
Revelle, Roger, 72

Rising Waters: Global Warming and the Fate of the Pacific Islands (Andrea Torrice documentary), I8I-82

Roberts, Mere, I43, I57

Robin, Libby, 22, 100

Robinson Crusoe (Daniel Defoe novel), 6, 167

Romantic literature, I3, I89

Rosaldo, Renato, 179, 186, 188, 190

Ruddiman, William, 23

ruin, $6, \mathrm{I} 3-\mathrm{I} 4, \mathrm{I} 8,27,29,3 \mathrm{I}-32,76,8 \mathrm{I}$, 84, 87, 91, 98-100, I31, I34, I85-86, 196; debris/ruin of history, 37, 57, 86, 97, 103, 167-68; imperial debris/ruin, 52, I04, I33; and mourning, 4, IO, 32, $42-43,46,53,167-70,184,186-89$, 193; and "petrified unrest," 22, 25, 102, I33; and ruinate, I2I-22. See also Benjamin, Walter; technofossil; waste

Runit Island, IOI, I74. See also Marshall Islands; Pacific Islands

rupture, 27, 51, 57, 92, 112; as analytic, 9; of Anthropocene and empire, 3, 7-10, $33,36-37,40,43,59,127,134,165$, 167-68; "irruption into modernity," 3, 14, 83, I33; of knowledge and narrative, $4,51,89$, 104, 152-53; representation of, 13-14, 22, 37-38, 51, 86; spatial, 4, II. See also Anthropocene; Benjamin, Walter; Glissant, Édouard; modernity; postcolonial studies

Said, Edward, 20, 84

Salkey, Andrew, I04, I23 salvage environmentalism, 32, 170, I8I-84, I89-92

salvage ethnography, 169-70, I78, 182, I86, 190

Samoa, 81, 181-82, I87, 190. See also

Oceania; Pacific Islands

scale, 176, 194; of climate, 177,187 , I92; and empire, 24, 34-35, 60-64; and globalization, 27, 99; of island, 
I65-96; of the ocean, $135,138-40$; parochializing the Anthropocene, $2-3$, I0, 20-21, 34, 65, 67, 133-35, I65, 170, 176, I9I; planetary, 2-10, I4, I9, 60, I51, 156, 169, 171, 176-78, 195; "planetary boundaries," 6, 166; of radiation, 26, 65-66, 70, 76, 81, 85, 89, 92-94, 172-74; spatial, 4-5, 14-15, 96, I55, I76-77; to species, $16,59,61$, 64, I22, I43, I52, I56, I59, I61, I63, I78; temporal, I33; universalizing the Anthropocene, 2, I0, 62, I22, I33, I9I, I95; of waste, 99-103, I15, I25, 134. See also planetarity; postatomic species Scanlan, John, I04, 229n25, 235nni32-33 Schwägerl, Christian, 30, 20 In 43 Scillacio, Nicolò, 36

Scott, David, I2 4 seabed mining, I34, I36, I39-40, I43-45, I60, $163-64$

sea-level rise, I-2, 7-8, I8, 29-3I, 40, 60, IOI, I34-38, I42, I45, I48, I5I, I54, I56-57, I64, I67, I69, I75-76, I79, 182-85, 188, 194. See also climate change

sea ontology, 22, 31, 134-36, I42-43, I46-48, I5 I, I55, 159-63. See also ontology

seasteading architecture, I45-46; pictured, 146

Senior, Olive, 36

Serres, Michel, 33, 61-62, I19-20, I5I, I57, 190, 192

Sharpe, Christina, II 4

Sharpe, Jenny, I4, I7, 43, II2

Shellenberger, Michael, I49

Shemak, April, II 3

slavery, 7, I8, 23-25, 33-40, 6I, II 4, I39, I68, I88; and abolition, 24, 38, 47; and emancipation, 4I, 44, 47-53, 56-60; Middle Passage, 4I, 44, IO4, IIO-I4; and progressive narrative, 46. See also Brodber, Erna; empire; modernity; plantation; Plantationocene
Slemon, Stephen, 5 I

slow violence, IO, 28, 70, 92, I49, 172-74, 176-77, 188. See also Nixon, Rob

Smith, Mick, 178, 194

soil, 23-25, 29, 33-62, 64, 76-77, 99, III, II5, I22-23, I27-35, 174. See also Earth

Sontag, Susan, 93, I88

South Seas idyll, 67, I82, 185-86. See also utopia

speculative fiction, $37-38,43,58,134$, 136, I47. See also Todorov, Tzvetan

Spitz, Chantal, 27, 77, 83-84

Spivak, Gayatri Chakravorty, 9, 27, 65, 74, 96, 168

Stam, Robert, II5, I20

Steffen, Will, 27, 69

Steinberg, Philip, I35, I45

Stoermer, Eugene, 21, 35, 100

Stoler, Ann Laura, 52, 104

Stonefish (Keri Hulme collection), I 42-43, I46-64; "Floating Words," I46-47, I5I-60, I63; "The Pluperfect Pā-wā," I58-64; "Some Foods You Should Try Not to Encounter," 158

Stoppani, Antonio, 19-20

Strachan, Ian, 36

Strathern, Marilyn, 194

stratigraphic record, 4, 8, 20-28, 34, 42, 85, 99-100. See also Anthropocene Suess, Hans E., 72

Summers, Larry, 102, II5

Szeman, Imre, 16

Szerszynski, Bronislaw, ı०o, I32

Tahiti, 27, 73, 77, 83-84. See also French Polynesia

TallBear, Kimberly, I54

Tangaroa (deity of the ocean), I4I, I43

Te Aho, Linda, I5o

technofossil, 98-III, I21-22, I32, 196;

Anthropocene rock, I22; technosphere, 28, 99. See also anthropogenesis; ruin; waste

Teaiwa, Teresia K., 77, 172, I74 
“Tell Them” (Kathy Jetñil-Kijiner poem), I, 3-4, II, I92-96

Teskey, Gordon, II7

There Once Was an Island: Te Henua e

Noho (Briar March documentary), I 84

Thiel, Peter, I45

Thirty Years War, I4

Thompson, Krista, iI 6

Thompson, Michael, I27

tidalectics (Kamau Brathwaite term), 2, $48,133,195,248 \mathrm{n} 25$

Tikao, Teone Taare, ${ }_{163}$

Time and Tide (Julie Bayer and Josh

Salzman documentary), I84-86

Todd, Zoe, 7, I49

Todorov, Tzvetan, 153-54. See also speculative fiction

Tokelau, I69, 175, 179-80, 190. See also

Oceania; Pacific Islands

Torrice, Andrea, I8I

totality, 6, II-I9, 34, 94, I08, III, II9, I34, I5I, I62, I66; “'bad' totality, I6; definition of, I4; "harmonious totality" ro8-9. See also scale

Tourell, Wayne, $182-83$

Trans-Pacific Partnership, I 40

Trouillot, Michel-Rolph, 13, 42

Trinity atomic test, 26, 67, 77, 84-92, 97. See also Alamogordo, New Mexico; radiation

Truman, Harry, 73, I39, I7I

Tsing, Anna Lowenhaupt, 8, I33, I55, 178

Tuvalu, 31, I69, 175, 178-79, I82-90;

Funafuti, 184-88. See also Oceania;

Pacific Islands

Tuwhare, Hone, 27; "No Ordinary Sun," 77-80, 85, 96

2012 (Roland Emmerich film), 5, I48, 188

uncanny, 31, 42, 64-66, 70, 74-76,

79, 93, 104, III, I13, I22, I53. See also

planetarity

United Nations, IIO, 179-80, I94;

climate summits, I, I8I, I93, I96; Com- mittee on the Elimination of Racial

Discrimination (CERD), I44; Convention on the Law of the Sea, I38-39; Economic and Social Council Commission on Human Rights (UNCHR), I44; General Assembly, 175

United States, 19, 67, 70-75, 104-5, II5-I6, I42, I48, I67, I76-82; Central Intelligence Agency, I20; and empire, 2, I8, 95, I39, I49, I64, I7I-74, 190-94. See also U.S. military

universalizing narratives, $10-1 \mathrm{I}, 15-16,21$, $23,26,62,77,89,92,94,108-9,122$, I33-35, I39, I42, I44, I65, I78, I84-85, I87, 191-92, 195. See also totality

University of California, Los Angeles (UCLA), 179-80

University of the South Pacific (USP), I4I, I75

U.S. Atomic Energy Commission (AEC), $26,70-75,84,91,17 \mathrm{I}-72,177$

U.S. military, 26, 63, 66, 69-75, 77, 84-88, 92, 95, IOI, I7I-74, I84, I88-89, I94; Coast Guard, I09-IO, II3-I4; Navy, I09-IO, I39, I45, I72; Operation Crossroads, I71; Operation Greenhouse, I72; Operation Sunshine, 75-76; as world's largest carbon emitter, 69. See also Cold War; empire; militarism; nuclearization; United States

utopia, 6, 31, 62, 139, I45-46, I58, 166-72, 193; Utopia (Thomas More), 6. See also aquadystopia; dystopia

“vanishing native," I68, I70, I78, I85, I87. See also imperialist nostalgia

Vernadsky, Vladimir, 20

Vietnam War, 86, 90, 94-96

Virilio, Paul, 77, 89, 94

Viveiros de Castro, Eduardo, I5O

Walcott, Derek, 56, IO4, IIO, II4, I4I waste, 8, 22, 27-29, 98-133, I38; deep time of, I27, I3I; ecologies of, IO3, I25, 
I29, I32; and (in)visibility, $\mathrm{IO}_{2-4}$, IO7, III-I2, II7, I2O-2I, I28, I32; narration of, I00-10I; "refuse of history," 32 , I00-IO4, III-I4, I22-24, I9O; and soil, 130-31; and toxicity, II5-16; trace of, I22-23, I3I; wasted lives, I8, I02-5, I09-17, I20-26, I32; waste imperialism, 28, I02, II5-16; wastescapes, II6, I22, I25-26. See also Anthropocene; disposability; garbage; globalization; Great Acceleration; ruin; technofossil "Water is Rising" (performance), 179-80 waterworld, I5I-55, I59-62

Weart, Spencer R., 26

Welsome, Eileen, 71, 76

Wendt, Albert, 77, 83; Black Rainbow, $8 \mathrm{I}-82$

whakapapa (genealogy), 136, I42-43, I46, I50, I57, I63

Whanganui River, I50
White, Hayden, 53, 55

Whyte, Kyle Powys, I49, I9I

Williams, Eric, 45

Williams, Mark, 69

Wills, Peter, I43

Wolfe, Patrick, I49

World War II, 13, 27, 66, 69, 87, 90, 93, 96, 139, 184, 188. See also militarism

Worster, Donald, 63, 69, 84-85

Wynter, Sylvia, 5, I5, 39-4I, 45-46, 49, $52,57,123$

yam, 24, 39-44, 50-59; and nyame, 42; as rhizomes, 43

Yoneyama, Lisa, 89, 92-93, 97

Yusoff, Kathryn, 8, is

Zalasiewicz, Jan, 22, 26, 69, 85

Žižek, Slavoj, IO 4

Zola, Émile, 126 
This page intentionally left blank 